\title{
At risk for pain : pain-related anxiety, cognition, and processing biases
}

Citation for published version (APA):

Vancleef, L. M. G. (2007). At risk for pain : pain-related anxiety, cognition, and processing biases.

[Doctoral Thesis, Maastricht University]. Universitaire Pers Maastricht.

https://doi.org/10.26481/dis.20071108lv

Document status and date:

Published: 01/01/2007

DOI:

10.26481/dis.20071108Iv

Document Version:

Publisher's PDF, also known as Version of record

\section{Please check the document version of this publication:}

- A submitted manuscript is the version of the article upon submission and before peer-review. There can be important differences between the submitted version and the official published version of record.

People interested in the research are advised to contact the author for the final version of the publication, or visit the DOI to the publisher's website.

- The final author version and the galley proof are versions of the publication after peer review.

- The final published version features the final layout of the paper including the volume, issue and page numbers.

Link to publication

\footnotetext{
General rights rights.

- You may freely distribute the URL identifying the publication in the public portal. please follow below link for the End User Agreement:

www.umlib.nl/taverne-license

Take down policy

If you believe that this document breaches copyright please contact us at:

repository@maastrichtuniversity.nl

providing details and we will investigate your claim.
}

Copyright and moral rights for the publications made accessible in the public portal are retained by the authors and/or other copyright owners and it is a condition of accessing publications that users recognise and abide by the legal requirements associated with these

- Users may download and print one copy of any publication from the public portal for the purpose of private study or research.

- You may not further distribute the material or use it for any profit-making activity or commercial gain

If the publication is distributed under the terms of Article $25 \mathrm{fa}$ of the Dutch Copyright Act, indicated by the "Taverne" license above, 


\section{At Risk for Pain}

Pain-related Anxiety, Cognition, and Processing Biases 
At Risk for Pain

Pain-related Anxiety, Cognition, And Processing Biases

L.M.G. Vancleef

ISBN: 978-90-5278-662-9

Universitaire Pers Maastricht

Graphic Design: Sonja Das

Production: Datawyse | Universitaire Pers Maastricht

(c) Linda M.G. Vancleef, Maastricht 2007

All rights reserved. No part of this thesis may be reproduced or transmitted in any form or by any means, electronic or mechanical, including photocopying, recording or any information storage or retrieval system, without permission in writing from the author, or, when appropriate, from the publishers of the publications. 


\section{At Risk for Pain}

Pain-related Anxiety, Cognition, and Processing Biases

PROEFSCHRIFT

$(\varphi$

Ter verkrijging van de graad van doctor aan de Universiteit Maastricht, op gezag van de Rector Magnificus, prof. mr. G.P.M.F. Mols, volgens het besluit van het College van Decanen, in het openbaar te verdedigen op donderdag 8 november 2007 om 16.00 uur

door

Linda Martha Gerda Vancleef 


\section{PROMOTORES}

Prof. dr. M. L. Peters

Prof. dr. J. W. S. Vlaeyen

\section{BEOORDELINGSCOMMISSIE}

Prof. dr. J. J. D. M. van Lankveld (voorzitter)

Dr. M. Cima

Prof. dr. G. Crombez (Universiteit Gent)

Dr. E. Keogh (University of Bath)

Prof. dr. R. W. Wiers 


\section{Contents}

\section{Chapter 1}

General Introduction

Part l: Conceptualizing pain-related anxiety and fear constructs in a hierarchical model

\section{Chapter 2}

Do fundamental fears differentially contribute to pain-related fear and pain catastrophizing? An evaluation of the Sensitivity Index

\section{Chapter 3}

A hierarchical representation of negative emotionality constructs contributing to pain: an empirical examination of the underlying dimensional and componential structure of its individual components

PART II: Experimental studies on the vulnerability role of psychological factors in the onset and maintenance of pain

\section{Chapter 4}

Understanding the role of injury/illness sensitivity and anxiety sensitivity in (automatic) pain processing: An examination using the Extrinsic Affective Simon Task

\section{Chapter 5}

Examining content specificity of negative interpretation biases with the Body Sensations Interpretation Questionnaire (BSIQ)

\section{Chapter 6}

Interpreting ambiguous health and bodily threat: are individual differences in pain-related vulnerability constructs associated with an on-line negative interpretation bias? 


\section{CHAPTER 7}

Pain catastrophizing, but not injury/illness sensitivity or anxiety sensitivity enhances attentional interference by pain.

\section{CHAPTER 8}

Does it hurt less when you are convinced you can control it? The influence of perceived control and self-efficacy on the subjective evaluation of experimentally induced pain.

\section{CHAPTER 9}

Summary and General Discussion

SAMENVATTING

References

DANKWOORD

Curriculum VitaE 


\section{- - \\ Chapter 1}

General Introduction 
Pain is a well recognizable and familiar experience to all human beings. In most cases, pain takes the form of an acute episode that temporarily disables individuals in their daily functioning, and that cures spontaneously within a short period of time, or after effective medical treatment has taken place. Nevertheless, there is a substantial part of the population that has to contend with daily recurrent pain complaints for a prolonged period of time. Although the prerequisite for pain duration has been debated, there is now general consensus that pain complaints lasting longer than three months can be considered 'chronic'. Apart from chronic pain complaints originating from evident physical or organic causes (e.g., cancer pain), a considerable part of the chronic pain patients suffers from non-specific pain complaints. That is, they experience pain even though no objective or somatic cause can be detected, or they suffer from persisting pain complaints after the somatic cause has been effectively treated. Non-specific chronic pain is predominantly localized at the musculoskeletal system, affecting the lower back, the lower- and upper limbs (knee, elbow, leg), the neck, and the shoulders (Kerssens, Verhaak, Bartelds, Sorbi, \& Bensing, 2002; Verhaak, Kerssens, Dekker, Sorbi, \& Bensing, 1998). An epidemiological study in a Dutch community sample demonstrated that about $75 \%$ of the general population indicates to have experienced pain at the musculoskeletal apparatus in the past period of twelve months. Moreover, for $45 \%$ of this group, these pain complaints persisted for longer then three months (Picavet \& Schouten, 2003). In another study, examining the prevalence of low back pain and associated disability in the Belgian population, $41,8 \%$ of the respondents indicated to have experienced low back pain for at least one day in the past period of six months. Moreover, for $8,2 \%$ of this group, low back pain was seriously impeding daily functioning (Goubert, Crombez, \& De Bourdeaudhuij, 2004). Although the group of chronic patients constitutes a relatively small proportion of the general population (5-10\%), this group is responsible for a large proportion of health-care costs and levels of work absenteeism in western societies (e.g., Waddell, 2004). In addition, chronic pain is known to have an enormous impact on the personal and social relations of the individual in pain (Morley \& Eccleston, 2004; Sullivan, Adams, \& Sullivan, 2004).

Given the detrimental effect of chronic pain on the individual and his or her surrounding, research into the factors and mechanisms that contribute to the aetiology, the persistence, and the effective management of chronic pain complaints has known a significant boost in the latest decades. This burgeoning research interest has amongst others resulted in the identification of a number of psychological factors and mechanisms that may predispose persons toward, or conversely protect them against the development and persistence of chronic pain complaints. The current thesis contributes to this line of research by zooming in on the specific contribution of some of these proposed vulnerability and resilience factors. Consequently, the main and overall objective of this thesis is to add to the understanding of factors, mechanisms, and processes that constitute a mediating or moderating role in pain and pain-related disability. Before introducing the exact research questions of this thesis, this first chapter will start with a brief overview of some of the most prevalent theoretical models of pain as they have been formulated throughout history. Next, the theoretical background against which this thesis has been conducted will be presented by introducing some central concepts and factors underlying the studies in this thesis. Last and concordantly with the outline of this thesis, the main research questions of the individual studies in this thesis will be presented. 


\section{IMPORTANT THEORETICAL APPROACHES TO PAIN}

Given the perpetual and universal nature of pain, various scholars have attempted to understand and explain the experience of pain throughout history. Over 2000 years ago, the illustrious philosopher Aristotle (384 vC $-322 \mathrm{vC})$ conceptualized pain as a purely affective experience, while conversely, the 17th century philosopher Descartes proposed pain as a purely sensory and mechanistic principle, that was not at all subject to emotional or rational input (Benini \& DeLeo, 1999; Bonica, 1991; Gardiner, Metcalf, \& Beebe Center, 1937). Building on Descartes' ideas, a biomedical perspective on pain has predominated the conceptualization of pain for quite some time. In short, the biomedical perspective considers pain as the pure consequence of tissue damage, and following this perspective pain relief can only be the result of medicinal or surgical treatment. However, from a biomedical point of view, several robust observations regarding pain are difficult to explain. As such, it cannot provide an adequate explanation for the presence of pain complaints when no objective injury can be detected, or conversely, for the abstinence of pain complaints even though physical injury is clearly present (e.g., Jensen et al., 1994). Furthermore, the biomedical perspective cannot account for observations of the so-called phantom limb pain, where pain is experienced in missing body parts (Giummarra, Gibson, Georgiou Karistianis, \& Bradshaw, 2007). Most importantly, the biomedical perspective cannot explain why such large inter-individual differences exist in the way in which persons experience, react to, and cope with a pain experience. Hence, it gradually became clear that in order to gain a thorough understanding of pain and its consequences, the influence of other than purely sensory factors had to be taken into consideration.

With the postulation of the 'Gate Control' theory, Melzack and Wall (1965) advocated the importance of interactive effects between psychological factors and physiological factors in experience of pain. In this theory, a 'modulating gate mechanism' was assumed to operate in the dorsal horn of the spinal cord that allowed for the ascending transmission of information from the periphery to the brain to be influenced by the descending transmission of information from the brain (Melzack \& Wall, 1965). Briefly, the 'Gate Control Theory' posits that each particular pain experience results from the integration of purely sensory information with cognitive and affective information in the central nervous system. Psychological processes can thus influence and modulate reactions to painful sensations. At present, the biopsychosocial perspective on pain is widely accepted as the theoretical framework for the understanding and treatment of chronic pain disorders (Turk \& Flor, 1999; Turk \& Gatchel, 2002; Waddel, 2004). The biopsychosocial model postulates that pain results from the dynamic interaction between physiological, psychological, and social factors. Although these three components of the model are strongly interconnected, they show small content overlap, since different processes are assumed in each individual component of the model (Turk \& Gatchel, 2002; Waddel, 2004). For example, it is easy to understand that factors that exert an influence on the biomedical aspects of pain, for example an injury, are different from factors that exert an influence on the daily functioning of individuals in pain, for example the affective evaluation of the sensory experience. In this multidimensional approach to pain, pain is conceived as a unique experience that can have divergent outcomes in terms of illness, disability and suffering. The major benefit of the biopsychosocial perspective concerns its flexibility in allowing a broad variety of factors to influence and determine each individual pain experience simultaneously. Due 
to its general nature, however, the model does not entail a specific operationalization of the exact factors and processes that are subsumed in each of the individual components. It goes without saying that the psychological component alone already embraces a broad range of factors and mechanisms (i.e., behavioural, emotional, psychophysiological, and cognitive) that might prove useful in determining how an individual experiences pain, whether or not acute pain will persist, and whether the individual in pain will respond to treatment. Over time, several specific explanatory models of pain have been developed under the biopsychosocial umbrella, in which the role of one or more crucial psychological factors is emphasized. Of these models, the so-called 'fearavoidance models' have proven to be very fruitful in offering an explanation for the perseverance of chronic pain complaints and the transition from acute to chronic pain.

\section{FEAR-AVOIDANCE MODELS OF CHRONIC PAIN}

With the introduction of a 'fear-avoidance model of exaggerated pain perception' in 1983, Lethem and colleagues were the first to reserve a critical role for fear of pain and avoidance behaviour in the explanation of perpetuating pain complaints in the absence of organic pathology (Lethem, Slade, Troup, \& Bentley, 1983). Some years later, Philips (1987) emphasized the influence of cognitions on avoidance of pain. From that point forward, various cognitive fear-avoidance models have been developed, commonly referred to as contemporary fear-avoidance models, in which pain disability is conceived as the result of a vicious process that is determined by the interaction between cognitions and behaviour (Asmundson, Norton, \& Norton, 1999; Vlaeyen, Kole Snijders, Rotteveel, Ruesink, \& et al., 1995; Waddell, Newton, Henderson, Somerville, \& et al., 1993). Subtle differences aside, contemporary fear-avoidance models share the same basic tenets, and these can be easily understood from the integrated model that is illustrated below (see Figure 1; Vlaeyen \& Linton, 2000). Upon the initial perception of pain, individuals will assign a certain meaning and purpose to the painful experience that is based upon current expectations regarding the pain and prior learning history. Although the majority of individuals will evaluate the pain experience as undesirable and unpleasant at this stage, most persons will not perceive it as an extreme threat or an insurmountable catastrophe, and as such, they will proactively and gradually confront their pain, and resume their daily activities until full recovery is accomplished. Nevertheless, a minority of individuals assigns a catastrophic meaning to the painful experience by exaggerating the possible meaning and consequences of the pain. This catastrophic interpretation does then lead to pain-related fear (fear of pain, fear of movement, fear of (re)injury), which in its turn initiates the avoidance of potential painful activities and hypervigilance for potential signals of additional pain and bodily harm. As such, a vicious and self-perpetuating spiral is activated with avoidance of more and more (daily) activities, leading to functional disability and possibly also to social isolation and depression. In addition, physical deconditioning and depression may fuel the fear-avoidance cycle by increasing pain intensity and increasing the fearful appraisal of and selective attention to pain. 


\section{toment}

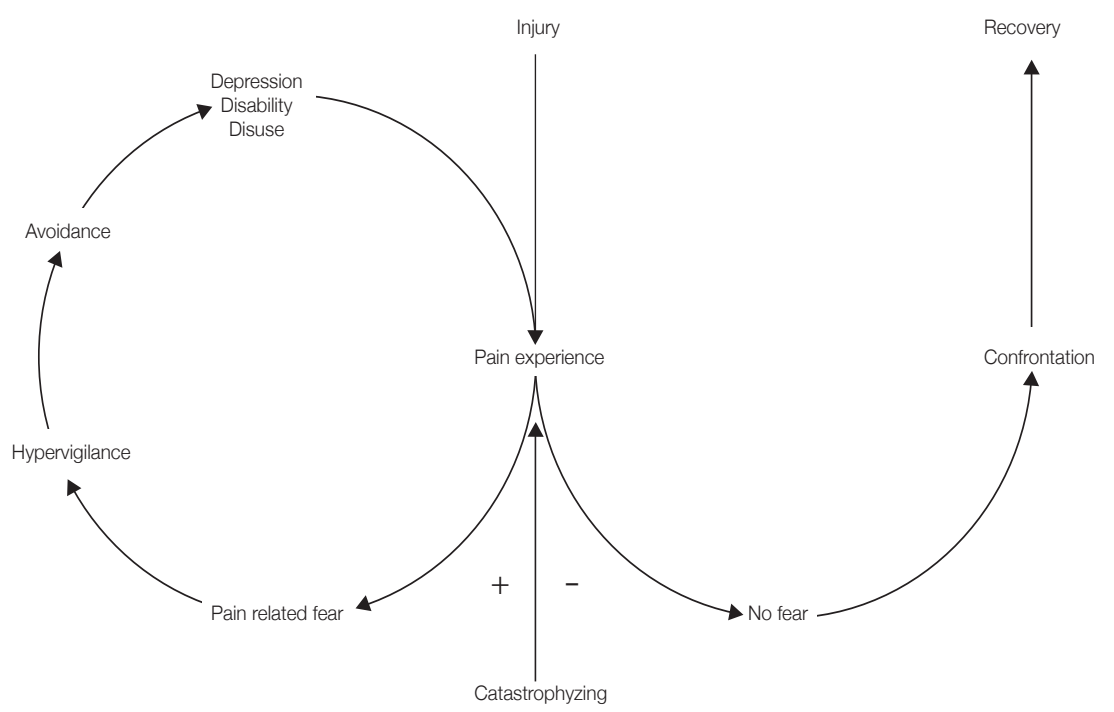

Figure 1. The Fear - Avoidance Model (Adapted from Vlaeyen \& Linton, 2000)

By the postulation of pain-related fear, pain catastrophizing, and avoidance behaviour as essential elements, fear-avoidance models have offered a fruitful framework within which the development and maintenance of persisting pain complaints can be understood. Empirical support for the fear-avoidance model has been found within the area of chronic low back pain, osteoarthritis, neck pain, and chronic headache (e.g., Fritz, George, \& Delitto, 2001; Leeuw et al., 2007; Vlaeyen \& Linton, 2000; Waddell et al., 1993). A multitude of studies in pain patients, but also in healthy controls possessing elevated levels of pain-related fear and pain catastrophizing, have consistently demonstrated the association between both constructs and (1) dysfunctional behavioural responses to pain: for example heightened disability, lower activity levels, lower pain tolerance, reduced endurance of pain, escape and avoidance behaviour; (2) dysfunctional subjective responses to pain: for example heightened pain intensity levels, more distress because of the pain; and (3) dysfunctional cognitive responses to pain: for example hypervigilance towards signals of pain, attentional interference by pain (e.g., Crombez, Eccleston, Baeyens, \& Eelen, 1998b; Crombez, Eccleston, Baeyens, Van Houdenhove, \& Van Den Broeck, 1999; Denison, Asenlof, \& Lindberg, 2004; McCracken, Gross, Aikens, \& Carnrike, 1996; McMurtry, 2005; McNeil \& Rainwater, 1998; Peters, Vlaeyen, \& Kunnen, 2002; Severeijns, Vlaeyen, van den Hout, \& Weber, 2001; Sullivan et al., 2001; Sullivan, Lynch, \& Clark, 2005; Sullivan, Stanish, Waite, Sullivan, \& Tripp, 1998; Vlaeyen \& Linton, 2000).

Although fear-avoidance models offer a good framework for explaining the transition from acute to chronic pain, they do not describe the pathways to entering this self-perpetuating negative spiral of pain in the first place. In other words: it remains unclear why certain people are inclined to respond to physical threat in an anxious, catastrophic, and avoidant manner, whereas others do 
not. In order to provide an answer to this question, it has been proposed that specific personality characteristics might make persons more or less prone to making these maladaptive responses. At present, an extensive body of literature is already available on factors that are considered to instigate dysfunctional responses to pain, including personality traits, affective factors, cognitive factors, and psychophysiological factors. To a much smaller extent, research has proposed factors that can exert a positive influence on the management of pain, thereby possible protecting persons against developing chronic pain. Providing a detailed overview of all subsumed vulnerability and resilience factors would exceed the scope of this dissertation significantly. Therefore, this introductory chapter will be limited to the discussion of only those factors that constitute a central role in the current thesis.

\section{Negative emotional personality traits}

Within the biopsychosocial perspective, pain is not only defined as a sensory experience, but also as an emotional one. The International Association for the Study of Pain (IASP) has formulated the following definition of pain: 'An unpleasant sensory and emotional experience associated with actual or potential tissue damage, or described in terms of such damage' (Merskey \& Bugduk, 1994). Congruently with findings in other emotional disorders (e.g., anxiety, depression), it has been proposed that negative emotional factors, more specifically anxiety-related factors, fulfil an important role in the way in which pain is perceived, interpreted and responded to (Lang \& Craske, 1997; Mathews \& MacLeod, 1994; Öhman, 2000). The link between pain and anxiety is adaptive from an evolutionary point of view, since a 'healthy fearfulness for pain' protects individuals against potential tissue damage (Öhman, 2000). As such, individuals will be reluctant to put their hands on a hot plate, or to grab the sharp blade of a knife with their bare hands because they fear the pain, injury, and disability that they anticipate to be associated with these actions. Nevertheless, as already described in the preceding section, the exaggerated fearfulness of pain and putative consequences of pain constitute critical factors in provoking the transition from acute to chronic pain (e.g., Vlaeyen \& Linton, 2000).

In addition to pain-specific fear constructs, more general and trait-like anxiety factors (i.e., general negative personality traits: negative affectivity and trait anxiety, and fundamental fears: anxiety sensitivity and injury/illness sensitivity) have been proposed as contributing factors to the exacerbation of acute pain episodes and the development of chronic pain (Hadjistavropoulos, Asmundson, \& Kowalyk, 2004; Keefe, Rumble, Scipio, Giordano, \& Perri, 2004; Keogh \& Asmundson, 2004). More precisely, it is assumed that elevated levels of these traits might make persons more prone to respond fearfully and catastrophically to pain, and as such contribute indirectly to the onset and maintenance of chronic pain.

The association between negative affectivity, trait anxiety and chronic pain has been demonstrated in several studies in both clinical and healthy populations. Both negative affectivity and trait anxiety are conceived as the general, stable, and trait-like tendency to view the world in a negative way and to respond fearfully to a broad range of situations (Clark \& Watson, 1991; Lilienfeld, Turner, \& Jacob, 1993). Heightened levels of both traits were found to be related to increased 


\section{$\Uparrow$ chapert}

pain intensity, increased discomfort and disability by the pain, hypervigilance for internal bodily sensations, and less adequate coping with and perceived control over pain (Keogh \& Asmundson, 2004; Stegen, Van Diest, Van de Woestijne, \& Van den Bergh, 2001). Furthermore, a large body of research in both clinical and healthy populations is supportive of the role of anxiety sensitivity in determining dysfunctional responses to pain (e.g., Asmundson, Wright, \& Hadjistavropoulos, 2000). Anxiety Sensitivity is commonly defined as the fear of anxiety-related symptoms and sensations that arises from the belief that these sensations are precursors of physical, social, or psychological harm (Reiss, Peterson, Gursky, \& McNally, 1986), and was originally conceived as a risk factor for panic disorder (Clark, 1986; Cox, 1996; Reiss, 1991; Teachman, 2005). Nevertheless, the sensitivity for somatic sensations that characterizes AS has instigated the examination of its role in the context of pain as well (Asmundson et al., 2000; Stewart \& Asmundson, 2006). Hence, elevated levels of anxiety sensitivity were found associated with increased disability by pain, increased medication use, decreased tolerance for pain, and negative cognitive biases for pain-related and health threatening stimuli (e.g., (Asmundson, Wright, Norton, \& Veloso, 2001; Greenberg \& Burns, 2003; Keogh \& Cochrane, 2002; Norton \& Asmundson, 2004; Stewart \& Asmundson, 2006). Anxiety sensitivity has been proposed to constitute one of three fundamental fears - together with the fear of negative evaluation and injury/illness sensitivity (Reiss, 1991; Taylor, 1993). These three fundamental fears are assumed to underlie the common fears and psychopathology that we encounter in our daily society (e.g., fear of spiders, blood-phobia, social phobia) (Reiss, 1991; Taylor, 1993). Unlike negative affectivity and trait anxiety, the fundamental fears are assumed to be more specifically related to affective responses to those situations that are congruent with the specific content or object of each fear. As is already indicated in its name, the fear of negative evaluation refers to the heightened sensitivity and fearfulness for social evaluative situations and rejection. This latter fear is assumed to constitute a risk factor within the development of social fears and social phobia predominantly, and is assumed to possess less relevance within the prediction and development of chronic pain. Injury/illness Sensitivity, on the other hand, is conceived as the fear of getting injured or becoming seriously ill in the future (Reiss, 1991; Taylor, 1993). Starting from this conceptualisation, this factor might serve a particularly good candidate to consider for its role in the onset and persistence of chronic pain. Nevertheless, contrasting the considerable amount of attention that has been devoted to studying the influence of AS to pain and pain-related disability, the study of this second putative important fundamental fear, injury/illness sensitivity, has been largely neglected in pain research. The putative value of studying the role of IS in the onset and persistence of chronic pain complaints has as such been limited to the sparse direct or indirect acknowledgement of this research gap by some authors (e.g., Keogh \& Asmundson, 2004; Reiss, 1991; Taylor, 1993).

The growing body of research on the contribution of individual anxiety constructs to pain, in combination with observations of significant correlations and putative content overlap between some of these constructs have stressed the need for an integrative view on the way in which these individual constructs diverge from, and relate to one another. To satisfy this need, a theoretical framework, taking the form of a hierarchical tree has been proposed that incorporates all the negative personality constructs that are assumed relevant for pain, while conceptualizing the subsumed 
relation between them (see Figure 2; Keogh \& Asmundson, 2004). In this model, the general negative traits, the fundamental fears, and the pain specific fear constructs are incorporated.

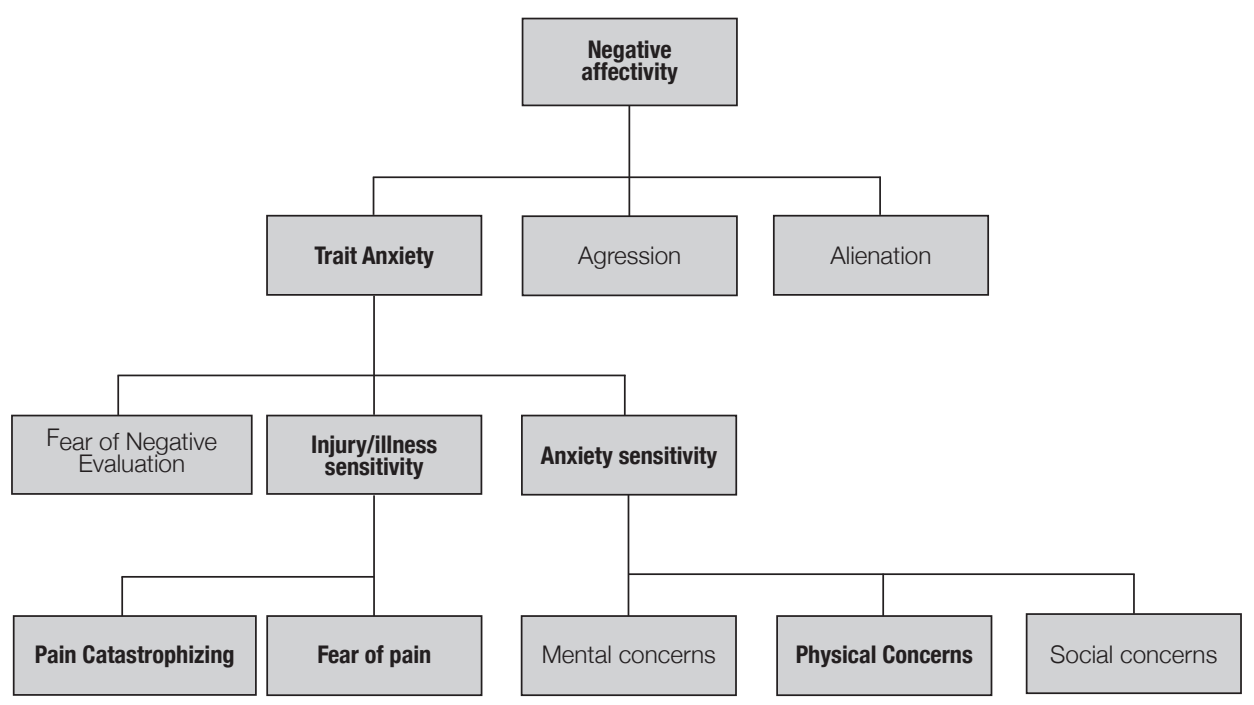

Figure 2. Representation of the hierarchical model as proposed by Lilienfeld et al. (1993), and the modified hierarchical model for pain (Keogh \& Asmundson, 2004). The constructs assumed relevant for pain-related fear and anxiety are printed in bold.

\section{A CONCEPTUAL THEORETICAL FRAMEWORK: A HIERARCHICAL MODEL OF NEGATIVE EMOTIONAL CONSTRUCTS}

According to Watson and Clark (1992), a hierarchical model requires that both general and specific factors influence the traits in the hierarchy. These authors proposed a two-level hierarchical model in which content-specific negative emotions (fear, guilt, hostility, and sadness) existed as covarying, yet distinguishable lower-order factors under the general trait construct NA (Watson \& Clark, 1992). Based on the ideas of Watson \& Clark, Lilienfeld and colleagues (1993) have proposed a more elaborated hierarchical model of negative emotional constructs, hereby distinguishing between levels of trait specificity of the incorporated constructs (see Figure 2). In a hierarchical model, the constructs that reside at the lower levels of the hierarchy are understood as specific lower-order constructs that subordinate to more general higher-order constructs residing in the higher levels of the hierarchy (Keogh \& Asmundson, 2004; Lilienfeld et al., 1993; Watson \& Clark, 1992). Hence, constructs at the lowest nodes of the hierarchy are assumed to have a very direct and specific influence on emotional-related problems, whereas constructs that reside at the top of the hierarchical structure will be more broadly and generalized related to a variety of problems. 
Another assumption of a hierarchical model is that each individual construct will have variance in common with the higher-order construct that it subordinates to, as well as with the neighbouring constructs that reside at the same hierarchical level. Nevertheless, each construct is assumed to possess unique predictive variance as well, and as such, they are conceived as distinguishable from one another (Lilienfeld et al., 1993; Watson \& Clark, 1992). Lilienfeld et al. (1993) proposed the hierarchical model as a putative solution for the ongoing debate in the literature on the 'difference' between the constructs of TA and AS in their predictive value of anxiety and anxiety disorders (see Lilienfeld, Turner, \& Jacob, 1998; McNally, 1996; Reiss, 1997), for details on this controversy). In adopting a hierarchical structure that contains higher (TA) and lower-order (AS) factors, AS is proposed to provide specific information (i.e., tendency to react anxious to one's own anxiety sensations and symptoms) that cannot be accounted for by the more general higher-order factor of trait anxiety (i.e., tendency to react anxiously to a broad range of anxiety provoking situations), even though both constructs are conceptually closely related.

The hierarchical model as proposed by Lilienfeld et al. (1993) can easily be adapted to the area of chronic pain, requiring the addition of specific pain-relevant fear constructs at the lowest level of the hierarchy only. As demonstrated in Figure 2, this modified hierarchical model situates the most pain-specific constructs, i.e., fear of pain and pain catastrophizing, at the lowest level of the model, directly under the higher order factor injury/illness sensitivity. Injury/illness sensitivity and anxiety sensitivity are assumed to co-exist at the same hierarchical model under the higherorder construct trait anxiety, which is at its turn subordinated to negative affectivity (Keogh \& Asmundson, 2004).

The hierarchical model as proposed here has never been formally tested yet, and constitutes a merely conceptual organisational structure, that helps researchers to understand relations between the various constructs. In this light, it should be noted that this model does not intend to be definite with respect to the constructs that it includes and the exact placement of constructs within each level (see also Keogh \& Asmundson, 2004).

\section{COGNITIUE FACTORS: AN INFORMATION PROCESSING APPROACH}

According to the cognitive behavioural approach to pain, emotional and behavioural responses to pain are to a great extent determined by the cognitive appraisal and interpretation of a situation (Gatchel, Peng, Peters, Fuchs, \& Turk, in press; Jensen, Romano, Turner, Good, \&Wald, 1999; Turk \& Okifuji, 2002). Following this perspective, cognitive mechanisms and processes are assumed to have a substantial impact on the manifestation of maladaptive responses to physical threat, and might mediate the relation between responses to threat and the presence of pain-related anxieties.

At present, the most dominant view in experimental cognitive psychology, the informationprocessing perspective, offers a good framework to elucidate the structure and function of cognitive processes that guide subsequent behaviour. One way to gain insight in these cognitive processes is by asking persons directly about their thoughts, feelings, and attitudes, and so forth. This direct assessment method relies on self-report measures, for example questionnaires or interviews, which are commonly referred to as explicit measures. However, self-report measures are 
known to possess several drawbacks, including a high susceptibility to social desirable response tendencies, response bias, and conscious consideration that affect responses (De Houwer, 2001; Fazio \& Olson, 2003; Paulhus, 1998). Moreover, it has been suggested that persons only have limited access to, and might thus not always be capable to accurately report, their own mental representations and processes (Asendorpf, 2007; Wilson, Lindsey, \& Schooler, 2000). As such, it can be questioned whether self-reported cognitions are reflective of the genuine fundamental cognitive processes that are subsumed to guide behaviour. To overcome these problems, automatized testing paradigms have been developed. These paradigms aim to assess cognitive processes indirectly; that is, by inferring them from behavioural responses (e.g., reaction times, reading times) within a specific context (Asendorpf, 2007; Fazio \& Olson, 2003). These so-called implicit measures do not only provide a more appropriate measure of the process of interest, they can also provide a more reliable insight in the temporal pattern of cognitive processes. As such, they allow the study of cognitive processes in the early stages of information processing, referred to as automatic processes, as well as the study of the strategic or controlled processes that occur in the later stages of information processing (McNally, 1995; Shiffrin \& Schneider, 1977). In short, automatic processes are conceived as largely unconscious and involuntarily, requiring a minimum of processing capacity, and being relatively difficult to regulate, whilst controlled processes are conceived as conscious and voluntarily, requiring considerable processing capacity, and being more easily to adjust (Beck \& Clark, 1997; McNally, 1995; Shiffrin \& Schneider, 1977). Automatic processes (implicit cognitions) are assumed to predict spontaneous, reflexive behaviour, whereas controlled processes (explicit cognitions) are assumed to steer controlled, reflective behavioural patterns predominantly (Fazio \& Olson, 2003; Mathews \& Mackintosh, 1998; McNally, 1995). As such, both automatic and controlled cognitions can exert separate, conjoint, competitive, or interactive influences on perceptions, actions, and judgements (Nosek, 2007). For example, implicitly and explicitly measured cognitions (e.g., implicit and explicit assessments of self-concept of being shy) have been found differentially predictive of divergent components of one behaviour (i.e., spontaneous shyness behaviour and controlled shy behaviour) (Asendorpf, Banse, \& Mucke, 2002). Other studies have demonstrated that explicitly measured attitudes (e.g., self-reported fear of spiders) can diverge from implicitly measured attitudes (negative associations towards spider pictures) (e.g., de Jong, Hout van den, Rietbroek, \& Huijding, 2003; Huijding \& De Jong, 2005). In addition, implicit attitudes have been found to possess explanatory value over and above this of explicit attitudes for certain problem behaviours, for example substance abuse (de Jong, Wiers, van den Braak, \& Huijding, 2007; Huijding \& de Jong, 2006). Taken together, the consideration of both implicit and explicit processes in the prediction of any behaviour or personality construct, so also pain, can contribute to a more thorough and complete understanding of the various components that constitute this behaviour or this personality construct.

\section{INFORMATION PROCESSING APPROACH TO PSYCHOPATHOLOGY}

Information processing approaches to psychopathology stipulate that the faulty processing of information, commonly referred to as cognitive bias, contributes to the onset 


\section{$\Uparrow$ chapert}

and maintenance of psychopathology (Beck \& Clark, 1997; Mathews \& MacLeod, 1994). More specifically, individuals' negative affective state or specific concerns are thought to be associated with favouring the processing of information that is congruent to these affective states and concerns, and this selective processing of information is then assumed to guide subsequent behaviour (Beck \& Clark, 1997; Eysenck, 1997; Mathews \& MacLeod, 1994; Williams, Watts, MacLeod, \& Mathews, 1988). Moreover, since many of the irrational behaviours that are observed in psychopathology are known to be largely involuntarily (e.g., compulsions, panic attacks, addictions, etc.), it has been suggested that automatic processes in particular will steer these irrational behaviours (McNally, Hornig, Hoffman, \& Han, 1999). At present, it is well established that cognitive biases play a major role in the aetiology and exacerbation of emotional and affective disorders. Cognitive models of emotional disorders state that a selective bias towards threat and the negative characterizes anxious and depressed individuals, and constitutes the core difference between individuals with and without anxiety and depression (Beck \& Clark, 1997; Mathews \& Mackintosh, 1998; Mathews \& MacLeod, 1994). Given the conceptualisation of pain as an emotional disorder, the same cognitive processes that operate in anxiety have been suggested assumed to apply to the area of chronic pain as well (McKellar, Clark, \& Shriner, 2003; Pincus \& Morley, 2001). Hence, cognitive models of anxiety might serve a useful framework for understanding the occurrence of cognitive biases in the context of pain as well.

In 1997, Beck and Clark have proposed a three-stage model of cognitive processing to clarify the occurrence of cognitive bias in anxiety, in which the sequential stages are described that are presumed to characterize the processing of threatening stimuli. Rather than holding on to a pure distinction between biases occurring at either the automatic or the controlled level of information processing (McNally, 1995), Beck and Clark (1997) advocate in their model that cognitive processing biases will be characterized by a mixture between automatic and strategic processing in each stage of information processing. The first stage of this model, the initial registration phase, involves the rapid, instantaneous, and automatic recognition of a stimulus and is referred to as the orienting mode. This mode is assumed to be entirely automatic, without any option for elaborative or strategic processing. The orienting mode functions as an 'early detection warning system' that aids the individual to allocate attention to putative threat. As such, this stage of information processing optimizes our chances of survival by signalling severe threat instantaneously.

The early detection of a threatening stimulus will then activate the second stage of information processing, referred to as the phase of immediate preparation. This stage is directed at minimizing danger and maximizing safety, and includes autonomic responses (fight/flight responses), behavioural responses (escape/avoidance), primal thinking (narrowing of attention towards the threat), feelings of fear, and hypervigilance for threat cues. As such, this stage is assumed to guide a cognitive/behavioural/affective/physiological response pattern very rapidly and automatically. This stage of processing allows for initial semantic analysis of the stimulus or a primary threat appraisal that ensures that processing priority is given to the detected threatening stimulus. Nevertheless, this second stage is still considered to be largely automatic, involuntarily and occurring outside awareness. Finally, in the last stage of information processing, the secondary elaboration phase, elaborative processing of the meaning and consequences of the threatening information will take place. This stage involves the activation of other related schemas that 
represent current concerns of the individual, and the reflective consideration of the meaning and context within which the threat occurs. Furthermore, the secondary elaboration phase involves the evaluation of possible coping resources that are available to the individual as well. Two important components of the secondary elaboration phase are excessive worrying and the search for safety signals. Excessive worrying is one of the core cognitive features of anxiety and is understood as an elaborative process that results from the activation of the primal threat mode and other more constructive modes of thinking. Excessive worrying can lead to an escalation of anxiety or pain because this process is often dominated by primal mode thinking that is actively directed at minimizing danger and maximizing safety, as such blocking off further constructive modes of processing. The search for safety signals refers to the strategic and elaborative search for means that can reduce the anxiety or pain. As such, the search for safety signals is aimed at counteracting the processes that were activated in the primal mode. Although the search for safety signals can effectively reduce anxiety or pain in the short term, it often results in unsuccessful attempts in the light of maintaining safety (e.g., avoidance, medication, coping, finding supports with others), leading to chronic suffering in the long term.

Congruent with the assumed orientation towards threat in anxious and depressed individuals, pain-related anxiety is assumed to be associated with a selective cognitive bias for personally relevant-threatening stimuli (i.e., stimuli that relate to pain, injury, illness, health, bodily sensations). This selective processing of information might incline persons towards maladaptive responses that contribute to increased pain and disability (McKellar et al., 2003; Pincus \& Morley, 2001). Following the three-stage cognitive model, the detection of pain-related information in the orienting mode will lead to the activation of a primal threat appraisal that instigates a cognitive/ affective/physiological/behavioural pattern of responses very rapidly, automatically, unintentionally, and involuntarily. Further elaborative processing of the threatening information in the secondary elaboration phase might then strengthen, or counteract dysfunctional response patterns through processes of excessive worrying and the search for safety signals.

In sum, the three-stage information-processing model assumes both automatic and strategic processes to be involved in cognitive biases in emotional disorders (Beck \& Clark, 1997). Following this, both the primary threat appraisal (as occurring in the second stage of information processing) and the secondary elaboration (as occurring in the third stage of information processing) require attention in treatment approaches. More specifically, Beck and Clark (1997) suggest that successful treatment approaches will have to aim at reducing processes that occur in the primal threat mode and augmenting functional, positive elaborative processing in the secondary elaboration phase.

\section{COGNITIVE BIAS AND CHRONIC PAIN: FAVOURING THE PROCESSING OF PAIN- RELATED INFORMATION}

Studying cognitive biases in the context of pain at both an automatic and a strategic level, as a function of pain and as a function of pain-related anxieties, can contribute significantly to our understanding of pain. Gathering knowledge on these processes and their temporal pattern 


\section{k $k$ atame}

provides (1) theoretical insight in the fundamental processes that underlie dysfunctional paininstigating behaviours, (2) information on the functionality of specific cognitive mechanisms as vulnerability factors within the aetiology of pain, and (3) information on the aspects of cognition that have to be rectified by treatment paradigms aimed at pain reduction and prevention of the development of chronic pain. To date, various studies have demonstrated the occurrence of cognitive processing bias within the context of pain in three main areas: (1) memory biases (2) attention biases, and (3) interpretation biases (McKellar et al., 2003; Pincus \& Morley, 2001).

Memory bias. With respect to memory bias, both explicit and implicit memory tasks have provided robust evidence for memory bias in chronic pain patients. This memory bias is characterized by better recall for pain-related, injury-related, and health-related stimuli in chronic pain patients in comparison to healthy controls (e.g., Edwards, Pearce, Collett, \& Pugh, 1992; Pincus, Pearce, McClelland, \& Isenberg, 1995). Nevertheless, substantial evidence on the relation between memory bias for pain-related information and individual pain-related anxiety levels is still lacking. Therefore, it is yet unclear whether the observed memory bias forms a mere by-product of the state of pain, or whether it might serve a latent vulnerability mechanism that instigates dysfunctional responses to the threat of pain in anxious individuals even so (Pincus \& Morley, 2001). Unlike memory biases, attentional and interpretation biases have both been studied as a function of the state of pain and as a function of pain-related anxieties. To date, attention is probably the most extensively studied cognitive process in relation to pain.

Attention bias. Most studies on the detection of attention bias towards pain and cues of pain have relied on experimental automatized testing paradigms such as the emotional Stroop task and the dot-probe task. To put it simple, these tasks present both pain-related stimuli (pictures or verbal stimuli) and non-pain-related stimuli to participants, and require fast responses to certain features of the presented stimuli that are irrelevant to the valence of the stimuli (e.g., presentation colour in emotional Stroop, presentation location in dot probe). Slowed down (Stroop) or facilitated (dot probe) responses to the pain-related stimuli are then assumed to reflect attention bias. Although some studies found support for attention bias in pain patients using these paradigms, these results proved to be difficult to replicate in other studies and seemed to depend on the specific task and the exact type of stimulus material that were used to assess the bias (i.e., sensory pain words, affective pain words, pictorial stimuli) (Asmundson, Kuperos, \& Norton, 1997; Asmundson, Carleton, \& Ekong, 2005; Roelofs, Peters, Fassaert, \& Vlaeyen, 2005; Roelofs, Peters, Zeegers, \& Vlaeyen, 2002). In healthy volunteers possessing elevated levels of pain-related anxiety (i.e., pain-related fear, anxiety sensitivity), results on the occurrence of attention bias towards pain-related stimuli showed more consistency (Asmundson et al., 1997; Asmundson et al., 2005; Keogh \& Cochrane, 2002; Keogh, Dillon, Georgiou, \& Hunt, 2001; Keogh, Ellery, Hunt, \& Hannent, 2001), although failures in replicating these findings have been reported as well (e.g., Roelofs, Peters, van der Zijden, Thielen, \& Vlaeyen, 2003; Roelofs, Peters, \& Vlaeyen, 2003). The anomaly of more consistent findings in healthy persons and inconsistent findings in pain patients might suggest that the test paradigms were not difficult enough for pain patients who have to allocate their attentional resources to the continuous presence of actual pain already (Pincus \& Morley, 2001). In a similar vein, Asmundson et al. (2005) postulated that the use of sensory and affective pain words as threatening stimulus material might fail in assessing attention 
bias in patients because these stimuli are not threatening enough for pain patients, in contrast to healthy persons who are not yet suffering from persistent pain. Altogether, emotional Stroop and dot probe paradigms might suffer from low ecological validity due to the use of verbal and pictorial stimulus material. Several studies in which an ecological more appropriate paradigm (i.e., the primary task paradigm) has been used, have consistently and robustly demonstrated the attention demanding properties of pain, and the interruptive affect that pain can have on the allocation of attention to other tasks (e.g., Crombez, Eccleston, Baeyens, \& Eelen, 1998a; Crombez et al., 1998b; Eccleston \& Crombez, 1999; Peters et al., 2002). In the primary task paradigm, the effect of the administration of electrical pain stimuli on the performance of a simple cognitive task (e.g., distinguishing high and low pitch tones) is examined. The resulting interruptive effect of pain on attention has proven to be amplified by the intensity, novelty, unpredictability, and threat value of the pain stimulus (Eccleston \& Crombez, 1999). Moreover, attentional interference has been found to be especially pronounced in persons high in pain catastrophizing and fear of pain (Carleton, Asmundson, \& Taylor, 2005; Crombez et al., 1998a, 1998b). Based on this latter line of research, it can thus be concluded that there is substantial evidence that pain demands attention, both in pain patients, but also in healthy individuals possessing elevated levels of specific pain-related fears. In addition, other studies have demonstrated that attention shifts to pain and pain-related cues and, once detected, pain is difficult to disengage from (e.g., Koster, Crombez, Verschuere, Van Damme, \& Wiersema, 2006; Van Damme, Crombez, \& Eccleston, 2004). In sum, it can be concluded that attention biases are important to be considered in the onset and exacerbation of maladaptive response to pain, although further clarification is necessary on the precise structure and impact of this process in relation to maladaptive responses to physical threat.

Interpretation bias. Finally, there is substantial evidence that both pain patients and persons with elevated levels of pain-related fear are inclined to interpret ambiguous and innocuous pain-related stimuli in a threatening or negative fashion (Edwards \& Pearce, 1994; Pincus, Pearce, McClelland, Farley, \& et al., 1994; Pincus, Pearce, \& Perrott, 1996). Recently, Keogh and colleagues (Keogh, Ellery et al., 2001; Keogh, Hamid, Hamid, \& Ellery, 2004) have demonstrated that negative interpretative bias for ambiguous situations mediated the relation between individual levels of anxiety sensitivity and tolerance for cold-pressor pain. Nevertheless, it should be noted that studies on interpretive bias in the context of pain have relied on explicit measures predominantly, using homophones (words with the same pronunciation, but a different spelling: e.g., dye/die; (McKellar et al., 2003; Pincus et al., 1994), homographs (words with the same spelling, but different meanings: e.g., needle; (Pincus et al., 1996), word-stem completion tasks (word stem can be completed in different ways: e.g., ten---: tender/tennis; (Edwards \& Pearce, 1994) or interpretation questionnaires (e.g., Keogh, Ellery et al., 2001; Keogh et al., 2004). Consequently, these studies cannot provide insight in the temporal pattern of the negative interpretative thoughts. More precisely, it remains unclear whether the negative bias results from elaborative, constructive, integrative processes at the moment of responding to ambiguity (i.e., in the second elaboration stage) only, or if negative interpretations occur at an automatic spontaneous level already (i.e., at the primal mode stage). 


\section{COGNITIVE PROCESSES PROMOTING ADJUSTMENT TO PAIN: PERCEIVED CONTROL AND SPECIFIC SELF-EFFICACY}

In addition to cognitive mechanisms assumed to influence maladaptive responses to pain, it is furthermore interesting to study cognitive mechanisms that might contribute to the adjustment to and adaptive coping with acute and chronic pain. As such, certain cognitive mechanisms or processes might counteract the activation of a primary threat mode, or promote adaptive functional processing in the elaborative phase of information processing, leading to beneficial effects on the pain experience and protecting against the development of chronic pain.

One cognitive construct that has been proposed as a mediator of decreased pain and disability is perceived control or the belief that one has at one's disposal a response that can influence the aversiveness of an event (Thompson, 1981). In (chronic) pain patients, perceived control over pain has been found predictive of patients' well-being and of better patient functioning (less depression, less disability, less interference by pain), and was found associated with increased activity levels, lower perceived pain severity, and increased patient satisfaction with treatment strategies (Jensen \& Karoly, 1991; Pellino \& Ward, 1998; Tan, Jensen, Robinson-Whelen, Thornby, \& Monga, 2002). In experimental studies conducted in healthy volunteers, perceived control over pain has been found related to increased tolerance and prolonged endurance of experimentally induced pain (Arntz \& Schmidt, 1989; Feldner \& Hekmat, 2001). Recently, Janssen, Spinhoven, and Arntz (2004) demonstrated that successful control over the pain has a positive influence on individuals' mood, whereas repetitive failures in controlling pain lead to increased anger and physiological reactivity. It seems noteworthy to mention that the idea that the pain can be controlled is already sufficient to achieve these beneficial effects, even when the control is not genuinely effective or utilized.

A second cognitive factor that is assumed to mediate pain and disability is specific selfefficacy. Specific self-efficacy refers to the belief one has in one's own capability and quality to achieve desired outcomes using a specific task, strategy, or technique (e.g., Litt, 1988; Rokke, Fleming Ficek, Siemens, \& Hegstad, 2004). Note that specific self-efficacy is distinguishable from the trait-like personality construct of generalized self-efficacy, which refers to the belief and confidence one has in one's own capability to achieve desired outcomes in every day life and a broad range of situations (Luszczynska, Gutierrez Dona, \& Schwarzer, 2005). As such, specific self-efficacy is situational determined and constitutes a cognitive state factor, rather than a trait construct. An extensive amount of studies has examined the relation between specific SE and pain both in clinical and non-clinical populations, demonstrating that specific SE beliefs are predictive of pain tolerance, pain endurance, and the degree of experienced disability by pain (Baker \& Kirsch, 1991; Denison et al., 2004; Litt, 1988; Rokke et al., 2004; Williams \& Kinney, 1991). In addition, prospective studies have demonstrated that confidence in one's ability to engage in a post-surgical rehabilitation program and an increase in this confidence in the course of the programme was associated with faster recovery and better long-term outcomes (e.g., Waldrop, Lightsey, Ethington, Woemmel, \& Coke, 2001). Studies on the relation between specific SE and pain have used different operationalizations of 'specific' SE; including the usage of medication, the 
engagement in a pain treatment programme, the performance of relaxation techniques, or simply the belief that one can cope well with a specific type of pain. It might therefore be suggested that the operationalization of specific SE as 'the belief in one's ability to manage pain by the use of a specific strategy or technique', can be understood as SE beliefs regarding perceived control on the pain experience (e.g., Arnstein, 2000; Jackson, lezzi, Gunderson, Nagasaka, \& Fritch, 2002; Rokke et al., 2004). Indeed, it is well acknowledged that both perceived control and specific selfefficacy are intrinsically related to each other (Lang \& Craske, 1997; Litt, 1988; Pellino \& Ward, 1998; Rokke et al., 2004). By manipulating both perceived control and specific self-efficacy beliefs in an experimental paradigm, Litt (1988) demonstrated that the benefits of perceived control over pain on pain tolerance were the greatest for those who were most confident (i.e., high selfefficacious) that they were able to exercise this control. In a similar vein, Jensen and Karoly (1991) have stressed that in order to achieve a positive influence on well-being and activity levels in pain patients, the belief in ones personal ability to control pain is as important as the belief in the control strategy itself.

Since both specific self-efficacy and perceived control have proven to be susceptible to manipulations, it might be suggested that these cognitive factors constitute attractive candidates for treatment approaches to pain.

\section{FoCUS AND OUTLINE OF THE PRESENT THESIS}

The central research objective of the present thesis constitutes the examination of specific psychological factors for their putative vulnerability or protective role in the development and persistence of chronic pain. More specifically, the current thesis aims to examine several anxiety traits and fear constructs out of the hierarchical model as risk factors for the development of chronic pain, as well as underlying cognitive mechanisms that might contribute to or protect against the persistence of pain complaints. These main objectives will be addressed by studying both the independent and interactive role of these anxiety traits and cognitive mechanisms in relation to responses to pain or the threat of pain.

The thesis will be built up of two parts: I: the validity of conceptualizing several pain-related anxiety and fear constructs in a hierarchical model, and II: the role of psychological vulnerability factors. The hierarchical model as outlined above incorporates both anxiety sensitivity and injury/ illness sensitivity as putative vulnerability factors within the context of pain, and proposes that IS forms the higher-order factor of fear of pain and pain catastrophizing. Nevertheless, when Keogh \& Asmundson (2004) proposed the hierarchical model, no studies that were directly supportive of the importance of IS within the development of chronic pain were available yet. The first study within this thesis (Chapter 2) aimed to address this gap in the literature by studying the differential predictive value of both IS and AS to pain-related fear and pain catastrophizing in a correlational design. In addition, the differential predictive validity of both IS and AS for subjective anticipatory fear ratings and pain tolerance for experimentally induced pain was examined in a second study of Chapter 2. After establishing the role of IS as an important factor to consider in the context of pain, the following chapter zooms in on the componential and dimensional structure of the proposed 


\section{$\Uparrow$ chapert}

hierarchical model of pain-relevant negative constructs. Each construct of the hierarchical model is commonly measured with a self-report measure that intends to represent a well-validated and reliable operationalisation of that construct. By gathering information regarding the perceived similarity between the individual items of these self-report measures, we have explored how these individual items are found to group together in larger units, and how they can be situated relatively to each other within a geographical dimensional space (Chapter 3). The resulting components and dimensional structure were then compared for their resemblance to the proposed theoretical conceptualisation of the constructs in the hierarchical model.

Part II of this thesis describes a series of cross-sectional experimental studies that aim to further substantiate the role and function of the psychological vulnerability factors that were described in the introduction sections above in the explanation of maladaptive responses to pain and the threat of pain. Each study starts from specific hypotheses that aim to light out several theoretically related factors in their relative relation to responses to (the threat of) pain. Four out of the five studies in this second part examine the cognitive processing of pain-related information in function of individual levels of anxiety and fear-related constructs (chapter 4, 5, 6, and 7). An additional focus in these studies concerns the further substantiation of IS as a valuable factor to consider in the context of pain, and the examination of putative differential roles of IS and AS in their contribution to cognitive and behavioural responses to pain.

In chapter 4, an indirect association measure (EAST; Jan De Houwer, 2003) will be adopted to examine whether individual levels of anxiety sensitivity and injury/illness sensitivity can be found to be related to an automatic threat appraisal of stimuli that are reflective of pain, injury, and illness. In this study, emphasis is put on the putative differential predictive value of injury/ illness sensitivity and anxiety sensitivity for the automatic threat appraisal as well. Furthermore, the differential value of injury/illness sensitivity and anxiety sensitivity in predicting dysfunctional behaviour will be addressed by examining their predictive power for two behavioural correlates; i.e., the tendency to engage in health protecting behaviour and the use of health care services.

In the following two chapters, a central role is assigned to the examination of a negative interpretation bias in the context of pain. First, evidence for the content-specificity of this cognitive bias will be sought by putting forward the Body Sensations Interpretation Questionnaire (Clark et al., 1997) as a useful measure to assess content-specific negative interpretations (Chapter 5). More specifically, this study examines whether individual levels of the global and more specific anxiety-related constructs of the hierarchical model are associated with a general or a rather content-specific negative interpretation bias. Starting from the notion that most evidence for negative interpretation bias in the context of pain has come from studies that have assessed this bias with explicit measures, a study is set up that aimed to provide an automatic measurement of negative interpretations of pain-related ambiguity (chapter 6). Drawing on research in the area of social phobia (Hirsch \& Mathews, 1997; hews, 2000), this study proposes a lexical decision paradigm as an adequate measure to capture the spontaneous and non-reflective interpretations that individuals make when they are confronted with ambiguity that implies illness, injury and painrelated threat. The relation between the resulting automatic interpretation bias as assessed with the lexical decision paradigm and individual levels of anxiety sensitivity, injury/illness sensitivity, pain catastrophizing, and fear of pain will be examined. It is hypothesized that heightened levels 
of the anxiety and fear constructs would be associated with an increased tendency to interpret ambiguous situations negatively. In addition to the biased processing of information, one robust finding within research on the role of cognition in pain concerns the observation that pain can have an interruptive effect on attention that is responsible for deteriorations in cognitive task performance (Crombez et al., 1998a, 1998b; Eccleston \& Crombez, 1999). This attentional interference effect seems to be highly dependent upon specific characteristics of the pain stimulus, and has been found to be particularly enhanced in individuals who are high in pain catastrophizing (Crombez et al., 1998a, 1998b; Eccleston \& Crombez, 1999). The current thesis aims to extend on these findings by examining whether individual levels of anxiety sensitivity and injury/illness sensitivity can found to be related to the interruptive affect of pain on attention as well (Chapter 7). The primary task paradigm as described by Crombez et al. (1998a, 1998b) is used to assess the interruptive effect, and in addition to anxiety sensitivity and injury/illness sensitivity, pain catastrophizing is assessed with the purpose of replicating prior reported findings. Furthermore, this chapter extends on discussing the context within which the interruptive effect of pain on attention is most likely to occur.

In the last and fifth study of the second part of this thesis, a shift is made from focussing predominantly on negative personality and cognitive factors to focussing on the role of positive personality and cognitive factors in determining responses to pain (Chapter 8). This chapter describes an experimental study that examines the influence of perceived control, specific selfefficacy and their interaction with optimism and general self-efficacy on the subjective evaluation of experimentally induced pain. It is hypothesized that persons who believe that they can control their pain will expect and report less pain and fear for experimentally induced pain, and this effect is hypothesized to be especially pronounced when individuals possess high specific self-efficacy on the pain control strategy. Furthermore, it is hypothesized that optimism and general self-efficacy moderate beneficial effects of perceived control and specific self-efficacy. Finally, the last chapter of this thesis will provide a summary and integrative discussion of the results that are described in the individual studies in this thesis (Chapter 9). Furthermore, some limitations to these studies as well as recommendations for further research will be provided in this last chapter.

Before going over to the following chapter, it is important to note that all the studies in this thesis are conducted within a healthy study population, and to inform the reader of about the rationale that has provoked this choice. First, since the main objective of this thesis is to substantiate the importance of personality constructs and cognitive mechanism as putative vulnerability or resilience factors within the onset and exacerbation of chronic pain problems, it is necessary to study their influence outside the presence of current pain complaints. As such, resulting findings in this thesis can be ascribed to the presence of these vulnerability or resilience factors, rather then to the presence of current pain complaints. In addition, injury/illness sensitivity, which constitutes one of the central personality constructs of interest in this thesis, is assumed to reflect the predisposing fear that persons possess regarding the possibility of getting injured or becoming ill in the near or far future. Consequently, the self-report measure that is used to assess this construct entails various items that ask directly about the respondent's concerns of becoming injured or seriously ill in the future. Hence, the assessment and study of this construct is not relevant in a clinical population that is already confronted with persistent pain complaints. 


\section{Part I}

Conceptualizing pain-related anxiety and fear constructs in a hierarchical model

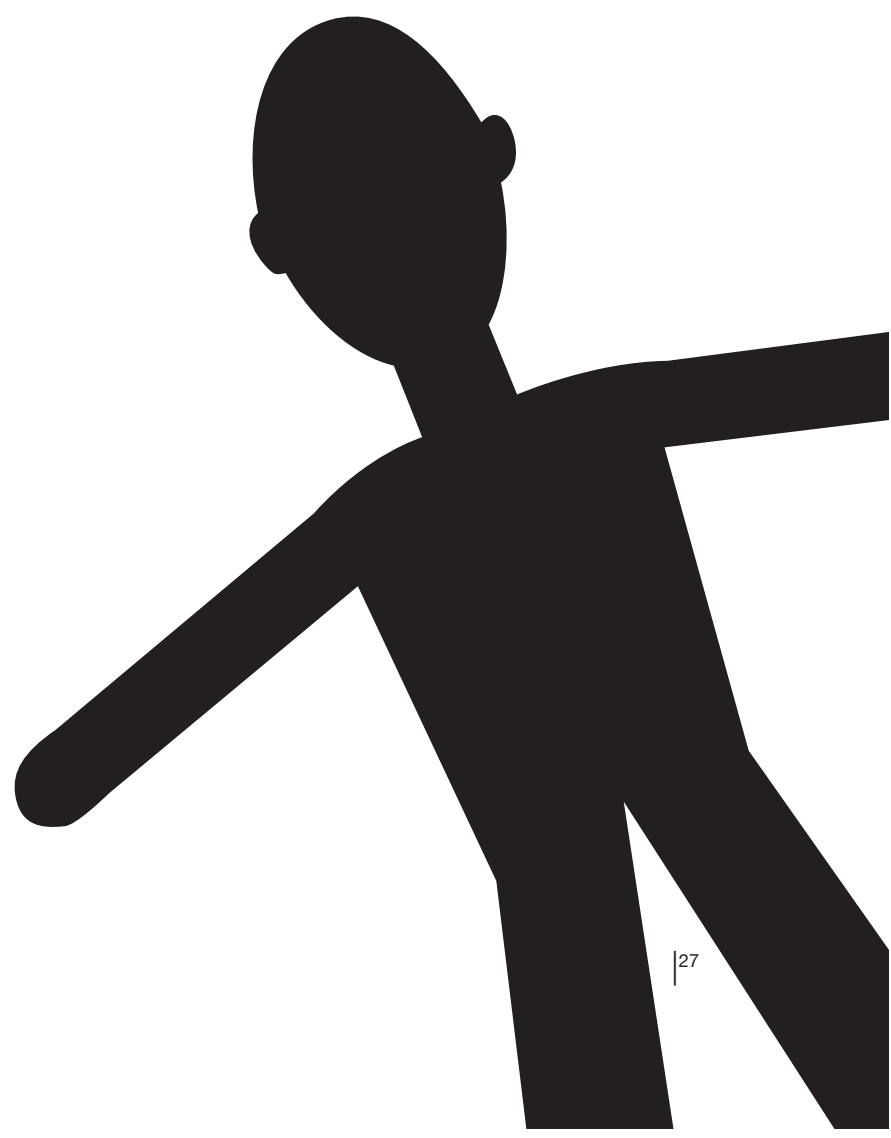




\section{- - \\ Chapter 2}

Do fundamental fears differentially contribute to pain-related fear and pain catastrophizing? An evaluation of the Sensitivity Index.

This chapter is published as:

Vancleef, L. M. G., Peters, M. L., Roelofs, J., \& Asmundson, G. J. G. (2006). Do fundamental fears differentially contribute to pain-related fear and pain catastrophizing? An evaluation of the Sensitivity Index. European Journal of Pain, 10, 527-536. 


\section{Abstract}

Three fundamental fears - anxiety sensitivity (AS), injury/illness sensitivity (IS) and fear of negative evaluation (FNE) - have been proposed to underlie common fears and psychopathological conditions. In pain research, the relation between AS and (chronic) pain processes was the subject of several studies, whereas the possible role of IS has been ignored. The current research examines the role of IS with respect to various pain-related variables in two studies. In the first study, 192 healthy college students completed the Sensitivity Index (SI; a composite measure assessing the three fundamental fears) and various pain-related questionnaires. In a second study, 60 students out of the original sample took part in a pain induction procedure and completed the SI as well. We first examined the properties of the SI. Factor analysis on the SI replicated the proposed factor structure (Taylor, 1993). However, some items of the ASI did show problematic loadings and were therefore excluded in subsequent analyses. The main hypothesis of the current study states that IS is a stronger predictor than AS of pain catastrophizing and fear of pain as assessed by self-report measures, and of pain tolerance and anticipatory fear of pain as assessed in a pain induction study. This hypothesis could be confirmed for all variables, except for pain tolerance, which was not predicted by any of the three fundamental fears. The current study can be considered as an impetus for devoting attention to IS in future pain research.

\section{INTRODUCTION}

Anxiety sensitivity (AS), or the fear of anxiety symptoms (e.g., heart palpitations) arising from the belief that these symptoms will lead to harmful somatic, psychological or social consequences (Reiss et al., 1986), has been suggested as an important personality trait in the development and maintenance of chronic musculoskeletal pain (Asmundson \& Norton, 1995). AS was found to be directly associated with fear of pain, and indirectly with pain-specific avoidance behaviour, irrespective of pain intensity and pain severity, in patients with chronic musculoskeletal pain (Asmundson \& Norton, 1995; Asmundson \& Taylor, 1996). Furthermore, elevated levels of AS influenced the pain experience, in response to a pain induction task, and appeared to be a stronger predictor than fear of pain for pain responses following a cold pressor task (Greenberg \& Burns, 2003; Keogh \& Birkby, 1999; Keogh \& Mansoor, 2001).

AS is considered as 1 of 3 fundamental fears (or sensitivities), together with injury/illness sensitivity (IS) and fear of negative social evaluation (FNE) (Reiss, 1991; Reiss, Peterson, \& Gursky, 1988; Reiss et al., 1986; Taylor, 1993, 1995). A fear is defined as fundamental when it satisfies two criteria: (1) it is a fear of inherently noxious stimuli, and (2) other common fears (e.g., fear of snakes, spiders, or heights) can be logically reduced to the fundamental fear (Reiss, 1991). The distinction between common fears and fundamental fears lies in the fact that fundamental fears provide reasons for fearing a wide range of stimuli whereas common fears do not. A person can, for example, be afraid of snakes and heights, but these fears seem unrelated to each other. However, it is possible that both fears arise from a heightened level of AS. That is: they can both originate from the fear of the confrontation with a snake or a height causing a panic attack (Taylor, 1995). 


\section{స chapter}

Taylor (1995) performed further research into the three fundamental fears by means of a factor analytic and correlational study. For this purpose, he created a measure that consisted of pooled items for each fear, which formed a questionnaire that was named the Sensitivity Index (SI). In this questionnaire, the items from the Anxiety Sensitivity Index (ASI) (Peterson \& Heilbronner, 1987) were included to assess AS, while the Injury/lllness Sensitivity Index (ISI) was incorporated to assess IS. FNE was measured in the SI with the 12-item version of the Fear of Negative Evaluation Scale (Leary, 1983). The resulting SI was subsequently submitted to a factor analytic analysis, which revealed three-factors that corresponded to the three fundamental fears as originally proposed by Reiss (1991). Intercorrelations of the three factors were low, with rs ranging from .26 to .32 (Taylor, 1993). Pearson correlations between the three factors and common fears revealed that AS was related to agoraphobia, IS to animal fears and blood-injury fears, and FNE to social fears and animal fears. Taylor concluded that the three fundamental fears are indeed distinct from each other, and that they are specifically related to common fears.

It is important to note that the fundamental fears should not be equated to trait anxiety (Lilienfeld, 1996; McNally, 1996; McWilliams \& Cox, 2001; Reiss, 1997; Sandin, Chorot, \& McNally, 2001). Lilienfeld (1996) proposed a hierarchical model in which the fundamental fears are lowerorder factors that are nested within the higher-order trait anxiety factor. In this hierarchical model, the lower-order factors share sufficient variance with the higher-order factor, while there remains unique variance that is unrelated to trait anxiety. Taylor's analyses revealed that fundamental fears do indeed account for $41 \%$ of the total variance in trait anxiety, leaving unique variance open that is unrelated to trait anxiety (Taylor, 1993,1995).

In pain research, most studies have focussed on AS (Asmundson et al., 2000). However, it may be proposed that IS plays a more fundamental role than AS in the maintenance and exacerbation of (chronic) health conditions. IS represents the specific fearfulness of imminent injury and illness, and might form a higher-order factor not only of animal fears, but also of other fears that are related to harm to the body and to fear of pain. Recently, Keogh and Asmundson (2004) suggested an adapted version of the hierarchical model outlined by Lilienfeld (1996), in which IS acts as a higher-order factor of pain-related constructs such as fear of pain and pain catastrophizing.

The present study was primarily set up to explore the role of fundamental fears in the explanation of pain-related variables in a healthy population. We choose to conduct the study in a healthy population for two reasons. First, it allows us to compare our results with the results of Taylor (1993), since he used a healthy sample as well. More important, the choice for a healthy population stems from the properties of the ISI. The ISI concerns worrying about getting injured and becoming ill, and is meant to assess a predisposing fear for future injury and/or illness experiences.

In the current research, two studies were set up to further validate the SI in a Dutch student sample and to examine the role of the fundamental fears in their explanation of painrelated variables. In the first study, we examined whether we were able to replicate the threefactor structure of the Sl, as it was proposed by Taylor (1993). Also, the associations between the fundamental fears and trait anxiety were examined. The main aim of this study was however to examine the association between the fundamental fears and fear of pain and pain catastrophizing. It is hypothesized that although both AS and IS will be associated with fear of pain and pain 
catastrophizing, IS will be the strongest predictor of these measures. FNE is not expected to contribute to the explanation of either fear of pain or pain catastrophizing.

The second study examined predictive validity of the fundamental fears using a pain induction procedure. A part of the original sample of study 1 underwent three experimental pain tests and anticipatory fear and pain tolerance for each of these tests was assessed. It is hypothesized that IS will predict anticipated fear and pain tolerance for experimental pain more strongly than AS. FNE is not expected to contribute to the explanation of anticipatory fear or pain tolerance.

\section{METHOD}

\section{PARTICIPANTS}

In study 1, 192 students of Maastricht University (42 males and 150 females), with a mean age of 21 ( $\mathrm{SD}=2.55$, range $=18-39$ years), completed a battery of questionnaires, including the SI (see Measures section).

In study 2, 60 unselected individuals ( 11 males, 49 females; mean age $=21, \mathrm{SD}=$ 2.04 , range $=18-28$ years) of the original sample were invited to take part in a pain induction experiment, and completed the questionnaires once again. The participants verbally reported to the experimenter to be free from (chronic) physical or mental illnesses in both studies. All participants gave informed consent and received financial compensation for their participation. The experimental protocol was approved by the Medical Ethics Committee of Maastricht University/ University Hospital Maastricht.

\section{Procedure}

All participants from study 1 were recruited at Maastricht University through advertisements and posters in the University building. They completed the questionnaires in small groups of approximately 10 persons in a room in the University building. Six months later, 60 participants from the original sample were randomly invited to take part in the pain induction study. The pain induction procedure consisted of an ischemic pain test, electrical stimulation, and heat pain stimulation that were presented in a counterbalanced order. Before the start of each pain test, anticipatory fear of pain was assessed. Participants rated the level of fear that they thought would be associated with the pain test on a 100-mm.visual analogue scale (VAS) with anchors 'no fear at all' to 'very fearful'. Pain tolerance scores were obtained for each of the three pain induction procedures. Pain tolerance in the ischemic pain test was measured as the maximum amount of time (milliseconds) that people could endure performing handgrip exercises while pressure on their forearm was sustained on $160 \mathrm{mmHG}$ through the cuff of a sphygmomanometer. In the electrical stimulation test, pain tolerance was defined as the maximum stimulus intensity $(\mathrm{mA})$ that was 


\section{木 1 oumen}

reached before participants indicated that pain tolerance was reached. The heat pain stimulation test measured pain tolerance as the maximum temperature $\left({ }^{\circ} \mathrm{C}\right)$ that participants could tolerate before they pushed a button to reduce temperature back to baseline level (for details on the pain induction procedure see Roelofs, Peters, Deutz, Spijker, \& Vlaeyen, 2005).

\section{MEASURES}

The Sensitivity Index (SI) includes 39 items and consists of pooled items of three subscales, which tap AS (16 items), IS (11 items), and FNE (12 items). The English version of the SI (S. Taylor, 1993) was translated into Dutch in a state-of-the-art manner, involving back translation, after which the item content was checked against the original content. AS was measured by the Anxiety Sensitivity Index (ASI; Peterson \& Heilbronner, 1987). This self-report measure consists of 16 statements that assert the negative consequences of experiencing anxiety (e.g., 'It scares me when my heart beats rapidly'). The ASI has been shown to be a reliable and stable measure of the fear of anxiety with Cronbach's $\alpha$ above .88 and test-retest correlations above .70. (Peterson \& Heilbronner, 1987; Reiss, 1991; Rodriguez, Bruce, Pagano, Spencer, \& Keller, 2004; Sandin et al., 2001). IS was measured with the Injury/illness Sensitivity Index (ISI; Taylor, 1993), containing 6 items pertaining to the fear of illness (e.g., 'I get scared if I think I'm coming down with an illness') and 5 items referring to the fear of injury (e.g., 'The thought of injury terrifies me'). Recent results of a factor analytic study on the ISI scale (Carleton et al., 2005) revealed two factors - Fear of IIIness ( 7 items) and Fear of Injury ( 4 items) - that load onto a single higher order factor (i.e., injury/ illness sensitivity or physical harm). The higher order factor of injury/illness sensitivity accounted for $74.3 \%$ of the variance in the lower-order factors and showed good simple structure with salient loadings of 0.86 for both the fear of IIIness and Fear of Injury lower-order factors. The same study also proved the ISI to possess adequate reliability, with an alpha coefficient for the ISI total (12 items) of 0.89. FNE was measured with the 11-item version of the Fear of Negative Evaluation Scale (Leary, 1983). This scale also has satisfactory reliability and validity, and taps fear of situations related to public observable behaviour and evaluation situations (e.g., 'I worry about what kind of impression I make on people'). Taylor adjusted the response format of the Fear of Negative Evaluation Scale such that participants rated all items of the SI using a 5-point Likert scale ranging from 1 (very little) to 5 (very much). The FNE had good internal consistency in this adapted format as well (Cronbach's alpha above .80) (Taylor, 1993).

The Pain Anxiety Symptoms Scale (PASS; McCracken, Zayfert, \& Gross, 1992) is a 40item self-report measure that measures pain-related fear. The PASS was originally developed for chronic pain patients, but it has proven to be applicable in pain free populations as well (Muris, Vlaeyen, \& Meesters, 2001). The PASS consists of 4 subscales, measuring fearful appraisal of pain (e.g., 'I think that if my pain gets too severe, it will never decrease'), cognitive anxiety (e.g., 'During painful episodes it is difficult for me to think of anything besides the pain'), physiological anxiety (e.g., 'Pain seems to cause my heart to pound or race'), and escape/avoidance behaviour (e.g., 'I try to avoid activities which cause pain'). The items are rated on a 6-point Likert scale ranging from 0 (never) to 5 (always). The validity as well as the reliability of this measure has been well 
established in several studies (Osman, Barrios, Osman, Schneekloth, \& Troutman, 1994; Roelofs, McCracken et al., 2004).

The Fear of Pain Questionnaire (FPQ: McNeil \& Rainwater, 1998) was specifically developed to measure fear of pain in a non-chronic pain population. It is a 30-item measure that assesses fear of severe pain (e.g., 'Breaking your leg'), minor pain (e.g., 'Getting a paper-cut on your finger'), and medical pain (e.g., 'Receiving an injection in your hip/buttocks'). The items are scored on a 5-point Likert scale ranging from 1 (not at all) to 5 (extreme). The psychometric properties of the English as well as the Dutch version (Peters et al., 2002) of the FPQ are satisfactory (McNeil \& Rainwater, 1998; Roelofs, Peters, Deutz et al., 2005).

The Pain Catastrophizing Scale (PCS; Sullivan, Bishop, \& Pivik, 1995) taps pain catastrophizing, which is defined as 'an exaggerated orientation towards pain'. Participants need to take painful past experiences in mind, and subsequently indicate on a 5-point scale ranging from 0 (not at all) to 4 (all the time) to what extent they experienced each of 13 feelings and thoughts during that pain (e.g., 'I feel as if I can't take this anymore'). The original and Dutch version has proven to be reliable and valid measures (Osman et al., 1997; Severeijns, van den Hout, Vlaeyen, \& Picavet, 2002; Van Damme, Crombez, Bijttebier, Goubert, \& Van Houdenhove, 2002).

The State-Trait Anxiety Inventory - Trait form (STAI-T; Spielberger, Gorsuch, \& Lushene, 1970) contains 20 items that tap a general anxiety disposition (e.g., 'I worry too much about unimportant things'). Participants have to indicate on a 4-point Likert scale, ranging from 1 (almost never) to 4 (almost always), to what extent these statements apply to them. A high score on this scale reflects a high general anxiety disposition. The original and Dutch versions (Ploeg van der, Defares, \& Spielberger, 1980) have proven to be reliable and valid measures.

\section{StATISTICAL ANALYSES}

We performed an exploratory factor analysis on the SI to see whether we could replicate the three-factor solution reported by Taylor (1993). The internal consistency was calculated using Cronbach's $\alpha$ for all subscales separately as well as for the whole SI. The total amount of variance in trait anxiety that was explained by the three fundamental fears was calculated by means of a simple linear regression analysis, in which all three fears were first entered independently into the model, and afterwards were tested simultaneously in the final model.

The association between the fundamental fears and trait anxiety and pain catastrophizing was examined with a stepwise linear regression analysis in which trait anxiety was entered in the first step and the predictors of interest (AS, IS, FNE) were simultaneously entered in the second step. The same analyses were performed to examine the unique predictive value of the three fundamental fears relative to pain tolerance and anticipatory fear of pain in the pain induction procedure. 


\section{RESULTS}

\section{STUDY 1}

Factor Analysis. The Kaiser-Meyer-Olkin Measure of Sampling Adequacy of .92 indicated that the items of the SI were suitable for factor analysis. The items were subsequently submitted to a principal components analysis with oblique (oblimin) rotation with Kaiser normalization. An oblimin rotation allows the obtained factors to be intercorrelated. Cattell's Scree test revealed three factors to be extracted, which accounted for $52 \%$ of the total variance. The factor loadings are shown in Table 1. This 3-factor solution corresponded with the three factors as originally proposed by Taylor (1993): Fear of Negative Evaluation (Factor 1), Anxiety Sensitivity (Factor 2) and Injury/illness Sensitivity (Factor 3). Correlations between the three factors were low to moderate, with $r=.26$ for the correlation between FNE and IS, $r=.40$ for the correlation between AS and IS, and $r=.37$ for the correlation between AS and FNE.

Taking salient loadings as those $\geq .30$, Table 1 shows that each factor corresponds to a fundamental fear. However, some ASI items do load on other factors (items 13, 14) or have secondary loadings on another factor (items 34, 36). Furthermore, two ASI items do not load on any of the three factors at all (items 29, 38). Four items (items 13, 14, 29, 36) are problematic in both the study of Taylor and the current study. Item 38, as it was formulated in the Dutch translation, appeared to deviate from the original item after the back translation, which can explain the fact that it doesn't load on any factor in the current study. This item has been changed in the most recent Dutch version. We created a reconstructed version of the SI in which the five problematic items were removed. Item 34 was left in the scale and assigned to the ASI subscale on theoretical grounds. All further analyses that are reported in this article were performed with the reconstructed version of the scale, although we also performed concordant analyses with the original scales in order to detect possible beneficial or detrimental effects of working with the original versus the reconstructed scale. Any deviations between both versions will be reported, if present.

\section{TABLE 1. Principal Components Analysis on the Sensitivity Index: Factor Loadings for the three-factor solution}

\section{Item-Scaleltem Description}

4 - FNE I am concerned about other people's opinions of me

2 - FNE I worry about what kind of impression I make on people

9 - FNE I worry what other people will think of me even when I know it doesn't make any difference

3 - FNE I am afraid that people will find fault with me

$1-\mathrm{FNE}$
Factors

\begin{tabular}{rrr} 
FNE & AS & IS \\
\hline .92 & -.04 & .02 \\
.92 & .05 & -.03 \\
& & \\
.90 & -.07 & .00 \\
.87 & -.05 & .05 \\
& & \\
.86 & -.02 & -.08 \\
.86 & .05 & .04
\end{tabular}




\begin{tabular}{|c|c|c|c|c|}
\hline \multirow[t]{2}{*}{$5-\mathrm{FNE}$} & \multicolumn{4}{|l|}{ When I am talking to someone, I worry about what they may } \\
\hline & be thinking of me & .85 & -.13 & .09 \\
\hline $12-\mathrm{FNE}$ & If I now that someone is judging me, it tends to bother me & .83 & -.13 & .00 \\
\hline $10-\mathrm{FNE}$ & It bothers me when people form an unfavourable impression of me & .81 & -.05 & .12 \\
\hline $6-\mathrm{FNE}$ & I am afraid that others will not approve of me & .80 & .15 & .04 \\
\hline $8-F N E$ & I am frequently afraid of other people noticing my shortcomings & .73 & .14 & .08 \\
\hline 11 - FNE & I often worry that I will say or do the wrong things & .71 & .22 & -.11 \\
\hline $28-\mathrm{ASI}$ & It scares me when I feel faint & .05 & .79 & -.01 \\
\hline $39-\mathrm{ASI}$ & It scares me when I feel shaky & .00 & .72 & .09 \\
\hline $37-\mathrm{ASI}$ & It scares me when I become short of breath & .09 & .72 & -.06 \\
\hline $27-\mathrm{ASI}$ & It scares me when my heart beats rapidly & -.03 & .72 & .04 \\
\hline $32-\mathrm{ASI}$ & When my stomach is upset, I worry that I might be seriously ill & -.12 & .70 & .11 \\
\hline \multirow[t]{2}{*}{$33-\mathrm{ASI}$} & \multicolumn{4}{|l|}{ When I cannot keep my mind on a task, I worry that I might be } \\
\hline & seriously ill & -.00 & .69 & -.00 \\
\hline \multirow[t]{2}{*}{$31-\mathrm{ASI}$} & \multicolumn{4}{|l|}{ When I notice that my heart is beating rapidly, I worry I might have a } \\
\hline & heart attack & .02 & .60 & .11 \\
\hline $35-\mathrm{ASI}$ & When I am nervous, I worry that I might be mentally ill & .07 & .58 & -.04 \\
\hline $30-\mathrm{ASI}$ & It scares me when I am unable to keep my mind on a task & .17 & .55 & .00 \\
\hline $25-\mathrm{ASI}$ & It scares me when I am nauseous & -.03 & .47 & .26 \\
\hline $36-\mathrm{ASI}$ & It scares me when I am nervous & .33 & .39 & -.08 \\
\hline $34-\mathrm{ASI}$ & Unusual body sensations scare me & .18 & .36 & .37 \\
\hline $14-\mathrm{ASI}$ & It is important to me to stay in control of my emotions & .30 & .19 & -.06 \\
\hline $13-\mathrm{ASI}$ & It is important for me not to appear nervous & .41 & -.02 & .00 \\
\hline $29-\mathrm{ASI}$ & It embarrasses me when my stomach growls & .25 & .25 & .09 \\
\hline $38-\mathrm{ASI}$ & Other people notice when I feel shaky & .16 & .09 & .18 \\
\hline $21-|S|$ & It would be awful to be injured in any way & .05 & -.21 & .84 \\
\hline $15-|S|$ & I am frightened of being injured & -.05 & .13 & .81 \\
\hline $16-|S|$ & The thought of injury terrifies me & .09 & -.10 & .72 \\
\hline $18-|S|$ & The thought of physical illness scares me & -.09 & .19 & .68 \\
\hline $24-|S|$ & I get scared if I think I am coming down with an illness & .02 & .18 & .65 \\
\hline $17-|S|$ & I worry about becoming physically ill & -.09 & .33 & .62 \\
\hline $26-|S|$ & I can't stand the thought of being injured & .03 & .10 & .62 \\
\hline $20-|S|$ & I worry that I might get a serious physical illness in the future & .03 & .24 & .55 \\
\hline $19-|S|$ & I worry about being injured & -.05 & .29 & .47 \\
\hline $22-|S|$ & It would be awful to have a serious physical illness & .05 & -.16 & .48 \\
\hline \multirow[t]{3}{*}{$23-|S|$} & I worry about my physical health & .08 & .28 & .30 \\
\hline & Eigenvalue & 12.9 & 5.1 & 2.3 \\
\hline & Variance (\%) & 33.2 & 13.2 & 6.0 \\
\hline
\end{tabular}

NoтE: AS, Anxiety Sensitivity; IS, injury/llness Sensitivity; FNE, Fear of Negative Evaluation. Salient loadings $\geq$ $|0.30|$ are listed in boldface type 
Descriptive Statistics and internal consistencies of the Sensitivity Index. Mean scores on the SI for both males and females are summarized in Table 2. Possible gender differences were investigated by means of independent sample t-tests for both test times separately. No differences on either the SI or the subscales were found. To evaluate the internal consistency of the $\mathrm{SI}$, Cronbach's alphas were computed. All scales had excellent reliability with alphas of .94, .88, .88 , and .96 for the $\mathrm{SI}$, the ASI, the ISI, and the FNE respectively.

TABle 2. Descriptive Statistics of the Sensitivity Index and its three subscales in study 1

\begin{tabular}{|c|c|c|c|c|c|c|}
\hline & \multicolumn{2}{|c|}{ Males $(n=42)$} & \multicolumn{2}{|c|}{ Females $(n=150)$} & \multicolumn{2}{|c|}{ Total $(n=192)$} \\
\hline & Mean & $\mathrm{SD}$ & Mean & $\mathrm{SD}$ & Mean & $\mathrm{SD}$ \\
\hline SI total & 65.05 & 17.24 & 66.74 & 18.77 & 66.37 & 18.41 \\
\hline ASI & 14.57 & 4.23 & 14.69 & 4.59 & 14.67 & 4.50 \\
\hline ISI & 23.36 & 7.55 & 23.42 & 7.35 & 23.41 & 7.38 \\
\hline FNE & 27.12 & 9.62 & 28.63 & 11.60 & 28.30 & 11.19 \\
\hline
\end{tabular}

Note. SI total, Sensitivity Index, total score; ASI, Anxiety Sensitivity Index (the four problematic items excluded); ISI, injury/lllness

Sensitivity Index; FNE = Fear of Negative Evaluation Scale

Fundamental Fears and Trait Anxiety. The contribution of the factors in the explanation of trait anxiety was explored with linear regression analysis (Table 3). We first examined the separate contribution of AS, IS, and FNE in three separate regression models with trait anxiety (STAI-T) as dependent variable. The Variance Inflation Factors (VIF) ranged between values of 1.61 and 1.80, indicating no severe collinearity between the independent measures. These analyses showed that FNE, AS, and IS accounted independently from each other for 34\%, $21 \%$, and .05\% of the variance of trait anxiety. Next, the final model was created in which all three fears were entered simultaneously as predictors in the model. A total of $40 \%$ of the variance in trait anxiety was explained by the three fundamental fears together; but, whereas both FNE and AS share sufficient variance with trait anxiety, IS does not significantly contribute to it in the final regression model. 
TABLE 3. Results of Regression Analyses with trait anxiety (STAl-t) as dependent variable

\begin{tabular}{|c|c|c|c|c|c|c|}
\hline & B & $R^{2}$ & Adj. $R^{2}$ & $F$ & $D f$ & $p$ \\
\hline \multicolumn{7}{|c|}{ Model 1} \\
\hline FNE & .59 & .35 & .34 & 102.19 & 1,190 & .000 \\
\hline \multicolumn{7}{|c|}{ Model 2} \\
\hline AS & .46 & .22 & .21 & 52.03 & 1,190 & .000 \\
\hline \multicolumn{7}{|c|}{ Model 3} \\
\hline IS & .23 & .06 & .05 & 11.04 & 1,190 & .001 \\
\hline \multicolumn{7}{|c|}{ Model 4} \\
\hline FNE & .48 & .41 & .40 & 43.30 & 3,188 & .000 \\
\hline AS & .32 & & & & & \\
\hline IS & -.12 & & & & & \\
\hline
\end{tabular}

Note. FNE, Fear of Negative Evaluation; AS, Anxiety Sensitivity; IS, Injury/illness sensitivity

Fundamental Fears, Fear of Pain, and Pain Catastrophizing. The differential contribution of $A S$, IS, and FNE to the explanation of the pain-related measures was examined with linear regression analysis. In these analyses, trait anxiety was entered in the first block of the model, and the three factors - AS, IS, and FNE - were inserted in the second block. Entering trait anxiety in the first step of the analysis allows us to disentangle the specific influences of the fundamental fears from the overlapping explanations through trait anxiety. All VIF's were below 3 (ranging between 1.63 and 1.96), indicating no severe multi-collinearity between the independent variables. Table 4 shows that IS is the only significant predictor of fear of pain and pain catastrophizing. Both AS and IS are significant predictors of the PASS total score.

In order to test for differences in predictive value of both AS and IS for the dependent measures, we tested the magnitude of the partial correlation coefficients against each other. A partial correlation coefficient reflects the specific association between the predictor and the dependent variable, while the influence of the other predictor is controlled for. The comparison between the partial correlations between the ASI and the PCS on the one hand and the ISI and the PCS on the other hand was significant $(z=-4.89$; $\mathrm{df}=190 ; p<001)$, indicating that the ISI was the best predictor for pain catastrophizing. The partial correlations between the ASI and the ISI with the FPQ also differed significantly from each other $(z=-5.02 ; \mathrm{df}=190 ; p<.001)$. Comparison of the partial correlations for AS and IS with the PASS revealed no significant effects. We subsequently performed a post hoc regression analysis on the four subscales of the PASS. Comparison of the partial correlation coefficients with the subscales of the PASS showed that IS (partial $r=.34$ ) was more strongly related to the escape/avoidance subscale than AS (partial $r=.12)(z=-3.57 ; p<$ .001). The PASS fearful appraisal of pain subscale showed a trend towards a stronger association with IS (partial $r=.41$ ) than with AS (partial $r=.30$ ), but this difference was not significant $(z=-$ $1.78 ; p=.075)$. AS, on the other hand, was a stronger predictor of the PASS physiological anxiety subscale, showing partial correlation coefficients of .36 and .07 with AS and IS, respectively ( $z=$ 4.73; $p<.001)$. The PASS cognitive anxiety subscale showed partial correlation coefficients of .26 
and .21 with AS and IS, respectively, and this did not result in a significant difference between both predictors for this subscale. FNE did not contribute significantly to the prediction of any of the four PASS subscales.

\begin{tabular}{|c|c|c|c|c|c|c|c|c|c|}
\hline Dependent variable & Step & Variable entered & $R^{2}$ & $\Delta R^{2}$ & $\Delta F$ & df & $p$ & B (Step 2) & Part $r$ \\
\hline \multirow[t]{4}{*}{$\mathrm{FPQ}$} & 1 & STAI-t & .02 & .02 & 5.63 & 1,190 & .019 & -.03 & -.02 \\
\hline & 2 & FNE & .23 & .22 & 16.68 & 4,187 & .000 & .15 & .14 \\
\hline & & AS & & & & & & .03 & .02 \\
\hline & & IS & & & & & & $.40^{\star \star}$ & .34 \\
\hline \multirow[t]{4}{*}{ PCS } & 1 & STAI-t & .14 & .14 & 30.00 & 1,190 & .000 & $.21^{*}$ & .20 \\
\hline & 2 & FNE & .40 & .26 & 26.91 & 4,187 & .000 & .00 & .00 \\
\hline & & AS & & & & & & .12 & .11 \\
\hline & & IS & & & & & & $.45^{\star \star}$ & .41 \\
\hline \multirow[t]{4}{*}{ PASS } & 1 & STAI-t & .16 & .16 & 35.77 & 1,190 & .000 & $.18^{\star}$ & .19 \\
\hline & 2 & FNE & .46 & .30 & 34.20 & 4,187 & .000 & -.05 & -.05 \\
\hline & & AS & & & & & & $.36^{\star \star}$ & .33 \\
\hline & & IS & & & & & & $.32^{\star \star}$ & .31 \\
\hline
\end{tabular}

NotE. STAI-t,= Spielberger's state-trait anxiety inventory (Trait version); AS, Anxiety Sensitivity; IS, IIIness/Injury Sensitivity; FNE, Fear of Negative Evaluation; FPQ, Fear of Pain Questionnaire; PCS, Pain Catastrophizing Scale; PASS, Pain Anxiety Symptoms Scale.; ${ }^{*} \mathrm{p}<.01 ;{ }^{* \star} \mathrm{p}<.001$

\section{STUDY 2}

Predictive Validity of Fundamental Fears for Responses to Pain Induction. The three fundamental fears were correlated with anticipated fear for each of the three pain induction procedures. FNE and AS did not correlate with anticipatory fear, whereas IS showed a significant correlation with fear of the ischemic pain test $(r=.36 p<.01)$, fear of electrical stimulation $(r$ $=.35, p<.01)$, and fear of heat pain stimulation $(r=.41, p<.01)$. Regression analyses (VIF's ranging between 1.34 and 1.93) also showed that IS contributed most in the explanation of anticipatory fear of pain for the three pain induction procedures (Table 5). For pain tolerance, mixed results were found. None of the fundamental fears correlated with time until termination of the ischemic pain test. Pain tolerance for the electrical stimulation correlated $-.26(p<.05)$ with AS and -.27 $(p<.05)$ with IS. Pain tolerance for heat pain stimulation showed a significant correlation of $-.27(p<.05)$ with AS only. When all three fundamental fears were entered simultaneously in a regression analysis after controlling for trait anxiety (for the three pain tests separately), neither AS, IS or FNE contributed significantly to the explanation of pain tolerance (Table 5). 
Fundamental fears and pain measures

TABLE 5. Results of Regression analyses with Fear of Negative Evaluation, Anxiety Sensitivity, and Injury/illness sensitivity as predictors in Step 2 of pain tolerance and anticipatory fear of pain, and trait anxiety entered in Step 1

\begin{tabular}{|c|c|c|c|c|c|c|c|c|c|}
\hline Dependent variable & Step & Variable entered & $R^{2}$ & $\Delta R^{2}$ & $\Delta F$ & df & $p$ & B(Step 2) & Part $r$ \\
\hline \multirow[t]{4}{*}{ Fear ischemic } & 1 & STAI- $t$ & .06 & .06 & 3.54 & 1,58 & .065 & .13 & .10 \\
\hline & 2 & FNE & .15 & .09 & 1.97 & 4,55 & .13 & -.09 & -.07 \\
\hline & & AS & & & & & & .06 & .06 \\
\hline & & IS & & & & & & $.27^{\star}$ & .27 \\
\hline \multirow[t]{4}{*}{ Fear electrical } & 1 & STAI-t & .12 & .12 & 7.69 & 1,58 & .007 & .26 & .20 \\
\hline & 2 & FNE & .17 & .06 & 1.27 & 4,55 & .29 & .00 & .00 \\
\hline & & AS & & & & & & -.04 & -.03 \\
\hline & & IS & & & & & & $.27^{+}$ & .25 \\
\hline \multirow[t]{4}{*}{ Fear heat } & 1 & STAI-t & .01 & .01 & .61 & 1,58 & .44 & .00 & .00 \\
\hline & 2 & FNE & .18 & .17 & 3.88 & 4,55 & .01 & -.09 & -.07 \\
\hline & & AS & & & & & & -.04 & -.04 \\
\hline & & IS & & & & & & $.46^{\star \star \star}$ & .40 \\
\hline \multirow[t]{4}{*}{ Tolerance ischemic } & 1 & STAI-t & .00 & .00 & .02 & 1,58 & .88 & .01 & .01 \\
\hline & 2 & FNE & .06 & .06 & 1.16 & 4,55 & .33 & .17 & .13 \\
\hline & & AS & & & & & & -.08 & -.06 \\
\hline & & IS & & & & & & -.21 & -.19 \\
\hline \multirow[t]{4}{*}{ Tolerance electric } & 1 & STAI-t & .04 & .04 & 2.13 & 1,58 & .15 & -.13 & -.10 \\
\hline & 2 & FNE & .13 & .09 & 1.96 & 4,55 & .13 & .24 & .19 \\
\hline & & AS & & & & & & -.24 & -.18 \\
\hline & & IS & & & & & & -.18 & -.16 \\
\hline \multirow[t]{4}{*}{ Tolerance heat } & 1 & STAI- $t$ & .06 & .06 & 4.11 & 1,58 & .047 & -.24 & -.18 \\
\hline & 2 & FNE & .11 & .05 & .99 & 4,55 & .41 & .22 & .17 \\
\hline & & AS & & & & & & -.22 & -.17 \\
\hline & & IS & & & & & & -.03 & -.03 \\
\hline
\end{tabular}

Note. STAI-t, Spielberger's state-trait anxiety inventory (Trait version); AS, Anxiety Sensitivity; IIS, Illness/Injury Sensitivity; FNE, Fear of Negative Evaluation; FPQ, Fear of Pain Questionnaire; PCS, Pain Catastrophizing Scale; PASS, Pain Anxiety Symptoms Scale; ${ }^{+} \mathrm{p}<.10 \quad{ }^{*} \mathrm{p}<.05 ;{ }^{* *} \mathrm{p}<.01 ;{ }^{* *} \mathrm{p}<.001$ 


\section{Discussion}

The main aim of this research was to examine the contribution of fundamental fears to fear of pain and pain catastrophizing. However, first we evaluated the psychometric properties of the instrument that measures fundamental fears, the Sensitivity Index (SI). The SI showed good to excellent internal consistencies for the scale as a whole and for the three subscales (ASI, ISI, FNE). The factor analysis on the Dutch version of the SI resulted in a 3-factor structure, thereby replicating Taylor's findings (Taylor, 1993). The three factors were labelled as corresponding to FNE, AS, and IS. The three factors together explained $52 \%$ of the total variance, but correlated low among each other. This indicates that it is likely that the factors do measure distinct constructs. The magnitude of the loadings revealed that most items were good representatives for the scales they belonged to. However, some items of the ASI had secondary loadings or loaded onto another factor, whereas two items didn't load substantially on any factor at all. This was also the case in Taylor's study, and raises questions about the applicability of some of the items. We created a revised version of the ASI scale, in which five problematic items were omitted, and this was used throughout all further analyses in this study. As an additional check, we also conducted concordant analyses with the original ASI scale to check whether results would deviate from our findings when the problematic items were kept in the scale. These concordant analyses revealed the same pattern of results as the one that is reported in this manuscript, and indicates that although some items appear bad representatives of the scale in the factor analyses, their inclusion does not affect the value of the ASI in this study. We therefore suggest considering the use of an adapted version of the ASI in subsequent studies. Throughout the literature, there have been several suggestions for dealing with the dubious items of the ASI through the use of revised scales. In line with our findings, some authors already suggested the use of a shortened version of the ASI, consisting of two lower-order factors (fear of somatic sensations and fear of loss of control) (e.g., Blais et al., 2001; Keogh \& Asmundson, 2004; Schmidt \& Joiner, 2002). Other studies suggest to use an expanded version of the ASI, consisting of 36 items, that support a four-factor structure of AS (beliefs about the harmful consequences of pain, fear of publicly observable anxiety reactions, fear of cognitive dyscontrol, and fear of somatic sensations without explicit consequences) (e.g., Deacon, Abramowitz, Woods, \& Tolin, 2003; Taylor, 1995).

Following Taylor (1993), we also examined the relationship between the three factors of the SI and trait anxiety as measured by the STAI-T. According to the hierarchical model proposed by Lilienfeld (1996) and later extended by Keogh and Asmundson (2004), AS, IS, and FNE form lowerorder factors that are nested within the higher-order factor of trait anxiety. The three fundamental fears do indeed explain variance in trait anxiety when their contribution to trait anxiety is examined independently from each other. The values of the Beta weights indicate, however, that the ability to account for variance in trait anxiety is smaller for IS than for the other two fears. When all three fears were subsequently entered together in the regression model, IS did not contribute to trait anxiety at all, in contrast to FNE and AS. This finding raises question about whether IS is indeed a lower order factor of trait anxiety, as one would expect that IS should explain unique variance in trait anxiety that is not accounted for by AS and FNE. Further investigation of the association between IS and trait anxiety is clearly warranted. This should also include other measures of trait anxiety or anxiety 
disposition in addition to STAI-t, e.g., the Behavioural Inhibition Scale. It is possible that STAI-t does not encompass all aspects of fear or anxiety that people experience in daily life.

The strong relation between FNE and trait anxiety is a replication of Taylor's (1993) findings. Taylor stated that FNE probably is the most fundamental fear of the three, since it is responsible for many common fears, which are displayed most often in the daily society (e.g., social fears, animal fears, and general anxiety).

The main focus of study 1 concerned the differential contribution of AS and IS in the explanation of pain-related fear and pain catastrophizing. Results of the regression analyses showed that both IS and AS contribute to the explanation of pain-related fear and catastrophizing, whereas FNE does not contribute significantly to these fears. In accordance with our hypothesis, IS was a stronger predictor of fear of pain (FPQ) and pain catastrophizing (PCS) than AS. Both AS and IS were approximately equally predictive of PASS total scores. However, post hoc analyses on the subscales of the PASS indicated that AS and IS may be differentially related to some of the PASS subscales. Most notably, IS was significantly stronger associated to the escape/avoidance subscale of the PASS than AS, whereas AS was significantly stronger related than IS to the physiological anxiety subscale. This may be a product of the item content of the different subscales. Items of the PASS physiological anxiety subscale concern the symptoms that are physiologically related to the experience of pain. This can explain the better prediction by AS, defined as the general fear of physical sensations. The PASS escape/avoidance subscale consists of items that possess the socalled 'harm-effect': the thought that pain is a predictor of a serious disorder or injury. This thought makes people engage in avoidance behaviour to avoid the development of injury.

In study 2, the differential predictive power of the fundamental fears was investigated for pain tolerance and anticipatory fear of pain for the three pain induction procedures separately. IS proved to be the only predictor for imminent fear of an impending pain stimulus. This unique association between IS and anticipatory fear of pain demonstrates that IS represents a specific sensitivity for the threat of pain and the fear of potential consequences that may go with injury and illness. This finding also supports the finding of an association between IS and pain catastrophizing and between IS and the escape/avoidance subscale of the PASS, since both of these measures also pertain to the fear and catastrophic appraisal of the forecast of pain. When examining the relation between the fundamental fears and pain tolerance, significant correlations were found for the electrical tolerance score with both AS and IS, and the thermal heat tolerance score with AS. However, in the regression analyses, pain tolerance was not predicted by the fundamental fears in any of the pain induction procedures. This finding may be ascribed to the characteristics of the pain tests and the lack of ecological validity that originates from them. Participants were aware that they would take part in a controlled study, in which pain duration and pain intensity would be limited (in comparison to real-life situations). Further investigation on the relation between the fundamental fears and the objective and subjective pain measures is therefore warranted.

The current study is the first to address the role of IS in predicting pain-related variables. However, some limitations should be taken into account when interpreting these results. Although informative, the present findings are still preliminary and resulting from multiple regression analyses, thereby leaving room for inflated type I errors. Subsequent research should further validate the relationships and findings that are currently discussed, using more elaborative statistical 
approaches, like structural equation modelling, that allow deriving conclusions on hierarchical relations between the variables, thereby accounting for the dependency between the dependent variables. The use of more sophisticated analyses can also give a clearer insight into the nature of the relationship between the fundamental fears (particularly IS) and trait anxiety. The absence of predictive power of IS for trait anxiety might raise questions on the value of the STAI-T as an accurate measure for trait anxiety. Second, the lack of predictive power of the fundamental fears for pain tolerance measures needs further attention in subsequent studies that should try to establish realistic pain situations. Third, it would be interesting to examine the association with the Tampa Scale of Kinesiophobia (TSK). The TSK is less suitable in a pain-free population, but especially with respect to pain-related fear, identifying the association between IS and the TSK would be valuable. It would furthermore add value to the SI research to test its predictive value in experimental paradigms, comparing the self-report data with more explicit or implicit behavioural, psychophysiological, and cognitive measures.

Despite these limitations, the current study is the first to provide evidence for the suggestion that IS might be equally or even more important than AS when identifying predictive traits in the (chronic) pain process. Although AS has provided valuable information in pain research, IS possibly forms a more relevant, if not crucial, construct in this area. Future research should therefore more thoroughly investigate the differential contributions of AS and IS to pain-related fear and pain catastrophizing, as well as to the pain process in general.

\section{AcKNOWLEDGEMENTS}

The authors would like to thank R. Nicholas Carleton for his help with the evaluation of the back translation of the SI. Furthermore, we are grateful to Judith Deutz and Joëlle Janssen for their help with the data collection.

This research was (partly) supported by a grant from the Netherlands Organisation for Scientific Research (NWO: grant no. 015-001-050). Dr. Asmundson is supported by a Canadian Institutes of Health Research Investigator Award. 


\section{- - \\ Chapter 3}

A hierarchical representation of negative emotionality constructs contributing to pain: an empirical examination of the underlying dimensional and componential structure of its individual components

This chapter is submitted for publication as:

Vancleef L. M. G., Vlaeyen, J. W. S., \& Peters, M. L. A hierarchical representation of negative emotionality constructs contributing to pain: an empirical examination of the underlying dimensional and componential structure of its individual components. 


\section{Abstract}

Research has identified several general (i.e., negative affectivity, trait anxiety) and more specific (i.e., anxiety sensitivity, injury/illness sensitivity, fear of pain, pain catastrophizing) anxietyrelated constructs to contribute directly or indirectly to the onset and maintenance of (chronic) pain. These constructs might be conceptualised within a hierarchical structure, from which the relative importance of and the relation between constructs can be understood. The current study sought to find evidence for the hierarchical organization of pain-relevant anxiety constructs by the conductance of exploratory analyses on the perceived similarity data of the individual items of the self-report measures commonly used to assess each construct. Results demonstrated that persons who are relatively naïve with respect to the theoretical constructs and their operationalizations created cluster groups of items that could be well interpreted along the lines of the constructs in the model. Moreover, resulting cluster groups corresponded largely to the self-report measures. In addition, multidimensional scaling analysis (MDS) indicated that the items could be structured along a specificity dimension that ran from general negative affective concerns towards painspecific negative concerns. A second interpretable dimension, running from inter-to intrapersonal concerns regarding pain was found in the MDS analysis as well. Implications and limitations of these findings are discussed in terms of evidence for the hierarchical model and the use of several individual self-report instruments to assess constructs residing in the model.

\section{INTRODUCTION}

Chronic pain patients are often characterized by a negative orientation towards stimuli in both the external and internal environment that entail a possible link to pain, disability, or illness. Congruent with findings in other emotional disorders (e.g., anxiety, depression) it has been proposed that this negative orientation is to a great extent fostered by elevated individual levels of negative emotionality constructs (Lang \& Craske, 1997; Mathews \& MacLeod, 1994; Öhman, 2000). Corroborating this view, several general (i.e., negative affectivity, trait anxiety) and more specific (i.e., anxiety sensitivity, injury/illness sensitivity, fear of pain, pain catastrophizing) anxiety and fear-related constructs have been proposed to contribute directly or indirectly to the onset and maintenance of (chronic) pain (e.g., Keogh \& Asmundson, 2004; Vancleef, Peters, Roelofs, \& Asmundson, 2006). As such, negative affectivity (NA) and trait anxiety (TA), which are both conceived as the general and stable tendency to view the world in a negative way and to react fearfully to a broad range of situations (Lilienfeld et al., 1993; Watson \& Clark, 1992), have found to be associated with increased pain severity, pain intensity and disability by pain, and with less adequate coping with pain (Keogh \& Asmundson, 2004). In addition, research has emphasized the role of anxiety sensitivity (AS) and injury/illness sensitivity (IS) in the development and exacerbation of chronic pain. AS is defined as the fear of anxiety-related symptoms and sensations (e.g., sweating, nausea, hart palpitations) that arises from the belief that these sensations are the precursors of serious somatic, psychological, or social harm (Reiss et al., 1986). Although AS was initially considered as a risk factor in the development of panic disorder specifically (Cox, 1996; Reiss, 


\section{$\hbar_{\text {chaperer }}$}

1991), a large body of research is currently available on the role of AS in determining dysfunctional responses to pain, in both clinical and non-clinical populations (e.g., Asmundson et al., 2000; Stewart \& Asmundson, 2006). IS, or the catastrophic fearfulness of getting injured or becoming seriously ill (Reiss, 1991; Taylor, 1993), has received significantly less research interest than AS for its role in (chronic) pain. Nevertheless, its intrinsic referral to somatic complaints (i.e., injury and or illness) has lead some authors to propose that this factor is at least as important for understanding (the chronic course of) pain as AS (Carleton et al., 2005; Keogh \& Asmundson, 2004; Taylor, 1993; Vancleef et al., 2006). Together with TA and NA, both AS and IS might constitute latent vulnerability traits that can predispose individuals towards maladaptive responses to (potential) pain. Because of the specific referral to somatic sensations, both AS and IS can be proposed to be more directly related to affective responses to the confrontation with (the threat of) pain than NA and TA (Reiss, 1987; Taylor, 1993). Pain catastrophizing (PC) and fear of pain (FoP) are conceived to be most proximally related to the actual confrontation with pain, and to influence responses to painful experiences directly (Keogh \& Asmundson, 2004). Both latter factors have been suggested to play a crucial role in the transition from acute to chronic pain (e.g., Lethem et al., 1983; Philips, 1987; Vlaeyen et al., 1995; Vlaeyen \& Linton, 2000). To date, a large body of research in clinical as well as non-clinical populations has supported the role of PC and FoP in the amplification of pain and pain-related disability (e.g., Crombez et al., 1999; McCracken et al., 1996; McMurtry, 2005; Peters et al., 2002; Severeijns et al., 2001; Sullivan et al., 1995; Sullivan et al., 1998; Vlaeyen \& Linton, 2000).

Each of the aforementioned anxiety and fear-related constructs has thus demonstrated to possess explanatory value for different maladaptive responses to (the threat of) pain. Nevertheless, the growing body of evidence on the role of each individual factor has stressed the need for an integrative view on the conceptualisation of these factors in relation to one another (Keogh \& Asmundson, 2004). Drawing on earlier work on the structure of personality and emotional constructs (Lilienfeld et al., 1993; Watson \& Clark, 1992), it has been proposed that a hierarchical model might offer an elucidating theoretical framework within which these relations can be understood (Keogh \& Asmundson, 2004; Lilienfeld et al., 1993). This hierarchical model can be derived from the hierarchical model of 'negative emotional constructs' that was earlier proposed by Lilienfeld and colleagues (1993; see Figure 1), as a solution for the ongoing debate in the literature on the conceptual difference between the constructs of TA and AS in their contribution to anxiety and anxiety disorders (see Lilienfeld et al., 1998 for details on this controversy). It has been suggested that such a hierarchical model includes both general and more specific elements (Lilienfeld et al., 1998; Watson \& Clark, 1992). More precisely, the lower levels of the model are assumed to represent content-specific constructs that are nested hierarchically within more general higher-order constructs. A hierarchical structure allows each individual construct to covary with the higher-order factor that it subordinates to, as well as with co-existing constructs at the same hierarchical level, whilst each construct is also assumed to possess unique variance that is unrelated to the higher-order factors and is predictive of specific affective responses (Lilienfeld et al., 1993). In the hierarchical model of 'pain-relevant negative emotional constructs' (Keogh \& Asmundson, 2004; see Figure 1), NA sits at the very top of the model, comprising three lowerorder factors that reflect the affect types subsumed in NA: aggression, alienation, and trait anxiety 
(Watson \& Clark, 1992). Trait anxiety is further subdivided into three lower-order factors, AS, IS, and fear of negative evaluation (FNE), which are conceived as fundamental fears or 'sensitivities' that exert specific influences on common fears and the specific psychopathological conditions that we encounter in daily society (i.e., panic disorder, blood phobias, social fears) (Lilienfeld et al., 1993; Reiss et al., 1988; Taylor, 1993). In this view, both AS and IS have been suggested to be of particular importance to consider for their contribution to pain and associated disability (Keogh \& Asmundson, 2004; Vancleef et al., 2006). At the lowest level of the hierarchy, and entailing the only addition to the originally proposed hierarchical structure by Lilienfeld et al. (1993), the pain-specific fear constructs (i.e., fear of pain and pain catastrophizing) are incorporated as lower-order factors of IS (Keogh \& Asmundson, 2004). Furthermore, physical concerns, cognitive concerns, and social concerns are conceived as lower-order factors of AS (Keogh \& Asmundson, 2004)'. Taken together, the hierarchical model offers an attractive conceptual framework for understanding and structuring the various anxiety-related construct relatively to each other, and can be of help for researchers who wish to understand the (in)direct contribution of each construct to the development and maintenance of chronic pain complaints.

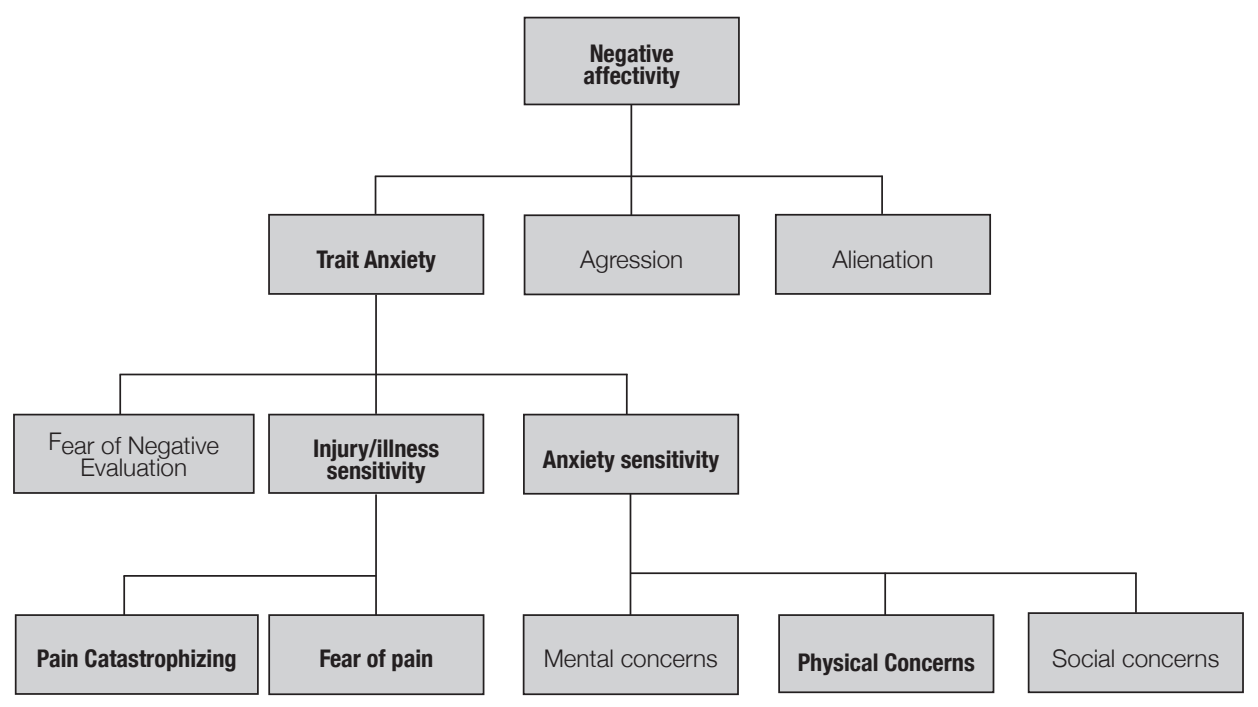

Figure 1. Representation of the hierarchical model as proposed by Lilienfeld (1993), and the modified hierarchical model for pain (Keogh \& Asmundson, 2004). The constructs assumed relevant for pain are printed in bold.

1 It should be noted that this proposed hierarchical structure is not definite, and that it is open to the restructuring of its components or the addition of other, yet to be identified constructs 


\section{$\hbar_{\text {chaperer }}$}

Along the lines of the hierarchical model, studies have demonstrated --through the simultaneous consideration of several constructs in the prediction of responses to pain-- unique contributions of the separate constructs for divergent responses to pain, despite correlations between them (e.g., Drahovzal, Stewart, \& Sullivan, 2006; Hadjistavropoulos et al., 2004; McCracken et al., 1996; Vancleef, Peters, Gilissen, \& de Jong, 2007; Vancleef et al., 2006). Furthermore, there is consensus on the conceptualisation of subparts of the hierarchical model, such as the higher-lower- order relation between NA and TA, or between TA and AS (e.g., Lilienfeld et al., 1998; Sexton, Norton, Walker, \& Norton, 2003; Watson \& Clark, 1992). Nevertheless, the hierarchical model of 'pain-relevant negative emotional constructs' has never been formally tested yet. Before doing such a test (e.g., with confirmatory factor analyses, structural equation modelling), it may valuable to examine some of the basic tenets of the model first; that is the appropriate operationalisation of the constructs in the model and the varying degrees of specificity that are assumed to characterize the constructs in the model.

It goes without saying that working with the constructs of the hierarchical model, as goes for working with any personality construct, often obliges researchers to rely on self-report measures that serve as their operationalisation. In the area of pain, a diversity of self-report instruments has been developed that intend to provide specific assessments of the higher and lower-order factors that reside in the hierarchical model. Often, researchers choose to work with one particular measure (often the most prevalently used measure in the field of research) to represent one particular construct, partially because of practical considerations (e.g., limiting time and workload constraints). In this light, it is important to point out that despite careful psychometric and validity evaluations of each self-report measure, caution is warranted in assuming a one-to-one relation between a self-report instrument and the latent construct that it represents (e.g., Kline, 2000). Careful inspection of the item content of the different self-report instruments demonstrates at least some content-overlap in their items. This content-overlap is qualified by similarities in the broad meaning or content of particular items, although slight deviations in item formulation reflect their belongingness to different instruments. For example the items 'I worry that I might get a serious physical illness in the future '(ISI), 'When my stomach is upset I worry that I might be seriously ill' (ASI), 'I worry all the time whether the pain will end' (PCS), and 'I worry when I am in pain' (PASS), all refer in a broad sense to worrying about injury and illness, despite their belongingness to different scales. It can be questioned if respondents are capable to understand and respond to these items along the lines intended by constructors of the measures, and whether they are thus sensitive to subtle differences in item content that determine the placement of items in different scales. Furthermore, it can be questioned whether these different self-report measures do indeed tap unique latent constructs, or if the segmentation in various measures has merely resulted in several separate measures that are reflective of one and the same latent construct.

The present study explored the way in which the separate items of some prevalently used measures of constructs in the hierarchical model group together on the basis of their perceived similarity. In addition, it was examined whether the operationalisations of these constructs offer support for the specificity dimensionality that is assumed to characterize the constructs in the hierarchical model. For these purposes, a large group of participants has performed a card-sorting task, in which the individual items of the questionnaires (written separately on small cards) had to be sorted into piles on the basis of perceived similarity in item content. As such, each different 
pile of cards is assumed to contain only those items that are perceived as belonging to the same theoretical construct. Prior studies have used the similarity sorting task to detect the underlying dimensional structure and the components of pain behaviour as described by a broad range of pain descriptive words (Clark, Ferrer Brechner, Janal, Carroll, \& Yang, 1989; Clark, Janal, Hoben, \& Carroll, 2001; Turk, Wack, \& Kerns, 1985; Verkes, Van der Kloot, \& Van der Meij, 1989; Vlaeyen, van Eek, Groenman, \& Schuerman, 1987), or to detect the organizational structure of implicit personality theory or human goals (e.g., Chulef, Read, \& Walsh, 2001; Rosenberg \& Gara, 1983).

\section{Method}

\section{PARTICIPANTS}

A total of 294 students performed the card-sorting task collectively at either Ghent University (Belgium) or Maastricht University (The Netherlands). The Ghent group ( $N=151$ ) consisted of 151 master students at the faculty of Pedagogical and Psychological Sciences, majoring in psychology. The students of the University of Maastricht $(\mathrm{N}=143)$ were bachelor students at the faculty of Health, Medicine, and Life Sciences, enrolled in the health science programme. Participation to the card-sorting test was voluntarily, and participants received compensation for participating in the form of a sweetener. All participants provided information on age, gender, and the presence and duration of pain complaints at the moment of testing. After data reduction (see data reduction and statistical analyses paragraph), analyses were conducted on the cardsorting outcomes of 249 participants. Two participants in this group provided missing data on the demographical information. The total group consisted of 214 females, and had a mean age of 21 years ( $\mathrm{sd}=1.80$, range $=18-29) .37 \%$ of the respondents indicated to experience pain at the moment of testing. In the group experiencing pain, $21 \%$ reported that the pain complaints persisted over three months, and $20 \%$ reported that the pain interfered with the performance of daily activities.

\section{MATERIALS AND MEASURES}

Card sorting task and selection of sorting stimuli. The items of 10 questionnaires (125 items; see appendix A) were printed on small cards (approximately $7 \times 4 \mathrm{~cm}$ ) without the inclusion of answer alternatives. The self-report measures were chosen to represent well-validated measures for the relevant hierarchical constructs (i.e., NA, TA, AS, IS, FoP, PC, physical concerns). To minimize the possibility that items would be sorted on the basis of lexical or grammatical similarity, some items were reformulated, and reversely scored items were excluded. In addition, questionnaires with a salient item format were replaced with another questionnaire assessing the same construct if possible (see description of questionnaires below for details). Whenever possible, the shortest questionnaire was chosen when more questionnaires representing one construct were available. 
Negative affectivity is represented by all items of the Negative Emotionality subscale (NEM) of the Multidimensional Personality Questionnaire (MPQ; Tellegen, 1982). The NEM consists of 14 items, which do not refer directly to a somatic or health-related content. High scores on the NEM indicate a nervous, apprehensive, irritable, and emotionally labile personality profile. All items of the NEM were included in the task.

To represent the trait anxiety construct, items from the anxiety subscale from the Hospital Anxiety and Depression scale (HADS; Spinhoven, Ormel, Sloekers, \& Kempen, 1997; Zigmund \& Snaith, 1983) and the trait form of the State Trait Anxiety Inventory (STAI-t; Spielberger, Gorsuch, Lushene, Vagg, \& Jacobs, 1983) were included. A high score on these scales is interpreted as reflective of a high general anxiety disposition. The HADS was originally developed for the fast assessment of the presence of generalized anxiety and depression symptoms in clinical and community samples. The items of the HADS do not relate to physical symptoms (Spinhoven et al., 1997; Zigmund \& Snaith, 1983), which makes the questionnaire insensitive to biased responses because of medical conditions. The anxiety subscale of the HADS contains 7 items, of which 6 items were included in the present study while 1 item was excluded because of its reversed scoring format. The STAl-t contains 20 items, of which only the 10 negatively worded items were included in the current study.

The Injury/illness Sensitivity Index (ISI; Taylor, 1993) and the Anxiety Sensitivity Index (ASI; Peterson \& Heilbronner, 1987) were incorporated to represent AS and IS, respectively. The ASI consists of 16 statements that assert the negative consequences of experiencing anxiety. The ASI total score is used to represent anxiety sensitivity, but it has been suggested that the questionnaire composes three lower-order subscales, namely physical concerns (8 items), cognitive concerns (4 items) and social concerns (4 items) (e.g., Peterson \& Heilbronner, 1987; Zinbarg, Barlow, \& Brown, 1997). Recent studies have suggested that especially the physical concerns subscale is important to consider in the context of pain (e.g., Keogh, 2004; Stewart \& Asmundson, 2006). The ISI contains 11 items of which 6 pertain to the fear of illness and 5 refer to the fear of injury. All items of both the ASI and the ISI are incorporated in the present study.

Several questionnaires were included to represent the specific pain-related constructs that are situated at the lowest level of the hierarchical model. As such, pain catastrophizing was represented by all 13 items of the Pain Catastrophizing Scale (PCS; Sullivan et al., 1995). Because the items of the PCS are characterized by a typical wording format (e.g., 'When I am in pain...I cannot think of anything besides my pain'), these items were slightly reworded (e.g., 'I cannot think of anything besides my pain'). All items of the short form of the Pain Anxiety Symptoms Scale (PASS-20; McCracken \& Dhingra, 2002) were included to represent pain-related fear. This measure contains 4 subscales, being fearful appraisal of pain (5 items), cognitive anxiety (5 items), physiological anxiety (5 items), and escape/avoidance behaviour (5 items). In addition, 13 items of the Tampa Scale of Kinesiophobia (TSK; Miller, Kori, \& Todd, 1991) were incorporated to assess fear of (re)injury due to movement. Four items of the total TSK are excluded from the current study because of their reversed scoring format. With exclusion of the inversely scored items, the TSK is proposed to consist of two subscales: somatic focus (8 items) and activity avoidance (5 items) (Goubert, Crombez, Van Damme et al., 2004; Roelofs, Goubert, Peters, Vlaeyen, \& Crombez, 2004). All 16 items of the Fear Avoidance Beliefs Questionnaire (FABQ; Waddell et al., 1993) were 
incorporated to represent the fearful beliefs regarding the influence of work and physical activities upon pain, and the avoidance of activities. The FABQ contains the following two subscales: beliefs regarding work-related activities (11items) and beliefs regarding physical activity (5 items). To date, no exact questionnaire is available to assess the physical concerns construct as residing at the lowest level of the hierarchy to our knowledge. It has been suggested that the physical concerns subscale of the ASI reflects this construct best. However, it can be argued that the FABQ and the PASS both possess subscales that can be conceived as measures of this construct as well. Nevertheless, at the stage of selecting measures for the present study, no definite allocation of one of the above described measures to the physical concerns construct has been made.

In addition to the questionnaires representing the anxiety-related hierarchical constructs, we incorporated 6 items of the Social Desirability Scale (SDS; Marlowe \& Crowne, 1961) to serve as control items in the present study. Because of the clearly deviating content of these items from all other items, it is assumed that these items will be sorted in one and the same category when participants perform the card-sorting task conscientiously.

Task validity checks. VAS scales were administered to assess participants' perceptions regarding specific properties of the card-sorting task. Three of these VAS scales ask about the extent to which the participants judged the task as tiring, boring, and interesting. One question is included that asks about the extent to which the cards of the sorting task were found legible. An additional question inquires the level of concentration that the participant had during task performance. All VASs are rated on a 10-mm horizontal line, anchored 'not at all' at one extreme and 'extremely' at the other extreme.

\section{Procedure}

At both locations (Ghent and Maastricht), participants were tested in a lecture hall of the respective university buildings. Testing took place as an addendum to a lecture that participants attended for course requirements (i.e., health psychology course). Prior to the start of the lecture, students were informed about the experimental study that would be conducted afterwards, and it was emphasized that participation at the study was anonymous and voluntarily. After the lecture, a 10-minute break was introduced to allow students who wished to refrain from participation to leave the lecture-hall. The remaining students were asked to spread over the lecture-hall leaving open places in between two persons. This way, we aimed at minimizing undesirable influences that might originate from students working together.

Prior to taking their places, all participants received a large envelope containing the demographical questionnaire, the validity check questions, a written card-sorting instruction sheet, a stack of cards each on which one of the 125 items was printed in 12pt Arial font, and some rubber bands. Participants were instructed to keep the envelope closed until the experimenters had provided additional verbal instructions and gave the signal to open the envelope.

In the verbal instruction, participants were invited to read the instruction sheet on 


\section{$\star$ chapers 3}

the card-sorting task carefully before initiating the sorting task. Furthermore, participants were instructed to perform the card-sorting task first, and to fill out the demographical questionnaire and the validity checks subsequently. Participants were asked to replace the completed questionnaires and the piles of cards back in envelope in which they had received them. The instruction on the card-sorting task was formulated as follows:

'On each of these cards, you will find one statement or sentence. Your task is to create piles with these cards. You can do this by placing cards into one and the same pile when you are in the opinion that these cards share a similar meaning. So, each card with a similar meaning ends up in the same pile. You can create as many piles as you think are necessary.'

During the sorting phase, which lasted between 20 and 80 minutes, the experimenters answered any individual questions that participants still might have after receiving and reading instructions. However, no help or information was provided with respect to the placements of cards in piles. When data collection was completed, the students were in the opportunity to attend a short debriefing session in which the exact goals and aims of the study were explained.

\section{DATA REDUCTION AND DATA PREPARATION}

Participants who handed in an incomplete dataset, or who created less than three piles in the sorting task were excluded from further analyses $(N=27)$. We suspected that the formation of maximally two sorting piles was indicative of non-conscientious task performance. This suspicion was strengthened by the observation that participants who created maximally 2 sorting piles also assigned scores to the VAS concentration measure that were equal or below the 10th percentile score $(<=14)$, and has lead to the exclusion of these participants from further analyses. Furthermore, participants who placed less then three of the control items in one and the same pile were excluded as well $(N=21)$. As such, card-sorting data of 249 participants were analyzed.

The mean scores on the validity checks in Table 1 indicate that the remaining participant group rated the task as moderately tiring and boring, and to a lesser extent as interesting. Furthermore, the self-reported concentration level during task performance was moderate. In addition, the individual items on the cards were judged to be well legible. A mean number of 8 piles $(s d=4$; range $=3-22)$ were created in the card-sorting task. 


\begin{tabular}{lllc}
\multicolumn{4}{l}{ TABLE 1. Descriptive statistics on the validity checks in the participants group that is included in data analyses $(N=249)$} \\
\hline \hline & Mean & sd & Range \\
VAS tiring & 48.43 & 28.74 & $0-100$ \\
VAS concentration & 54.29 & 20.23 & $2-100$ \\
VAS interesting & 33.83 & 22.72 & $0-100$ \\
VAS legible & 78.93 & 19.40 & $14-100$ \\
VAS boring & 56.71 & 26.88 & $0-100$ \\
\hline \hline
\end{tabular}

A $125 \times 125$ frequency matrix was created on the basis of the sorting data of 249 participants. Each cell in this matrix represented the number of times that participants had placed two cards together in the same pile. The maximum value in a cell is thus 249 and the minimum value is 0 . The resulting matrix is called a similarity matrix, in which higher cell numbers indicate a higher perceived similarity between the two items that are connected by that cell.

\section{StATISTICAL ANALYSES}

Multidimensional scaling (MDS; proxscal, SPSS 11.0) was used to identify the meaningful underlying dimensions of the obtained data. MDS represents the items in a geometrical configuration of points in such a manner that highly similar items are placed closely to each other, and items with low similarity are placed at a larger distance from each other. The stress value, which is the principal measure of model fit, was inspected to decide on the most appropriate dimensional solution (Kruskal \& Wish, 1978).

In order to explore how the individual items of the card-sorting task grouped together into interpretable clusters on the basis of their proximity relation, additive tree analysis (ADDTREE/ P; Corter, 1982) was conducted. An additive tree represents the items as nodes in a connected graph with path-lengths between two nodes representing the distance between these two nodes. In an additive tree, inter-cluster distances are allowed to exceed intra-cluster distances, and the distance between an object outside a cluster and all objects in a cluster is not forced to be equal. Additive trees have been proposed to be less restrictive and more flexible than ultrametric models (e.g., hierarchical cluster trees), and to be more suitable to represent the relations between observed items or objects in a similarity matrix (Corter, 1996; Sattah \& Tversky, 1977). ADDTREE/P has been proposed as a highly flexible, easily interpretable program that makes use of an efficient and robust combinatorial algorithm to fit tree structures to a dataset (Corter, 1996; Corter, 1982). This algorithm examines and compares all possible quadruples (combinations of four elements) of objects to find an optimal set of objects to be combined at each step, based on the neighbours relation (see Corter, 1996 for mathematical details). When in one stage pairs of objects are joined, they are considered as one single object in each following stage. The tree construction procedure results in a robust measure of closeness between each pair of objects. The tree construction is independent of the model distances (arc lengths), and employs a least-square criterion to estimate 
the parameters of the tree. In the graphical tree representation, the horizontal distance from an object in the tree to the root of the tree reflects how similar this object is to all other objects, relatively to the other objects that join the particular object in the same subtree. Moreover, the distance of each object to the root may be interpreted as indicative of the typicality of this object for the whole set of objects. The arcs (connecting lines) between an object and its node can be interpreted as the weight of this object in the cluster, or as the distinctiveness of a cluster (Corter, 1996).

\section{RESULTS}

\section{MULTIDIMENSIONAL SCALING (MDS)}

MDS solution. Solutions in 1 to 6 dimensions were obtained from the MDS analyses. The Scree plot in Figure 2 illustrates the stress values for the 1 to 6 dimensional solutions. This graph shows a "stress elbow" at two dimensions, suggesting that two dimensions are the most appropriate way to interpret the data. A two-dimensional solution was furthermore supported by an observed stress value of .021 , accounting for $98 \%$ of the variance in the obtained data set. In addition, the decision for two dimensions was supported when the interpretability of each dimension was taken as an additional decision criterion (Kruskal \& Wish, 1978).

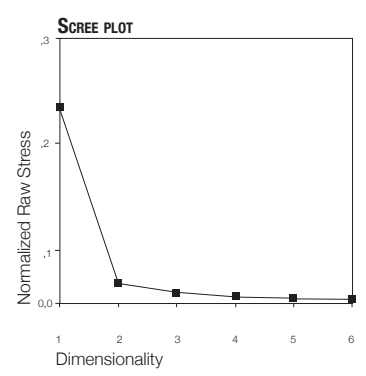

FIGURE 2. Scree plot MDS

Labelling. Labels were assigned to the dimensions by examining the items that fall at their extreme poles. Figure 3 situates each item within the two-dimensional representation of the MDS solution, as determined by the coordinates on each dimension. The first dimension was labelled 'general - specific' and appears to offer support for the specificity dimension that is assumed to run through the hierarchical model. Some examples of items that reside at the positive pole of the first dimension are: 'I feel restless as if I have to be on the move' (HADS), 'It is important to me to stay in control of my emotions' (ASI), 'My feelings are rather easily hurt' (NEM), 'I feel nervous 
and restless' (STAI), and 'When I make a mistake, I will not resent admitting this' (control item). At the negative pole of dimension 1, the following items were situated: 'Pain lets me know when to stop exercising so that I don't injure myself' (TSK), 'My pain was caused by physical activity' (FABQ), 'My work aggravated my pain' (FABQ), and 'As soon as pain comes on I take medication to reduce it' (PASS). The items on the positive pole of this first dimension thus refer to negative emotions, feelings, and anxiety, whereas descending this dimension involves increasing specificity with respect to the content and object of the negative feelings, anxiety and worrying regarding pain.

The second dimension that resulted from the MDS can be labelled as 'intrapersonal concerns- interpersonal concerns'. Some examples of the items that are situated at the negative pole are: 'It scares me when my heart is beating fast' (ASI), 'When I notice that my heart is beating rapidly I worry that I might have a heart attack' (ASI), 'I worry that I might get a serious physical illness in the future' (ISI), and 'I worry about becoming physically ill' (ISI), whereas the following items are situated at the negative pole of the second dimension: 'My work is too heavy for me' (FABQ), 'I have a claim for compensation for my pain' (FABQ), 'I never hesitate to offer help when someone is in trouble'(control item), 'People aren't taking my medical condition seriously enough' (TSK), and 'Other people notice when I feel shaky'(ASI). These items appear to reflect the concerns that individuals have about the consequences, meaning and impact of pain and health problems for themselves, whereas items that are situated towards the positive pole of this dimension reflect concerns about the way in which individual pain and health complaints will have an impact on the evaluation by others and the work environment of the individual. By adopting a two-dimensional solution from the card sorting data, a meaningful dimensional structure could be assigned to the obtained data (Figure 3).

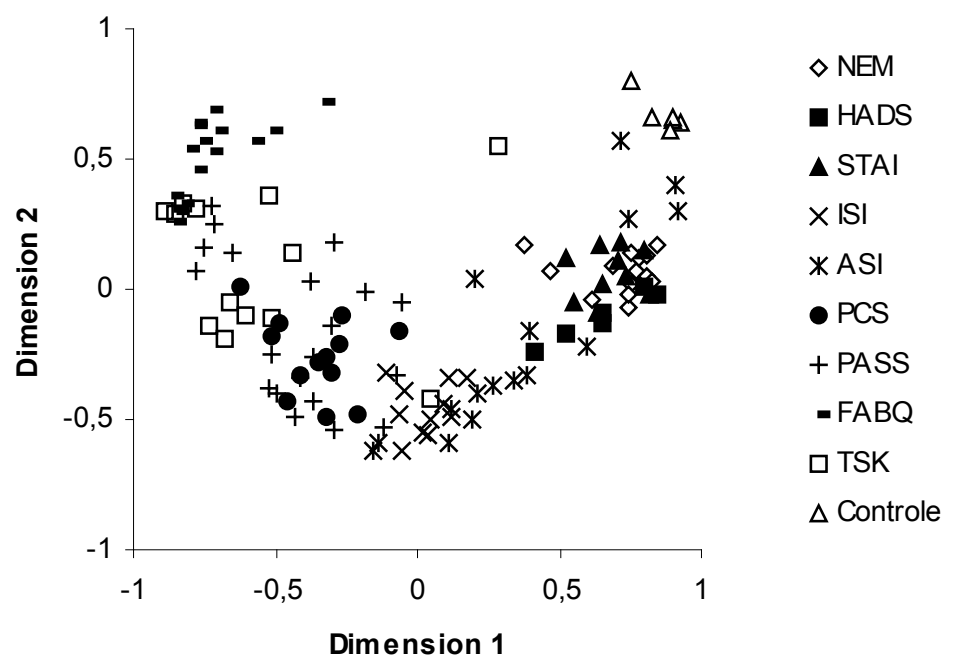

FIgURE 3. Two dimensional MDS solution with Dimension 1 running form pain specific concerns to general negative affective concerns and Dimension 2 running from intrapersonal concerns to interpersonal concerns 


\section{k $k$ anter}

\section{Additive tree ANALYsis}

ADDTREE solution. The additive tree is presented in Figure 4. The mathematical solution of this tree resulted in a stress score of .07 , accounting for $87 \%$ of the variance of the observed similarities. The additive tree in Figure 4 reveals four main groups of items (see Table 2), and within those four groups, various meaningful subgroups can be detected (see Table 3).

Interpreting main groups and subgroups in the additive tree. The first main group contains all items from the NEM, the HADS, and the STAI, as well as the control items, the items of the social sensations subscale of the ASI, and two items out of the mental concerns subscale of the ASI. Items in this group refer to negative mood, negative emotions, distress, worrying, nervousness, and anxiety, without entailing a specific referral to pain, physical health, or bodily symptoms As such this first main group can be labelled as representing 'general negative emotions and anxiety'.

The first main group clearly distinguishes two subgroups. The first subgroup contains the control items, the items of the social concerns subscale of the ASI, and 1 TSK item ('People aren't taking my medical condition seriously enough'). This subgroup reflects negative cognitions about the way in which people's behaviour or health problems are perceived and evaluated by others. The label 'negative view on others perceptions' therefore seems to summarize this subgroup appropriately. The second subgroup consists of all items of the STAI, the NEM, two items of the mental concerns subscale of the ASI, and all but 1 item of the HADS. This second subgroup reflects negative emotions, distress, worrying, nervousness and anxiety in general, and can thus be labeled as 'negative affect'. 
Hierarchical model
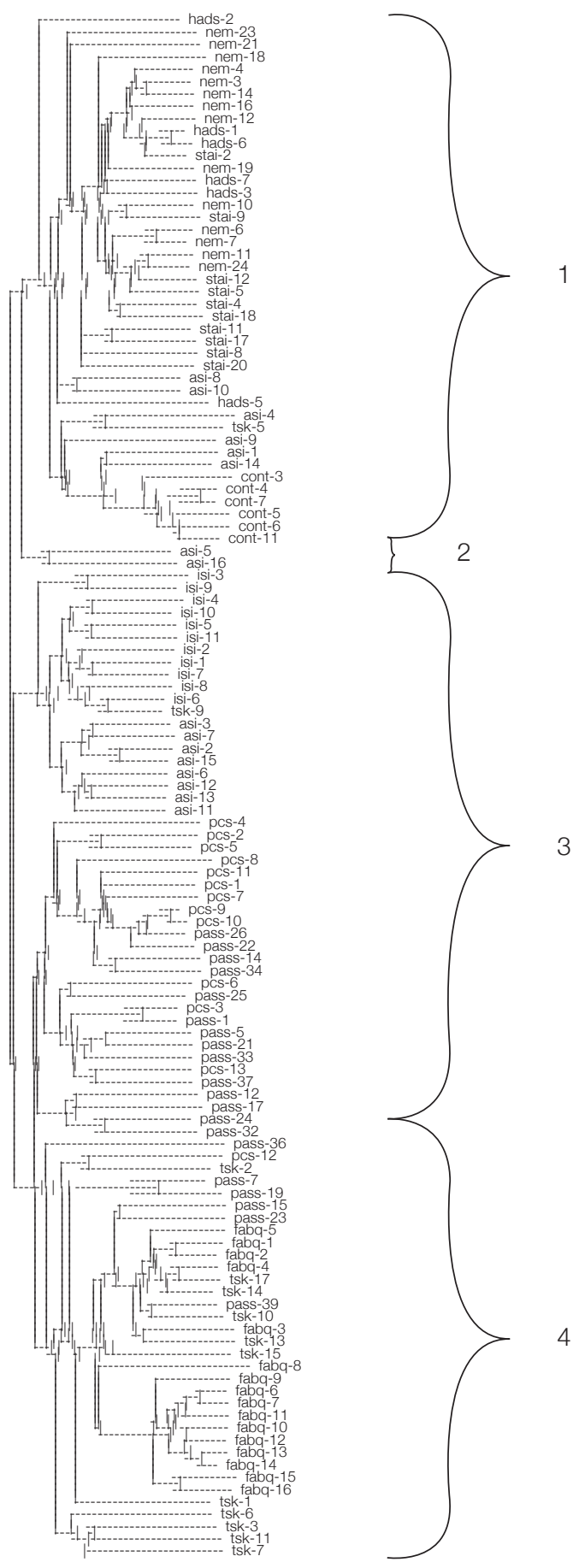

Figure 4. ADDTREE Solution 


\section{$\pi$ chapter 3}

One item of the HADS ('I get a sort of frightened feeling as if something awful is about to happen') is only loosely linked to this second subgroup. This item might be perceived as more distinct from the other items because of its content. More specifically, this item describes the negative feeling that accompanies the expectation that something terrible will and can happen at any given time, and thereby implies the direct expectation for a terrible future event to happen. This direct expectancy of future disaster is not implied in the other items in this second subgroup, which are more hypothetically formulated. It might thus be suggested that this singular item refers to generalized anxiety in particular.

The second main group forms a tight, distinct, and small combination of two items of the mental concerns subscale of the ASI. The close relation between these two items can be understood from their specific content. These two items refer to concerns and negative beliefs that persons can have when they are not able to keep their mind on a task. Unlike any other item that is included in the dataset, these items refer to attentional and concentration problems, and as such, this cluster might be labelled as 'cognitive performance concerns'.

TABLE 2. Four main Clusters in additive tree solution

\begin{tabular}{|c|c|c|c|}
\hline \multicolumn{2}{|r|}{ Items in cluster } & Content items & Label cluster \\
\hline 1 & $\begin{array}{l}\text { NEM ; HADS; STAI; Control-items; } \\
\text { ASI } 14891014 \text { (social concerns } \\
\text { and two mental concerns) }\end{array}$ & $\begin{array}{l}\text { negative mood, negative emotions, distress, } \\
\text { worrying, nervousness, and anxiety, without } \\
\text { specific referral to pain, physical health, or } \\
\text { bodily symptoms }\end{array}$ & $\begin{array}{l}\text { Negative emotions } \\
\text { and anxiety }\end{array}$ \\
\hline 2 & ASI 516 (mental concerns subscale) & $\begin{array}{l}\text { worrying about task performance in terms of } \\
\text { attentional and concentrational levels }\end{array}$ & $\begin{array}{l}\text { Cognitive performance } \\
\text { concerns }\end{array}$ \\
\hline 3 & $\begin{array}{l}\text { ISI; ASI } 236711121315 \text { (physical } \\
\text { concerns); TSK } 9 \text { ('I'm afraid that I } \\
\text { might injure myself accidentally') }\end{array}$ & $\begin{array}{l}\text { anxiety, worrying, and catastrophizing about } \\
\text { health, injury, illness, and the meaning of } \\
\text { internal bodily sensations }\end{array}$ & Physical health concerns \\
\hline 4 & $\begin{array}{l}\text { PCS; PASS; TSK (except item } 9 \text { 5); } \\
\text { FABQ }\end{array}$ & $\begin{array}{l}\text { catastrophic cognitions on negative impact } \\
\text { of pain on physical and mental functioning; } \\
\text { the uncontrollable nature of pain; feelings of } \\
\text { helplessness; worrying about impact of work } \\
\text { and activity on pain }\end{array}$ & Pain-specific concerns \\
\hline
\end{tabular}


Hierarchical model

\begin{tabular}{|c|c|c|c|}
\hline Main cluster & Sub clusters & Items & Item Description \\
\hline \multirow[t]{3}{*}{$\begin{array}{l}\text { 1. Negative } \\
\text { emotions and } \\
\text { anxiety }\end{array}$} & $\begin{array}{l}1.1 \text { Negative view on } \\
\text { others perceptions }\end{array}$ & $\begin{array}{l}\text { Control items; } \\
\text { ASI } 14914 ; \\
\text { TSK } 5\end{array}$ & $\begin{array}{l}\text { Negative cognitions concerning the way } \\
\text { in which 'others' perceive and evaluate a } \\
\text { person's physical health complaints }\end{array}$ \\
\hline & 1.2 Negative affect & $\begin{array}{l}\text { NEM; } \\
\text { HADS; } \\
\text { STAI; } \\
\text { ASI } 810\end{array}$ & $\begin{array}{l}\text { Negative mood, negative emotions, } \\
\text { distress, worrying, nervousness, and } \\
\text { anxiety with no specific referral to pain, } \\
\text { physical health, or bodily symptoms }\end{array}$ \\
\hline & 1.3 Generalized anxiety & HADS 2 & $\begin{array}{l}\text { 'I get a sort of frightened feeling as if } \\
\text { something awful is about to happen.' }\end{array}$ \\
\hline $\begin{array}{l}2 \text { Cognitive } \\
\text { performance } \\
\text { concerns }\end{array}$ & & $\begin{array}{l}\text { ASI } 5 \\
\text { ASI } 16\end{array}$ & Attention, concentration \\
\hline \multirow[t]{2}{*}{$\begin{array}{l}3 \text { Physical health } \\
\text { concerns }\end{array}$} & 3.1 Physical concerns & $\begin{array}{l}\text { ASI } 236711 \\
121315\end{array}$ & $\begin{array}{l}\text { Fear of anxiety related bodily sensations, e.g., } \\
\text { sweating, nausea, heart } \\
\text { palpitations }\end{array}$ \\
\hline & $\left.\begin{array}{l}3.2 \\
3.3\end{array}\right\} \begin{array}{l}\text { Fear of } \\
\text { injury and } \\
\text { illness }\end{array}$ & $\begin{array}{l}\text { ISI } 124567 \\
81011 \\
\text { TSK } 9 \\
\text { ISI 3; } \\
\text { ISI } 9\end{array}$ & $\begin{array}{l}\text { Worrying and catastrophizing thoughts about } \\
\text { potential physical illness or injury } \\
\text { 'I would be awful to have a serious illness'; } \\
\text { 'It would be awful to be injured in any way.' }\end{array}$ \\
\hline \multirow[t]{3}{*}{$\begin{array}{l}\text { 4. Pain-specific } \\
\text { concerns }\end{array}$} & 4.1 Catastrophizing & $\begin{array}{l}\text { PCS } 123456 \\
789101113 \\
\text { PASS } 151214 \\
172122242526 \\
32333437\end{array}$ & $\begin{array}{l}\text { Catastrophic cognitions concerning the } \\
\text { negative impact of pain on physical and } \\
\text { mental functioning, the uncontrollable nature } \\
\text { of pain; feelings of helplessness }\end{array}$ \\
\hline & 4.2 Escape/Avoidance & $\begin{array}{l}\text { PCS 12; } \\
\text { PASS } 7151923 \\
36 \text { 39; } \\
\text { FABQ; } \\
\text { TSK } 121714101315\end{array}$ & $\begin{array}{l}\text { Impact that activity and work will have on the } \\
\text { deterioration and persistence of pain } \\
\text { problems }\end{array}$ \\
\hline & 4.3 Harm & TSK 63117 & Cognitions on body as signaler of harm \\
\hline
\end{tabular}

The third main group combines all items of the ISI, the items of the physical concerns subscale of the ASI, and one TSK item ('I am afraid that I might injure myself accidentally'). Items in this cluster reflect anxiety, worrying, and catastrophic cognitions concerning health, injury, illness, and the meaning of internal bodily sensations, and are thus characterized by the specific referral to physical health and putative consequences of future physical health problems. This cluster might best be labelled as representing 'physical health concerns'. Two demarcated subgroups can be derived within this third main cluster. The first subgroup contains ASI physical concerns items only, 


\section{$\hbar_{\text {chaperer }}$}

and can be labelled 'physical concerns'. The other subgroup contains all but two items of the ISI and one TSK item, and can therefore be labelled as 'fear of injury and illness'. In addition to these two subgroups, a third subgroup combines two ISI items that reflect how terrible it would be to get injured someday in one or the other way, and how terrible it would be to have a serious physical injury. It might be suggested that these two items are found to form a distinct cluster because of their salient negative formulation (i.e., 'awful'; 'vreselijk' in Dutch). Based on the content of the items, it might be suggested that they are most appropriately considered and interpreted as belonging to the fear of injury and illness cluster.

The fourth main group that resulted from the additive tree contains all items of the PCS, the FABQ, the PASS, and all but two items of the TSK. As such, this cluster covers catastrophic cognitions and negative beliefs regarding the impact of pain on physical and mental functioning, and on the uncontrollable nature of pain. This group can be labelled as 'pain-specific concerns' and subsumes two larger subgroups of items. One of these subgroups can at its turn be subdivided in two interpretable subgroups. According to Corter (1996), interpretability forms a criterion for deciding on the demarcation of coherent entities in the tree model. Consequently, three meaningful and interpretable clusters are considered to exist within the fourth main group of the additive tree. The first subgroup entails all items of the fearful appraisal, the cognitive anxiety and the physiological anxiety subscales of the PASS, as well as all but one items of the PCS. This subscale reflects catastrophic cognitions that one can hold concerning the negative impact that pain exerts on physical and mental functioning, the uncontrollable nature of pain, and feelings of helplessness because of the pain. This cluster can be labelled as 'catastrophizing'. The second subgroup contains the items of the FABQ, items of the TSK activity avoidance subscale (except the items that appeared in main group 1 and 3), and the items from the escape-avoidance behaviour subscale of the PASS. As such, this subgroup can be labelled as 'escape/avoidance'. The third subgroup, then, contains items of the harm subscale of the TSK only, and can be labelled 'harm'. Interpreting relative distances from items to the root of the tree. The additive tree that results from the ADDTREE program provides information on the extent to which items form a typical representation of the entire set of items as well (Corter, 1996). Since all items of the cardsorting task were derived from self-report instruments assessing pain-relevant negative emotionality constructs, the entire dataset (i.e., all items) is assumed to reflect the broad concept of negative emotions relevant for pain. By inspecting the distance from each item to the root of the tree, one can derive conclusions about each item's representativeness for this broader concept. Figure 3 shows that items of the ASI, the ISI, and the physical sensations subscale of the PASS show the smallest distance to the root of the tree, suggesting that these items are the best representatives of negative emotions relevant for pain within the current dataset. On the other hand, the control items of the SDS and the FABQ items show the largest distance to the root of the tree, indicating that these items are less good representatives of pain-relevant negative emotions. 


\section{Discussion}

The present study explored the dimensional and organisational structure of various painrelevant negative emotional constructs that have been proposed to reside within a hierarchical model of pain-relevant negative emotional constructs (Keogh \& Asmundson, 2004; Lilienfeld et al., 1993). Since these emotional constructs are commonly assessed by means of separate self-report measures, empirical study methods were used to examine the cluster formation and the underlying dimensional structure of the most elementary representatives of the hierarchical model: the individual items of self-report scales that function as operationalisation of the theoretical constructs in the model. Results of these analyses demonstrated that naive persons structured and perceived the content of the self-report items in a way that echoes the proposed theoretical hierarchical structure significantly.

The additive tree analysis revealed four main clusters to exist within the current data set: (1) negative emotions and anxiety, (2) cognitive performance concerns; (3) physical health concerns; and (4) pain-specific concerns. Tracking these clusters back to the hierarchical model, cluster 1 can be conceived as representing the upper two 'general negative construct' levels, cluster 2 and cluster 3 represent the 'fundamental fear' level, and cluster 4 reflects the 'pain-specific' lowest level of the model (Keogh \& Asmundson, 2004). Moreover, meaningful subgroups could be detected within each main cluster, which corresponded largely to the individual constructs that reside in the model (i.e., negative affect, physical concerns, fear of injury and illness, catastrophizing, escape/ avoidance, and harm).

The additive tree solution reveals a number of noteworthy findings regarding the formation of clusters within the current dataset in relation to the self-report measures that were chosen as representatives for the theoretical constructs within the hierarchical model. First, items of 'general' constructs (i.e., NEM, HADS, and STAI) were found to be scattered within their main cluster and over its subclusters, whilst items of 'specific' constructs (ASI, ISI, and specifically the fear-of pain measures) showed less dispersion within and across (sub)clusters. This finding can be interpreted as additional support for the general and specific content of these self-report scales. Hence, items of the NEM, the HADS, and the STAI all refer to general negative affectivity without them being focussed at a specific object of negative emotionality. Conversely, the ASI, ISI, PASS, TSK, PCS, and the FABQ are directly focussed at a specific feared object (i.e., injury, illness, disability, bodily sensations, etc.) and this can account for the formation of more tight clusters with these particular items. Furthermore, the spreading of NEM, HADS, and STAI items over different subclusters corroborates the suggestion that negative affectivity and trait anxiety are likely to reflect the same psychological construct because of similarity in their primary characteristics (Barlow, 2000; Zinbarg \& Barlow, 1996).

Second, when the four main groups are taken as the cluster criterion, it is remarkable that for most self-report measures (i.e., the NEM, the STAl, the ISI, the HADS, the PCS, the FABQ, and the PASS) items belonging to one of these scales are found to cluster together with the other items of this specific scale. This indicates that items of each of these scales are perceived as highly similar to each other, supporting the robustness of the separate measures in reflecting a homogeneous and coherent content. At the lower levels of the additive tree solution, meaningful 


\section{$\hbar_{\text {chaperer }}$}

(sub)clusters are rarely found to contain items of one and the same self-report measure only, but are formed by the combination of items that originate from different questionnaires. From this finding, additional support for the constructional strength of the self-report instruments can be derived. After all, it is well acknowledged that a 'good' questionnaire needs to have a balanced degree of variability and overlap in its item content, in order to capture all components of the construct that it aims to tap (e.g., Kline, 2000). Nevertheless, since the meaningful subclusters that correspond to the theoretical constructs of the hierarchical model are formed by inter-scale clustering predominantly, caution is warranted in relying on one singular self-report measure when one wants to tap one latent psychological construct of the model.

When inspecting the item content of the meaningful (sub)clusters, it is remarkable that items of the ASI, the PASS, and the TSK cluster on the basis of their subscales. The items of the ASI physical concerns subscale consistently cluster together in a 'physical concerns cluster', and form the main 'physical health concerns' cluster in combination with items of the ISI. Based on this observation, it might be speculated that associations between the ASI and the ISI in previous studies might have originated predominantly from associations between the ISI and the physical concerns subscale of the ASI (Carleton et al., 2005; Vancleef \& Peters, in press; Vancleef et al., 2007; Vancleef et al., 2006). Moreover, corroborating the suggestions made by several authors, it might be argued that the ASI physical concerns subscale, rather than the other two subscales, is particularly important to examine in relation to maladaptive behavioural patterns in the context of pain (e.g., Hunt, Keogh, \& French, 2006; Keogh, 2004; Stewart \& Asmundson, 2006). The social concerns and the cognitive concerns subscales of the ASI are found to cluster together with items that refer to general negative emotions and anxiety. The spreading of ASI subscale items is suggestive of different levels of specificity to be perceived in the content of the ASI items in the current card-sorting context, and may pose difficulties for considering the ASI total score in examining the influence of AS in the context of pain. It has been recognized that various levels of specificity contribute in a different extent to varying responses to pain (e.g., Hadjistavropoulos et al., 2004; McCracken et al., 1996).

The PASS and the TSK were also found to group on subscale level. Three of the four PASS subscales cluster together with the PCS items in the 'catastrophizing' cluster. The escape/ avoidance subscale of the PASS was found to cluster in the 'escape/avoidance' cluster with the FABQ and activity avoidance items of the TSK. The splitting of the PASS into its subscales is perfectly matched to the content and supposed measurement of each subscale, and stresses the importance and relevance of working with the subscales of the PASS in predicting responses to pain (Coons, Hadjistavropoulos, \& Asmundson, 2004; McCracken \& Dhingra, 2002) Unlike the ASI subscales, the PASS subscales are found to cluster within the same main cluster group (i.e., painspecific concerns'), indicating that all PASS items are perceived to possess a similar specificity level. Congruently with advocates of a two-factor structure of the TSK (i.e., 'somatic focus' and 'activity avoidance'), the current results furthermore offer support for the consideration of two subscales in the TSK (Goubert, Crombez, Van Damme et al., 2004; Roelofs, Goubert et al., 2004), although TSK subscales do not cluster coherently together, with some items falling into other main cluster groups as well. Recently, it was suggested that an 11-item version of the TSK (i.e., with exclusion of the reversely scored items, item 9 , and item 14) is a psychometrically more sound 
measure than the 17-item TSK (Roelofs et al., in press; Woby, Roach, Urmston, \& Watson, 2005). Sustaining this suggestion, item 9 was found to deviate significantly with respect to its content from the other TSK-items in the additive tree solution as well. Taken together, observations on the splitting of the ASI, the PASS, and the TSK in their subscales offer reasons to reconsider the usage of total scores of these questionnaires as representatives for specific constructs, and argue in favour of working with the respective subscales of these constructs. Conversely, the FABQ, the ISI, and the PCS are not found to group together on the basis of their subscales. Therefore, it may be speculated that it is not meaningful to adopt the subscales of these measures in pain research since respondents perceive items of these subscales as similar in content.

In addition to information on the grouping of individual items into meaningful clusters, the additive tree offers information on the belongingness of each individual item to the general concept of 'pain-relevant negative emotional constructs'. Showing the smallest distance to the root of the tree, the items of the ISI, the physical concerns subscale of the ASI, the escape/avoidance subscale of the PASS, and the somatic focus subscale of the TSK can be interpreted as the most 'prototypical' examples of the general concept that is represented by the total item set. All of these items refer directly to worrying and anxiety on the meaning and consequences of (potential) physical sensations, injury, and illness. It may be proposed that these (sub)scales are particularly suitable to adopt when one wants to examine pain-relevant affective states. Conversely, together with the control items, the FABQ items are found to be most distally related to the general concept of pain-relevant negative emotions. The FABQ items refer to cognitions and beliefs that persons hold concerning the impact of work and activity on the causation, persistence and deterioration of pain complaints (Waddell et al., 1993). Since these fear/avoidance beliefs are directed at the deteriorative effects of activity and work on pain, rather than being directed at negative affective states because of the pain (anxiety, worrying, catastrophizing), they are less suitable to reflect pain relevant negative emotions. In a similar vein, items of the escape avoidance subscale of the PASS and the activity avoidance subscale of the TSK are also found to show rather distal relations with the concept of pain-relevant negative emotions.

Besides support for the hierarchical organization of distinguishable pain-relevant negative constructs, the current study furthermore provided empirical evidence for the proposed generalspecific dimensional structure to underlie the constructs in the hierarchical model (Lilienfeld et al., 1993; Watson \& Clark, 1992). More specifically, the MDS analyses resulted in two interpretable dimensions, of which one could be easily labelled as running from general negative concerns on one pole to pain-specific negative concerns on the other pole. In addition, the MDS analysis revealed a second underlying dimension along which the items of the current data set could be structured. This second dimension was labeled to run from inter- to intra personal concerns. Although not originally expected, this dimension makes sense within the current biopsychosocial view on pain that stresses the importance of biological, psychological, and social influences on pain and pain-related disability (e.g., Turk \& Flor, 1999). Moreover, it has been suggested that a wide range of fears, affecting varying life domains, does occur in the context of pain. These fears are not restricted to the actual presence of pain, injury, and illness; but are directed at future possible health status and interpersonal relationships as well (Morley \& Eccleston, 2004). The finding of two dimensions to underlie the items in the current task indicate that respondents who 


\section{Chapter 3}

performed the card-sorting task do acknowledge and recognize this range of feared objects in the items of the incorporated self-report measures.

Some limitations have to be taken in consideration when interpreting the current findings. Obviously, there is a considerable degree of subjectivity in interpreting resulting dimensions and clusters that is inherently connected to the exploratory methods that are used to detect meaningful clusters and underlying dimensionality. The current study should therefore be perceived as a first step towards detecting meaningful clusters in the categorization of items of general anxiety and pain-relevant anxiety constructs. Replication in other samples, including pain patient samples is warranted. Furthermore, further studies should address the issue of external validity of the current findings by including self-report measures that intend to tap the same constructs as the selfreport measures that have been incorporated in the current study (e.g., the Depression Anxiety Stress Scale (DASS), the posttraumatic stress disorder checklist (PCL), the survey of pain attitudes (SOPA), the fear of pain questionnaire (FPQ) etc...). Relating to this latter issue, it is furthermore evident that the self-report items that were chosen to be included in the card-sorting task (i.e., the input) determine the resulting organizational structure in clusters and dimensions (i.e., the output). In this perspective, the incorporation of only pain-relevant self-report measures might have impeded sorting of the items that do not directly refer to pain or physical health. The current findings can therefore not be generalized to the broadened area of negative emotional disorders. Other cluster solutions might be revealed when self-report measures for other negative emotional constructs had been incorporated as well (e.g., fear of negative evaluation scale (FNE); Beck Depression Inventory (BDI); Social Phobia and Anxiety Inventory (SPAl), etc. ).

In sum, the present study demonstrates that naive persons, who do not possess prior knowledge on the organisational structure of the 125 items in the card-set, are well able to categorize items of different self-report measures into the theoretical constructs that they intend to represent. To our knowledge, this study is the first to provide empirical support for the hierarchical structure of pain-relevant negative emotional constructs by examining the individual items of selfreport measures that are commonly used to reflect these constructs. Further research, including formal statistical testing of the hierarchical model, will be needed to clarify the merits of working with the hierarchical constructs in explaining maladaptive behavioural, cognitive and affective responses to pain and disability.

\section{AcKNOWLEDGEMENTS}

The authors wish to thank Miriam Egberink, Adrienne Storm-Van Leeuwen, Roseanne Janssen, Charlie Bonnemayer, Erik Schouten and Prof. Dr. Gert Storms (University of Leuven, Belgium) for technical support, help with data-collection and advise on data analyses. This research was partially supported by a grant from the Netherlands organisation for Scientific Research (NWO) with grant no. 015-001-050. 
Appendix. Items in the card-sorting task

Item Item description Dutch

NEM-3 I wissel vaak van een gelukkig naar een droef gevoel, of omgekeerd, zonder dat daar een goede reden voor is.

NEM-4 Ik voel me dikwijls 'gewoon ellendig' zonder enige goede reden.

NEM- 6 Kleine tegenvallers ergeren me soms teveel.

NEM-7 Ik raak dikwills geërgerd door kleine irritaties.

NEM-10 Ik maak me vaak bezorgd over iets

NEM-11 Mijn gevoelens worden nogal snel gekwetst.

NEM-12 Ik lijd aan zenuwachtigheid.

NEM-14 Mijn stemming gaat dikwills op en neer.

NEM-16 Af en toe ervaar ik sterke emoties (zoals angst, woede) zonder dat ik echt weet wat ze veroorzaakt.

NEM-18 Ik schrik vlug van dingen die zich onverwacht voordoen.

NEM-19 Ik raak vaak in een toestand van spanning en onrust als ik aan dagelijkse dingen denk

NEM-21 Ik laat mijn slaap soms omwille van mijn zorgen.

NEM-23 Er zijn dagen dat ik voortdurend het gevoel heb dat ik het niet aankan.

NEM-24 Ik ben gevoeliger dan goed voor me is.

HADS-1 Ik voel me de laatste tijd gespannen.

HADS-2 Ik krijg de laatste tijd het angstige gevoel alsof er elk moment iets vreselijks zal gebeuren.

HADS-3 Ik maak me de laatste tijd ongerust.

HADS-5 Ik krijg de laatste tijd een soort benauwd, gespannen gevoel in maag.

HADS-6 I _ I voel me de laatste tijd rusteloos.

HADS-7 Ik krijg de laatste tijd plotseling gevoelens van angst en paniek.

STAl-2 Ik voel me nerveus en onrustig.

STAl-4 Ik kan een tegenslag maar heel moeilijk verwerken.

STAl-5 Ik voel me in vrijwel alles tekort schieten.

STAI-8 Ik voel dat de moeilijkheden zich opstapelen zodat ik er niet meer tegenop kan.

STAl-9 Ik pieker te veel over dingen die niet zo belangrijk zijn.

STAl-11 Ik word geplaagd door storende gedachten.

STAI-12 Ik heb gebrek aan zelfvertrouwen.

STAl-17 Er zijn gedachten die ik heel moeilijk kan loslaten.

STAl-18 Ik neem teleurstellingen zo zwaar op dat ik ze niet van me af kan zetten.

STAl-20 Ik raak helemaal gespannen en in beroering als ik denk aan mijn zorgen van de laatste tijd.

ISI-1 De gedachte aan verwonding benauwt me.

ISI-2 Ik kan de gedachte dat ik gewond zou kunnen raken niet verdragen.

ISI-3 Het is vreselijk om een ernstige lichamelijke ziekte te hebben.

ISI-4 Ik maak me zorgen dat ik in de toekomst een ernstige lichamelijke ziekte kan krijgen.

Ik maak me zorgen over mijn lichamelijke gezondheid.

Ik word bang als ik er aan denk dat ik ziek ga worden

Ik ben bang om gewond te raken.

De gedachte aan lichamelijke ziekte maakt me angstig.

Het zou verschrikkelijk zijn om op enigerlei wijze gewond te raken.

Ik maak me zorgen om geblesseerd te raken.

Ik maak me zorgen om lichamelijk ziek te worden.

Ik vind het belangrijk om niet zenuwachtig over te komen.

Als ik merk dat mijn hart snel klopt, maak ik me zorgen dat ik een hartaanval zal krijgen.

Het maakt me bang als ik misselijk ben.

ASI-4 Andere mensen merken het aan me als ik me trillerig voel.

ASI-5 Het maakt me bang als ik mijn gedachten niet bij een taak houden.

ASI-6 Ik ben bang als ik me slapjes voel (trillerig).

ASI-7 Het maakt me bang als mijn hart snel klopt.

ASI-8 Als ik nerveus ben maak ik me zorgen dat ik mentaal niet in orde ben.

\section{Item description English translatio}

often change from a happy to a sad feeling or reversed

without having any good reasons for it

I often feel 'just miserable' without any good reason for it

Minor setbacks sometimes irritate me too much.

Often I get irritated at little annoyances.

often find myself worrying about something

My feelings are rather easily hurt

I suffer from nervousness.

My mood often goes up and down.

Occasionally I experience strong emotions - anxiety,

anger- without really knowing what is causing them

I am easily 'rattled' at critical moments.

I often feel tensed and agitated when thinking about daily matters

often find it difficult to sleep at night.

I often feel fed up.

lam more sensitive than is good for me

I feel tense or 'wound up'.

I get a sort of frightened feeling as if something awful is about to happen.

Worrying thoughts go through my mind.

I get a sort of frightened feeling like 'butterflies' in my mijn stomach.

I feel restless as if I have to be on the move.

I get sudden feelings of panic.

I feel nervous and restless

I find it difficult to cope with misfortune

I feel like putting short in lots of things

I feel as if the difficulties are accumulating so I can't stand

them no longer

I worry about things that are

am teased by unpleasant thoughts

I have a lack of self-confidence

There are thoughts that I find difficult to let go of

I take disappointments so hard that I cannot let go

I feel tensed and agitated if I think of my latest concerns

The thought of injury terrifies me.

I can't stand the thought of being injured.

I would be awful to have a serious illness.

I worry that I might get a serious physical illness in the

future.

I worry about my physical health.

get scared if I think I am coming down with an illness.

I am frightened of being injured.

The thought of physical illness scares me.

It would be awful to be injured in any way.

I worry about being injured.

I worry about becoming physically ill.

It is important to me not to appear nervous.

When I notice that my heart is beating rapidly I worry that

I might have a heart attack.

It scares me when I am nauseous.

Other people notice when I feel shaky.

It scares me when I am unable to keep my mind on a kan

It scares me when I feel shaky (trembling).

It scares me when my heart is beating fast.

When I am nervous, I worry that I am mentally ill. 


\section{$\Uparrow$ chanerer}

\section{Appendix (CONTINUed)}

ASI-9 Ik schaam me als mijn maag rommelt.

ASI-10 Ik word bang als ik zenuwachtig ben.

ASI-11 Het maakt me bang wanneer ik me wee voel.

ASI-12 Het maakt me bang wanneer ik buiten adem raak.

ASI-13 Ongewone lichamelijke gevoelens maken me bang.

ASI-14 Ik vind het belangrijk om mijn emoties de baas te blijven.

ASI-15 Als mijn maag van streek is maak ik me zorgen dat ik ernstig ben.

ASI-16 Als ik mijn gedachten niet bij mijn werk kan houden maak ik me zorgen dat ik gek word.

PCS-1 Ik vraag mij voortdurend af of de pijn wel zal ophouden

PCS-2 Als ik pijn heb voel ik dat ik zo niet verder kan.

PCS-3 Als ik pijn heb is dat verschrikkelijk en denk ik dat het nooit beter zal worden.

PCS-4 Pijn is afschuwelijk en overweldigt mij.

PCS-5 Als ik pijn heb voel ik dat ik het niet meer uithoudt.

PCS-6 Ik word bang dat de pijn erger zal worden.

PCS-7 Ik blijf denken aan andere pijnlijke gebeurtenissen.

PCS-8 Ik verlang hevig dat de pijn weggaat.

PCS-9 Ik kan de pijn niet uit mijn gedachten zetten.

PCS-10 Ik blijf eraan denken hoeveel pijn het wel doet.

PCS-11 Ik blijf eraan denken hoe graag ik zou willen dat de pijn ophoudt.

PCS-12 Er is niets dat ik kan doen om de intensiteit van de pijn te verminderen

PCS-13 Als ik pijn heb vraag ik mij af of er iets ernstigs kan gebeuren. may happen.

PASS-1 Ik denk dat als mijn pijn te erg wordt, hij nooit meer minder worden.

PASS-5 Wanneer ik pijn voel, ben ik bang dat er iets vreselijks gaat gebeuren.

PASS-7 Ik ga onmiddellijk naar bed wanneer ik hevige pijn voel.

PASS-12 Ik begin te trillen wanneer ik bezig ben met iets dat de pijn erger maakt.

PASS-14 Ik kan niet helder nadenken wanneer ik pijn heb.

PASS-15 Ik houd op met waar ik ook mee bezig ben als ik pijn voel opkomen.

PASS-17 Pijn lijkt mijn hart te laten bonzen of sneller te laten kloppen. PASS-19 Zodra pijn opkomt neem ik medicijnen om het te verminderen. PASS-21 Wanneer ik pijn voel, denk ik dat ik ernstig ziek zou kunnen zijn.

PASS-22 Tijdens perioden met pijn is het moeilijk voor me om aan iets anders dan de pijn te denken.

PASS-23 Ik vermijd belangrijke bezigheden wanneer ik pijn lijd.

PASS-24 Als ik pijn bespeur, voel ik me duizelig of slap.

PASS-25 Pijngevoelens zijn angstaanjagend.

PASS-26 Als ik pijn lijd, dan denk ik voortdurend aan de pijn.

PASS-32 Van pijn word ik misselijk.

PASS-33 Wanneer pijn sterk opkomt, denk ik dat ik verlamd of meer gehandicapt zou kunnen worden.

PASS-34 Ik vind het moeilijk om me te concentreren wanneer ik pijn lijd.

PASS-36 Ik vind het moeilijk mijn lichaam tot rust te laten komen na perioden met pijn.

PASS-37 Ik maak me zorgen wanneer ik pijn heb.

PASS-39 $\mathrm{k}$ probeer bezigheden te vermijden die pijn veroorzaken.

FABQ-1 Mijn pijn is het gevolg van lichamelijke activiteit.

FABQ-2 Door lichamelijke activiteit wordt mijn pijn erger.

FABQ-3 Lichamelijke inspanning kan schadelijk zijn voor mijn rug.

FABQ-4 Ik zou geen lichamelijke activiteit moeten verrichten waardoor mijn pijn erger wordt of zou kunnen worden.

FABQ-5 Ik kan geen lichamelijke activiteit verrichten waardoor mijn pijn erger wordt of zou kunnen worden.

FABQ-6 Mijn pijn is het gevolg van mijn werk of van een ongeval op mijn werk.

FABQ-7 Door mijn werk is mijn pijn verergerd.

FABQ-8 Ik heb een eis tot schadevergoeding ingediend vanwege mijn pijn.
It embarrasses me when my stomach growls.

It scares me when I am nervous.

It scares me when I feel faint.

It scares me when I am out of breath.

Unusual body sensations scare me.

It is important to me to stay in control of my emotions

When my stomach is upset, I worry that I might be ziek

seriously ill.

When I cannot keep my mind on on a task, I worry that I

might be going crazy.

I worry all the time about whether the pain will end.

When I am in pain I feel I can't go on.

If I am in pain, this is terrible and I think it's never going to

get any better.

Pain is awful and overwhelms me.

If I'm in pain I feel as if I can't stand it anymore.

I become afraid that the pain may get worse.

I keep thinking of other painful experiences.

I anxiously want the pain to go away.

I can't seem to keep the pain out of my mind.

I keep thinking about how much it hurts.

I keep thinking about how badly I want the pain to stop.

There is nothing I can do to reduce the intensity of the

pain.

When I'm in pain I wonder whether something serious

I think that if my pain gets too severe, it will never zal

decrease.

When I feel pain, I am afraid that something terrible will

happen.

I go immediately to bed when I feel severe pain.

I begin trembling when engaged in an activity that

increases pain.

I can't think straight when in pain

I will stop any activity as soon as I sense pain coming on.

Pain seems to cause my heart to pound or race.

As soon as pain comes on I take medication to reduce it. When I feel pain I think I might be seriously ill.

During painful episodes, it is difficult for me to think of

anything besides the pain.

I avoid important activities when I hurt.

When I sense pain, I feel dizzy or faint.

Pain sensations are terrifying.

When I hurt, I think about the pain constantly.

Pain makes me nauseous.

When pain comes on strong I think that I might become

paralyzed or more disabled.

I find it hard to concentrate when I hurt.

I find it difficult to calm my body down after periods of

pain.

I worry when I am in pain.

I try to avoid activities that cause pain.

My pain was caused by physical activity.

Physical activity makes my pain worse.

Physical activity might harm my back.

I should not do physical activities which (might) make my pain worse.

I cannot do physical activities which (might) make my

pain worse.

My pain was caused by my work or an accident.

My work aggravated my pain.

I have a claim for compensation for my pain. 
Hierarchical model

\section{Appendix (CONTINUed)}

FABQ

FABQ-10 Door mijn werk verergert mijn pijn of, als ik zou werken, zou mijn pijn verergeren.

FABQ-11 Mijn werk kan schadelijk zijn voor mijn rug.

FABQ-12 Ik zou mijn normale werk eigenlijk niet moeten doen met de pijn die ik nu heb.

FABQ-13 Ik kan mijn normale werk niet doen met de pijn die ik nu heb.

FABQ-14 Ik kan mijn normale werk niet doen zolang ik niet word behandeld voor mijn pijn.

FABQ-15 Ik denk niet dat ik binnen drie maanden mijn normale werk weer kan doen.

FABQ-16 Ik denk niet dat ik ooit mijn normale werk kan hervatten. normal work.

TSK-1 I $\quad$ ben bang om bij het doen van lichaamsoefeningen letsel op te lopen.

TSK-2 Als ik me over de pijn heen zou zetten, dan zou hij erger worden.

TSK-3 Mijn lichaam zegt me dat er iets gevaarlijk mis mee is wrong.

TSK-5 Mijn gezondheidstoestand wordt door anderen niet serieus genoeg genomen

TSK-6 Door mijn pijnprobleem loopt mijn lichaam de rest van mijn leven gevaar.

TSK-7 Mijn pijn betekent dat er sprake is van letsel.

TSK-9 Ik ben bang om per ongeluk letsel op te lopen.

TSK-10 De veiligste manier om te voorkomen dat mijn pijn erger wordt, is gewoon oppassen dat ik geen onnodige bewegingen maak. pain from worsening

TSK-11 Ik had wellicht minder pijn als er niet iets gevaarlijks aan de hand zou zijn met mijn lichaam.

TSK-13 Mijn pijn zegt me wanneer ik moet stoppen met lichaamsoefeningen doen om geen letsel op te lopen.

TSK-14 Voor iemand in mijn toestand is het écht af te raden om lichamelijk actief te zijn.

TSK-15 Ik kan niet alles doen wat gewone mensen doen, omdat ik te gemakkelijk letsel oploop.

TSK-17 Ik zou geen lichaamsoefeningen hoeven doen wanneer ik pijn heb.

CONT-3 Ik heb wel eens van iemand geprofiteerd. someone

CONT-4 Als ik een fout maak, ben ik altijd bereid deze toe te geven.

CONT-5 Ik ben altijd beleefd, zelfs tegen onprettige mensen

CONT-6 Ik aarzel nooit me in te spannen om iemand te helpen die in moeilijkheden verkeert

CONT-7 Als ik iets niet weet, vind ik het helemaal niet erg om dat toe geven

CONT-11 Ik heb nooit iets met opzet gezegd waardoor de gevoelens ander werden gekwetst
My work is too heavy for me.

My work makes or would make my pain worse.

My work might harm my back.

I should not do my normal work with my present pain.

I cannot do my normal work with my present pain.

I cannot do my normal work till my pain is treated.

I do not think that I will be back to my normal work within

3 months.

I do not think that I will ever be able to go back to my

I am afraid that I might injure myself if I exercise.

If I were to try to overcome it, my pain would increase. My body is telling me I have something dangerously

People aren't taking my medical condition seriously enough.

My accident has put my body at risk for the rest of my life.

Pain always means I have injured my body. I am afraid that I might injure myself accidentally. Simply being careful that I do not make any unnecessary movements is the safest thing I can do to prevent my

I wouldn't have this much pain if there weren't something potentially dangerous going on in my body.

Pain lets me know when to stop exercising so that I don't injure myself.

It's really not safe for a person with a condition like mine to be physically active.

I can't do all the things normal people do because it's too easy for me to get injured

No one should have to exercise when he/she is in pain.

There have been occasions when I took advantage of

When I make a mistake, I will not resent admitting this I am always polite, even if people are not polite to me I never hesitate to offer help when someone is in trouble

When I don't know something, I don't at all mind admitting it

I have never deliberately said something that hurt van een someone's feelings 


\section{Part II}

Experimental studies on the vulnerability role of psychological factors in the onset and maintenance of pain

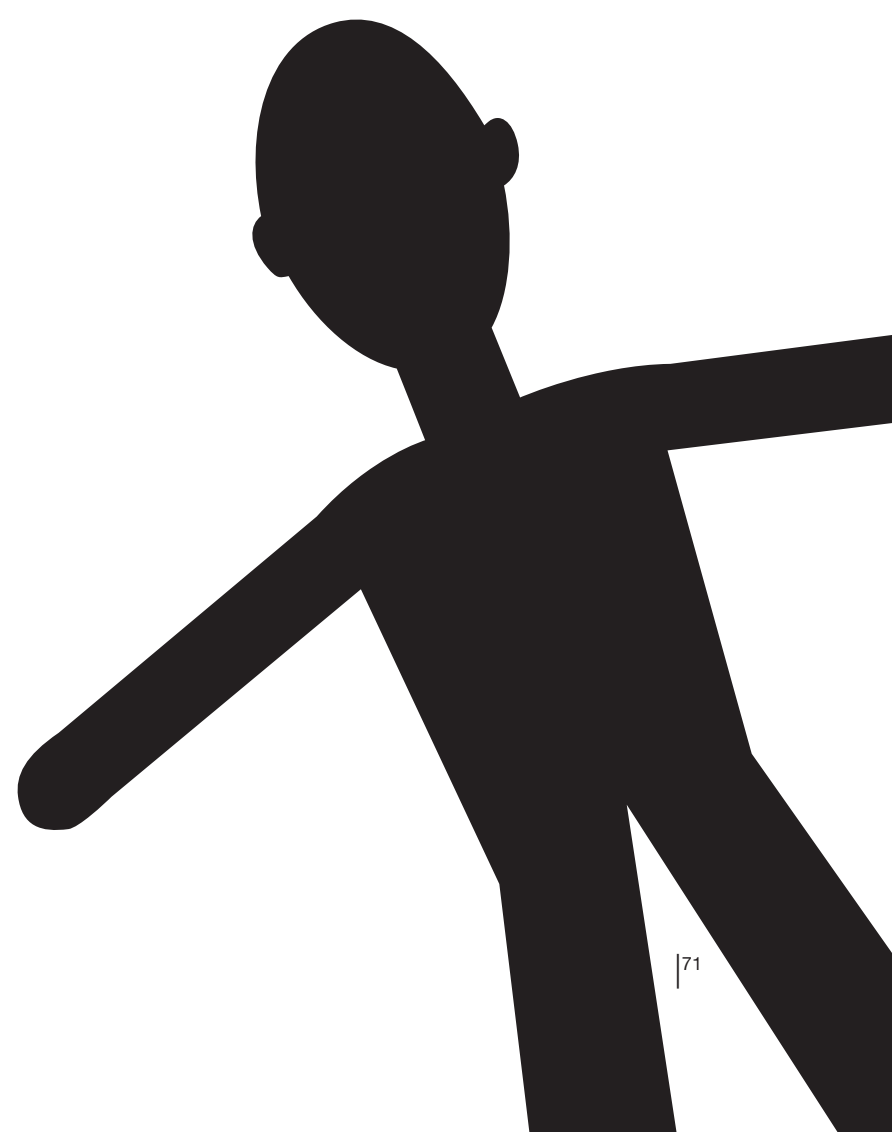




\section{- - \\ Chapter 4}

Understanding the role of injury/illness sensitivity and anxiety sensitivity in (automatic) pain processing: An examination using the Extrinsic Affective Simon Task

This chapter is published as:

Vancleef, L. M. G., Peters, M. L., Gilissen, S M. P., De Jong, P. J. (2007) Understanding the role of injury/illness sensitivity and anxiety sensitivity in (automatic) pain processing: an examination using the Extrinsic Affective Simon Task. The Journal of Pain, 8, 563-572 


\section{Abstract}

Three fundamental fears are assumed to underlie psychopathology: Anxiety Sensitivity (AS), Injury/illness sensitivity (IS), and Fear of Negative Evaluation (FNE). Both AS and IS may form risk factors for the development and exacerbation of chronic pain. The current research examines the relation between these fears and automatic threat appraisal for pain-related stimuli. Study 1 $(\mathrm{N}=48)$ additionally examined content-specific associations of AS and FNE with the automatic threat appraisal of respectively panic and social evaluative cues. Study $2(\mathrm{~N}=60)$ additionally focussed on the association of IS and AS with the engagement in health protecting behaviour, and the use of health care services. Both studies found evidence for an automatic threat appraisal of aversive stimuli. Study 2 demonstrated a positive association between the automatic threat appraisal for pain-related stimuli and individuals' IS levels. IS was found to be the single best predictor of the tendency to engage in health protecting behaviour, whereas AS was the single best predictor of the reported use of health care services.

Perspective. This study contributes to the field of knowledge on putative risk factors for chronic pain. Results demonstrate an automatic threat appraisal towards pain-related stimuli that is related to vulnerability traits for pain. This automatic threat appraisal might initiate relatively spontaneous (non-strategic) pain-maintaining behavioural responses.

\section{INTRODUCTION}

When trying to understand why some people develop chronic pain whereas others do not, an important role is assigned to the presence of vulnerability factors. One such vulnerability factor is anxiety sensitivity (AS). AS is defined as the fear of anxiety symptoms (e.g., heart palpitations) arising from the belief that these symptoms will lead to harmful somatic, psychological or social consequences (Reiss et al., 1986). Together with injury/illness sensitivity (IS) and fear of negative evaluation (FNE), AS is considered to be one of the three fundamental fears that are assumed to underlie various psychopathological conditions (Taylor, 1993). AS has been studied mostly as a risk factor for panic disorder (Schmidt \& Cook, 1999). Yet, since AS is characterized by dysfunctional cognitions regarding bodily sensations, AS has also been considered as a potential risk factor for maladjustment to (chronic) pain (Asmundson \& Norton, 1995; Asmundson et al., 2000). Accordingly, AS was found to be associated with fear of pain, pain-specific avoidance behaviour and elevated medication use in chronic pain patients, and negative pain responses after experimental pain induction (Asmundson et al., 2001; Keogh \& Birkby, 1999; Keogh \& Mansoor, 2001).

IS, defined as exaggerated and excessive worrying about future injury and illness, may be another vulnerability factor for the development of chronic pain and disability (Vancleef et al., 2006). In support of this, IS was found to be a better predictor for fear of pain and pain catastrophizing than AS, and to be the single best predictor of imminent fear of experimentally induced pain (Vancleef et al., 2006). 


\section{tomente}

Besides personality traits, dysfunctional cognitions can be considered as latent vulnerability factors for the chronic course of pain. According to the cognitive-behavioural model of chronic pain, emotional and behavioural responses to pain are largely determined by the interpretation and cognitive appraisal of a situation (Pincus \& Morley, 2001). Information processing theories state that dysfunctional beliefs and interpretations of innocuous stimuli as threatening form the core of anxiety and affective disorders (Beck \& Clark, 1997). The identification of a personally relevant negative stimulus is assumed to automatically activate a threat-processing template that guides reflexive responses on the basis of the initial threat impression (Beck \& Clark, 1997). Similar processes are assumed to be involved in (fear of) pain. If indeed confrontation with a pain-related stimulus automatically triggers an affective evaluation of this stimulus as threatening, this may subsequently elicit pain-maintaining behaviours and cognitions, contributing to the chronic course of pain.

The automatic evaluation of stimuli can be studied by means of indirect measures such as the Extrinsic Affective Simon Task (EAST; De Houwer, 2003). Indirect measures overcome the disadvantage of limited cognitive accessibility and differential self-presentation tendencies inherent to direct, self-report measures (De Houwer, 2003; Fazio \& Olson, 2003). Moreover, they offer the advantage of studying individuals' automatic and spontaneous responses that putatively differ from their controlled responses (Fazio \& Olson, 2003; Huijding \& de Jong, 2006).

In two subsequent studies we used the EAST to examine whether elevated levels of IS and AS are associated with the automatic threat appraisal of pain-related stimuli. Study 1 additionally explored the relation between enhanced levels of the fundamental fears and the content-specificity of the automatic threat appraisals. Based on the specific content of each fundamental fear, it is expected that FNE and AS will show a strong and unique association with a threat appraisal towards social threat and panic-related stimuli, respectively. Although both IS and AS are hypothesized to be associated with an enhanced threat appraisal towards pain-related stimuli, IS is assumed to show the strongest association with this threat appraisal.

Study 2 zoomed in on the association between AS and IS and automatic threat appraisals of stimuli directly related to health-threats. In addition, Study 2 examined the predictive validity of IS and AS for the use of health care services and individuals' self-reported tendency to engage in health protecting behaviours, and the putative additional predictive value of automatic threat appraisals over and above IS and AS. 


\section{STUDY 1}

\section{MeTHOD}

\section{PARTICIPANTS}

Forty-eight healthy participants (36 female) with a mean age of 21.8 years (range: 18-43, $\mathrm{SD}=4.36$ ), recruited at Maastricht University's local community, took part in this study. Inclusion criteria for participation were being in good physical and mental health, and having Dutch as a mother tongue. Colour blindness and dyslexia were exclusion criteria. Compliance with these criteria was verbally checked prior to making an appointment by asking participants directly whether they were (i) currently free from acute or chronic (> 3 months) pain complaints, and (ii) not currently diagnosed as having a mental health disorder. All participants gave informed consent and were financially compensated for their participation. The research proposal was approved by the Ethics Committee of the Academic Hospital Maastricht/Maastricht University.

\section{Materials and Measures}

Extrinsic Affective Simon Task (EAST). In the present EAST, coloured target words (panicrelated, pain-related and social evaluation-related nouns) and white attribute words (threatening and neutral adjectives) were presented one-by-one on a computer screen. Participants are instructed to respond to the colour of the target words (green or blue) and to the content of the white attribute words (threatening or neutral meaning) by pressing a left or a right response button. Participants first practiced with these instructions and the different type of response required during two practice phases. In the first practice phase, white attribute words are presented and participants learn to react to the content of the words; one button (e.g., left) has to be pressed for words with a threatening meaning and the other button (e.g., right) for words with a neutral meaning. The assignment of the attribute with either the threatening or neutral meaning to a specific response button results in an intrinsic association between the location of the response button and the attribute meaning (e.g., left button becomes associated with threat; right button becomes associated with neutral). In the second practice phase, the coloured target words are presented and participants now learn to respond to the colour of the words; one button (e.g., left) has to be pressed for green words, the other button (e.g., right) for blue words. In the subsequent test phase of the EAST white attribute and coloured target words are randomly presented and responses have to be made as learned in the prior practice phases. The coloured target words of the test phase constitute of the critical trials; participants have to respond to colour only and ignore the meaning of these words, but it is assumed that this meaning will be processed automatically. Under this assumption, compatible and incompatible trials can be identified. The compatible trials are those trials in which the response button and the target word share the same evaluative meaning (e.g., 


\section{tomente}

press the left button for coloured pain-related words), and the incompatible trials are those trials in which the response button and the target word share a contradictive evaluative meaning (e.g., press the right button for coloured pain-related words). It is expected that responses will be faster and more accurate on compatible than on incompatible trials.

Panic-related (6), pain-related (6), and social evaluation-related (6) nouns were used as target words in the present EAST. The attributes consisted of threatening (6) and neutral (6) adjectives (see Appendix 1). All words were presented on a black background on a 17"computer screen. Before the presentation of each word, a fixation dot appeared during $500 \mathrm{~ms}$ in the centre of the computer screen. Participants responded by pressing the right or the left button of a response box. The time between the onset of the word and the first key press and response accuracy were measured. If the wrong response was given, an error message appeared on the screen, which disappeared after the correct response was given. The next word was presented $1200 \mathrm{~ms}$ after a correct response. To counteract potential response location effects, we counterbalanced the location of the required response button over participants, giving four different versions of the task. We created a fixed random word list using the following restrictions: (1) the same word was never presented on two or more consecutive trials, (2) the same stimulus colour did never appear on more than four consecutive trials, and (3) the required response was never the same on four or more consecutive trials. The task was implemented with MEL V 2.0 and was executed on a Pentium- S, $133 \mathrm{mHz}$ computer.

Self-report measures. In correspondence with our previous studies, the three fundamental fears (AS, IS, FNE) are assessed by administering one questionnaire to participants that combines items from three scales that measure each fear separately (Vancleef \& Peters, 2006; Vancleef et al., 2006). As such, this questionnaire incorporates the Anxiety Sensitivity Index (ASI) to measure AS with 16 items that ask about possible negative consequences of experiencing anxiety. IS is assessed with the Injury/illness Sensitivity Index (ISI), of which 6 items pertain to the fear of illness and 5 items refer to the fear of injury. The Brief Fear of Negative Evaluation Scale (BFNE) measures the fear of negative evaluation with 12 items. Participants indicated their degree of agreement with all statements on a 5-point Likert scale, ranging from 1 (not at all agree) to 5 (absolutely agree). The psychometric properties of the English version of the ASI (Peterson \& Heilbronner, 1987), the BFNE (Carleton, McCreary, Norton, \& Asmundson, 2006; Leary, 1983) and recently the ISI (Carleton et al., 2005) have well been documented. Internal consistency and 6-month test retest reliability of the ASI, ISI, and BFNE in our combined questionnaire proved to be satisfactory (Vancleef \& Peters, 2006; Vancleef et al., 2006).

\section{Procedure}

Participants were seated behind a pc to perform the EAST and to fill out the questionnaires. All participants started with the implicit measure (i.e., EAST) and completed the self-report measures subsequently (Bosson, Swann, \& Pennebaker, 2000). Instructions for the EAST appeared on the 
screen and encouraged participants to work as fast and accurate as possible. After reading the instructions, participants could initiate the task by pressing a button on the response box. In the first practice phase, the 12 attribute words were each presented twice in a random order. In the second practice phase, the 18 target words were each presented twice - once in each colour- in a random order. The test phase consisted of 60 trials, presenting all attribute and target words twice. The whole task consisted of 120 trials, and it took about 15 minutes to complete the task. The experimenter followed task progress in an adjacent room.

\section{ANALYTICAL PLAN}

Data analyses were conducted on the coloured trials from the EAST test phase only. Because affective Simon effects are known to emerge in error data as well, analyses were performed on both the reaction time data and the error percentages (De Houwer, 2003). For the reaction time analyses, only reaction times on trials with a correct first response were taken into account. Following the recommendations made by Greenwald, McGhee, and Schwartz (1998), reaction times below $300 \mathrm{~ms}$ and above $3000 \mathrm{~ms}$ were set at $300 \mathrm{~ms}$ and $3000 \mathrm{~ms}$ respectively, and all reaction times were log-transformed (log-rt). For reasons of clarity, however, raw reaction times are used when presenting means and standard deviations (De Houwer, 2003).

Mean reaction times and error percentages were calculated for the 'compatible' trials and for the 'incompatible' trials. Next, a 3 (category: pain vs. panic vs. social evaluation) $x 2$ (compatible vs. incompatible) repeated-measures ANOVA was conducted on the log-rt and the errors. The automatic threat appraisal was further examined with paired-t-tests for each category separately. Next, an EAST-score was calculated by subtracting the mean compatible score from the mean incompatible score for each target category separately, for both the reaction times (EASTrt) and the errors (EAST-error). A positive EAST-score reflects a threatening appraisal of the target category. Correlations between the self-report measures and the EAST scores are computed with Pearson correlation coefficients.

\section{RESULTS}

Descriptive statistics for the target categories are presented in Table 1 . The $3 \times 2$ ANOVA on the log-rt revealed a main effect of compatibility $(F(1,47)=9.92, p=.003, d=.17)$. Participants responded generally faster when the required response was associated with a threatening meaning (compatible trials; $M=662$, $s d=109$ ) than when it was associated with a neutral meaning (incompatible trials; $M=701$, $s d=139)$. There was no main effect of category $(F(2,46)=.26, p=$ .77), nor an interaction effect of category $x$ compatibility $(F(2,46)=1.28, p=.28)$. The repeated measures ANOVA on the error data revealed no significant effects. 


\begin{tabular}{|c|c|c|c|c|}
\hline & \multicolumn{2}{|c|}{ Reaction time } & \multicolumn{2}{|c|}{ Error percentage } \\
\hline & Compatible & Incompatible & Compatible & Incompatible \\
\hline Panic & $654(124)$ & 699 (147) & 9 (14) & 11 (19) \\
\hline Pain related & 661 (139) & $711(181)$ & $10(14)$ & $9(15)$ \\
\hline Negative evaluation & 672 (136) & $692(155)$ & 9 (13.) & $7(11)$ \\
\hline
\end{tabular}

Although the ANOVA revealed a non-significant interaction, inspection of the raw mean scores in Table 1 indicates differences within categories. Post hoc t-tests demonstrated significant faster responses on compatible trials for the panic category, $t(48)=-2.35, p=.023$, the painrelated category, $t(48)=-2.99, p=.004$, but not for the negative evaluation category, $t(48)=-.67$, $p=.51$. Table 2 presents descriptive statistics of the ASI, ISI, and BFNE, and Pearson correlations with the EAST scores. Only the correlation between the EAST-error score and the BFNE reached significance.

Following De Houwer (2003), the reliability of the EAST was determined by calculating the correlations between the EAST-scores on the first and the second half of the experimental test phase for each category. For the log-rt data, this resulted in a significant correlation for the panic words only, $r=.35, p=.015$. The correlations for the pain-related words $(r=-.042)$ and the social evaluation words ( $r=.21$ ) were not significant. The same pattern emerged from the error data, $r=$ $.44, p=.002$ for the panic words and non-significant correlations for the pain-related $(r=.09)$ and the social evaluation words $(r=.12)$.

\begin{tabular}{|c|c|c|c|c|c|c|c|c|c|c|}
\hline & \multicolumn{10}{|c|}{ Descriptives } \\
\hline & Mean & Range & ASI & BFNE & EAST-rt & EAST-rt & EAST-rt & EAST-err & EAST-err & EAST-err \\
\hline & (sd) & & & & Pain & Panic & Neg. Eval & Pain & Panic & Neg. Eval. \\
\hline ISI & $\begin{array}{c}23.92 \\
(8.34)\end{array}$ & $13-48$ & $.66^{*}$ & .13 & .06 & .17 & .19 & -.09 & -.07 & -.02 \\
\hline $\mathrm{ASl}^{\mathrm{a}}$ & $\begin{array}{l}11.19 \\
(7.05)\end{array}$ & $1-36$ & 1 & $.43^{*}$ & .25 & .12 & .10 & -.10 & -.17 & .16 \\
\hline BFNE & $\begin{array}{r}27.40 \\
(9.86)\end{array}$ & $12-55$ & & 1 & -.04 & .10 & -.00 & .02 & -.07 & $.39^{*}$ \\
\hline
\end{tabular}

NotE. EAST-rt = the EAST score for the log-transformed reaction times; EAST-err = the EAST score for the error percentage; $\mathrm{ASI}=$ Anxiety sensitivity Index; ISI = Injury/illness Sensitivity Index; BFNE = Brief Fear of Negative Evaluation Scale; a because the scoring format of the ASI in this study (1-5) deviates from the original ASI (0-4), we transformed ASI scores to correspond with the original scale to enhance comparability with other research reporting about the $\mathrm{ASI}{ }^{*} \mathrm{p}<0.01$ 


\section{Discussion}

Results indicate the presence of an automatic threat appraisal towards the pain-related and panic-related words. However, no evidence emerged to sustain the idea that this threat appraisal relates to the presence of elevated levels of AS or IS. Likewise, no evidence emerged for a specific relation between AS levels and a threat appraisal for panic-related stimuli. However, although no significant EAST effect is found for the negative evaluation category, the EAST-error score of this category is the only score that correlates positively with FNE. This might be due to the affective value of the stimulus words. The words that represent the social evaluation category are more ambiguous of nature (e.g., stranger), probably only triggering negative affective valence for those who are especially sensitive to the negative content of these words. The pain-related and the panic stimuli on the other hand, have a generally negative affective valence (e.g., heart palpitation, physician), which might make it difficult to reveal individual variability. The ability to detect these individual differences might require a more sensitive EAST than the current one.

We therefore conducted a second study, in which we modified the EAST so that it became a more sensitive tool to study the hypothesized association between an automatic threat appraisal for stimuli that are reflective of pain, injury, and illness, and individual differences in IS and AS levels. Study 2 furthermore incorporates two measures that contribute to studying the predictive value of IS and AS for health related behaviours, namely the use of health care services and the self-reported tendency to engage in health protecting behaviour.

\section{StUdy 2}

\section{Method}

\section{PARTICIPANTS}

Sixty participants (46 female) with a mean age of 22.6 years (range: 18-47; sd = 5.64), recruited at the local community of Maastricht University participated in Study 2. Inclusion and exclusion criteria were identical to Study 1, with the additional exclusion criterion of prior participation in Study 1. All participants gave informed consent and received financial compensation for participating. Due to technical problems, the EAST data from two participants were missing, and data analyses were conducted on 58 participants. The research protocol was approved by the internal ethical review committee of the research institute Experimental Psychopathology (EPP). 


\section{to nome}

\section{Materials and Measures}

EAST. The EAST was modified in order to obtain a more sensitive measure of the automatic threat appraisal (De Houwer, 2003). First, we focussed on pain-related stimuli only. This allowed us to incorporate more compatible and incompatible trials in the test phase of the EAST, increasing task reliability without affecting task duration. It has been suggested that the EAST yields more reliable and accurate results as more trials are included, but the advantage of more trials needs to be weighed against the potential disadvantage of boredom and fatigue that may accompany long tasks (De Houwer, 2003; Teige, Schnabel, Banse, \& Asendorpf, 2004). Second, because it has been suggested that in priming measures such as the EAST, associations are being activated on basis of the exemplars of a target category, rather then category labels we replaced some target words (De Houwer, 2001). Replacements were based on a pilot in which 15 volunteers rated the degree to which putative stimuli words were representative for the categories injury or illness, threat or safety. Third, we changed the unipolar attribute dimension (i.e., neutral - threatening) into a bipolar attribute dimension (i.e., safe- threatening). Finally, we changed the software that delivered the EAST from MEL to E-Prime (Psychology Software Tools, Inc., 2002). The better clock facilities of E-prime may contribute to the task's sensitivity as well.

The target category in the EAST consisted of 6 nouns, referring to illness (e.g., cancer), injury (e.g., invalid), and pain (e.g., wound). The attribute categories consisted of 6 'threatening' words and 6 'safe' words (Appendix 1). In the first practice phase, each attribute word was presented three times, resulting in 36 trials. The second practice phase consisted of 12 trials presenting each target word once in each colour. In accordance with De Houwer (2003), the test phase started with two warm-up trials that were randomly chosen from the attribute list. Next, target words were presented three times in each colour, and the attribute words were presented equally often as the coloured words. Increasing the number of attribute words in the test phase helps to maintain and strengthen the association between the response buttons and the assigned attribute, increasing task sensitivity as well. Following the recommendations of De Houwer (2003), two identical test blocks were presented consecutively, creating the possibility to check for eventual boredom or fatigue effects.

The test phase consisted of 148 trials (two identical blocks of 74 trials), and the entire EAST consisted of 196 trials, taking about 20 minutes to complete. Counterbalancing principles, presentation times, and randomization restrictions were applied conform Study 1. The task was executed on a Pentium-S, $133 \mathrm{mHz}$ computer in a laboratory setting. 


\section{Self-report measures.}

Anxiety sensitivity and Injury/illness sensitivity. Anxiety sensitivity and Injury/illness sensitivity were measured with the ASI and ISI (see Study 1).

Health protecting behaviour. Individuals' tendency to act in a health-protecting manner was assessed with twelve vignettes that were created for this study (see Appendix 2). Each vignette contains a description of a situation that implies a certain health risk. Respondents need to imagine themselves being in these particular situations. The description is then followed by a question that asks about a health-protecting behaviour that can be posed as a reaction to the described situation. The vignettes cover two groups of health protecting behaviours; i.e., medical help seeking behaviour (6 descriptions) and escape/avoidance behaviour (6 descriptions). Participants have to indicate the degree of certainty with which they belief they would engage in the proposed behaviour ('definitely not'; 'probably not'; 'probably'; 'certainly'). The answers to each question are scored from 1 to 4 , with higher scores on the vignettes indicating more engagement in the health protecting behaviour. The internal consistency of the vignette list was satisfactory (Cronbach's $\alpha=0.66$ ).

Use of health care services. A second behavioural measure in this study was obtained by administering a self-created 6-item questionnaire, inquiring for the use of health care services in the last twelve-months. Three items referred to the number of visits to the general practitioner, and the over-the-counter and prescription medication usage in the past three months. The other three items referred to the number of visits to a medical specialist, a physical or manual therapist, and an alternative healer in the past twelve months. The questions could be answered by choosing between four alternatives that quantified the use of the specific health care service ('not at all'; 'once or twice'; 'three or four times', and 'more then four times'). The answers are scored from 1 to 4 , and a sum score is calculated with higher scores indicating more use of health care services.

\section{Procedure}

The procedure was largely the same as in Study 1. Upon termination of the EAST, participants completed the vignettes, the use of health care questionnaire, the ASI, and the ISI. 


\section{ANALYTICAL PLAN}

Data preparation followed the same procedure as in Study 1. After calculating compatible and incompatible scores, analyses were performed on the log-rt and the error percentages with a 2 (evaluative response: compatible vs. incompatible) $\times 2$ (experiment half: half 1 versus half 2 ) repeated-measures ANOVA. Paired-t-tests examined whether participants were faster and more accurate on compatible trials than on incompatible trials, and EAST scores (EAST-rt and EASTerror) were computed. Next, scores on the ISI, the ASI, the vignettes, and the use of health care services were correlated with each other and with the EAST scores using Pearson correlation coefficients. To examine the contribution of AS and IS in the explanation of the automatic threat appraisal we carried out linear regression analyses with AS and IS as the independent variables and EAST scores as the dependent. Next, separate linear regression analyses were performed with the vignette scores and the use of health care services as the dependent variables. In the first step of this regression analysis, AS and IS were entered as predictors. The implicit threat appraisal score was entered in the second step to test whether the implicit measure had additional predictive value for both behavioural measures.

\section{RESULTS}

Mean reaction times and error percentages were calculated for the compatible $\left(M_{r t}=\right.$ $\left.618, s d=136 ; M_{\text {error }}=4.07, s d=4.83\right)$ and the incompatible trials $\left(M_{r t}=631, s d=113 ; M_{\text {error }}=\right.$ 8.33, $s d=6.80$ ). The 2 (compatible vs. incompatible) $\times 2$ (half $1 \mathrm{vs.} \mathrm{half} \mathrm{2)} \mathrm{ANOVA} \mathrm{revealed} \mathrm{a} \mathrm{main}$ effect of experiment half $(F(1,57)=5.38, p=0.024, d=.086)$ for the log-rt, with faster responses in the second half than in the first half of the experiment, and a main effect of compatibility for the $\log$-rt $(F(1,57)=5.21, p=.026, d=.084)$ and the errors $(F(1,57)=19.53, p=.000, d=.25)$. The interaction between compatibility and experiment half was not significant.

Table 3 shows the descriptive statistics for the self-report measures, the vignettes, and the use of health care services questionnaire. The correlation matrix in Table 3 shows a positive correlation between the EAST-rt and the ISI, indicating that higher levels of IS were associated with stronger automatic threat associations. The correlation with the ASI was marginally significant ( $p$ $=$. .066). The correlations between the EAST-error and the ISI or the ASI were not significant. The predictive value of IS and AS for the EAST-rt was examined by entering both measures in a linear regression analysis. The resulting model did not reach significance $\left(F(2,55)=2.79, p=.07, R^{2}=\right.$ $.09, R^{2}$ adjusted $=.06$ ), with $B=.12, t=.741, p=.46$ for $\mathrm{AS}$ as predictor, and $B=.22, t=1.42, p$ $=.16$ for IS as predictor. When the same analysis was conducted on the error data, again neither AS or IS proved significant predictors.

The reliability of the EAST was calculated as in Study 1 , showing a significant correlation between the first and the second experimental half, $r=.36, p=.005$ for the log-rt data. The correlation that was calculated within the error data did not reach significance $(r=.19)$. 


\begin{tabular}{|c|c|c|c|c|c|c|c|}
\hline & \multicolumn{7}{|l|}{ Descriptives } \\
\hline & $\begin{array}{l}\text { Mean } \\
(\mathrm{sd})\end{array}$ & Range & ASI & $\begin{array}{c}\text { Use health care } \\
\text { services }\end{array}$ & $\begin{array}{c}\text { Health protect } \\
\text { behaviour }\end{array}$ & EAST-rt & EAST-err \\
\hline ISI & $\begin{array}{r}22.05 \\
(8.38)\end{array}$ & $11-47$ & $.58^{\star \star}$ & .00 & $.44^{\star \star}$ & $.29^{*}$ & -.00 \\
\hline $\mathrm{ASI}^{\mathrm{a}}$ & $\begin{array}{l}8.28 \\
(6.86)\end{array}$ & $0-40$ & 1 & $.42^{\star \star}$ & $.38^{\star \star}$ & $.24^{+}$ & -.02 \\
\hline $\begin{array}{l}\text { Use health care } \\
\text { services }\end{array}$ & $\begin{array}{c}9.22 \\
(2.30)\end{array}$ & $6-15$ & & 1 & $.28^{\star}$ & .12 & .08 \\
\hline \multicolumn{8}{|l|}{ Health protect } \\
\hline behaviour & $\begin{array}{r}28.65 \\
(4.87)\end{array}$ & $19-43$ & & & 1 & $.22^{+}$ & $.25^{+}$ \\
\hline
\end{tabular}

Note. EAST-rt = the EAST score for the log-transformed reaction times; EAST-err = the EAST score for the error

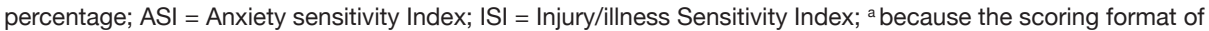
the ASI in this study (1-5) deviates from the original ASI (0-4), we transformed ASI scores to correspond with the original scale to enhance comparability with other research reporting about the ASI; ${ }^{* \star} p<0.01 ;{ }^{*} p<0.05 ;{ }^{+} p<$ 0.10

Table 3 also shows that the vignette scores correlate positively and significantly with both IS and AS, whereas the use of health care services correlates significantly with AS only. Furthermore, the EAST-rt showed a marginally significant $(p=.094)$ correlation with the score on the vignettes. Table 4 presents the results of the regression analyses on the behavioural measures. Entering both IS and AS as predictors of health protecting behaviour resulted in an overall significant model $\left(F(2,55)=7.66, p=.001, R^{2}=.22, R^{2}\right.$ adjusted $\left.=.19\right)$ with IS being the only significant predictor ( $B=.33, t=2.28, p=.027$ ). Entering the EAST-rt in the second step of the analysis did not significantly add explanatory variance to the scores on the vignettes $(F(3,54)$ $=5.22, p=.003, R^{2}=.22, R^{2}$ adjusted $\left.=.18 ; \Delta F(1,54)=.50, p=.48, \Delta R^{2}=.007\right)$. The regression analysis on the use of health care services showed significance for the overall model when AS and IS were entered in the first step of the analysis $\left(F(2,55)=6.52, p=.003, R^{2}=.19, R^{2}\right.$ adjusted $=$ .16), with AS being the only significant predictor $(B=.51, t=3.44, p=.001)$. The EAST-rt score could not explain additional variance $\left(F(3,54)=4.33, p=.008, R^{2}=.20, R^{2}\right.$ adjusted $=.15 ; \Delta F(1,54)$ $=.15, p=.70, \Delta R^{2}=.002$ ). 


\begin{tabular}{|c|c|c|c|c|c|c|c|}
\hline Dependent & & Variable & B & SE B & B & $t$ & $p$ \\
\hline \multirow{5}{*}{$\begin{array}{l}\text { Health protecting behaviour } \\
\text { (Analysis 1) }\end{array}$} & Step 1 & ASI & .13 & .10 & .19 & 1.31 & .20 \\
\hline & & ISI & .19 & .09 & .33 & 2.28 & .03 \\
\hline & Step 2 & ASI & .13 & .10 & .19 & 1.29 & .22 \\
\hline & & ISI & .19 & .09 & .33 & 2.24 & .04 \\
\hline & & EAST-rt & 4.47 & 6.36 & .09 & .70 & .48 \\
\hline \multirow{6}{*}{$\begin{array}{l}\text { Use of health care services } \\
\text { (Analysis 2) }\end{array}$} & Step 1 & ASI & .17 & .05 & .51 & 3.44 & .001 \\
\hline & & & & & & & \\
\hline & & ISI & -.00 & .04 & -.16 & -1.07 & .29 \\
\hline & Step 2 & ASI & .17 & .05 & .50 & 3.37 & .001 \\
\hline & & $|S|$ & -.00 & .04 & -.17 & -1.12 & .27 \\
\hline & & EAST-rt & 1.19 & 3.04 & .05 & .40 & .69 \\
\hline
\end{tabular}

Note. Analysis 1, Step $1 R^{2}=.19$, Step $2 \Delta R^{2}=.007$. Analysis 2, Step $1 R^{2}=.19$, Step $2 \Delta R^{2}=.002$.; $A S I$ = Anxiety Sensitivity Index; ISI = Injury/illness Sensitivity Index; EAST-rt= EAST score for the log-transformed reaction times; Significant predictors are presented in boldface

a Regression analyses were performed with an EAST-index as implicit variable as well, which was calculated as the average of the $z$-transformed it scores and the $z$-transformed error scores, and is suggested to counteract possible speed-accuracy variations, resulting in maximized predictive power of the EAST. Results of the regression analysis did not deviate from the results presented with the rt scores however.

\section{General Discussion}

Results of both studies showed that aversive stimuli (either pain-related or panicrelated) automatically elicit threat associations. The strength of these threat associations appeared independent of individuals' specific fear levels. The latter finding may be explained by the fact that the pain- and panic-related words in the current task hold a generally negative or threatening affective connotation. Therefore, it is likely that irrespective of specific fears people will have negative attitudes towards these stimuli, and previous research using similar implicit tasks showed that general threat words may elicit automatic threat associations irrespective of prior fear (de Jong et al., 2003). Similarly, Goubert, Crombez, Hermans, and Vanderstraeten (2003) report about a general implicit negative attitude towards back-stressing pictures in healthy individuals, using an affective priming task. In Study 2, we implemented several modifications to the EAST to obtain a more sensitive measure. To check if the modifications were beneficial for the reliability of the 
measure, we examined split-half reliabilities of the EAST effects, demonstrating an increase in the reliability from Study $1(-.042)$ to Study $2(.36)$ for the EAST effect on the pain-related target category.

As hypothesized, Study 2 demonstrated that higher IS levels were associated with more pronounced automatic threat appraisals of health-threatening stimuli. A similar relationship between AS and automatic threat appraisal did not reach significance although a trend was observed. It should be acknowledged, however, that the target words in Study 2 were chosen in such a way that they captured 'pain-related targets' that are relevant for a healthy population (i.e., injury, illness, and general pain stimuli). This choice has the drawback that these words are less content-specific for AS. Using highly specific targets that referred to anxiety-related sensations (e.g., breathless, palpitation), it was recently found that high AS individuals automatically associated these stimuli with harmful health consequences (Lefaivre, Watt, Stewart, \& Wright, 2006). So, it seems that the automatic elicitation of threat appraisals depend on whether stimuli are used that correspond to the current concerns of the individual. Although the importance of current concerns in the occurrence of specific cognitive biases was already demonstrated in previous studies (Riemann \& McNally, 1995), the suggestion of automatic elicitation of content-specific cognitive bias conflicts with the assumption that automatic negative biases do not show content-specificity (Mathews \& MacLeod, 1994).

Up to now, only a few studies have looked into automatic processing biases in relation to chronic pain. These studies gave evidence for negative biases at the strategical, but not at the automatic level (Snider, Asmundson, \& Wiese, 2000). Further research is necessary to establish the robustness and conditional circumstances of the operation of automatic biases in chronic pain. As such, it remains to be established if AS and IS also relate to automatic threat appraisals when target words are specific for chronic pain, like sensory pain (e.g., stabbing, pulsating), or emotional pain (e.g., unbearable, killing). However, since the present target words were already closely connected to the central cue of chronic pain (i.e., pain), it seems safe to predict that automatic threat appraisals will extend to specific pain stimuli as well.

It might be that AS and IS relate to different aspects of biased processing of information in which pain is somehow involved. IS has been identified by prior research as the single best predictor of fear of imminent pain prior to a pain induction procedure (Vancleef et al., 2006), whereas AS has been found to be associated with more pain following pain induction (Keogh \& Birkby, 1999; Keogh \& Mansoor, 2001; Lang, Sorrell, Rodgers, \& Lebeck, 2006), and elevated analgesic use in chronic pain patients (Asmundson \& Norton, 1995; Asmundson et al., 2000; Vincent \& Walker, 2001). Consistent with this IS in the present study was found to be the single best predictor of the engagement in health protecting behaviour, whereas AS was the sole predictor for the use of health care services. Hence the present findings stimulate further speculation on the specific predisposing role that both constructs may play in the pain process. Since IS embodies worrying about getting injured or becoming ill, it refers to the expected catastrophic consequences of future pain experiences. Likewise, the vignettes tap individuals' opinion on how they will react should they ever encounter the described situation, thereby mirroring future-oriented behaviour. In contrast, AS refers to the negative consequences of current bodily sensations. The use of health care services reflects action that one undertakes in response to experienced bodily sensations. Thus, the present 


\section{$\Uparrow$ chaperer}

findings add to the idea that IS and AS may be relevant for explaining complementary aspects of pain-related behaviours, and it seems worthwhile to study further their potentially differential contribution to the chronic course of pain. Following on from this, it would be interesting to test in future research whether IS will be most predictive of automatic threat appraisals for stimuli specifically referring to future physical harm (e.g., disability) and AS for automatic threat appraisals when stimuli are used that describe common and 'daily' painful sensations (e.g., pain, cramp, headache).

Earlier studies using the affective Simon test in the context of substance abuse and specific phobia not only demonstrated that implicit attitudes (reflexive associations) can diverge from explicit attitudes (reflective associations), they also showed that implicit associations with complaint-related stimuli have predictive value for problem behaviours over and above explicit attitudes (de Jong et al., 2007; Huijding \& De Jong, 2005), and have superior predictive value for relatively spontaneous (non-reflective) problem behaviours (Huijding \& de Jong, 2006). In apparent contrast, the EAST-effects in the present study showed no additional predictive power in predicting health behaviour. One testable explanation for the absence of additional predictive value in the present study might be that implicit and explicit associations with respect to health threats are less discrepant than with respect to alcohol and spiders. In addition, it might be that relatively spontaneous (reflexive) behaviours are less important in the context of health threats than in the context of phobic complaints and substance misuse. If so, health behaviours would be guided predominantly by explicit considerations that can be more efficiently tapped by means of selfreport measures than by performance measures such as the EAST. However, because in the present study health behaviours were explicitly measured using self-report measures rather than observation or physiological measurement it seems more plausible to assume that the behavioural measures did simply not capture spontaneous behaviours that are assumed to be guided by automatic associations (e.g., Huijding \& de Jong, 2006). To more definitely settle this issue it would be necessary to include indirect measures of strategic and spontaneous pain-related behaviours (e.g., reflexive increase in muscle tension when confronted with potential pain-related threat) in future research (e.g., Vlaeyen et al., 1999).

Apart from the lack of an objective behavioural measure, several other limitations need to be considered when interpreting the current results. Relatively few studies have used the EAST to examine the relation between automatic associations and individual levels of personality constructs such as anxiety, stressing the need for replication of the current findings. Moreover, several authors report about unsatisfactory reliability of the EAST (Teige et al., 2004), and this concords with the low split-half reliability that was observed in Study 1. Nevertheless, Study 2 illustrates the possibility to create a more reliable and sensitive EAST by extending the number of trials and by modifying target category and attributes. (see also Huijding \& De Jong, 2005). In addition, evidence exists that the EAST can be sensitive enough to predict actual behaviour (Houben, Gijsen, Peterson, De Jong, \& Vlaeyen, 2005; Huijding \& De Jong, 2005) and to differentiate between individuals with and without anxiety complaints (Lefaivre et al., 2006). Furthermore, the tendency to engage in health protecting behaviour was measured with situational descriptions that were developed for the current study, and further validation of this measure is recommendable. Finally, it cannot be ruled out that participants' current physical or mental conditions may have affected task 


\section{Automatic threat appraisal for pain}

performance, since compliance with in- and exclusion criteria were only queried when participants were scheduled for a test appointment, and not on the day of testing itself. Furthermore, we did not use validated questionnaires to assess participant's mental or physical state. In addition, despite the fact that the shift in programming software from the first to the second study is assumed to contribute to the measure's sensitivity, caution is warranted when comparing data between both studies because differences might be partly attributable to the programming software.

To conclude, the present study stresses the need for further research of biases in information processing that may originate from fast and automatic associations in memory. Furthermore, it opens the way for further research on the relation between automatic evaluations of pain-related situations and specific pain behaviour, like escape and avoidance behaviours that are frequently observed in chronic pain patients. Finally, the current study provides evidence for the importance of both IS and AS as vulnerability factors in pain processing, suggesting that both constructs may account for different aspects of the pain process.

\section{ACKNOWLEDGEMENTS}

This research was supported by a grant from the Netherlands Organization for Scientific Research (NWO: 015-001-050). The authors are grateful to Charlie Bonnemayer for technical help and support in programming and implementing the EAST. 
Chapter 4

APPENDIX 1: Target and attribute words in Study 1 and Study $2^{a}$

\begin{tabular}{|c|c|c|}
\hline & Study 1 & Study 2 \\
\hline Target & Panic-related: Hart palpitation (hartklopping), panic (paniek), & Health-threatening: Physician (dokter), blood (bloed), \\
\hline words & $\begin{array}{l}\text { tension (spanning), crowd (menigte), dyspnoea (ademnood), } \\
\text { nerves (zenuwen) } \\
\text { Pain-related: Physician (dokter), wheelchair (rolstoel), } \\
\text { disabled (invalide), bandage (verband), } \\
\text { diagnosis (diagnose), hospital (ziekenhuis) } \\
\text { Social- evaluation-related: Stranger (vreemde), criticism } \\
\text { (kritiek), shame (schaamte), rejection (afwijzing), } \\
\text { impression (indruk), acceptation (acceptatie) }\end{array}$ & $\begin{array}{l}\text { infection (infectie), disabled (invalide), } \\
\text { cancer (kanker), wound (wond) }\end{array}$ \\
\hline Attribute words & $\begin{array}{l}\text { Threat: Fatal (fataal), threatening (dreigend), } \\
\text { dangerous (gevaarlijk), mortal (dodelijk), hostile (vijandelijk), } \\
\text { terrible (vreselijk), violence (geweld) }\end{array}$ & $\begin{array}{l}\text { Threatening: Burglary (inbraak), hate (haat), war } \\
\text { (oorlog), hold-up (overval), terrorism (terrorisme), }\end{array}$ \\
\hline & $\begin{array}{l}\text { Neutral: Customary (gewoon), neutral (neutraal), objective } \\
\text { (objectief), adult (volwassen), oval (oval), modern (modern) }\end{array}$ & $\begin{array}{l}\text { Safe: Hug (knuffel), nice (lief), home (thuis), enjoyable } \\
\text { (gezellig), friendship (vriendschap), fortune (geluk) }\end{array}$ \\
\hline
\end{tabular}

aDutch words in parentheses; words are matched on word length, frequency and number of syllables.

APPENDIx 2. The situational descriptions, formulated in the vignettes assessing the engagement in health protecting behaviour, divided in medical help seeking behaviour and escape/avoidance behaviour

\begin{tabular}{|c|c|c|}
\hline & \multicolumn{2}{|l|}{ Medical help seeking behaviour } \\
\hline & Situation & Behaviour \\
\hline 1 & $\begin{array}{l}\text { Falling while walking on your socks. } \\
\text { Break the fall on your wrists. Your wrist hurts. }\end{array}$ & Visiting a GP to have your wrist examined \\
\hline 2 & Girl in the neighbourhood has meningitis. You spoke to her two weeks ago & Visiting a GP for preventive medication \\
\hline 3 & Employer offers opportunity for free medical check-up & Participate in the medical check-up \\
\hline 4 & $\begin{array}{l}\text { Wisdom tooth needs to be removed. You received a prescription to } \\
\text { purchase analgesics before the procedure, even if probably not } \\
\text { necessary }\end{array}$ & Purchase the analgesics \\
\hline 5 & $\begin{array}{l}\text { Sudden stomach pain during the weekend. Own GP is unreachable, } \\
\text { possible to visit unfamiliar GP }\end{array}$ & Visit the unfamiliar GP \\
\hline 6 & $\begin{array}{l}\text { Reading about birth marks on the internet and their possible health } \\
\text { danger }\end{array}$ & Having the spots examined \\
\hline & Escape/avoidance behaviour & \\
\hline & Situation & Behaviour \\
\hline 7 & Hearing about SARS in China after you have booked a trip to China. & Still travelling to China as planned * \\
\hline 8 & $\begin{array}{l}\text { Few weeks ago you twisted your ankle. This has healed; } \\
\text { friends ask if you want to go indoor skiing with them? }\end{array}$ & Agree to go skiing with friends * \\
\hline
\end{tabular}


Automatic threat appraisal for pain

After cleaning of the water pipes the baths are open for visitors again

Reading about chemical substance in your favorite diet

drink that heightens the risk at cancer

Once in a while problems with your knee.

Family members ask if you will join them in a long walk

12 Anti-RSI adaptations at work.

At home you work at the computer for your hobby.

* Reversely scored items
Visiting the thermal baths one week after re-opening ${ }^{*}$

Drink less of your favorite drink

Wearing a supportive brace for your knee

Use anti-RSI adaptations at home 


\section{- - \\ Chapter 5}

Examining content specificity of negative

interpretation biases with the Body Sensations

Interpretation Questionnaire (BSIQ)

This chapter is in press as:

Vancleef, L. M. G., \& Peters, M. L. Examining content specificity of negative interpretation biases with the Body sensations Interpretation Questionnaire (BSIQ). Journal of Anxiety Disorders. 


\section{AbstRact}

Cognitive biases have been suggested to act as latent vulnerability factors for the onset and maintenance of affective and emotional disorders. Additionally, several global and specific personality constructs are known to influence the course of psychopathology (e.g., trait anxiety, optimism, anxiety sensitivity (AS), injury/illness sensitivity (IS), fear of negative evaluation (FNE)). The current study examined the specificity of the relation between these constructs and a negative interpretation bias. 154 Healthy participants completed the Body Sensations Interpretation Questionnaire (BSIQ: Clark et al., 1997), measuring negative interpretations on four domains. A confirmatory factor analysis offered support for four factors in the BSIQ. Multiple linear regression analyses demonstrated that optimism is predictive of less negative interpretations. AS, IS, and FNE are specifically predictive of negative interpretations on the panic, other bodily symptoms, and social situations subscale, respectively. In addition, specific pain-related constructs were found most predictive of the other bodily sensations subscale. It is concluded that individual variability in global and specific psychological constructs is associated with a content-specific negative interpretation bias.

\section{INTRODUCTION}

It is now widely accepted that cognitive processing biases can act as latent vulnerability factors for the onset and the maintenance of emotional and affective disorders (Mathews \& MacLeod, 1994). Cognitive theories on emotional disorders state that highly anxious and depressed individuals prioritize the encoding of threatening and negative information to prepare themselves to flee from potential harmful or dangerous situations (Beck \& Clark, 1997; Eysenck, 1997). Such prioritizing of information has been suggested to be specific for information that is congruent to the emotional state and current concerns of the individual (Mathews \& MacLeod, 1994). One cognitive bias that has frequently been studied in this light is a negative interpretation bias, which reflects the tendency to interpret innocuous situations, symptoms or sensations in a negative or threatening fashion. Research has shown that social anxious individuals often interpret social ambiguous situations in a negative fashion (Amir, Beard, \& Bower, 2005; Amir, Foa, \& Coles, 1998; Vassilopoulos, 2006), and that chronic pain patients negatively interpret ambiguous pain-related information (Pincus \& Morley, 2001). Furthermore, there is a large amount of evidence that panic patients interpret innocuous ambiguous sensations and situations as negative or threatening (e.g., Clark, 1986; Harvey, Richards, Dziadosz, \& Swindell, 1993).

Clark et al. (1997) developed the Body Sensations Interpretation Questionnaire (BSIQ), as well as a brief version of the BSIQ (BBSIQ) to study the specificity of the relation between panic disorder and negative interpretations of autonomous bodily sensations relating to panic (e.g., heart palpitations, dizziness). The BSIQ assesses interpretations on four different domains: (1) panic-related sensations, (2) other bodily symptoms, (3) social events, and (4) general events. Patients with panic disorder have been found to make significantly more negative interpretations on the panic-related sensations subscale than patients with other anxiety disorders and healthy 


\section{$\Uparrow$ chanerer}

controls (Austin, Richards, \& Klein, 2006; Clark et al., 1997). In non-clinical populations, elevated levels of anxiety sensitivity (AS) have been found associated with negative interpretations on the panic-related sensations subscale as well (Richards, Austin, \& Alvarenga, 2001; Teachman, 2005). AS, defined as the fear of anxiety symptoms (e.g., heart palpitations) that arises from the belief that these symptoms will lead to harmful somatic, psychological or social consequences (Reiss et al., 1986) has been proposed as a specific risk factor for the onset and course of panic disorder (Schmidt \& Cook, 1999; Taylor, 1995). As such, the negative interpretation bias towards ambiguous bodily sensations is considered to form not only a by-product of panic disorder, but to characterize healthy individuals who are at risk for developing panic disorder as well.

Hitherto, the BSIQ has rarely been used to study interpretation biases beyond the specified domain of panic. Nevertheless, there are reasons to assume that the measure can provide information on biased interpretations in other domains. Clark et al. (1997) have suggested that the tendency to negatively interpret bodily sensations might be characteristic of other conditions than panic disorder, for example hypochondria. Furthermore, several studies found that panic patients, anxiety patients, and healthy individuals high in AS made significantly more negative interpretations on all BSIQ subscales compared to healthy individuals low in AS (Clark et al., 1997; Keogh \& Cochrane, 2002; Keogh et al., 2004; Richards et al., 2001; Teachman, 2005). Even though the negative bias was most specifically related to panic-related ambiguity in these studies, it is remarkable that anxiety pathology and individual levels of anxiety traits were predictive of negative interpretations in other domains as well. Keogh and Cochrane (2002) and Keogh et al. (2004) have extrapolated the applicability of the BSIQ outside the research area of panic to this of chronic pain. Starting from the knowledge that AS is conceived to serve an important role in the onset and maintenance of chronic pain complaints as well (e.g., Asmundson et al., 2000), they demonstrated that the negative interpretation bias (as assessed by the BSIQ) acted as a mediating mechanism in the relation between AS and affective pain responses to experimentally induced cold-pressor pain. This mediating effect was initially observed when the panic-related sensations subscale of the BSIQ was taken as the measure of negative interpretative bias (Keogh \& Cochrane, 2002), and was later replicated when the overall BSIQ score was adopted as the mediating variable (Keogh et al., 2004).

The BSIQ is a direct self-report measure, and offers respondents the opportunity to reflect on their responses, and to rely on pre-existing beliefs and schemes in providing responses to each situational description. As such, the BSIQ is assumed to affect later rather than early stages of information processing (Beck \& Clark, 1997). According to information processing theories, particularly cognitive biases that occur at these later elaborative stages of information processing are domain-specific and relate to individuals' current concerns (Mathews \& MacLeod, 1994). In line with this, it may be suggested that the BSIQ can act as an adequate instrument to measure domain-specificity of interpretations in relation to both global and specific emotional constructs involved in psychopathology. The current study was set up as a first step to test this suggestion. For this purpose, several emotional constructs were included in the current study. These constructs were partly adopted from the hierarchical model of negative emotional constructs as proposed by Lilienfeld (1996). This model contains several general and specific negative emotional constructs that are assumed to be involved in psychopathology (i.e., anxiety). The hierarchical model is built 
up of several levels with the higher levels representing more global and stable personality traits and the lower levels representing more specific constructs that are closely related with specific manifestations of psychopathology (Keogh \& Asmundson, 2004; Lilienfeld, 1996; Vancleef et al., 2006). At the higher levels of this model, dispositional fear or trait anxiety can be found, which is conceived as the general tendency to react fearfully to a broad range of situations. Trait anxiety is assumed to constitute an important trait in the onset and exacerbation of various emotional and affective disorders (e.g., Lilienfeld, 1996; Spielberger et al., 1970). In the current study, it is hypothesized that elevated levels of trait anxiety are predictive of the tendency to make more negative interpretations on all subscales of the BSIQ. In contrast to trait anxiety, optimism has been proposed as a resilience factor for the development and maintenance of psychopathology (for an overview see Carver \& Scheier, 2005; Scheier \& Carver, 1992). Optimism contributes to physical and psychological well being in general and thereby protects against maladaptive behavioral responses and cognitions (Scheier \& Carver, 1992). Therefore, it is hypothesized that heightened levels of optimism are predictive of less negative interpretations on all BSIQ subscales.

Both trait anxiety and optimism are global measures that are assumed to influence negative interpretations of ambiguity referring to panic related sensations, other bodily sensations, social events, and general events. To study the domain specificity of negative interpretations we included measures of AS, injury/illness sensitivity (IS), and fear of negative evaluation (FNE). In the hierarchical model of negative emotional constructs, these three constructs are nested directly under the higher-order factor trait anxiety. Moreover, AS, IS, and FNE are conceived as three fundamental fears that underlie the daily and common fears (e.g., fear of heights, blood phobia) that we encounter in daily society (Lilienfeld, 1996; Reiss et al., 1986; Taylor, 1993). As was already stated in the previous paragraph, AS is conceived as a specific risk factor for panic disorder, and has been suggested to contribute to chronic pain as well (Asmundson et al., 2000; Taylor, 1995). IS is commonly defined as the exaggerated fearfulness and excessive worrying of getting injured or becoming seriously ill in the future (Carleton et al., 2005; Taylor, 1993). Given its intrinsic referral to injury and illness, IS is conceived to form a vulnerability factor for the maintenance and exacerbation of chronic health disorders, such as chronic pain (Keogh \& Asmundson, 2004; Peters \& Vancleef, in press; Vancleef et al., 2006). FNE, then, stands for the fear of being negatively evaluated by others (e.g., speaking in public, eating in public) and is proposed as an important factor in social anxiety and social phobia (Leary, 1983; Taylor, 1993). Corroborating the specific content of each fear, Taylor (1993) has reported about specific predictive power of FNE for social phobia, IS for blood phobia, and AS for agoraphobia. Furthermore, each fundamental fear has been found specifically related to biased processing of content-congruent information. As such, several studies have demonstrated the association between elevated levels of AS on the one hand, and the memory biases, interpretation biases, and attentional biases in which innocuous stimuli are processed as indicators of threat or danger on the other hand (e.g., Keogh \& Cochrane, 2002; Lefaivre et al., 2006; Teachman, 2005). Using an automatic association task, IS was found to be specifically related to the automatic threatening evaluation of stimuli that referred to health threats (Vancleef et al., 2007). In addition, it has been demonstrated that persons possessing elevated levels of FNE react catastrophically to innocuous social events, have a focused attention for social threat words, associate positive words implicitly to a smaller degree to themselves than 


\section{$\Uparrow$ chaperer}

to others, and endorse more negative thoughts when they are in the prospect of performing a socially threatening activity (Stopa \& Clark, 2001; Tanner, Stopa, \& De Houwer, 2006). Regarding the content-specificity of the direct negative interpretations in this study, we hypothesized that AS, IS, and FNE would be specifically related to negative interpreting ambiguous panic-related sensations, other bodily symptoms, and social events, respectively.

Because the aim of this study is to examine content-specificity of the interpretative bias we additionally explored the supplementary predictive value of specific negative constructs that are assumed to influence psychopathology directly. More specifically, we included measures of two pain-specific constructs that have been proposed to form lower-order factors of IS; Fear of Pain (FoP) and Pain Catastrophizing (PC) (Keogh \& Asmundson, 2004; Vancleef et al., 2006). These constructs are known to be very closely related to the experience of pain and have been proposed as crucial variables in predicting the transition from acute to chronic pain (e.g., Vlaeyen \& Linton, 2000). We expected that these constructs would show a unique association with the negative interpretation of items from the other bodily symptoms subscale of the BSIQ only, based on the fact that this particular subscale contains items that are reflective of pain, injury and disability.

In sum, the main aim of the current study is to address domain-specificity of negative interpretative bias with the BSIQ by examining the relation between levels of both global and more specific emotional constructs and negative interpretations on four domains i.e., panic-related sensations, other bodily symptoms, social events and general events. However, in order to be able to draw reliable conclusions about associations with each separate BSIQ subscale, it is advisable to first examine the factor structure of the BSIQ. The BSIQ was developed to comprise ambiguous situations on four domains that are represented by the four subscales of the measure. Both the total BSIQ as its subscales have proven to possess well internal consistency (Clark et al., 1997; Keogh et al., 2004), and the BSIQ can effectively discriminate between individuals with panic disorder and other anxiety disorders (Clark et al., 1997). However, no studies reporting on the factor structure of the measure are available to our knowledge. Therefore, we started our study with a confirmatory factor analysis on the BSIQ in order to verify whether the four-factor structure of the measure does indeed provide the best model fit to the current data.

\section{METHOD}

\section{PARTICIPANTS}

A total of 154 participants ( 51 male, 103 female), with a mean age of 26.76 years (SD = 9.26; range: 18 -50) was included in the study. Participants were recruited both inside and outside the local community of Maastricht University. Participants from within Maastricht University $\left(N=79 ; M_{\text {agee }}=24.03, S D=6.73\right)$ registered by entering their name on enlistment folders that were spread throughout the university buildings. Furthermore, the experimenters personally approached persons outside the university community $\left(N=76 ; M_{\text {age }}=29.06, S D=10.65\right)$ with the question if they were willing to participate at the study. This latter group of participants was mainly recruited 
within the near and far acquaintance environment of the experimenters. All participants were naive as to the study aims of the research. Since all measures were administered on the pc, participants within the age group of 18 to 50 years were asked to participate, assuming that this group is likely to be acquainted with the use of computers. Before an actual test appointment was planned, the experimenters verbally checked whether all inclusion and exclusion criteria were fulfilled by asking candidate participants directly whether they were (1) in good mental health (not diagnosed with mental disorder- Yes or no), (2) free from acute or chronic (over three months) pain complaints (yes versus no), and (3) natively and fluently Dutch speaking (yes or no).

\section{MeAsures}

Interpretation bias : Body Sensations Interpretation Questionnaire (BSIQ). The BSIQ (Clark et al., 1997) consists of 27 ambiguous descriptions that are placed under four subscales: (1) panic-related bodily sensations (7 items; e.g., 'You notice your heart is beating quickly and pounding'); (2) other bodily symptoms (6 items; e.g., 'You have developed a small spot on the back of your hand'); (3) social events ( 8 items; e.g., 'You go into a shop and the assistant ignores you'); and (4) general events ( 6 items; e.g., 'A member of your family is arriving home late'). Although the first two subscales both refer to bodily sensations, they differ in that the panic related sensation subscales contains autonomous sensations that are highly specific for and typically associated with panic attacks. The other bodily symptoms subscale relates to non-autonomous sensations and symptoms, not typically associated with panic, and referring to injury, illness and pain in general.

The ambiguous descriptions are presented one-by-one on the computer screen, accompanied with the question 'Why? Each description remains on screen for 5 s, enabling participants to think about this description and possible explanations for it. Next, three alternative explanations are provided, one of which is negative and two neutral explanations. For the item 'You notice your heart is beating quickly and pounding', the negative explanation states 'Because there is something wrong with your heart', the two neutral explanations state 'Because you have been physically active' and 'Because you are feeling excited'. Participants then indicate which of these three alternatives comes closest to their personal interpretation (ranking score). Next, participants rate the likelihood of each alternative explanation in percentages (0-100; rating score).

Clark et al. (1997) reported about good content and construct validity of the BSIQ, in that the measure was able to differentiate between patients with panic disorder and patients with other anxiety disorders. Furthermore, Keogh et al. (2004) have demonstrated satisfactory internal consistencies for the subscales of the BSIQ with reliability coefficients ranging between 0.71 and 0.83 . In the current sample Cronbachs alpha values showed satisfactory to good internal consistency as well with $\alpha=.78$ for the panic-related sensations subscale, $\alpha=.75$ for the other bodily symptoms subscale, $\alpha=.86$ for the social events subscale, and $\alpha=.73$ for the general events subscale. 
Self-report measures. The State-Trait Anxiety Inventory - Trait form (STAI-T; Spielberger et al., 1970) contains 20 items that tap a general anxiety disposition (e.g., 'I worry too much about unimportant things'). Participants have to indicate on a 4-point Likert scale, ranging from 1 (almost never) to 4 (almost always), to what extent these statements apply to them. A high score on this scale reflects a high general anxiety disposition. The original and Dutch version (Ploeg van der et al., 1980) proved to be reliable and valid measures.

Optimism was assessed with the Life Orientation Test (LOT; Scheier \& Carver, 1985). This measure consists of 12 items, of which four are filler items. The remaining eight items consist of four positively worded statements ('I always look on the bright side of things'), and four negatively worded statements (e.g., 'Things never work out the way I want them to'). Participants have to respond to each statement on a 4-point Likert scale ranging from 0 (strongly disagree) to 4 (strongly agree). The LOT has good reliability and validity (Scheier \& Carver, 1985). Scheier and Carver (1985) originally developed the measure as a unipolar measure of general optimism, with reverse scoring of the negatively stated items. Although some authors state that the measure consists of two subscales, assessing optimism and pessimism (Andersson, 1996) the constructors of the scale argue that the original scoring method can be used to obtain a general measure of optimism (Scheier, Carver, \& Bridges, 1994). Moreover, if two subscales are adopted, these subscales correlate highly among each other, raising the question if the proposed two-factor solution might not originate from the wording of the items, rather than the fact that they measure two separate constructs. We choose to follow the original scoring methods of the LOT, with reverse scoring of the negatively stated items and calculating a sum score that reflects a degree of general optimism.

The three fundamental fears (AS, IS and FNE) were assessed with the Dutch version of the Sensitivity Index (SI) ${ }^{2}$ (Vancleef et al., 2006). This questionnaire is a composite measure consisting of three subscales (ASI, ISI, FNE), which tap anxiety sensitivity (AS), injury/illness sensitivity (IS) and fear of negative evaluation (FNE), respectively. The Anxiety Sensitivity Index (ASI) (Peterson \& Heillbronner, 1987) includes 16 items concerning the negative consequences of experiencing anxiety (e.g., 'It scares me when my heart beats rapidly'). The Injury/illness Sensitivity Index (ISI) (Taylor, 1993; Vancleef et al., 2006) contains 6 items pertaining to the fear of illness (e.g., 'I get scared when I think I'm coming down with an illness') and 5 items referring to the fear of injury (e.g., 'The thought of injury terrifies me'). The Brief Fear of Negative Evaluation Scale (BFNE) (Leary, 1983) consists of 12 items measuring the fear of negative evaluation (e.g., 'I worry about what kind of impression I make on people'). Participants indicate their degree of agreement with all statements of the SI on a 5-point Likert scale, ranging from 1 (very little) to 5 (very much) ${ }^{3}$. Psychometric properties of both the original and the Dutch version of the SI are satisfactory (Taylor, 1993; Vancleef et al., 2006). Furthermore, the psychometric properties of the ASI (Peterson \& Heilbronner, 1987; Rodriguez et al., 2004; Sandin et al., 2001), the brief FNE (Collins, Westra, Dozois, \& Stewart, 2005; Leary, 1983) and recently the ISI (Carleton et al., 2005) separately have

2 The English version of the Sensitivity Index was translated in Dutch in a state-of-the-art manner, involving back translation, after which the item content was checked against the original content. The Dutch version of the Sensitivity Index is available from the corresponding author.

3 Note that the scoring format from the original ASI (Peterson \& Heilbronner, 1987) ranges from 0 (very little) to 4 (very much). 
well been documented.

The Fear of Pain Questionnaire (FPQ: McNeil \& Rainwater, 1998) was administered to measure fear of pain. In this 30-item measure, respondents indicate how fearful they are of three types of pain: severe pain (e.g., 'Breaking your leg'), minor pain (e.g., 'Getting a paper-cut on your finger'), and medical pain (e.g., 'Receiving an injection in your hip/buttocks'). The items are scored on a 5-point Likert scale ranging from 1 (not at all) to 5 (extreme). The psychometric properties of the English as well as the Dutch version of the FPQ are satisfactory (McNeil \& Rainwater, 1998; Roelofs, Peters, Deutz et al., 2005; van Wijk \& Hoogstraten, 2006).

The Pain Catastrophizing Scale (PCS; Sullivan et al., 1995) taps pain catastrophizing, which is defined as 'an exaggerated orientation towards pain'. Participants need to recall painful past memories, and subsequently indicate on a 5-point scale ranging from 0 (not at all) to 4 (all the time) to what extent they experienced each of 13 feelings and thoughts during that pain (e.g., 'I feel as if I can't take this anymore'). The original and Dutch version (Crombez \& Vlaeyen, 1996) of the PCS has proven to be reliable and valid (Osman et al., 1997; Severeijns et al., 2002; Van Damme et al., 2002).

\section{Procedure}

Prior to participation, all participants received verbal instructions by the experimenter and gave written informed consent. Participants first filled out the BSIQ and subsequently completed the other self-report measures. All measures were completed on the computer. Testing occurred individually, and at the participant's own pace. In general, it took about 45 to 60 minutes to fill out all questionnaires. When all questionnaires were completed, participants received remuneration in the form of a gift voucher.

The ambiguous descriptions of the BSIQ are presented in the centre of the computer screen and remain on the screen for 5000 milliseconds, after which time period the three alternative explanations are offered. Each alternative is preceded by the letter A, B, or C, and participants choose the alternative that is most likely for them by pressing the corresponding letter as labeled on the left $(A)$, right $(B)$, and down $(C)$ arrow key of the keyboard. The chosen alternative then lights up in red font color. Next, a textbox appears behind each alternative explanation, and the participant allocates a likelihood percentage (rating score) between 0 and 100, using the numerical keypad. A rating score needs to be assigned to each alternative, before the program continues with the presentation of the next item. Upon finishing the BSIQ, participants completed the selfreport measures (SI, PCS, FPQ, LOT, STAI).

The test procedure differed for participants recruited inside and outside the local community of Maastricht University with respect to the test location. The first group of participants completed all measurements on a PC that was situated in a room in the university building, while participants who were recruited outside the university completed the measures on a portable PC in their home environment. In both settings, the experimenter was present during test performance, without interacting with the participant. In order to keep the test procedure in the home environment comparable to the laboratory study, the experimenter made sure that the questionnaires were 
completed in a quiet and silent location, and that no distraction by for example other persons, or telephone took place.

\section{DATA REDUCTION AND STATISTICAL ANALYSES}

Because the negative alternative was rarely chosen as first choice interpretation in the $B S I Q$, the ranking scores showed floor effects and little dispersion $(M=8.61 \%$; $s d=10.28)$. Therefore, we performed all analyses on the rating scores of the BSIQ only.

Confirmatory Factor Analysis (CFA). The factor structure of the BSIQ was examined with a Confirmatory Factor Analysis (CFA) on the negative rating scores of the BSIQ items (Lisrel 8.54; Jöreskog \& Sörbom, 2001). The Maximum Likelihood estimation method was used to assess goodness-of-fit, and covariance matrices were analyzed. It was assumed that each item loaded onto one single factor in such a way that every item of a specific BSIQ subscale loaded together on the same latent factor. The chi-square statistic gives an overall test of the model fit, and should result in a non-significant value to indicate good fit of the hypothesized model with the data. Multiple fit indices were used to decide on goodness-of-fit of the hypothesized factor structure: (a) root mean square error for approximation (RMSEA); (b) the comparative fit index (CF); (c) the non-normed fit index (NNF); (e) standardized root mean square residual (SRMR). For the RMSEA, values of about .08 or less indicate a "reasonable error of approximation"(Browne \& Cudeck, 1993). For the $C F I$ and the NNFI, values above 0.90 indicate reasonable fit, whereas values above .95 indicate good to very good fit. For the $s R M R$, values close to .08 are indicative of good fit ( $\mathrm{Hu}$ \& Bentler, 1999).

Interpretation bias in relation to general and specific psychological constructs. Mean ratings on negative and neutral alternatives for each item were calculated for the four BSIQ subscales separately (note that two neutral alternatives accompanied each item, and that the ratings for the neutral alternatives were averaged for each item). A paired samples t-test was then conducted to compare the scores on the neutral and the negative alternatives. Subsequent analyses were performed on the negative rating scores only, since the neutral rating scores do not contribute to the hypotheses of the current study.

The association between the specific negative interpretation scores and the scores on the questionnaire measures was first examined with Pearson correlations. We next performed hierarchical regression analyses in order to determine which psychological constructs contribute to the explanation of the negative rating scores for each subscale separately. In these analyses, age and gender were entered as control variables in the first step of the model, the global trait measures (STAI and LOT) were entered in the second step, the more specific fundamental fears (ASI, ISI, FNE) were entered as predictors in the third step, and the specific pain related constructs (FPQ and PCS) were entered as predictors in the last step of each analysis. 


\section{RESULTS}

Confirmatory Factor Analysis. Testing the four-factor model resulted in a significant chisquare statistic $\left(\chi^{2}(317, N=154)=647.18 ; p<.001\right)$. Although this value was significant, the other goodness-of-fit estimates were found sufficient to good, with an RMSEA =.08; NNFI = .94; $C F I=.95, s R M R=.07$ indicating reasonable fit of the data to the suggested model. The factor solution supports a four-factor solution in which each factor corresponds to a subscale of the $\mathrm{BSIQ}$ (Table 1). When we adapt the criterion that loadings above 0.40 show good belongingness to the scale, item 2, item 10, and item 24 show loadings below this criterion. However, inspection of the precise content of these items does not provide reasons for removal of these items. Although the goodness-of-fit indices indicate relative good fit, high intercorrelations are observed between the four factors, in particular between the panic factor and the other bodily symptoms factor (Table 1). ${ }^{4}$

Interpretation bias in relation to general and specific psychological constructs. Mean scores on the BSIQ and the self-report measures are presented in Table 2. For the BSIQ, significant higher ratings were given to the neutral alternatives than to the negative alternatives on the panicrelated sensations subscale $(t(153)=-41.47, p<.001)$, the other bodily symptoms subscale $(t(153)$ $=-29.97 ; p<.001)$, the social events subscale $(t(153)=-14.70 ; p<.001)$, and the general events subscale $(t(153)=-31.47 ; p<.001)$. So, participants generally assign a higher likelihood to the neutral than to the negative interpretation of the presented ambiguous situations.

4 Because of these high intercorrelations, the 3-factor model (factor 1: panic-related sensations + other bodily symptoms; factor 2: social events; factor 3 general events), the 2-factor model (factor 1: panic-related sensations + other bodily symptoms; factor 2: social events + general events) and the 1-factor model solutions of the BSIQ were tested as well and compared with the 4-factor model fit by performing delta Chisquare tests $\left(\Delta \chi^{2}\right)$. None of the other models resulted as significantly better than the 4-factor model. Moreover, the fit indices of the 3-factor model, the 2-factor model, and the 1-factor model resulted in poorer values than these of the 4-factor model. Details on these analyses can be obtained with the corresponding author. 


\section{$\Uparrow$ chapter 5}

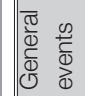

ஜํ

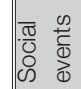

น م

fọ
$-\infty$
$+\infty$
0

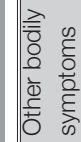

ํ.

守夺

बृ
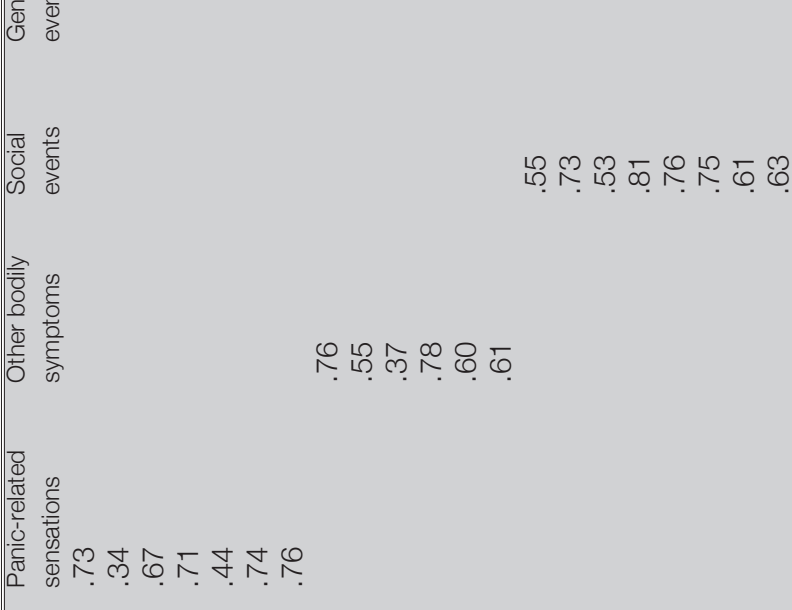

ชิธ

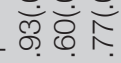

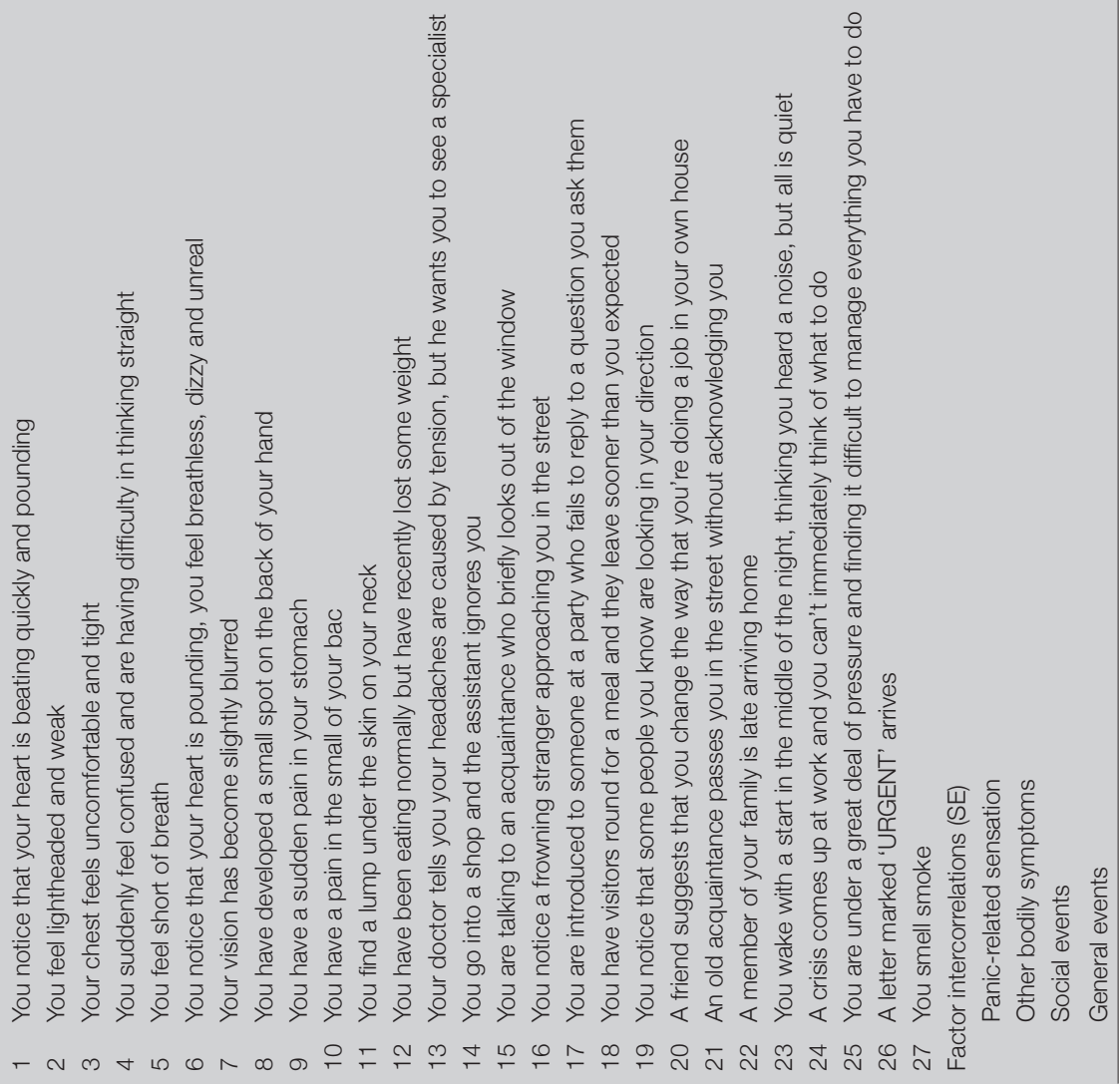


TABLE 2. Descriptives for the BSIQ rating and ranking scores and the self-report measures $(N=154)$

\begin{tabular}{lcc}
\hline \hline & $M$ & SD \\
BSIQ Negative Other Bodily Symptoms & 15.49 & 13.04 \\
BSIQ Negative Panic-related sensations & 11.73 & 10.36 \\
BSIQ Negative Social Events & 27.80 & 16.79 \\
BSIQ Negative General events & 18.05 & 12.87 \\
BSIQ Neutral Other Bodily Symptoms & 54.65 & 12.16 \\
BSIQ Neutral Panic-related sensations & 55.50 & 11.08 \\
BSIQ Neutral General events & 50.51 & 11.12 \\
BSIQNeutral general & 57.17 & 11.73 \\
STAI-T & 36.69 & 8.19 \\
LOT & 29.71 & 5.19 \\
ASI & 25.13 & 4.78 \\
ISI & 22.10 & 6.64 \\
BFNE & 27.91 & 10.39 \\
PCS & 12.31 & 6.76 \\
FPQ & 74.74 & 14.91 \\
\hline \hline
\end{tabular}

Note. STAI, State trait anxiety inventory- trait version; LOT, Life Orientation test; ASI, Anxiety Sensitivity Index; ISI, Injury/illness sensitivity Index; BFNE, Brief Fear of Negative Evaluation scale; PCS, Pain Catastrophizing scale; $F P Q,=$ Fear of Pain Questionnaire

Further analyses were performed on the ratings for the negative alternatives only. We calculated Pearson correlation coefficients to study the association between scores on the selfreport measures and the negative ratings that were assigned to the four subscales of the BSIQ (Table 3). As expected, trait anxiety, the fundamental fears and the pain-specific constructs all correlate positively with the negative ratings, whereas a negative association was found between the optimism score and the negative ratings. Table 3 shows that no unique correlations exist between a particular construct and a subscale of the BSIQ corresponding with this construct, but that associations are rather generalized in nature. However, careful inspection of the correlation matrix does indicate a pattern that might suggest at least some specificity. It is remarkable that pain catastrophizing shows the highest correlation coefficient with the other bodily symptoms scale, and that the fear of negative evaluation shows the highest correlation with the social events subscale. 


\begin{tabular}{|c|c|c|c|c|}
\hline & Panic-related Sensations & Other Bodily Symptoms & Social Events & General Events \\
\hline STAI-T & .18 & .23 & .42 & $.30^{\star \star}$ \\
\hline LOT & $-.30^{\star *}$ & $-.36^{\star *}$ & $-.44^{\star \star}$ & $-.39^{* *}$ \\
\hline ASI & $.37^{\star \star}$ & $.36^{\star \star}$ & $.34^{\star \star}$ & $.38^{\star \star}$ \\
\hline ISI & .22 & $.33^{\star \star}$ & $.29^{\star \star}$ & .20 \\
\hline BFNE & .23 & $.30^{\star \star}$ & $.57^{\star \star}$ & $.43^{\star \star}$ \\
\hline PCS & $.28^{\star \star}$ & $.45^{\star \star}$ & $.37^{\star *}$ & $.35^{\star \star}$ \\
\hline $\mathrm{FPQ}$ & $.33^{\star \star}$ & $.35^{\star \star}$ & $.35^{\star \star}$ & $.30^{\star \star}$ \\
\hline
\end{tabular}

Note. STAI-t, State trait anxiety inventory- trait version; LOT, Life Orientation test; ASI, Anxiety Sensitivity Index; ISI, Injury/illness sensitivity Index; BFNE, Brief Fear of Negative Evaluation scale; PCS, Pain Catastrophizing scale; FPQ, Fear of Pain Questionnaire ${ }^{* \star} p<.0017$ (Significant correlations after Bonferroni correction for multiple correlations; $\alpha=.05 / 28=.0017$ )

We conducted multiple linear regression analyses to further examine specific predictive power of the global trait measures, the fundamental fears, and the pain-specific measures for the four BSIQ subscales separately. Entering age and gender in the first step of the analysis did not reveal significant prediction for any subscale and these variables were therefore removed from all further analyses ${ }^{5}$. When LOT and STAI were considered as predictors of the negative interpretation scores, LOT resulted as the only significant predictor for the panic-related sensations subscale $(B$ $=-.33$, SE $B=.11, t=-3.12, p<.01)$, the other bodily symptoms subscale $(B=-.37$, SE $B=.10$, $t=-3.58, p<001$ ), the social events subscale $B=-.28$, SE $B=10, t=-2.83, p<.01$ ), and the general events subscale ( $B=-.34$, SE $B=.10, t=-3.31, p<.001$ ). Thus, higher levels of optimism are predictive of lower negative interpretations for ambiguous situations implying physical, social or general threat.

Entering the three fundamental fears in the second step of the analyses (Table 4) resulted in significant model changes for the prediction of the panic-related sensations subscale $\left(\Delta R^{2}=.09\right.$; $\Delta F(3,148)=5.14 ; p<.01)$, the other bodily symptoms subscale $\left(\Delta R^{2}=.11 ; \Delta F(3,148)=6.78\right.$; $p<.001)$, the social events subscale $\left(\Delta R^{2}=.16 ; \Delta F(3,148)=13.04 ; p<.001\right)$, and the general events subscale $\left(\Delta R^{2}=.13 ; \Delta F(3,148)=8.88 ; p<.001\right)$. Although optimism remains a significant general predictor for all subscales, adding the fundamental fears results in specific additional predictive value of AS for the panic related sensations subscale, IS for the other bodily symptoms subscale, and FNE for the social situations subscale. This finding supports our hypothesis of specific predictive power of the fundamental fears for negative interpretations. Both AS and FNE are significant predictors of the general events subscale.

5 Parallel analyses were conducted for all regression models in which age and gender were entered as predictors in the first step of each regression analysis. These analyses revealed the same pattern of findings. 


\begin{tabular}{|c|c|c|c|c|c|}
\hline Dependent variable & Predictor & B & SE $B$ & $t$ & $p$ \\
\hline \multicolumn{6}{|l|}{ Panic-related sensations } \\
\hline$R^{2}=.18$ & STAI-T & -.15 & .11 & -1.31 & .19 \\
\hline$F(5,148)=6.30 ;$ & LOT & -.24 & .11 & -2.27 & .03 \\
\hline \multirow[t]{3}{*}{$p<.001$} & ASI & .27 & .09 & 2.87 & .005 \\
\hline & $|S|$ & .03 & .09 & .36 & .72 \\
\hline & BFNE & .12 & .09 & 1.27 & .21 \\
\hline \multicolumn{6}{|l|}{ Other bodily symptoms } \\
\hline$R^{2}=.23$ & STAI-T & -.15 & .11 & -1.34 & .18 \\
\hline$F(5,148)=9.04$ & LOT & -.29 & .10 & -2.84 & .005 \\
\hline \multirow[t]{3}{*}{$p<.001$} & ASI & .16 & .09 & 1.73 & .09 \\
\hline & ISI & .17 & .09 & 2.06 & .04 \\
\hline & BFNE & .17 & .09 & 1.89 & .06 \\
\hline \multicolumn{6}{|l|}{ Social Events } \\
\hline$R^{2}=.38$ & STAI-T & -.02 & .10 & -.24 & .81 \\
\hline$F(5,148)=18.39$; & LOT & -.22 & .09 & -2.44 & .02 \\
\hline \multirow[t]{3}{*}{$p<.001$} & ASI & .07 & .08 & .84 & .40 \\
\hline & $|S|$ & .09 & .08 & 1.16 & .25 \\
\hline & BFNE & .44 & .08 & 5.43 & .000 \\
\hline \multicolumn{6}{|l|}{ General events } \\
\hline$R^{2}=.28$ & STAI-T & -.13 & .11 & -1.24 & .22 \\
\hline$F(5,148)=11.66$ & LOT & -.26 & .10 & -2.63 & .01 \\
\hline \multirow[t]{3}{*}{$p<.001$} & ASI & .23 & .09 & 2.70 & .008 \\
\hline & $|S|$ & -.04 & .08 & -.49 & .63 \\
\hline & BFNE & .33 & .09 & 3.79 & .000 \\
\hline
\end{tabular}

Note. STAI-t, State trait anxiety inventory- trait version; LOT, Life Orientation test; ASI, Anxiety Sensitivity Index; ISI, Injury/illness sensitivity Index; BFNE, Brief Fear of Negative Evaluation scale

In an additional linear regression analysis we entered the specific pain-related constructs (FoP and PCS) as a third step in the regression model (Table 5). Adding these two variables results in significant changes from the previous step for the panic-related sensations subscale $\left(\Delta R^{2}=\right.$ $.06 ; \Delta F(2,146)=5.39 ; p<.01)$, the other bodily symptoms subscale $\left(\Delta R^{2}=.07 ; \Delta F(2,146)=\right.$ 7.49; $p<.01)$, the social events subscale $\left(\Delta R^{2}=.04 ; \Delta F(2,146)=5.14 ; p<.01\right)$, and the general events subscale $\left(\Delta R^{2}=.04 ; \Delta F(2,146)=4.70 ; p<.05\right)$. A remarkable finding is that FoP results as an additional significant predictor of all four subscales of the BSIQ. Together with FoP, PCS becomes an additional significant predictor of the other bodily symptoms subscale, whereas the prediction of IS for this subscale (Step 2) disappears after the incorporation of the two specific pain constructs in the model. 


\begin{tabular}{|c|c|c|c|c|c|}
\hline Dependent variable & Predictor & B & SE $\beta$ & $t$ & $p$ \\
\hline \multicolumn{6}{|l|}{ Panic-related sensations } \\
\hline$R^{2}=.23$ & STAI-T & -.18 & .13 & -1.67 & .10 \\
\hline$F(7,146)=6.31 ;$ & LOT & -.24 & .13 & -2.29 & .02 \\
\hline \multirow[t]{5}{*}{$p<.001$} & ASI & .27 & .11 & 2.89 & .004 \\
\hline & $|S|$ & -.07 & .11 & -.75 & .46 \\
\hline & BFNE & .11 & .11 & 1.23 & .22 \\
\hline & FPQ & .27 & .24 & 3.17 & .002 \\
\hline & PCS & .00 & .05 & .003 & .99 \\
\hline \multicolumn{6}{|l|}{ Other bodily symptoms } \\
\hline$R^{2}=.31$ & STAI-T & -.16 & .09 & -1.55 & .12 \\
\hline$F(7,146)=9.16$ & LOT & -.24 & .08 & -2.41 & .02 \\
\hline \multirow[t]{5}{*}{$p<.001$} & ASI. & .10 & .07 & 1.17 & .24 \\
\hline & $|S|$ & .04 & .08 & .42 & .68 \\
\hline & BFNE & .16 & .07 & 1.82 & .07 \\
\hline & FPQ & .18 & .17 & 2.29 & .02 \\
\hline & PCS & .22 & .07 & 2.41 & .02 \\
\hline \multicolumn{6}{|l|}{ Social Events } \\
\hline$R^{2}=.42$ & STAI-T & -.05 & .10 & -.48 & .63 \\
\hline$F(7,146)=15.36$ & LOT & -.20 & .09 & -2.25 & .03 \\
\hline \multirow[t]{5}{*}{$p<.001$} & ASI & .05 & .08 & .61 & .54 \\
\hline & $|S|$ & -.01 & .08 & -.14 & .89 \\
\hline & BFNE & .43 & .08 & 5.48 & .000 \\
\hline & FPQ & .19 & .18 & 2.67 & .008 \\
\hline & PCS & .08 & .03 & 1.02 & .31 \\
\hline \multicolumn{6}{|l|}{ General events } \\
\hline$R^{2}=.33$ & STAI-T & -.15 & .10 & -1.48 & .14 \\
\hline$F(7,146)=10.09$; & LOT & -.23 & .10 & -2.39 & .02 \\
\hline \multirow[t]{5}{*}{$p<.001$} & ASI &. .21 & .09 & 2.41 & .02 \\
\hline & $|S|$ & -.15 & .09 & -1.66 & .10 \\
\hline & BFNE & .32 & .09 & 3.78 & .000 \\
\hline & FPQ & .19 & .20 & 2.43 & .02 \\
\hline & PCS & .10 & .04 & 1.17 & .25 \\
\hline
\end{tabular}

Note. STAI-t, State trait anxiety inventory- trait version; LOT, Life Orientation test; ASI, Anxiety Sensitivity Index; ISI, Injury/illness sensitivity Index; BFNE, Brief Fear of Negative Evaluation scale; PCS, Pain Catastrophizing scale; FPQ, Fear of Pain Questionnaire 


\section{Discussion}

The current study examined how global personality traits, fundamental fears, and painspecific constructs are related to the tendency to negatively interpret ambiguous information on four specific domains, i.e., panic-related sensations, other bodily symptoms, social events and general events.

After introduction of the BSIQ by Clark et al. (1997) several authors have used its four subscales, although no studies pertaining the factor structure of the measure have been conducted to our knowledge. We performed a CFA to test whether the data of the current study supported the hypothesized four-factor structure of the BSIQ. The Chi-square value of model fit was significant, while it should have a non-significant value to indicate good fit to data. However, because the chi square test is sensitive to degrees of freedom and sample size, it is possible that this test will reject or accept a model inappropriately (Bentler \& Bonnet, 1980; Jöreskog, 1990). Moreover, other goodness-of-fit statistics resulted in reasonable to good values indicating that each BSIQ subscale can independently be adopted as a domain-specific measure. Nevertheless, it should be noted that the four factors showed close interrelations. One possible explanation for these high intercorrelations is that the BSIQ might better be considered as a general threat-specific measure, assessing the tendency to interpret ambiguous situations as threatening or negative in general. This suggestion was not supported by additional analyses however, in which the onefactor model, the two-factor model and the three-factor model were tested and compared with the four-factor model. In these additional analyses, the four-factor model resulted as significantly better than all other models. Alternatively, the high intercorrelations might be attributed to the fact that the separate BSIQ items share the same skewness in their distributions, resulting in high correlations that are based on distribution similarities rather than on item content. Respondents in this study were healthy volunteers varying in levels of optimism and the other anxiety constructs. A large proportion of these respondents assigned very low or no probability at all to the negative alternatives resulting in skewed distributions to the left of the separate item scores. One could argue that this skewness violates the necessary condition of normality for performing CFA. However, Jöreskog (1990) suggests that in the case of moderate non-normality in continuous scores, the goodness-of-fit indices can be interpreted using the ML estimation method in covariance analyses. Nevertheless, in interpreting the results of the CFA, the matter of non-normality should be kept in mind, and further examination of the factor structure with a more heterogeneous population is warranted.

To study domain specificity of the negative interpretation bias, we incorporated several measures of psychological constructs that are known to play a role in psychopathology. We expected that more global and generalized trait constructs like trait anxiety and optimism would be associated with the negative interpretation bias on all BSIQ domains, whereas more specific anxieties and fear constructs would be associated with negative interpretations on that subscale of the $B S I Q$ that is congruent with the content of the individual's fear. Although the correlation matrix did not provide immediate support for the hypothesized domain specificity, regression analyses demonstrated specific predictive value for optimism, AS, IS, FNE, FoP, and PC. A first and robust finding concerns the strong predictive value of optimism for all subscales of the BSIQ. Higher levels 


\section{$\Uparrow$ chanerer}

of optimism are predictive of making less negative interpretations to the ambiguous descriptions of the BSIQ. This effect is independent of the influence of other anxiety and fear factors and supports the notion that optimism can serve a protective function in the development and maintenance of psychopathology (Scheier \& Carver, 1992). We did not find support for the hypothesis that that trait anxiety would show the opposite effect of optimism. Even when trait anxiety and optimism were considered as the only two predictors of the negative interpretation indexes optimism resulted as the only significant predictor.

Second, specific predictive value of AS, IS, and FNE was found for negative interpretations made on the panic-related sensations subscale, the other bodily symptoms subscale, and the social events subscale of the BSIQ, respectively. This finding supports our hypothesis of domainspecificity of the interpretation bias in relation to specific fundamental fears. This specific predictive value is found to exists independently and additionally to the proportion of variance that was already explained by optimism for each subscale. The unique relation between AS and the panic related sensations subscale once again stresses the close relation between AS and panic (Richards et al., 2001; Teachman, 2005). Furthermore, the fact that IS proves a good predictor for the negative interpretation scores on the other bodily symptoms subscale only, indicates the importance of IS in pain processing. In line with the expectations, the FNE is the only fundamental fear that contributes significantly to the explanation of the negative interpretations in response to ambiguous social situations. A third objective of the current study was to explore the influence of the addition of two specific pain constructs (PC and FoP) to the prediction of the negative interpretations on the four domains. It was hypothesized that these constructs would be particularly associated with the negative interpretation scores on the other bodily symptoms subscale based on their proximal relation with pain experiences and pain processing (e.g., Vlaeyen \& Linton, 2000). Results indeed showed that both FoP and PC were significant predictors of the negative interpretation scores on the other bodily symptoms subscale. Moreover, after adding both constructs in the regression model the earlier observed predictive power of IS disappeared. This provides extra evidence for the high specificity of both constructs in relation to the more fundamental IS factor. Findings were not entirely in line with our expectations, however. Whereas PC was found to be uniquely predictive of the other bodily symptoms subscale, FoP possesses additional predictive value over and above the prediction of optimism and the fundamental fears for each other subscale of the BSIQ as well. The predictive value of FoP for the panic-related sensations subscale can be accounted for, given that the situations in this subscale involve internal and external bodily symptoms that might be interpreted as health threatening, and can thus be related to the fear of pain as well. However, FoP also contributes significantly to the other two subscales of the $B S I Q$, which do not show links with pain, injury or illness. This finding is difficult to account for, and needs further examination.

Some limitations and recommendations should be taken into consideration when interpreting the current results. First, although the CFA supports four factors in the $B S I Q$, there were some problems regarding high factor intercorrelations. These problems are probably inherent to the healthy status of the study population. A more heterogeneous population, including patients with social anxiety, panic disorder, and chronic pain would probably result in more dispersion on the item scores. Additional support for this suggestion can be found in the results from the regression analyses, which show specific relations between individual levels of fundamental fears and scores 
on the BSIQ subscales. This augments the likelihood that the four factors are indeed distinct from each other rather than representing one general construct. In line with the research already conducted within the area of panic disorder, future research should examine whether the other bodily symptoms subscale and the social event subscale can be adopted to discriminate pain patients from non pain patients, and social anxious individuals from non-social anxious individuals, respectively. Relating to the inclusion of a healthy study population, it is noteworthy to mention that the current healthy population was representative for the general community sample with respect to the dispersion and mean scores on the anxiety-related constructs. More precisely, mean scores and standard deviations on the self-report measures in the current sample were similar to the scores as observed in other studies assessing these constructs in college student or community samples. This was especially true for the STAI (e.g., Ploeg van der et al., 1980), LOT (e.g., Scheier \& Carver, 1985; Vinck, Wels, Arickx, \& Vinck, 1998), ASI (e.g., Peterson \& Reiss, 1992; Sandin et al., 2001; Vancleef et al., 2006), ISI (e.g., Carleton et al., 2005; Vancleef et al., 2006), BFNE (e.g., Carleton et al., 2006; Vancleef et al., 2006), and FPQ scores (e.g., Roelofs, Peters, Deutz et al., 2005; van Wijk \& Hoogstraten, 2006). The only exception here constituted the PCS scores, for which lower scores were observed $(M=12)$ in the current sample from prior findings in other college student and community samples ( $M=16$ ) (Crombez et al., 1998b; Van Damme et al., 2002). A second limitation in this study concerns the omission of including specific lower-order constructs of AS and FNE. AS in particularly consists of lower-order factors that could have offered a valuable contribution to the goal of the current study regarding the degree of specificity of the negative bias. In the literature, there has been quite some debate regarding the one-dimensional or multidimensional nature of AS (Blais et al., 2001; Keogh, 2004; Schmidt \& Joiner, 2002). Although it is established that AS serves an important role in the pathogenesis of anxiety, pain, and panic, recent evidence has suggested that it may be the lower-order factors of AS (i.e., physical concerns, mental incapacitation concerns, and social concerns) that explain these findings the best (Brown, Smits, Powers, \& Telch, 2003; Hunt et al., 2006; Keogh \& Asmundson, 2004; Zinbarg et al., 1997; Zvolensky, Goodie, McNeil, Sperry, \& Sorrell, 2001). However, since both AS and the subscales were measured with the ASI in the current study, it was not possible to study the predictive value of its lower-order factors because this would imply serious violations of collinearity assumptions. At the time that this study was conducted, we were not aware of any other adequate measure to assess the lower-order factors of AS or the overlapping AS construct. In recent studies though, the Anxiety Sensitivity Profile (ASP) has been suggested to constitute a good alternative measure for assessing AS and lower-order components (Keogh, Barlow, Mounce, \& Bond, 2006; Olatunji et al., 2005). It is therefore suggested that future studies aiming to detect differential predictivity of AS and its lower-order components incorporate the ASP in addition to the ASI. Third, the BSIQ is a self-report measure, and is therefore subject to response bias and conscious reconsideration. It can be questioned to what extent these conscious processes reflect the spontaneous, automatic interpretations that will occur in daily life (Fazio \& Olson, 2003; Greenwald et al., 1998). Therefore it is suggested that in addition to subjective measures further research will have to make use of automatic and objective tasks (e.g., lexical decision paradigm, moving window paradigm) to study negative interpretation bias in relation to psychopathology more thoroughly (Calvo, Eysenck, \& Castillo, 1997; Hirsch \& Mathews, 1997). Using automatized paradigms provides insight in the 
temporal pattern of interpretative responses. Moreover it offers the opportunity to decide whether specific negative interpretations are made routinely and immediately upon the confrontation with ambiguity or if they are the mere result of a more elaborative process of integrating prior knowledge, experiences, and dysfunctional cognitive schemes with new incoming information. Last, due to the lack of behavioral measures, it was not possible to investigate if negative interpretation biases on a specific domain have a mediating role in the exacerbation of emotional and affective disorders.

The current study provided preliminary evidence that levels of a global resilience trait (optimism), or specific vulnerability traits (AS, IS, FNE) are related with a general or specific negative interpretation bias, respectively. Furthermore, there is evidence that proximal and very specific vulnerabilities for chronic pain are specifically predictive of the tendency to interpret pain-related ambiguous material negatively. The current findings constitute only a first step, though, in studying the exact role of a negative interpretation bias in the onset and maintenance of emotional and affective disorders. Understanding how emotional traits and cognitive biases act as latent risk factors for the development and maintenance of a disorder can contribute to the development of treatment approaches. As such, it offers helpful information to the early detection for those at risk for developing emotional or affective disorders in acute phases and it helps therapists and doctors to tailor treatment to the relevant cognitions.

\section{ACKNOWLEDGEMENTS}

The authors are grateful to Nicole van den Ham, Vera Matti, Claudia Bongers, and Kristie van Montfort for their help with the data collection.

This research is supported by a grant from the Netherlands organisation for Scientific Research (NWO) with grant no. 015-001-050. 


\section{- - \\ Chapter 6}

Interpreting ambiguous health and bodily threat: are individual differences in pain-related vulnerability constructs associated with an on-line negative interpretation bias?

This chapter is submitted for publication as:

Vancleef, L. M. G., Peters, M. L., \& De Jong, P. J. Interpreting ambiguous health and bodily threat: are individual differences in pain-related vulnerability constructs associated with an on-line negative interpretation bias? 


\section{Abstract}

The present study examined the association between individual levels of pain-related anxieties and an on-line negative interpretation bias for ambiguous descriptions implying threat to one's body and health (i.e., injury, illness, pain). Healthy volunteers $(n=80)$ performed a lexical decision task that indirectly assessed on-line interpretations. Results demonstrated a general facilitation of responses to target words that endorsed a threatening resolution of ambiguity. This effect correlated positively with individual levels of fear of pain, but was found to be unrelated to levels of anxiety sensitivity, injury/illness sensitivity or pain catastrophizing. Implications of the findings and recommendations for future research are discussed.

\section{INTRODUCTION}

It is nowadays well acknowledged that information processing biases can act as latent vulnerability factors for the onset and maintenance of affective and emotional disorders like anxiety and depression (Beck \& Clark, 1997; Mathews \& MacLeod, 1994). Given the core role of anxiety and other emotions in chronic pain, it has been suggested that the same cognitive mechanisms that work in emotional and affective disorders may play a role in the development and persistence of chronic pain as well (Pincus \& Morley, 2001). Indeed, several studies have demonstrated the occurrence of information processing biases in relation to (chronic) pain that are characterized by the prioritizing of information relating to health threats or pain at both an explicit and an implicit level (Asmundson et al., 2005; Keogh, Dillon et al., 2001; Pincus \& Morley, 2001; Roelofs et al., 2002).

One cognitive bias that has been frequently studied in relation to pain is the negative interpretation bias, or the tendency to interpret innocuous situations, symptoms, or sensations in a negative or threatening fashion. Studies using homophones (words with the same pronunciation, but a different spelling: e.g., dye/die (McKellar et al., 2003; Pincus et al., 1994), homographs (words with the same spelling, but different meanings: e.g., needle (Pincus et al., 1996), and wordstem completion tasks (word stem can be completed in different ways: e.g., ten---: tender/tennis (Edwards \& Pearce, 1994) have demonstrated that pain patients make more threat and painrelated interpretations in comparison with healthy controls. Additionally, this negative interpretation bias has been observed in healthy individuals possessing elevated levels vulnerability constructs for chronic pain as well; i.e., trait anxiety, negative affectivity, anxiety sensitivity, injury/illness sensitivity, fear of pain, or pain catastrophizing (Keogh \& Cochrane, 2002; Pincus \& Morley, 2001; Vancleef \& Peters, in press). Parallel to former research findings in panic disorder and social phobia, it may be suggested that the interpretation bias acts as a latent vulnerability construct in the development and exacerbation of pain problems in those who are vulnerable for developing chronic pain conditions (Mathews \& MacLeod, 1994; Pincus \& Morley, 2001). Corroborating this suggestion, Keogh and colleagues (Keogh \& Cochrane, 2002; Keogh et al., 2004) recently demonstrated that the relation between levels of anxiety sensitivity and tolerance for cold-pressor pain in pain-free participants was mediated by a negative interpretation bias.

There is thus accumulating evidence for the importance of negative interpretation bias

part two $\mid 115$ 


\section{$\Uparrow$ chaperer}

in pain processing. However, up to now, studies have predominantly relied on direct self-report measures to assess the interpretation bias. Because these measures are subject to response bias and conscious reconsideration, it is not possible to decide if the negative interpretations are the result of (1) respondents wanting to comply with experimenter demands, (2) retrospective judgements that are made on the basis of negative beliefs and representations at the moment of responding, or (3) the routinely, automatic interpretation of ambiguity (Hirsch \& Mathews, 1997; Hirsch \& Mathews, 2000). One possible way to overcome these problems is to use paradigms that allow the assessment of automatic and spontaneously interpretations (i.e., on-line interpretations), like the lexical decision paradigm (Hirsch \& Mathews, 1997; Hirsch \& Mathews, 2000). In the lexical decision paradigm, narrative texts that incorporate critical incomplete ambiguous sentences are presented to respondents. The incomplete sentences can have a threatening resolution, and they are completed by the appearance of a probe word that either confirms or disconfirms the implied threat. It is assumed that if respondents make on-line inferences regarding the likely outcome of the incomplete sentence, then responses will be faster and more accurate to probe words that match this inference. Because respondents are instructed to respond "as fast as possible" to the probe words, they are no longer in the opportunity to construe retrospective judgements to the probe words. Moreover, the lexical decision to the probe words does not require referral to the preceding text and thus fosters spontaneous inferences.

Using the lexical decision paradigm, the current study examined the relation between individual levels of pain-related vulnerability constructs in healthy individuals (anxiety sensitivity, injury/illness sensitivity, fear of pain, and pain catastrophizing) and the tendency to make on-line negative interpretations of ambiguous situations implying health-threat (relating to pain, injury or illness). Both anxiety sensitivity and injury/illness sensitivity are conceived as fundamental fears that comprise vulnerability factors for the onset and maintenance of chronic pain (e.g., Keogh \& Asmundson, 2004; Vancleef et al., 2006). Elevated levels of anxiety sensitivity have been found associated with heightened medication use, increased disability by pain, and decreased tolerance for pain in both clinical and non-clinical populations (Asmundson et al., 2000; Stewart \& Asmundson, 2006). In healthy volunteers, elevated levels of injury/illness sensitivity have been found predictive of an enhanced tendency to engage in health protective behaviour (Vancleef et al., 2007), and of pain catastrophizing and fear of pain levels (Vancleef et al., 2006). Pain catastrophizing and fear of pain are considered very specific pain-related constructs that play a crucial role in the transition from acute to chronic pain (e.g., Vlaeyen \& Linton, 2000). Both in pain patients and in a pain-free population, pain catastrophizing has been brought into relation with increased pain experiences, diminished tolerance for pain, and hypervigilance for pain (e.g., Crombez et al., 1998a; Sullivan et al., 1995; Vlaeyen \& Linton, 2000). Elevated levels of fear of pain have frequently been found to be associated with escape and avoidance behaviour from pain, increased disability and distress because of pain, and attentional biases for pain-related stimuli (Keogh, Ellery et al., 2001; Roelofs, Peters, Deutz et al., 2005; Vlaeyen \& Linton, 2000). In the current study, it is hypothesized that elevated levels of the pain-related anxiety and fear constructs are associated with an enhanced tendency to automatically and spontaneously interpret the ambiguous situations in a negative manner. 


\section{METHOD}

\section{PARTICIPANTS}

Eighty participants (69 female; $M=24$ years; $s d=6.70$ ) were recruited at Maastricht's University local community to take part in the study. Inclusion criteria constituted being in good mental health (no diagnosis of current psychopathology) and being free of acute or chronic (over three months) pain complaints. Compliance with these criteria was verbally checked prior to inclusion in the study. Participants who were dyslexic or whose mother tongue was other than Dutch were excluded from the study. All participants gave informed consent and received financial compensation for participating.

\section{MeAsures}

Self-report Measures. Both anxiety sensitivity and injury/illness sensitivity were assessed with the Dutch version of the Sensitivity Index (SI) ${ }^{6}$ (Vancleef et al., 2006). This questionnaire is a composite measure consisting of three subscales tapping anxiety sensitivity, injury/illness sensitivity and fear of negative evaluation. The latter construct was disregarded since it did not contribute to the focus of the study. In the SI, anxiety sensitivity is measured with the 16-item Anxiety Sensitivity Index (ASI) (Peterson \& Heilbronner, 1987) and injury/illness sensitivity is assessed with the 11-item Injury/illness Sensitivity Index (ISI) (S. Taylor, 1993). Participants indicate their degree of agreement with all items on a 5 -point Likert scale $(1=\text { not at all; } 5=\text { very much })^{7}$. Psychometric properties of the SI and its subscales are satisfactory (Taylor, 1993; Vancleef et al., 2006).

Fear of pain was assessed with the 30-item Fear of Pain Questionnaire (FPQ: McNeil \& Rainwater, 1998). Respondents indicate how fearful they are of three types of pain; i.e., severe pain, minor pain, and medical pain on a 5 -point Likert scale ( $1=$ not at all; $5=$ extreme). The psychometric properties of the FPQ are satisfactory, and the measure is appropriate for usage in both healthy and clinical populations (McNeil \& Rainwater, 1998; Roelofs, Peters, Deutz et al., 2005).

Pain catastrophizing is assessed with the Pain Catastrophizing Scale (PCS; Sullivan et al., 1995). Participants indicate on a 5 -point Likert scale $(0=$ not at all; $4=$ all the time) to what extent they have experienced each of 13 feelings and thoughts when they were in pain. The PCS has proven to be a reliable and valid measure and was found suitable to measure pain catastrophizing in both healthy volunteers and clinical populations (Severeijns et al., 2002; Van Damme et al., 2002).

$6 \quad$ The English version of the Sensitivity Index was translated in Dutch in a state-of-the-art manner, involving back translation, after which the item content was checked against the original content. The Dutch version of the Sensitivity Index is available from the corresponding author.

7 Note that the scoring format from the original ASI (Peterson \& Heilbronner, 1987) ranges from 0 (very little) to 4 (very much). 
On-line interpretation paradigm. The on-line interpretation task consisted of 124 situational descriptions with a length of four lines (mean amount of words for each description $=22$ ) (See Appendix for examples). The final sentence of each description was incomplete, lacking the end word that was presented as the probe requiring a lexical decision. The task incorporated 52 ambiguous descriptions that could lead to either a health threatening ${ }^{8}$ (A_H) or a safe (A_S) resolution. Of these 52 ambiguous descriptions, 26 ended on a word leading to a health threatening resolution (A_H_W) or a safe (A_S_W) resolution, and the other 26 ended on a non-word leading to a health-threatening (A_H_NW) or a safe (A_S_NW) resolution. The non-words were created by shuffling the letters of a putative target word through each other. In order to control for the possible influence of particular descriptions, both groups of ambiguous word and non-word descriptions were again split-up, such that for each participant half of the descriptions were presented in their health-threatening resolution and the other half in their safe resolution. These groups were counterbalanced over participants so that one and the same ambiguous description was never presented in its two possible resolutions to the same participant. Thus, each participant received 13 ambiguous descriptions with a health-threatening word resolution (A_H_W_1 or A_H_W_2), 13 descriptions with a safe word resolution (A_S_W_1 or A_S_W_2), 13 descriptions with a healththreatening non-word resolution (A_H_NW_1 or $\left.A \_H \_N W \_2\right)$ and 13 descriptions with a safe nonword resolution (A_S_NW_1 or A_S_NW_2).

Additionally, forced-inference descriptions were incorporated in the task (see Mathews \& Hirsch, 2000). These descriptions were created in such a way that they led inevitably to either a health threatening $\left(F_{-} H\right)$ or a safe $\left(F_{-} S\right)$ probe resolution and are therefore reflective of pure online inference responses. Within participants, the forced-inference descriptions shared the end word or non-word with the ambiguous descriptions, and they are thus inextricably bound up to an ambiguous description. Because the forced-inference descriptions are assumed to yield on-line inferences, responses to this type of descriptions can be regarded as baseline measures of making on-line inferences, against which the responses to ambiguous descriptions can be set. Last, we included twenty control ambiguous descriptions $(\mathrm{C})$ in the task of which half ended on a non-word. These descriptions dealt with trivial situations and were not at all related to health-threats. The logic for including these descriptions was that they could provide an additional check for the effect of individual differences for dealing with ambiguity altogether, in the case that a relation between levels of pain-related anxiety and a negative on-line bias is detected.

The ambiguous descriptions that were used in the task were chosen on the basis of a pilot study that was conducted in 17 volunteers. In this pilot, 64 experimenter-created ambiguous descriptions were presented with the omission of the end word. Respondents were required to first write down the word that they expected to complete the description. Next, respondents were offered the two experimenter forecasted end words (health-threatening and safe), and a likelihood percentage between 0 and 100 was assigned to each alternative. We first eliminated those descriptions in which the spontaneous completion by respondents in no case matched with one

8 Note that the health threatening resolutions imply resolutions of ambiguity that refer to sickness, injury, pain, or dead. A broad spectrum of health threatening situations was chosen in order to make the descriptions relevant for this healthy study population that is free from specific pain-related pathology. 
of the intended resolutions of the experimenters. From the remaining descriptions, we selected 26 descriptions that reached likelihood percentages above 50\% for each alternative end word to be included in the task.

\section{Procedure}

Participants were seated in front of a computer screen and the on-line interpretation task started with six practice trials, to get the participant acquainted with the test procedure and the response format. The descriptions appeared line-by-line on the computer screen and participants could navigate through each description at their own pace. A next line appeared each time when the participant pressed the middle button of a three-button response box. When the last line of a description had been presented, pressing the middle button of the response box led to the presentation of red fixation crosses in the centre of the screen. These crosses signalled the appearance of the probe word and remained on screen for $750 \mathrm{~ms}$ In this time frame, participants could prepare the lexical decision response by placing their fingers on the outer left (labelled with a 'W' (word)) and the outer right (labelled with a ' $N$ ' (non-word)) button of the response box. The probe word remained on the screen for maximally $2500 \mathrm{~ms}$. Incorrect responses or responses that were not given within $2500 \mathrm{~ms}$ were signalled by a sound and the first line of the next description was presented at $1000 \mathrm{~ms}$ after the response or the sound. Reaction times and errors were registered

To ensure that participants remained concentrated during the task they were led to believe that they would be tested on content of the descriptions afterwards. To increase credibility of this argument participants already had to answer some questions regarding the content of the practice descriptions in between the practice and test phase of the task. Following the completion of the task participants answered questions regarding the professions and sports they remembered from the descriptions in the task, and they indicated which description was most notable for them. Next, participants filled out the self-report measures on the computer and received financial compensation.

\section{StATISTICAL ANALYSES}

Based on inspection of the distributions of the dependent variables, one participant was deleted from further analyses since error percentage deviated more than three standard deviations from the mean error percentage. Altogether, the mean error percentage was 2.03 (sd $=1.57$ ), indicating that only few errors were made on the lexical decision trials. Because the error percentage was to low in order to conduct meaningful data analyses on them, further analyses were conducted on the reaction time data only. Only trials with a correct first response were incorporated in these analyses.

In addition to the data analyses that were needed to answer the research hypotheses, we first conducted a paired sample t-tests to verify whether responses were faster to the word 


\section{$\star$ chaperer}

trials than to the non-word trials. These analyses served as a control for the effectiveness of the task in measuring semantic inferences. Reading through the descriptions is assumed to activate semantic processing that makes participants expect a word rather than a non-word to finish the incomplete sentence. Faster reaction times to the word trials are therefore indicative of semantic processing of the descriptions.

Further analyses were conducted on the data of the word descriptions only, since reaction times on these descriptions provide the critical information that is necessary for answering our research hypotheses. The effects of description type and valence were examined with a 2 (Description Type: ambiguous versus forced inference) $\times 2$ (Valence: health-threatening versus safe) repeated measures ANOVA on both the reaction times. All variables were within subject.

We calculated a negative interpretation index (INT-rt) by subtracting the mean it on the ambiguous health-threatening descriptions from the mean it on the ambiguous safe descriptions. To increase the sensitivity of the interpretation bias index (reflecting the advantage of threatening interpretations specific for ambiguous descriptions), we next subtracted the difference score for the forced inference descriptions (calculated in the same manner) from the obtained difference score on the ambiguous descriptions. The interpretation index was thus calculated as follows: INT_rt

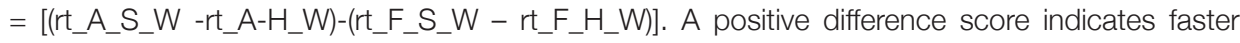
responses on the ambiguous descriptions that have a health-threatening resolution. A positive value of INT-rt thus reflects the tendency to interpret the ambiguous descriptions in a negatively biased manner. The relation between the interpretation bias index and the scores on the self-report measures is examined with Pearson correlation coefficients.

\section{Results}

The overall mean reaction time in the task was $685.79 \mathrm{~ms}(\mathrm{sd}=130.11)$. Sustaining the validity of the task, a paired samples t-test showed that responses were significantly faster on descriptions that ended on a word $(661.33 \mathrm{~ms})$ than descriptions that ended on a non-word ( 710.24 $\mathrm{ms})$, with $t(78)=-6.62, p<.001$. Mean reaction times for the ambiguous and forced inference word descriptions, as well as the descriptives of the self-report measures are presented in Table 1. 


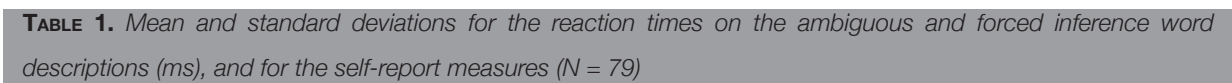

\begin{tabular}{lcccc}
\hline \hline On-line inference task & Mean & SD & \\
Ambiguous safe & 761.00 & 188.66 & & \\
Ambiguous health-threatening & 703.73 & 152.26 & & \\
Forced inference safe & 566.88 & 116.84 & & \\
Forced inference health-threatening & 606.16 & 136.98 & Min \\
\hline Self report measures & Mean & SD & 18 & 48 \\
ASI & 24.36 & 4.84 & 12 & 39 \\
ISI & 21.73 & 6.32 & 0 & 29 \\
PCS & 11.64 & 6.57 & 40 & 115 \\
FPQ & 75.28 & 15.13 & 40 \\
\hline \hline
\end{tabular}

Note. ASI, Anxiety Sensitivity Index; ISI, Injury/illness Sensitivity Index; PCS, Pain Catastrophizing Scale; FPQ, Fear of Pain Questionnaire

The 2 (Description Type) $\times 2$ (Valence) ANOVA revealed a significant main effect of Description Type $(F(1,78)=188.96, p<.001, d=.71)$ with faster reaction times on the forced inference descriptions than on the ambiguous descriptions (586.52 ms versus $732.36 \mathrm{~ms}$ ). There was no significant main effect of Valence. The Description Type $x$ Valence interaction was significant: $F(1,78)=42.06, p<.001 . d=.35)$. The interaction effect was further examined with post hoc paired-sample t-tests, demonstrating that on the ambiguous descriptions, reaction times were significantly faster for the descriptions with a health-threatening resolution $(t(78)=-5.47, p$ $<.001)$, whereas on the forced inference descriptions, reaction times were significantly faster on descriptions with a safe resolution $(t(78)=4.91, p<.001)$.

We next calculated the interpretation index $(M=-146.74, s d=132.31)$ that was then correlated with the self-report measures (Table 2). Fear of pain correlated significantly with INT_rt. None of the other individual difference measures showed a significant correlation with the INT_rt.

TABLE 2. Pearson correlation between the interpretation bias index and the self-report measures $(N=79)$

\begin{tabular}{llccc}
\hline \hline & ASI & ISI & PCS & FPQ \\
ISI & $.44^{*}$ & 1 & & \\
PCS & $.53^{*}$ & $.50^{*}$ & 1 & 1 \\
FPQ & .13 & $.46^{*}$ & $.41^{*}$ & $.29^{*}$ \\
INT_rt & -.12 & .03 & .15 & 15 \\
\hline \hline
\end{tabular}

Note. ASI = Anxiety Sensitivity Index; ISI = Injury/illness Sensitivity Index; PCS = Pain Catastrophizing Scale; FPQ = Fear of Pain Questionnaire; INT_rt = interpretation bias index ${ }^{*} p<.01$ 


\section{Discussion}

The present study aimed to examine whether individual levels of anxiety sensitivity, injury/illness sensitivity, fear of pain, and pain catastrophizing are associated with on-line negative interpretations of ambiguous situations implying bodily and health threat. Results demonstrated a general facilitation of responses to the ambiguous descriptions that were disambiguated by a health-threatening resolution. This effect was most pronounced in participants possessing elevated levels of fear of pain. No relation was found between the negative interpretations and levels of the other pain-related constructs, i.e., injury/illness sensitivity, anxiety sensitivity, and pain catastrophizing.

These findings suggest that people may be generally inclined to make spontaneous and automatic negative inferences when confronted with ambiguity that can imply health threat. This echoes results of a recent study in which automatic associations towards verbal stimuli representing injury, illness, and pain were examined with an indirect association measure (Extrinsic Affective Simon Task ([EAST]; De Houwer, 2003), demonstrating a generalized automatic threat appraisal that was even more pronounced in persons possessing elevated levels of anxiety sensitivity and injury/illness sensitivity (Vancleef et al., 2007). There is thus accumulating evidence for negatively biased processing of pain and health-related information in the fast and early stages of information processing. The confrontation with information that insinuates health or bodily threat seems to automatically activate a negative processing template in healthy individuals, which can be enhanced by the presence of pain-related anxieties. It should not be concluded that healthy individuals possess a negative interpretation bias in general, however. In contrary, research into the occurrence of an on-line interpretation bias for social anxiety-related material demonstrated that healthy participants were characterized by a positive on-line interpretation bias, that was absent in anxious individuals, who in turn were found to make no on-line inferences at all (Hirsch \& Mathews, 1997; Hirsch \& Mathews, 2000). The difference between these latter studies and the current one concerns the object of implied threat, being either health threat (current study) or social threat referring to social encounters, speaking in public, or job interview situations. Mathews and Mackintosh (1998) and Mogg and Bradley (1998) offer an explanation for the occurrence of both positive and negative information processing bias in healthy individuals by stressing the importance of the threat value of target stimuli. According to their cognitive models, stimuli that entail severe threat are prioritized and negatively processed by both anxious and healthy individuals because of the beneficial effect that the early detection of severe threat can have from an evolutionary point of view for all individuals. Conversely, non-anxious individuals are assumed to avoid or positively process stimuli entailing moderate or no threat at all (Mathews \& Mackintosh, 1998; Mogg \& Bradley, 1998). Following this perspective, it might be suggested that because of the severe threat value of stimuli in the present study (implying death, serious injury, and illness), all individuals process these stimuli negatively, irrespective of their pain-related anxiety level.

It should be acknowledged, however, that it cannot be ruled out on the basis of the present study, that the general automatic negative interpretation bias may be (partly) due to an undesirable priming effect. Since many of the situational descriptions in the lexical decision paradigm related to pain and disease, this might have induced expectations of a pain or disease- 
related resolution for the subsequent ambiguous description. Although descriptions in the task were based on a pilot-study and intended to entail full ambiguity, it cannot be ruled out that a general negative framework was activated by the task.

Independent of whether persons generally hold a negative automatic bias towards ambiguous health-related situations, or whether this was strengthened by task-specific priming effects it is notable that fear of pain resulted as the only pain-related construct that was positively related with the negative interpretation bias. Fear of pain has been suggested as a very specific construct that forms a lower-order factor of the more generalized anxiety constructs injury/illness sensitivity and anxiety sensitivity (Keogh \& Asmundson, 2004; Vancleef et al., 2006). It might be suggested that the content-specificity and the proximal relation of the fear of pain construct account for the observed unique relation with the interpretation bias. In the past, fear of pain has been found associated with hypervigilance an attentional bias for pain-related information (Crombez et al., 1999; Peters et al., 2002; Roelofs et al., 2002), and recently, fear of pain emerged as a strong predictor of an explicitly measured negative interpretation bias, offering predictive value over and above the proportion of variance that was already explained by other pain-related anxieties (Keogh \& Cochrane, 2002; Pincus \& Morley, 2001; Vancleef \& Peters, in press). Nevertheless, the content-specificity argument cannot form a valid explanation for the non-significant relation between pain catastrophizing and the negative bias, considering that both fear of pain and pain catastrophizing are assumed to possess similar content-specificity (Keogh et al., 2004; Vancleef et al., 2006). The non-significant correlation with pain catastrophizing is puzzling, especially since pain catastrophizing refers to the exaggerated orientation towards pain and the meaning of pain (Sullivan et al., 1995), and thus holds a threatening interpretation tendency in its definition. One possible explanation can be sought in the relative low scores on the PCS (mean $=11.64$ ) in the present group of participants. Other studies report remarkably higher PCS mean scores in both healthy populations (mean = 16 (Crombez et al., 1998b; Van Damme et al., 2002)), and clinical populations ( mean $=21.99$ in a fibromyalgia sample (Van Damme et al., 2002); mean $=27.96$ in patients with soft-tissue injury (Sullivan et al., 1998). Scores on the FPQ, on the other hand, showed a better dispersion, and with a mean score of 75.28 , this sample is comparable to other healthy samples (e.g., mean $=74$ (Roelofs, Peters, Deutz et al., 2005); mean $=69.10$ (van Wijk \& Hoogstraten, 2006); mean = 79 (McNeil \& Rainwater, 1998) as well as to a medical sample (mean $=78.1$ ) and a chronic pain population (mean =79.7) (McNeil \& Rainwater, 1998). Further research is clearly warranted in order to examine whether the absence of a meaningful association between PCS scores and threat-confirming interpretation bias can indeed be explained by the relatively low PCS scores in the present sample.

Next to the already mentioned limitation of a putative priming effect, other possible shortcomings to the current study need to be addressed. One of these shortcomings concerns the content of the descriptions in the task. All descriptions were created in such a way that they either had a negative meaning involving death, injury, illness, and pain, or a safe meaning involving happiness, health, marriage, pregnancy, and other more neutrally valenced resolutions. The safe descriptions thus referred to a broad range of situations, whereas the negative descriptions could all be chunked together as representative of health threats. The discrepancy between the homogeneity in negative meaning and the heterogeneity in safe meaning might have provoked 


\section{Chapter 6}

unequal expectations regarding the target word. Participants are primed to expect a putative health threatening resolution whereas no clear expectation is raised regarding the alternative putative solution of ambiguity. It is therefore suggested that future studies include two well-specified and demarcated resolution categories in order to raise equal expectations regarding the potential meaning of the target word. Furthermore, the healthy status of participants may be posited as another shortcoming of the present study. However, in order to examine whether the pain-related constructs act as latent risk factors for development and maintenance of chronic pain disorders, it is necessary to study their contributing role in information processing outside the context of current pain problems. As such, findings can be interpreted in the light of the presence of elevated levels of pain-related constructs, without them being contaminated by present pain problems. Nevertheless, future studies could benefit from the inclusion of participants that are selected as extreme scorers on the pain-related anxiety constructs. This might allow for firmer conclusions regarding the putative differences in the occurrence of negative interpretation bias in both high and low pain anxious individuals.

Despite these shortcomings, it should be stressed that the lexical decision paradigm emerged as a suitable paradigm to assess the on-line interpretations. Faster and more accurate responses were observed in response to word trials in comparison with non-word trials, indicating that participants make semantic inferences while reading the descriptions. The lexical processing of the descriptions probably activates expectations of a word probe rather than a non-word probe to follow the incomplete sentence, leading to a facilitation of responses to word trials. Furthermore we are quite confident in concluding that the ambiguity in the descriptions was effective based on the finding that within the word trials, responses were faster and more accurate on the forcedinference descriptions than on the ambiguous descriptions. Responses to ambiguous descriptions are thus slowed down, and this is probably due to the fact that inferences can only be made at the very end of the ambiguous description, whereas inferences evolve fast and logically in the forced inference descriptions.

The current study is the first to our knowledge that attempts to measure automatic interpretations in relation to vulnerability constructs for chronic pain. Further research should pay attention to the valuable information that studying automatic cognitive biases can offer to the understanding of underlying mechanisms of pain maintaining behaviours and dysfunctional responses to pain.

\section{AcKNOWLEDGements}

This research was supported by a grant from the Netherlands Organization for Scientific Research (NWO: 015-001-050). The authors wish to thank Vera Matti and Nicole van den Ham for their help in the data collection. Furthermore, we are grateful to Charlie Bonnemayer for his technical help and support in programming and implementing the on-line interpretation paradigm. 
APPENDIX. Examples of ambiguous word and non-word descriptions and their linked forced inference descriptions used in the task.

$\begin{array}{ll}\text { WORDS } & \text { A_H_W } \\ \text { Line } 1 & \text { You are visiting your grandmother. She tells } \\ \text { Line } 2 & \text { you she has a doctor appointment tomorrow } \\ \text { Line } 3 & \text { for the removal of two spots on the back of her } \\ \text { Line } 4 & \text { hand. These spots are a consequence of her } \\ \text { Target word } & \text { cancer }\end{array}$

Target word

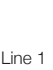

Line 2

Line3

Line 4

Target Word

NON_WORDS

Line 1

unit.

Line 2

Line3

Line 4

Target Word

Line 1
Line 2
Line3
Line 4

Target Word cancer

\section{A_S_W}

you she has a doctor appointment tomorrow

For the removal of two spots on the back of her

hand. These spots are a consequence of her

age

\section{A H NW}

The boy lies in the bed for some

time now. He lies there very

calm and does not respond to you

He is in a deep

moac

\section{A_S_NW}

time now. He lies there very

calm and does not respond to you

He is in a deep

pesle
You are visiting your grandmother. She tells

The boy lies in the bed for some

\section{F_H_W}

You have a birth mark that itches.

You have had it examined by a GP,

but luckily nothing was wrong

The birth mark was no indication of

cancer

\section{F_S_W}

Your grandmother's sight is getting worse.

She needs reading glasses. The optician

told her that it is common that sight

deteriorates when you reach an older

age

\section{F $\mathrm{H} \_$NW}

The woman is staying at the intensive care

Her family hopes she will ever

wake up again. Since a grave traffic

accident, she has been in a deep

moac

\section{F_S_NW}

Your brother has a strange

Habit. When he is in his bed

at night, he speaks out

loud, although he is in a deep

pesle

Note. A_H_W, Ambiguous description with a health-threatening word resolution; A_S_W, Ambiguous description with a safe word resolution; A_H_NW, Ambiguous description with a health-threatening non-word resolution; $A_{-}$ S_NW, Ambiguous description with a safe word resolution; F_H_W. Forced inference description with a healththreatening word resolution; F_S_W, Forced inference description with a safe word resolution; F_H_NW, Forced inference description with a health-threatening non-word resolution; F_S_NW, Forced inference description with a safe non-word resolution. 


\section{- - \\ Chapter 7}

Pain catastrophizing, but not injury/illness

sensitivity or anxiety sensitivity enhances attentional interference by pain.

This chapter is published as:

Vancleef, L. M. G. \& Peters, M. L. (2006). Pain catastrophizing, but not injury/illness sensitivity or anxiety sensitivity enhances attentional interference by pain. The Journal of Pain, 7, 23-30. 


\section{Abstract}

Pain draws upon attentional resources, thereby disturbing the pursuit of ongoing activities. Several studies have made use of the primary task paradigm to study the disruptive function of pain on attention. In this paradigm, participants perform an attentionally demanding task, while they are occasionally distracted by mild electrical stimulation. Deterioration in task performance (in terms of speed and accuracy) is then taken as an index of attentional interference. One major finding with this paradigm was that pain catastrophizing enhances attentional interference. The current study aims to replicate this finding and to explore the possible influence of anxiety sensitivity and injury/ illness sensitivity upon attentional interference. Healthy volunteers $(n=48)$ performed an auditory discrimination task and were thereby occasionally distracted by low electrocutaneous stimulations. The performance on the discrimination task was subsequently related to participants' scores on the Pain Catastrophizing Scale, the Anxiety Sensitivity Index, and the Injury/illness Sensitivity Index. We were unable to demonstrate an association of either injury/illness sensitivity or anxiety sensitivity with attentional interference. Results did however confirm the finding that pain catastrophizing enhances attentional interference.

Perspective. The present study showed that pain disrupts ongoing activities. This effect is enlarged in those with high levels of pain catastrophizing and is related to the threatening nature of pain stimuli. The role of anxiety sensitivity and injury/illness sensitivity seems to differ from the role of catastrophizing and needs further research.

\section{INTRODUCTION}

Anxiety sensitivity (AS) is defined as the heightened sensitivity or fear of anxiety sensations (e.g., hart palpitations) that arises from the belief that these sensations will lead to harmful somatic, psychological or physical consequences (Reiss et al., 1986). AS has been suggested to play a role in the development and maintenance of various acute and chronic pain-related conditions, such as headaches, gastro-intestinal pain, menstrual pain, asthma, low-back pain and musculoskeletal pain (Asmundson et al., 2000). Studies in both clinical and non-clinical populations have demonstrated the association between anxiety sensitivity levels and pain related variables. AS was found to be associated with elevated fear of pain, a heightened reported cognitive disruption by pain, and heightened analgesic use in pain patients (Asmundson \& Norton, 1995). In a nonclinical population, high levels of AS were associated with decreased pain threshold and more self reported pain in response to a cold pressor task (Keogh \& Cochrane, 2002; Keogh \& Mansoor, 2001), and AS proved to be a stronger predictor of cold-pressor pain than fear of pain (Greenberg \& Burns, 2003). Moreover, AS may be related to cognitive biases for physically threatening and pain-related material (Keogh, Dillon et al., 2001; Stewart, Conrod, Gignac, \& Pihl, 1998). Using a dot-probe task, Keogh et al. found that pain free volunteers high in anxiety sensitivity showed an increased attentional bias towards physically threatening material (Keogh, Dillon et al., 2001). In a subsequent study, participants scoring high on AS also demonstrated an increased interpretational 


\section{$\Uparrow$ chaper}

bias specifically for pain-related situations, which in addition mediated the relation between AS and pain threshold in the cold pressor test (Keogh \& Cochrane, 2002).

Thus, evidence is accumulating that AS influences the way people react to pain and thereby may be a potential vulnerability factor for chronic pain. However, recently it has been suggested that another personality trait, namely injury/illness sensitivity (IS), may play an equally or even more important role in determining someone's reaction to pain (Keogh \& Asmundson, 2004). According to Reiss's expectancy model (Reiss, 1991), three fundamental fears (also called sensitivities) can be distinguished, i.e., anxiety sensitivity, injury/illness sensitivity and fear of negative evaluation. These fundamental fears may underlie all common fears that we encounter in our daily society (e.g., fear of heights, fear of animals) and can be proposed to explain various psychopathological conditions (e.g., panic disorder, blood phobia, social phobia) (Taylor, 1993). The fundamental fears itself may in turn be nested within the higher order factor of trait anxiety. By administering measures of fundamental fears, common fears and trait anxiety to 100 community volunteers, Taylor (Taylor, 1993) was able to demonstrate that the three fundamental fears are indeed factorially distinct, minimally intercorrelated, and explain substantial proportions of variance in several common fears, as well as in trait anxiety.

Although this study provided evidence for IS as a distinct fundamental fear, its relation to common fears and specific forms of psychopathology has - in contrast to AS - remained largely unexplored. It was only recently that interest in IS as a potential vulnerability factor for chronic pain has arisen. Presenting an adapted version of the hierarchical model of fundamental fears, Keogh and Asmundson (2004) have proposed that IS may be a higher order factor of the common fear of pain and pain catastrophizing. Vancleef et al. (2006) tested the association between the three fundamental fears and other pain-related variables in a correlational study. Results showed that both AS and IS were correlated with several pain measures, but that IS was a better predictor of pain catastrophizing and fear of pain than AS. Furthermore, IS was found to be associated with a heightened fearfulness of an impending pain stimulus prior to the actual stimulus presentation, while this heightened anticipatory fearfulness could not be established for AS (Vancleef et al., 2006).

The present study further examined the putative role of AS and IS on pain responses in pain free volunteers. More specifically, it was investigated whether these two fundamental fears would lead to heightened attentional interference by pain on ongoing activities. Cognitive models of fear state that an important function of fear is the early detection of potential threatening situations, and accordingly fear is accompanied by vigilance or heightened awareness of possible sources of threat (Eysenck, 1997). Since IS represents a fearfulness for illness and injury, people with high levels of IS may be prone to prioritize signals of potential injury, and show more disruption of ongoing activities when confronted with a pain signal. AS may also be associated with increased attention towards pain. It has been speculated that a defining feature of AS is an increased awareness of bodily sensations in general (Keogh \& Cochrane, 2002), and indeed a selective attentional bias for physical threat words was found in pain free volunteers scoring high on AS (Keogh, Dillon et al., 2001). Moreover, back pain patient with high AS reported to experience greater cognitive disruption in response to pain (Asmundson \& Norton, 1995).

The attentional interference effect of pain can be experimentally established with the 
so-called primary task paradigm, in which participants perform an attention-demanding task while at some points pain stimuli are administered (Eccleston \& Crombez, 1999). The critical parameter is deterioration of performance during pain. For the present study we used the primary task as adapted by Crombez et al. (1998a), in which participants perform a simple tone discrimination task, while they are occasionally distracted by low intensity non-painful electrical stimulation. With this paradigm, it was demonstrated that in clinical and non-clinical populations the degree of interference is determined by the intensity, the novelty, the predictability and the threat value of the stimulus (Crombez, Baeyens, \& Eelen, 1994; Crombez, Eccleston, Baeyens, \& Eelen, 1996, 1997; Crombez et al., 1998a, 1998b; Crombez, Eccleston, van den Broeck, van Houdenhove, \& Goubert, 2002). Since threat appraisal is one of the determining features of attentional interference, those who amplify threatening somatic information are expected to show increased attentional interference (Crombez et al., 1998b). Indeed, persons with high levels of pain related fear and persons who score high on pain catastrophizing showed larger attentional interference than those who were low in pain related fear and pain catastrophizing (Crombez et al., 1998b).

Extending these findings to AS and IS, it can thus be expected that the presence of these traits may enhance the threat value of somatic stimuli, thereby resulting in larger disruption on attention as well. Persons who are high in IS may amplify the threat value since they perceive the somatic stimuli as signallers of injury, whereas persons who are high in AS may do this because they generally interpret bodily sensations negatively. In addition, both AS and IS are found to be closely related to pain catastrophizing and fear of pain (Vancleef et al., 2006). We therefore hypothesized in the present study that the degree of attentional interference by low intensity electric stimulation is dependent upon participants' level of AS and IS. Furthermore, we attempt to replicate previous findings concerning the association between pain catastrophizing and attentional interference.

\section{METHOD}

\section{PARTICIPANTS}

Forty-eight healthy participants (12 males; 36 females) with a mean age of 21.75 years (range: $18-43, S D=4.36$ ) took part in this study. All participants were recruited at Maastricht University's local community through advertisements in the university paper and posters in the university building. Inclusion criteria for participation were a good state of health (free from chronic pain symptoms, free from mental illness) and good hearing abilities. All participants gave informed consent and received a financial compensation for their participation. Participants were informed that they could decline to participate at any given time during the experiment. Two participants were excluded from the VAS analysis, because of missing pre-experimental data. The Ethics Committee of the Academic Hospital Maastricht/Maastricht University approved the research protocol. 


\section{Chapter 7}

\section{Materials and Measures}

Self-report measures. Pain catastrophizing is assessed with the Dutch version of the Pain Catastrophizing Scale (PCS) (Sullivan et al., 1995). In this 13- item scale, respondents indicate on a 5-point scale to what extent they experience each of 13 feelings and thoughts when they experience pain (e.g., 'I feel as if I can't take this anymore'). Both the original and the Dutch version of the PCS have proven to be reliable and valid measures (Severeijns et al., 2002; Van Damme et al., 2002).

The Dutch version of the Sensitivity Index (SI) ${ }^{9}$ (Taylor, 1993) consists of three subscales (ASI, ISI, FNE), which tap anxiety sensitivity (AS), injury/illness sensitivity (IS) and fear of negative evaluation (FNE) respectively. The Anxiety Sensitivity Index (ASI) includes 16 items concerning the negative consequences of experiencing anxiety (e.g., 'It scares me when my heart beats rapidly'). The Injury/illness Sensitivity Index (ISI) (Taylor, 1993) contains 6 items pertaining to the fear of illness (e.g., 'I get scared when I think I'm coming down with an illness') and 5 items referring to the fear of injury (e.g., 'The thought of injury terrifies me'). The Fear of Negative Evaluation Scale (FNE) (Leary, 1983) consists of 12 items measuring the fear of negative evaluation (e.g., 'I worry about what kind of impression I make on people'). Participants indicate their degree of agreement with all statements of the SI on a 5-point Likert scale. Psychometric properties of both the original and the Dutch version of the SI are satisfactory (Taylor, 1993; Vancleef et al., 2006), with internal consistencies in the Dutch version of .88 (ISI), .84 (ASI), .96 (FNE) and .94 (whole SI). The test retest reliability coefficients for the Dutch version of the SI showed intra class correlation coefficients (ICC's) ranging from .60 to .64 with a six-month test interval. Furthermore, the psychometric properties of the ASI (Peterson \& Heilbronner, 1987; Rodriguez et al., 2004; Sandin et al., 2001), the FNE (Garcia Lopez, Olivares, Hidalgo, Beidel, \& Turner, 2001; Leary, 1983) and recently the ISI (Carleton et al., 2005) separately have well been documented.

Two Visual Analogue Scales were administered before and after the experimental phase, on which participants rate the unpleasantness and the experienced intensity of the electrical stimulation. These scales consisted of a horizontal line $(10 \mathrm{~cm})$ representing a continuum, ranging from 'not at all unpleasant/ not at all intense' to 'very unpleasant/ very intense'. Participants marked the line at the position within this continuum that reflects their opinion/experience concerning unpleasantness and intensity of the ES.

9 The English version of the Sensitivity Index was translated in Dutch in a state-of-the-art manner, involving back translation, after which the item content was checked against the original content. The Dutch version of the Sensitivity Index is available with the corresponding author. 
Auditory discrimination task. In the auditory discrimination task, high (1000 Hz) and low $(250 \mathrm{~Hz})$ pitch tones (duration $=200 \mathrm{~ms}$ ) were presented through a headset to the participants. Participants responded to the tones by pressing a button of a two-buttoned console with their dominant hand. A total of 48 tones were presented, with an interstimulus-interval between $1200 \mathrm{~ms}$ and $1800 \mathrm{~ms}$ (mean=1500ms). Half of the tones presented were high in pitch.

Electrical stimulation. The electrical stimulation (ES) was delivered by a constant current stimulator (IDEE, Maastricht University) with an internal frequency of $50 \mathrm{~Hz}$. The electrical stimuli all had an instantaneous rise and fall time, and a duration of $1500 \mathrm{~ms}$. The stimulation was delivered through one pair of $\mathrm{Ag} / \mathrm{AgCl}$ electrodes, filled with hypertonic gel (spectra eeg gel), and an interelectrode distance of $1 \mathrm{~cm}$. The electrodes were attached at the under-arm of the non-dominant arm, after the skin area beneath the electrodes was first rubbed with peeling gel to reduce skin resistance. The ES all had an intensity of $0.8 \mathrm{~mA}$. In a pilot study, this intensity was found to be well noticeable, although it remained under the pain threshold for all participants.

\section{Procedure}

Pre-experimental phase. Participants were tested individually after informed consent was obtained. They were kept unaware of the true nature of the experiment, to control for possible demand characteristics. In line with previous studies by Crombez et al. (e.g., Crombez et al., 1998a, 1998b) participants were led to believe that they took part in a study that attempted to investigate the putative influence of distracters upon a psychophysiological measure of stimulus perception, whereby the electrodes were used to measure electrodermal activity.

Experimental phase. First, the participants were familiarized with the ES. Therefore, a series of ES with increasing intensity $(0.2 \mathrm{~mA}-0.4 \mathrm{~mA}-0.6 \mathrm{~mA}-0.8 \mathrm{~mA})$ was administered through the attached electrodes. In this familiarization phase, each ES intensity was only presented once to the participant. Participants were kept ignorant with respect to which of these intensities they would receive in the experimental phase. After this series of ES, participants rated the unpleasantness and the perceived intensity of the last received ES, which corresponded to the intensity of the ES that would be used throughout the experiment. Next, participants practiced the auditory discrimination task without distracters. The tones (15 low pitch and 15 high pitch) were presented randomly, with an inter-stimulus interval between 1200 and $1800 \mathrm{~ms}$ (mean =1500 ms). Finally, participants received further instructions about the progress of the experiment. They were told that the primary goal of the study was to investigate the influence of an unfamiliar, painful stimulus upon electrodermal activity. Following Crombez et al. (1998b), we enhanced the threat value of the ES by providing intrinsically threatening somatic information concerning the ES through telling participants that the ES would directly stimulate pain fibres. In addition, we told participants that in prior studies, the reactions to ES varied across persons, with some persons judging them as very 
painful, whereas others did not. Finally, participants were instructed that they should try to ignore the pain stimuli and concentrate on performing the auditory task as good and as fast as possible. When all these preparation phases were fulfilled, the experimental phase began. This phase consisted of three identical blocks that were presented to the participant in a serial order, without pauses in between. Each block consisted of 8 ES trials that all had duration of $1500 \mathrm{~ms}$ and a fixed intensity of $0.8 \mathrm{~mA}$. Half of the ES trials ( 4 trials) were combined with the presentation of a tone. In two of these, the tone was presented at $250 \mathrm{~ms}$ after onset of the ES, whereas in the other two ES trials, the tone was presented at $750 \mathrm{~ms}$ after ES onset. These two times of tone presentations (250ms versus $750 \mathrm{~ms}$ ) were chosen following Crombez et al. (1996, 1997), who showed that the distractive influence of the ES was most pronounced when a reaction was expected at pain onset (i.e., $250 \mathrm{~ms}$ ). Four ES trials without a combined tone were inserted, to avoid the electrical stimulation to become predictive of a tone. The amount of tones that preceded an ES varied between 4 and 6 (mean =5). Over the three blocks, a total of 144 tones were presented (48 tones in each block), of which half were high in pitch. No more than 3 consecutive trials consisted of a tone with the same pitch. The computer registered reaction times and errors while the participant executed the experiment.

Post-experimental phase. Immediately upon finishing the experimental phase, participants rated once again the unpleasantness and the experienced intensity of the last presented ES and completed the self-report measures (PCS, SI). The self-report measures were administered after the experimental procedure in order to avoid demand characteristics. Presenting the questionnaires before the experimental procedure might result in transparency of the research aims as studying pain processes, thereby affecting the task performance of the participants in an undesirable manner.

\section{RESULTS}

Interference effect. The overall percentage of errors during the task was $1.5 \%$, with a total of 12 errors (2.1\%) occurring during the electrocutaneous stimuli and 90 errors (1.4\%) on the stimuli that were not presented during a shock. Only $0.6 \%$ of the Reaction times were missing or invalid. In accordance with Crombez et al. (e.g., Crombez et al., 1997) invalid reaction times were defined as reaction times below $150 \mathrm{~ms}$ or above $2000 \mathrm{~ms}$.

The mean reaction times and their standard deviations on trials within or outside an electrical stimulation are depicted in Table 1. We calculated baseline reaction times as the average of reaction times on tones occurring outside an experimental event, and experimental reaction times as the average of reaction time scores on the tones falling within the duration of an electrical stimulus. Interference scores are calculated as the change score in reaction time from the baseline scores to the experimental scores. These interference scores are used in the following analyses and should be interpreted as the mean deterioration on task performance, caused by the ES. 


\begin{tabular}{|c|c|c|c|}
\hline & Baseline & Experimental & Interference \\
\hline & Mean RT (sd) & Mean RT (sd) & Mean (sd) \\
\hline 1 & 460.31 (88.44) & 543.89 (115.70) & 83.58 (73.94) \\
\hline 2 & 436.17 (78.45) & 488.16 (115.68) & $52.00(71.57)$ \\
\hline 3 & 430.78 (78.04) & 466.88 (94.64) & $36.10(58.51)$ \\
\hline Total & 442.42 (82.22) & 499.64 (113.15) & 57.22 (70.69) \\
\hline
\end{tabular}

A $2 \times 3$ repeated measures analysis of variance with Condition (Baseline versus Experimental) as within subjects factor and Block (Block 1 versus Block 2 versus Block 3) as between subjects factor resulted in a main effect of Condition $\left(F(1,141)=100.95, p<.001, \eta^{2}=\right.$ $.42)$ and a main effect of Block $\left(F(2,141)=4.54, p<.05, \eta^{2}=.01\right)$. The main effect of Condition indicates that participants responded faster on the baseline tone trials than on the trials within electrical stimulation (Table 1). The main effect of Block shows that participants became faster in their responses throughout the experiment, with the slowest responses in Block 1 (mean = 466,19; $s d=72.75$ ), faster responses in Block 2 (mean $=439,63$; $s d=11,58$ ) and the fastest responses in Block 3 (mean = 431,84; sd = 11.24). The Condition $\times$ Block interaction was significant as well $\left(F(2,141)=6.00, p<.01, \eta^{2}=.08\right)$, indicating that interference was the highest in the first block (Table 1).

To explore a possible effect of time of tone presentation (250 ms or $750 \mathrm{~ms}$ after onset ES), interference scores for the tones at $250 \mathrm{~ms}$ after ES onset and the interference score for tones at $750 \mathrm{~ms}$ after ES onset were calculated separately (see Table 2).

TABLE 2. Mean interference scores and standard deviations for the tones at $250 \mathrm{~ms}$ after ES onset and at $750 \mathrm{~ms}$ after ES onset in the three blocks. $(N=48)$

\begin{tabular}{lcclc}
\hline \hline & Interference 250 & & Interference 750 & \\
Block & Mean & SD & Mean & SD \\
\hline 1 & 108.73 & 114.19 & 55.05 & 94.71 \\
2 & 43.54 & 88.27 & 60.45 & 93.51 \\
3 & 25.97 & 72.56 & 39.32 & 96.43 \\
\hline \hline
\end{tabular}

An 2 x 3 ANOVA with Time (250 ms versus $750 \mathrm{~ms}$ ) as within subjects factor and Block (1 versus 2 versus 3) as between subjects factor revealed a main effect of Block $(F(2,141)=6.05$, $\left.\mathrm{p}<.01, \eta^{2}=.09\right)$ and a significant interaction between Time and Block $(F(2,141)=4.78, p<.05$, $\left.\eta^{2}=.06\right)$. No main effect for Time $(F(1,141)=.553, n s)$ was found. Post hoc analyses with paired t-tests showed an effect of Time in the first block only $(t(47)=2.59, p=.013, d=.27)$, indicating a 
higher interference score at the $250 \mathrm{~ms}$ time than at the $750 \mathrm{~ms}$ time. No time of tone effects could be identified in block 2 or block 3 .

Association between the questionnaire scores and the interference effect. In the current sample, the mean PCS score was 14.17 ( $s d=7.83$ ). The mean scores for the ASI, the ISI and the $\mathrm{FNE}^{10}$ were respectively 27.19 ( $\left.s d=7.05\right), 23.92(s d=8.34)$ and $27.39(s d=9.86)$.

The association between the self-report questionnaires and the mean interference score over the three blocks was explored by calculating Bivariate Pearson correlation coefficients (Table 3). The correlations showed a significant correlation between the interference score and the PCS $(r(48)=.326, p=.024)$, whereas the ASI $(r(48)=.191, n s)$ and the ISI $(r(48)=.044, n s)$ did not correlate significantly with the interference scores ${ }^{11}$. Furthermore, Table 3 shows the correlations between the different measures used in this study. All measures correlate significantly with each other. The highest correlations exist between ASI and ISI $(r(48)=.668, p<.01)$ and between ASI and PCS $(r(48)=.606, p<.01)$.

\begin{tabular}{|c|c|c|c|}
\hline & INTERFERENCE & PCS & ASI \\
\hline PCS & $.33^{*}$ & & \\
\hline ASI & .19 & $.61^{\star \star}$ & \\
\hline$|S|$ & .04 & $.49^{\star *}$ & $.67^{\star \star}$ \\
\hline
\end{tabular}

NoтE. PCS, Pain Catastrophizing Scale; ASI, Anxiety Sensitivity Index; ISI, Injury/lllness Sensitiviy Index; ${ }^{*} \mathrm{p}<.05 ;{ }^{* *} \mathrm{p}<.01$

Subjective responses to electrical stimuli. Participants rated the 'intensity' and the 'unpleasantness' of the last experienced ES once after the familiarization with the ES and once again after the experimental procedure. Table 4 shows that these subjective responses were both rated higher before the experimental event than after the experimental procedure. Paired t-tests comparing the pre-experimental scores with the post-experimental scores did indeed result in significant differences for both 'intensity' $(t(45)=5.27, p<.001, d=.61$ ) and 'unpleasantness' ( $t$ $(45)=5.04, p<.001, d=.51$ ) ratings.

10 Since the FNE scale was not of interest in the current study, this measure was ignored in further analyses.

11 One way ANOVA on the interference score, with the median-split scores on the questionnaires as between subjects factor, revealed a significant group effect of pain catastrophizing as well $(F(1,46)=4.16, p=.047)$, but no group effects for the AS or IS were found. 
TABLE 4. Pre- and post experimental mean VAS scores on 'Experienced intensity' and 'Unpleasantness'. ( $N=46)$

\begin{tabular}{lllll}
\hline \hline & Pre-experimental & & Post-experimental & \\
& Mean & SD & Mean & SD \\
Intensity & 51.23 & 21.61 & 33.28 & 20.71 \\
Unpleasantness & 48.00 & 25.12 & 31.02 & 22.27 \\
\hline \hline
\end{tabular}

A possible association between the scores on the VAS scales and the questionnaire scores was explored with correlational analyses. None of these correlations reached significance, with correlation coefficients ranging between .03 and .23).

\section{Discussion}

The present study looked into the interruptive nature of pain on attention with the primary task paradigm. Thereby, it was examined whether IS, AS, or pain catastrophizing affect the degree in which a somatic threatening stimulus distracts attention from the performance on a simple cognitive task in pain-free volunteers.

Results confirmed previous findings concerning the disrupting function of pain on attention (Crombez et al., 1996, 1998a, 1998b; Crombez et al., 1999; Eccleston, 1994; Eccleston \& Crombez, 1999). The administration of a somatic threatening stimulus (the ES) caused task deterioration on tone trials that fell within an ES, indicating that the sudden experience of this stimulus drew upon the attentional resources of our participants. In addition, we could replicate the finding that attentional interference is larger at the onset of the ES, since interference scores were larger when a response was required at $250 \mathrm{~ms}$ after ES onset, in comparison to a required response at $750 \mathrm{~ms}$ after onset. Based on conditioning principles (Öhman, 1979) and cognitive motivational models (Norman \& Shallice, 1986), Crombez et al. (1998a) suggest that the threat value of a stimulus primes the attentional system of the individual, thereby disrupting task performance. Attention will then be switched to the somatic threatening stimulus, which is subsequently evaluated with respect to its meaning and gravity. When this evaluation results in a non-threatening appraisal of the stimulus, the individual will pursue the activities that were interrupted by pain onset. The difference in interference at $250 \mathrm{~ms}$ and $750 \mathrm{~ms}$ after ES onset applies to the first test block only, which is in agreement with previous findings (Crombez et al., 1996, 1997). Possibly, the easy nature of the auditory discrimination task is responsible for the fact that, even though the ES keeps slowing down reaction times, the strongest initial influence of pain declines when the participant is more familiarized with the task procedure.

The current study furthermore confirmed the previous finding that individual differences in pain catastrophizing influence attentional interference scores (Crombez et al., 1998b; Crombez et al., 2002). High scores on the pain catastrophizing scale were associated with larger task deterioration on the auditory discrimination task. We were, however, unable to demonstrate a likewise influence of either IS or AS on task deterioration. The correlations between the interference scores and the fundamental fear constructs were small, indicating that the presence of these traits 
does not influence the allocation of attentional processes. So, it seems appealing to conclude that the hypothesized amplifying effect of both IS and AS on the threat value of the ES does not exist. However, some alternative explanations for the lack of finding our hypothesized effect should be taken in consideration. With respect to IS, the lack of ecological validity might be responsible for the low correlations with the interference effect. IS is related to general negative expectations and anticipations of putative future injury and illness. In the current study, participants were aware that they take were taking part in a controlled study in which intensity and duration of the used stimuli were limited (in comparison to real-life situations), thereby not likely resulting in serious tissue damage. Consequently, the anticipative fear of possible long-term health complaints is not realistically present in this experimental set-up.

With respect to AS, it is conceivable that the relation between AS and the interference scores could not be detected due to the nature of the threatening bodily sensations that are caused by the ES. In the definition of AS, a specific sensitivity for the experience of anxiety sensations is stated (Reiss et al., 1986). However, in the current study, the ES is externally administered to the person, and may not be evaluated as an internally threatening sensation to the participant. In addition, it can be argued that the ES in the current study is not aversive enough to elicit strong general anxiety for the experienced bodily sensations. Indeed, Eccleston et al. (1994) reported the magnitude of the pain intensity as a crucial variable in its effect upon attentional awareness. However, Crombez et al. (1998a) provided evidence that in a healthy population, the threat of pain (either internal or external), in combination with the novelty and unpredictability of the ES satisfy the necessary conditions to obtain an enhanced disruption on attention in persons with high levels of pain catastrophizing (Crombez et al., 1996, 1998a, 1998b; Eccleston \& Crombez, 1999). The present results support these findings with respect to pain catastrophizing. Nevertheless, since we failed to assess whether the ES used in this study were indeed evaluated as unpredictable and threatening to the participants, we cannot fully exclude the possibility that the ES actually did not possess our intended threat value and unpredictability. Yet, it is possible that the primary task paradigm as adapted in the current study provides not enough sensitivity to obtain likewise effects in persons with high levels of AS and IS, since the fundamental fears are less specific and of a higher order than pain catastrophizing is. Further research should address the facet of the sensitivity of the primary task paradigm as it is used in the current set-up.

An additional interesting and remarkable finding of the current study concerns the correlations between the questionnaire measures, more specifically the relation between AS, IS, and pain catastrophizing. A prior study showed that although both AS and IS are associated with pain catastrophizing, IS was the strongest predictor for this factor (Vancleef et al., 2006). However, inspection of the correlations between the questionnaire measures in the current sample learns that AS, and not IS correlates the highest with pain catastrophizing. This may be caused by the time of assessment of the questionnaires. In the current study, all questionnaires were assessed after the experimental procedure, and that may have affected participants' response tendencies. Although AS and IS are both considered as dispositional personality traits, the possibility exists that the specific item characteristics of the measures assessing these traits have an undesirable effect on the eventual scores on these measures. Both the PCS and the ASI possess items that ask directly for experienced pain and experienced bodily sensations. It may therefore be the case 
that respondents take the pain from the experiment as referent in their mind while filling in the questionnaires, with a resulting high correlation between the two measures. The ISI consists of items that are posited in such a way that they refer to the general fearfulness of experiencing injury or illness at some time in the future, and is therefore less applicable to the low intensity pain stimulus from the experiment. Comparable findings were recently reported by Thorn et al. (2004), who showed that PCS scores that were assessed before an experimental pain induction did not predict pain intensity ratings, whereas post PCS scores did. These authors argued that the PCS might measure situational catastrophizing when it is administered after experimental pain stimulation rather than dispositional catastrophizing, that it measures when it is assessed before the experimental pain procedure. Further research should pay attention to state-like properties of particularly the ASI that result from the specific item content of this measure.

Several limitations should be taken into consideration when interpreting the results of the current study. First, one could argue that the rather small sample size $(N=48)$ is responsible for the lack of finding significant effects for the ASI and the ISI with the interference scores. However, this possibility seems unlikely since the found association between the interference effect and pain catastrophizing does not differ substantially from the effects that Crombez and colleagues found in earlier studies with resembling sample sizes (Crombez et al., 1998b; Crombez et al., 2002). Moreover, the strong general interference effect that is found in the current study, gives further indication that the failure to find effects with AS and IS are not resulting from sample size problems. Particularly with respect to IS, the correlation with the interference score is so small that an increase in sample size would still not lead to a sufficient high correlation to obtain the hypothesized association. Rather than problems with sample size, however, it is possible that extreme values of AS and IS are required to establish their influence on attentional interference. In the current study, these extreme values are particularly missing for AS. Future research with these factors should considerate a prior selection on extreme values for these traits in order to verify this possibility. One could furthermore raise the argument that a clinical research population would have yielded better interpretable results. However, the current study was specifically conducted in a non-clinical population, for it is theorized that both IS and AS are dispositional risk factors in the aetiology of acute and chronic pain, being present before pain develops. Putative results of this study can then be assigned to the presence of IS and AS, disentangling their influence from the effect that the actual presence of chronic pain could have on the task performance. Moreover, the measure that assesses IS, the injury/illness sensitivity index, consists of items that ask for worrying and fearfulness of future injury and illnesses. Therefore, it is unadvisable to administer this measure in a clinical pain population, since their actual pain experience will affect the interpretation and response mode on the questions.

The lack of evidence for an influential role of both AS and IS on attention interference emphasizes the need for further research in the validation of these concepts, and the role they play in pain processing. It is possible that IS is not so much related to attentional interference by pain once it is there, but rather to the interpretation and validation of future injury or illness. Therefore, it may be proposed that the role of IS should be investigated with an interpretation bias paradigm in which the schema of a person concerning several (pain related) situations can be investigated.

Despite the negative findings concerning the role of AS and IS, the current study has 


\section{đ crapeler}

proven convincingly that pain has the characteristic of demanding attention and that it interferes with other cognitive tasks that have to be fulfilled. Also, this attentional distraction is enhanced in pain catastrophizers, who amplify threatening information and exaggerate the negative consequences of pain. The role of IS and AS in the (chronic) pain problem needs further attention and research

\section{AcKNOWLEDGMENTS}

This research is supported by a grant from the Netherlands organisation for Scientific Research (NWO) with grant no. 015-001-050. 


\section{Commentary: The interruptiue effect of Pain ON ATTENTION}

A large body of research has been conducted to study the relation between pain and attention. It has been suggested that focussing attention on the performance of a high attentiondemanding task can serve as a cognitive coping strategy to deal with pain, as all attentional resources will be devoted to task performance. On the other hand, evidence exists that pain can automatically enter focal attention, even when attention is being devoted to the performance of an attention-demanding task. Eccleston (1994) found that pain patients with high levels of selfreported pain performed worse on an attention-demanding task than those reporting lower pain levels, even though they were instructed to ignore their pain and focus on task performance. When trying to explain the disturbing effect of pain on attention, it is important to consider the parameters that influence this effect. Several studies have used the primary task paradigm in their search for these parameters and revealed that besides the pain intensity, the novelty, the unpredictability, and the threat value of pain stimuli enlarge attentional disruption by pain (Crombez et al., 1994; Crombez et al., 1996, 1997, 1998a; Eccleston \& Crombez, 1999; Eccleston, Crombez, Aldrich, \& Stannard, 1997). So, attentional interference by pain is larger when the pain stimulus is new and unfamiliar to the individual, or when the pain stimulus holds an implicit or explicit threat. But not only qualities of the pain stimulus itself determine the degree in which pain will interrupt attention. Individual characteristics may also moderate the attentional interference effect. Research found that persons who interpret pain as threatening, and persons who tend to catastrophize on the possible meaning and consequences of pain show an enhanced disruptive effect on attention (Crombez et al., 1998b; Crombez et al., 2002).

It can be concluded that pain does interrupt attention, but that its intrusion into focal awareness is dependent upon several characteristics of the pain stimulus and the meaning that is assigned to it. The apparent contradictive outcomes of the study by Veldhuijzen, Kenemans, de Bruin, Olivier, \& Volkerts (2006), and our study (Vancleef \& Peters, 2006) should be interpreted in this light. We made use of an electrical pain stimulus of short duration that we administered randomly at several times during task performance. The imminent threat value of the pain stimulus was manipulated through instruction. Veldhuijzen et al. used a more tonic pain stimulus (i.e., cold pressor pain) that was continuously present during task performance. Previous studies, as well as or own study show that interruption by pain on attention is largest immediately after pain onset, after which the interruptive effect diminishes quickly (Crombez et al., 1996, 1997, 1998a). Immediately upon pain onset, an automatic orienting reflex occurs, in which attention is devoted to the pain, and a fast evaluation of the meaning and gravity of the pain is made. When the result of this evaluation reveals that the pain is not threatening, attention will be devoted again to the task and performance will no longer suffer. In the study of Veldhuijzen et al., the pain stimulus may have lost its meaningfulness to the participants due to its long duration, making it easier 


\section{Thapter 7}

to distract from. Furthermore, Veldhuijzen et al. didn't include measures of individual variability between participants. Both our and previous studies convincingly demonstrated that attentional interference was enhanced in persons with high levels of pain catastrophizing, fear of pain or somatic awareness (Crombez et al., 1998b; Crombez et al., 1999; Crombez et al., 2002; Eccleston et al., 1997).

This commentary is published as:

Vancleef, L. M. G. \& Peters, M. L. (2006). The Interruptive Effect of Pain on Attention. The Journal of Pain, 7, 21-22. 


\section{- 一 \\ Chapter 8}

Does it hurt less when you are convinced you can control it? The influence of perceived control and self-efficacy on the subjective evaluation of experimentally induced pain.

This chapter is submitted for publication as:

Vancleef, L. M. G. \& Peters, M. L. Does it hurt less when you are convinced you can control it? The influence of perceived control and self-efficacy on the subjective evaluation of experimentally induced pain. 


\section{Abstract}

Perceived control and self-efficacy (SE) beliefs over pain have been proposed as mediators of reductions in pain and pain-related disability and as important factors to consider in the management of pain. The present study $(\mathrm{N}=79)$ sought to examine the effects of manipulated perceived control and SE beliefs on subjective expectancy and experience ratings (i.e., pain intensity, pain unpleasantness, fear of pain) of an experimentally induced electrical pain stimulus. In addition, the moderating effects of positive stable personality traits (i.e., optimism and general SE) were explored. Results demonstrated that having perceived control over pain influenced the fear that was elicited by the pain stimulus. Inducing high SE beliefs regarding the ability to exert control over pain resulted in a significant reduction in anticipated pain intensity and pain unpleasantness. Additionally, the anticipated pain intensity mediated the relation between SE and experienced pain intensity. Optimism and general SE were found to be inversely related with fear of pain ratings only. It is concluded that in order to observe beneficial effects of offering control over pain on the actual pain experience, it is important that individuals are convinced (i.e., have high SE) that they are able to exert this control successfully.

\section{INTRODUCTION}

Although a substantial body of research is available on potential vulnerability and risk factors for chronic pain, research into factors and mechanisms that influence the course of pain beneficially is still sparse. Nevertheless, gathering knowledge on processes and factors that might contribute to reductions in pain and pain-related disability provides useful information for theoretical and management perspectives on chronic pain. One cognitive construct that has been proposed as a mediator of decreased pain and disability is perceived control, or the belief that one has at one's disposal a response that can influence the aversiveness of an event (Thompson, 1981). In (chronic) pain patients, perceived control over pain has been found predictive of patients' well-being and of better patient functioning (less depression, less disability, less interference by pain), and was found associated with increased activity levels, lower perceived pain severity, and increased patient satisfaction with treatment strategies (Jensen \& Karoly, 1991; Pellino \& Ward, 1998; Tan et al., 2002). In healthy volunteers, perceived control over pain has been found related to increased tolerance and prolonged endurance of experimentally induced pain (Arntz \& Schmidt, 1989; Feldner \& Hekmat, 2001). Recently, Janssen, Spinhoven, and Arntz (2004) demonstrated that successful control over the pain has a positive influenced on individuals' mood, whereas repetitive failures in controlling pain lead to increased anger and physiological reactivity. It is important to note that the idea of being able to control pain already seems to lead to beneficial effects, irrespective of the fact whether this control is genuinely effective or utilized (Arntz \& Schmidt, 1989). Nevertheless, effects of perceived control over pain appear to be restricted to behavioural and emotional responses to pain (pain tolerance, pain endurance, happiness). Arntz and Schmidt (1989) have suggested that perceived control over pain particularly alters the perceived threat value and thus the meaning of the pain, leading to observable benefits in objective responses to pain that do not extend to 


\section{$\Uparrow$ chaperer}

its subjective sensory experience. Supporting this suggestion, perceived control over anxietyrelated events (interpreted as control over threatening, anxiety inducing situations) appeared to be associated with longer tolerance and endurance of cold-pressor pain, but not with decreases in subjective pain intensity, heart rate, or pain threshold (Feldner \& Hekmat, 2001).

A second cognitive factor that is assumed to mediate pain and disability is self-efficacy (SE), or the belief one has in one's ability to organize and perform the behaviours that are necessary to achieve desired goals (Bandura, 1977). A distinction can be made between generalized SE and specific SE. Generalized SE is conceived as a broad and stable personality construct that reflects the belief and confidence one has in one's own capability to achieve desired outcomes in everyday life across a broad range of situations (e.g., Luszczynska et al., 2005; Peters \& Vancleef, in press). Specific SE, on the other hand refers to the belief one has in one's own capability and quality to achieve desired outcomes using a specific task, strategy, or technique (e.g., Litt, 1988; Rokke et al., 2004). Most research that examined the effects of SE on responses to pain has focussed on specific SE, operationalized as the belief in the ability to use a specific strategy or technique to reduce pain, or the belief in the ability to cope with a specific pain stimulus (e.g., cold pressor pain). Specific SE has been identified as a mediating factor in the relation between pain intensity and disability, and was found predictive of the degree of disability that one experiences (Arnstein, 2000; Denison et al., 2004). Furthermore, high SE beliefs appeared to be predictive of pain tolerance and pain endurance, irrespective of the amount of pain that one expected to receive (Baker \& Kirsch, 1991; Litt, 1988; Rokke et al., 2004; Williams \& Kinney, 1991). Congruently with findings on perceived control, the beneficial effects of SE appear to be predominantly restricted to behavioural pain responses, although effects of SE on reported pain intensity have been observed occasionally (e.g., Jackson et al., 2002; Rokke et al., 2004).

Even though most of the research on the influence of perceived control and SE on pain has focussed on one of both constructs, it well acknowledged that both constructs are intrinsically related to each other (Litt, 1988; Pellino \& Ward, 1998; Rokke et al., 2004). Litt (1988) demonstrated that the benefits of perceived control over pain on pain tolerance were the greatest for those who were most confident (i.e., high self-efficacious) that they were able to exercise this control. In a similar vein, Jensen and Karoly (1991) have stressed that in order to achieve a positive influence on well-being and activity levels in pain patients, the belief in ones personal ability to control pain is as important as the belief in the control strategy itself. Since many of the studies that examined the effects of SE beliefs on the perception of pain have operationalized SE as the belief in one's ability to manage pain by the use of a specific strategy or technique, it might be suggested that these studies can be understood as studies that examined the influence of SE beliefs regarding a perceived control possibility on the pain experience (e.g., Arnstein, 2000; Jackson et al., 2002; Rokke et al., 2004).

The current study was set up to examine the beneficial effects of perceived control and manipulated SE regarding this control on subjective ratings of pain intensity, pain unpleasantness, and fear of pain as provided prior to and following upon experimentally induced pain. It was hypothesized that having perceived control over pain will lead to a decrease in anticipatory and experienced subjective responses to pain, and that these beneficial effects will be especially pronounced in those who possess high SE regarding the control strategy. We also hypothesized 
that no effects of SE will be observed for participants in the no perceived control condition: SE beliefs are only relevant for participants who believe that they have a control possibility.

In addition, the current study examined the influence of two psychological trait constructs, generalized SE and optimism, on anticipatory and experienced subjective responses to pain directly and in interaction with the control and self-efficacy manipulations. Generalized SE was found to be predictive of better coping after surgery, and higher levels of general SE have recently found to be associated with less psychological distress and disability by pain (Schwarzer, Boehmer, Luszczynska, Mohamed, \& Knoll, 2005; Taylor, Dean, \& Siegert, 2006). General SE has been associated with a large set of psychological constructs, amongst which optimism (Luszczynska et al., 2005). Optimism is conceived as a stable personality characteristic that reflects generalized positive expectations about the future and has been proposed as an important personality trait in relation to adjustment to chronic illnesses (Scheier \& Carver, 1992). In prospective studies, high levels of optimism have been found associated with faster recovery and enhanced well-being after a surgical procedure, and higher levels of perceived global recovery and higher quality of life at 6 months post operation (Fitzgerald, Tennen, Affleck, \& Pransky, 1993; Peters et al., 2006; Scheier, Matthews, Owens, Magovern, \& et al., 1989). It is hypothesized that heightened levels of generalized SE and or optimism are associated with lower levels of anticipated and experienced pain, irrespective of the manipulations of SE and optimism. In addition, we explored whether optimism and general SE moderated the effects of perceived control and specific SE. It might be speculated that both the effects of specific SE and of perceived control are especially prominent in individuals who possess elevated levels of generalized SE and or optimism.

\section{METHOD}

\section{PARTICIPANTS}

Participants ( $N=80 ; 59$ female; $M_{\text {age }}=24.49$ years, $s d=6.78$, range $\left.=18-49\right)$ were recruited at Maastricht's university local community. Because pain was induced by administering electrical stimulation on the forearm, wearing a pacemaker, suffering from cardiovascular disorders, thrombosis, or recent injury at the non-dominant forearm formed exclusion criteria. Because current pain complaints at the moment of testing might impact the results in an undesirable way, this was also formulated as an exclusion criterion for participation. All exclusion criteria were formulated at the recruitment posters as prerequisites for participation at the study, and compliance with the criteria was verbally checked when a test appointment was scheduled telephonically, and was once again queried when the participant arrived the test appointment. All participants gave informed consent and received financial compensation for participating. One participant was excluded from data analyses, because for this person, pain tolerance was not reached within the preset boundaries of electrical stimulation intensity (between 0.4 and $10.0 \mathrm{~mA}$ ). As such, data analyses were conducted on 79 participants (59 female, $M_{\text {age }}=24.51$, $s d=6.83$, range $=18$ 


\section{to}

- 49). The Ethics Committee of the University Hospital Maastricht/Maastricht University approved the research protocol.

\section{Materials and Measures}

Electrical stimulation (ES). The electrical stimulation (ES) was delivered through one pair of $\mathrm{Ag} / \mathrm{AgCl}$ electrodes (diameter $=8 \mathrm{~mm}$; interelectrode distance $10 \mathrm{~mm}$ ), filled with hypertonic gel (spectra eeg gel) that was attached to the ventral forearm of the non-dominant arm. The skin area beneath the electrodes was first rubbed with peeling gel to reduce skin resistance. The stimulation consisted of rectangular pulses at a rate of $2 \mathrm{~Hz}$, produced by a constant current stimulator (IDEE, Maastricht University). The electrical stimuli had a duration of $3 \mathrm{~s}$ in the calibration phase and of $16 \mathrm{~s}$ in the experimental phase (procedure section). The intensity of the ES was individually established with a maximum intensity of $10 \mathrm{~mA}$. (see procedure section).

Skin conductance. Skin conductance was (fictively) measured through two $9 \mathrm{~mm}$ Ag-AgCl electrodes that were attached to the middle bones of the index and third finger of the nondominant hand. The participants could monitor the course of their (fictive) skin conductance level over a two-minute period on a computer screen that was located in front of them. All participants were presented with the same skin conductance pattern on the pc, which was created by adding a constant decreasing factor to a genuine skin conductance pattern. This resulted in an optical decrease of the skin conductance curve for all participants. After two minutes, a pre-programmed number was shown in the bottom right corner of the computer screen that reflected the mean (fictive) decrease in skin conductance. This number was generated by the computer and was programmed in such a way that this number could either have a high value $(30 \pm 10 \%)$ or a low value $(10 \pm 10 \%)$, reflecting high or low decrease in skin conductance, respectively.

Anticipatory and experience variables. Visual Analogue Scales (VAS) were administered to assess fear of pain before and during the ES ('How fearful are you of the pain that will accompany the next ES'; ' How fearful were you of the ES'), and anticipated and experienced pain intensity ('How painful do you expect the next ES to be'; 'How painful did you find the ES'), and pain unpleasantness ('How unpleasant do you think the next ES will be'; ' How unpleasant did you find the ES'). Each VAS had a length of $10 \mathrm{~mm}$ anchored with 'not at all fearful/not at all painful/ not at all unpleasant' on one end and 'very fearful/ very painful/ very unpleasant' on the other end. 
Individual difference measures. The Life Orientation Test (LOT; Scheier \& Carver, 1985) was administered to assess dispositional optimism. This measure consists of 12 statements: 4 positively worded (e.g., 'I always look on the bright side of things'), 4 negatively worded (e.g., 'Things never work out the way I want them to'), and 4 filler items. Participants have to respond to each statement on a 4-point Likert scale ranging from 0 (strongly disagree) to 4 (strongly agree). The LOT has good reliability and validity (Scheier \& Carver, 1985; Vinck et al., 1998), and is suitable to obtain a general measure of optimism (Scheier et al., 1994).

General self-efficacy was assessed with the General self-efficacy scale (GSES; Schwarzer \& Jerusalem, 1995). This 10-item questionnaire measures optimistic self-beliefs to cope with a variety of difficult demands in life, more specifically the belief that one's actions are responsible for successful outcomes (e.g., "I can usually handle whatever comes my way"). Participants have to respond to each item on a 5-point Likert scale ranging from 1 (not at all true) to 4 (exactly true). Both the original and Dutch version of the GSES possess good psychometric properties (Scholz, Dona, Sud, \& Schwarzer, 2002).

Manipulation check. The effectiveness of the manipulation of both perceived control and SE was checked immediately after practicing with the biofeedback strategy and the induction of the SE beliefs. At this stage, participants were both acquainted with the strategy, and had received instructions regarding their ability to use the strategy successful (see Procedure). The effect of the perceived control manipulation was checked with the following question: "To what extent do you believe that performing this biofeedback strategy will have an influence on the pain stimulus?" The effect of the manipulation of SE was queried as follows: "How good do you think that you are in practicing the biofeedback strategy in comparison to others?" Both questions were answered on a 10mm VAS anchored with "not at all" and "very much".

\section{Design and Procedure}

For an overview of the experimental procedure see the flowchart in Figure 1. Prior to the start of the experiment, participants were randomly assigned to either the perceived control condition or the neutral condition, based on differential instructions as provided prior to the experimental session. Within the perceived control condition and the neutral condition, participants were randomly assigned to a high SE group and a low SE group. This way, four groups were created: (1) perceived control-low SE ( $N=21, M_{\text {age }}=24.14$, sd =6.76); (2) perceived control-high SE $\left(\mathrm{N}=20, M_{\text {age }}=26.45, s d=8.67\right)$; (3) neutral-low $\mathrm{SE}\left(\mathrm{N}=19, M_{\text {age }}=23.63, s d=6.68\right)$; and (4) neutralhigh SE group ( $\left.N=19, M_{\text {age }}=23.74, s d=4.63\right)$. Participants were tested individually in a soundattenuated room in the university building, specifically designed for experimental procedures and the use of the electrical stimulator. The experimental procedure was identical for all participants, and differences between the groups could be ascribed to differences in instructions only. 


\section{tomence}

Written and verbal instruction by participant information: perceived control / neutral group

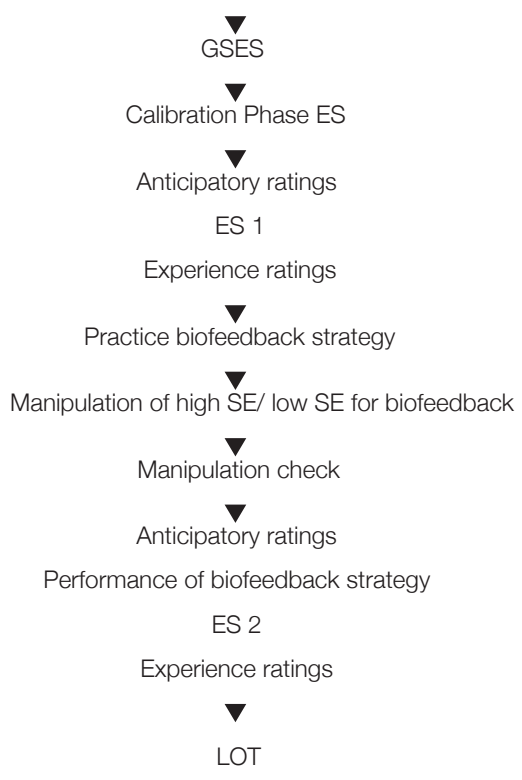

FIGURE 1. Flowchart for the experimental procedure.

Upon arrival to the laboratory, participants in the perceived control condition were instructed that they took part in a study that aimed to examine the beneficial influence of performing a biofeedback strategy on the pain experience. Participants in the neutral condition were instructed that they took part in a study that aimed to examine how the administration of a pain stimulus might influence the efficacy of performing a biofeedback strategy. These instructions were provided in two ways. First, participants read these in the participant information letter that accompanied the informed consent form, and which was mandatory to read prior to giving informed consent. Second, the experimenter explained the goal of the study verbally, thereby stressing the aim of the biofeedback strategy in both conditions. Participants then completed the GSES in order to ensure that answers on this measure were not influenced by the SE manipulations that were implemented in a later stage of the experiment. The electrodes for the ES were attached and the calibration phase was started.

Calibration phase and baseline stimulus (ES 1). The individual intensity level of the ES was determined on the basis of the individual tolerance level for this specific pain stimulus (see Janssen et al., 2004; Peters et al., 2002; Roelofs, Peters, Deutz et al., 2005). The calibration phase consisted of the administration of series of ESs (duration $=3 \mathrm{~s}$ ) of gradual increasing intensity, with a start intensity of $0.4 \mathrm{~mA}$ and a stepwise increase of $0.4 \mathrm{~mA}$. Participants had to indicate pain treshold (the lowest intensity level that is rated as painful) and pain tolerance (the highest intensity 
level that is rated as tolerable). The participant could communicate with the experimenter through an intercom that connected the test room with the adjacent experimenter room. The experimenter started each ES manually and could stop the presentation of the ES instantly if necessary. In addition, participants had an emergency button at their disposal, which could be pushed to break off the ES instantaneously in case of extreme distress. The procedure was ended when the participant indicated that pain tolerance was reached, and was repeated four times with 1 min intervals in between them. Taking into account possible sensitization effects, we disregarded the first ES series, and the highest tolerance level out of the last three trials was chosen as the intensity that would be administered as the experimental ES. Before the experiment continued, however, it was tested whether this intensity level could be tolerated for $16 \mathrm{~s}$, corresponding to the duration of the ES that would be adopted in the experimental phase. This was done by administering the ES for $16 \mathrm{~s}$ under the instruction that participants had to indicate if and when the stimulus was no longer tolerable for them. When the ES was not tolerable for $16 \mathrm{~s}$, the intensity level was decreased in steps of $0.4 \mathrm{~mA}$ and the procedure was repeated, just until the ES was tolerable for $16 \mathrm{~s}$. After the calibration phase, a 2-minute break was introduced upon which participants rated anticipated pain intensity, pain unpleasantness, and fear of pain. The first experimental ES (ES 1) was then administered for $16 \mathrm{~s}$, and ratings of experienced pain intensity, pain unpleasantness, and fear of pain were provided.

Concretization Biofeedback strategy. The skin conductance electrodes were attached and participants received instructions about how to perform the (fictive) biofeedback strategy. This strategy consisted of making a squeeze movement with the dominant hand (open and close at a regular pace) for a total duration of 2 min while the arm rested stretched out on the table. Participants were instructed to concentrate and focus attention on this movement while performing it. Further instructions regarding the rationale and objective of this strategy differed for participants in the perceived control and the neutral group. Participants in the perceived control group were led to believe that the biofeedback strategy would enable them to control their pain experience in a positive way. They were told that lower pain is experienced in areas with low skin conductance, and that the squeezing activity leads to reduction in skin conductance in inactive areas (nondominant arm side, i.e., site of ES administration). They were furthermore told that it has been scientifically proven that diverting attention away from the pain site to something else can lead to a significant reduction of pain, because relaxation and concentration on things other than pain lead to lowered skin conductance. Participants in the neutral group were told that scientific medical research has demonstrated that individuals are capable of reducing their own skin conductance, for example through the use of biofeedback procedures. They were told that it is yet unclear however, whether such strategies are still effective in reducing skin conductance level when a pain stimulus is administered during performance of the strategy. After these instructions, participants in both groups practiced the biofeedback procedure, while the skin conductance was fictively measured and a skin conductance curve ran synchronously on the computer screen in front of the participants. 


\section{$\Uparrow$ chapter 8}

Self-efficacy manipulation. After two minutes, the experimenter indicated that participants could stop the squeezing movement, and a number that represented the mean decrease in skin conductance appeared in the right bottom corner of the computer screen. SE beliefs were then induced by comparing this number to a (fictive) norm table. Several studies have shown that comparing performance of persons with that of their peers is an effective way to manipulate selfefficacy expectations (Litt, 1988). Participants in the high SE group were told that they were very good in comparison to their peers in reducing their skin conductance, while participants in the low SE group were told that they were rather bad in reducing their skin conductance. This SE feedback was strengthened by showing participants the norm table. In order to increase credibility of the manipulation, participants were then instructed to practice the biofeedback strategy once again, to verify whether the first outcome was not biased because it only constituted the first practice with the strategy. The number that reflected the decrease in skin conductance was programmed to result in a comparable, but not identical value as before, and enabled the experimenter to stress whether someone was really good or really bad in reducing the skin conductance. Next, participants completed the manipulation check questions.

Test stimulus (ES2). BeforeES2 participants rated anticipated pain intensity, pain unpleasantness, and fear of pain. They were then instructed to initiate the biofeedback strategy. Ten seconds later, the second experimental ES (ES 2) was administered and participants performed the strategy until the ES ended (after $16 \mathrm{~s}$ ). This time, the skin conductance curve was not shown to participants. Immediately after the ES, participants rated the experienced pain, pain unpleasantness, and fear of pain. When data collection was completed, all participants received a debriefing letter, explaining the exact research hypotheses and the implemented manipulations.

\section{StATISTICAL ANALYSIS}

The effectiveness of the manipulations of perceived control and SE was tested with independent samples t-tests on the manipulation check questions, with Perceived Control (control vs. no control) and SE (high vs. low) as group factors, respectively.

The effects of the manipulations of Perceived Control and SE on the anticipatory and experience variables were analyzed with 2x2x2 mixed ANOVA's with Time (ratings associated with experimental ES1 vs. ratings associated with experimental ES 2) as within-subjects factor and SE (high vs. low) and Perceived Control (control vs. neutral) as between-subjects factors. Resulting main effects and interaction effects were further explored with post hoc t-tests.

Next, mediation analyses following the recommendations by Baron and Kenny (1986) were conducted in order to determine whether the expectations regarding ES 2 mediated the relation between the manipulations and the experience ratings as provided in response to ES 2. A necessary condition for mediation is that a significant linear relation exists between predictor and mediator, predictor and outcome, and mediator and outcome variable. Mediation is then specified by a significant decrease in or total disappearance of the significant prediction of the predictor 
variable on the outcome variable, when both mediator and predictor are considered as predictors of the outcome variable (Baron \& Kenny, 1986). As such, four regression models are conducted in order to test for mediation effects for the dependent variable.

To examine the influence of general SE and optimism on the pain ratings, we first calculated partial correlations between the personality traits and VAS ratings accompanying ES 1, hereby controlling for the effect of perceived control. Furthermore several regression analyses were conducted in order to explore the predictive value of the manipulations, the personality constructs, and their interactions in the prediction of rating scores accompanying ES 2. In these analyses, both perceived control and SE were entered as Dummy variables $(0,1)$ in the first step of each model. The additional predictive value of GSES and LOT was tested by entering these variables separately in the second step of the model. Last, we tested whether generalized SE or dispositional optimism moderated the effects of the manipulation by entering the interaction terms GSES x perceived control, GSES $\times$ SE, LOT $x$ perceived control, and LOT $\times$ SE one by one in the final step of the model for the pain intensity, pain unpleasantness and fear of pain.

\section{RESULTS}

Pain threshold, pain tolerance and effectiveness of the manipulation. Mean pain threshold level in the study was $2.75 \mathrm{~mA}(s d=1.15)$, and mean pain tolerance level was $4.30 \mathrm{~mA}$ $(s d=1.70)$. The assignment to either the perceived control or the neutral condition at the start of the experiment did not result in differences between both groups for pain threshold $\left(M_{\mathrm{p}}=2.80 \mathrm{~mA}\right.$; $\left.M_{n}=2.68 \mathrm{~mA}\right)$ and pain tolerance $\left(M_{\mathrm{p}}=4.54 \mathrm{~mA} ; M_{\mathrm{n}}=4.04 \mathrm{~mA}\right)$.

Supporting the effectiveness of the SE manipulation, participants in the high SE group believed to a larger extent $(M=70.43, s d=14.63)$ that they were good in reducing their skin conductance with the biofeedback strategy than participants in the low SE condition $(M=23.08$, $s d=14.77)$, with $t(77)=-14.32 ; p<.001$. No significant difference was observed between the perceived control group $(M=47.44, s d=21.71)$ and the neutral group $(M=45.66, s d=19.23)$ for the control manipulation check, $t(77)=-.39, p>.10$. Thus, both groups believed to the same moderate extent that the biofeedback strategy would have an influence on the pain stimulus. Further post-hoc t-tests demonstrated an effect of SE on the control manipulation check $(t(77)=$ $-6.58, p<.001)$, with higher scores in the high SE group $(M=58.92, s d=14.79)$ than in the low SE group $(M=34.55, s d=17.94)$. In addition, participants in the perceived control-high SE group ( $M$ $=61.80, s d=16.08)$ assigned higher scores to the control manipulation check question compared to participants in the neutral -high SE group $(M=55.89$; $s d=13.03)$, whereas participants in the perceived control-low SE group $(M=33.76$; $s d=17.15)$ and the neutral-low SE group $(M=35.42$; $s d=19.22)$ assign comparable scores to the manipulation check question. 
Effects of perceived control and specific SE on anticipatory ratings. Descriptive statistics on the anticipatory ratings accompanying ES 1 and ES 2 are presented in Table 1.

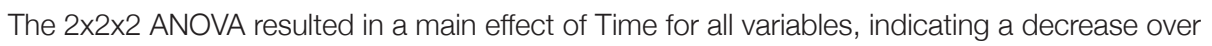
time for the ratings of pain intensity $(F(1,75)=29.82, p<.001)$, pain unpleasantness $(F(1,75)=$ $14.10, p<.001)$, and fear of pain $(F(1,75)=15.68, p<.001)$. A significant Time $\times$ SE interaction was found for pain intensity $(F(1,75)=6.31, p<.05)$, which was explained by a significant larger decrease in pain intensity ratings from ES 1 to ES 2 in the high SE group $(M=13.74, s d=16.18)$ compared to the low SE group $(M=5.05, s d=14.09), t(77)=-2.55, p<.05$. Further independent samples t-tests indicated that the effect of SE was significant in the perceived control condition only $(t(39)=-2.51, p<.05)$, with a larger decrease in pain intensity ratings from ES 1 to ES 2 in the perceived control-high SE group $(M=16.45, s d=14.59)$ than in the perceived control-low SE group $(M=4.90, s d=14.88)$. The $2 \times 2 \times 2$ ANOVA furthermore resulted in a Time $\times$ Perceived Control $x$ SE interaction for the pain unpleasantness ratings $(F(1,75)=4.08, p<.05)$, specified by a significant decrease in pain unpleasantness ratings in the perceived control-high SE group only, $t(19)=2.55, p<.05$. Furthermore, the effect of perceived control was significant for the fear of pain rating $(F(1,75)=4.01, p<.05)$, indicating higher fear of pain ratings in the neutral group $(M=27.92)$ compared to the perceived control group $(M=19.12)$. This overall main effect was further examined with post-hoc t-tests on the fear of pain ratings associated with ES 1 and ES 2 separately. Results indicated lower fear of pain ratings in the perceived control group $(M=22.76$, $s d=23.11)$ than in the neutral group $(M=30.79, s d=22.07)$ in the prospect of ES 1 already, $t(77)=1.58, p=.12$. The difference between fear of pain ratings prior to ES 2 in the perceived control group $(M=15.68, s d=18.13)$ and the neutral group $(M=25.05$, $s d=19.80)$ was significant $(t(77)=2.20, p<.05)$.

TABLE 1 Means (sd) for the anticipated VAS ratings, displayed per condition ( $N=79)$

\begin{tabular}{|c|c|c|c|c|c|}
\hline \multirow[b]{3}{*}{ Anticipatory ratings } & \multicolumn{2}{|l|}{ Neutral group } & \multicolumn{2}{|c|}{ Perceived control group } & Total \\
\hline & Low SE & High SE & Low SE & High SE & \\
\hline & $M \quad(s d)$ & (sd) & (sd) & (sd) & (sd) \\
\hline Pain intensity ES 1 & $57.47(20.24)$ & $60.26(16.33)$ & $61.43(11.15)$ & $55.25(21.33)$ & $58.63(17.46)$ \\
\hline Pain intensity ES 2 & $52.26(19.36)$ & 49.37 (19.69) & $56.52(15.48)$ & $38.80(25.62)$ & $49.29(21.02)$ \\
\hline Pain Unpleasantness ES 1 & $66.74(21.27)$ & $63.37(22.62)$ & $67.14(11.49)$ & 65.05 (22.79) & $65.61(19.62)$ \\
\hline Pain Unpleasantness ES 2 & $58.37(21.58)$ & $60.68(24.91)$ & $63.05(15.81)$ & $50.85(28.79)$ & $58.27(23.20)$ \\
\hline Fear of pain ES 1 & $32.68(25.60)$ & $28.89(18.41)$ & $26.38(24.35)$ & 18.95 (21.69) & $26.62(22.83)$ \\
\hline Fear of pain ES 2 & $29.42(23.61)$ & $20.68(14.44)$ & $20.05(21.41)$ & $11.10(12.91)$ & $20.19(19.41)$ \\
\hline
\end{tabular}


Effects of perceived control and specific SE on experience ratings. Table 2 depicts descriptive statistics on the experience ratings accompanying ES 1 and ES 2. The 2x2x2 mixed ANOVA on the experience ratings resulted in a main effect of Time, indicating a decrease over time on all variables, with $F(1,75)=33.34, p<.001$ for the rated pain intensity, $F(1,75)=31.93$, $p<.001$ for the rated pain unpleasantness, and $F(1,75)=19.10, p<.001$ for the rated fear of pain. The Time $\times$ SE interaction was significant for pain intensity $(F(1,75)=5.07, p<.05)$, and was explained by a significant larger decrease in pain ratings from ES 1 to ES 2 in the high SE group $(M=13.56, s d=14.92)$ compared to the low SE group $(M=6.05, s d=15.49), t(77)=-2.20, p$ $<.05$. Further independent samples t-tests demonstrated that this effect of SE was marginally significant for the neutral group $(t=-2.02, p=.05)$, but not for the perceived control group $(t=$ $-1.08 ; p>$.05). For the experienced pain unpleasantness ratings, no effects of perceived control or SE were observed , $p>.05$. The 2x2x2 ANOVA furthermore revealed significant main effects of perceived control $(F(1,75)=5.06, p<.05)$ and $\operatorname{SE}(F(1,75)=4.70, p<.05)$ for the fear of pain variable, indicating higher fear of pain ratings in the neutral group $(M=21.60, s d=15.67)$ than in the perceived control group $(M=13.71, s d=16.43)$, and higher fear of pain ratings in the low SE group ( $M=21.28, s d=18.79)$ than in the high SE group $(M=13.64, s d=12.76)$. The main effect of perceived control was further explored with separate t-tests on the ratings provided in response to ES 1 and ES2. A trend towards significant lower fear of pain ratings in the perceived control group ( $M=16.56 s d=19.39)$ than in the neutral group $(M=23.87, s d=17.39)$ was observed in response to ES 1 already $(t(77)=1.76, p=.08)$. In response to ES 2 , the difference between the perceived control group $(M=10.85, s d=15.04)$ and the neutral group $(M=19.34, s d=15.37)$ was significant $(t(77)=2.48, p=.01)$. The main effect of SE was clarified by a trend towards a significant Time $\times$ SE interaction $(F(1,75)=2.77, p=.10)$, indicating a larger decrease in fear of pain ratings in the high SE group $(M=7.07, s d=10.90)$ than in the low SE group $(M=3.25, s d=$ 9.77). Additional post hoc t-tests demonstrated a significant difference between the high and the low SE group ( $M=10.10, s d=10.55$ versus $M=19.65$, $s d=18.39)$ on the fear of pain variable in response to ES 2 only $(t(77)=2.82, p=.006)$.

TABLE 2 Means (sd) for the experienced VAS ratings, displayed per condition $(N=79)$

\begin{tabular}{|c|c|c|c|c|c|}
\hline \multirow[b]{3}{*}{ Experience ratings } & \multicolumn{2}{|l|}{ Neutral group } & \multicolumn{2}{|c|}{ Perceived control group } & Total \\
\hline & Low SE & High SE & Low SE & High SE & \multirow[b]{2}{*}{$M \quad(s d)$} \\
\hline & $M \quad(s d)$ & $M \quad(s d)$ & $M \quad(s d)$ & $M \quad(s d)$ & \\
\hline Pain intensity ES 1 & $53.63(21.50)$ & 58.95 (18.69) & $62.29(12.60)$ & $50.10(29.28)$ & $56.32(21.44)$ \\
\hline Pain intensity ES 2 & $51.58(23.72)$ & $46.32(21.98)$ & $52.62(17.20)$ & 35.65 (31.76) & $46.56(24.69)$ \\
\hline Pain Unpleasantness ES 1 & $63.21(23.35)$ & $64.74(24.72)$ & $66.38(15.47)$ & $66.60(28.03)$ & $65.28(22.84)$ \\
\hline Pain Unpleasantness ES 2 & $56.42(24.65)$ & $52.89(26.69)$ & $55.62(18.41)$ & $51.85(34.26)$ & $54.20(26.09)$ \\
\hline Fear of pain ES 1 & $26.05(18.87)$ & $21.68(16.00)$ & $20.05(21.75)$ & $12.90(16.31)$ & 20.08 (18.70) \\
\hline Fear of pain ES 2 & $24.37(17.53)$ & $14.32(11.19)$ & $15.38(18.51)$ & 6.10 (8.33) & $14.94(15.70)$ \\
\hline
\end{tabular}




\section{$\Uparrow$ chapter 8}

Examining mediating effects of the anticipatory variables on the experience variables. The analyses of variance indicated an effect of SE on both anticipatory and experienced pain intensity ratings. It might be suggested that anticipatory ratings mediate the relation between SE and experience ratings. This was examined with mediation analyses following the recommendations of Baron and Kenny (1986) (Figure 2). The regression analyses indicated that SE was a significant predictor of the experienced pain intensity (path $a ; B=-.23, t=-2.07, p=.04$ ), and of anticipatory pain intensity (path $b ; \beta=-.25, t=-2.29, p=.02$ ). Furthermore, the experienced pain intensity was significantly predicted by anticipated intensity ratings (path $c ; B=.77, t=10.61, p<.001$ ). When both SE and the anticipatory pain intensity ratings were simultaneously entered as predictors of experienced pain intensity in the last step of the mediation model, SE no longer resulted as a significant predictor of the experienced pain intensity ( $B=-.04, t=-.50, p=.62)$. This finding confirms a full mediation of the anticipatory pain intensity on the relation between SE and experienced pain intensity.

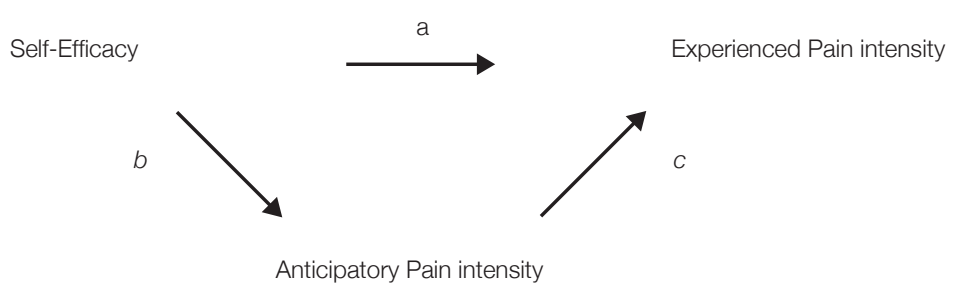

FIGURE 2. Mediation model

Association between the personality constructs and pain expectancies and experiences. The scores on the GSES $(M=31.58, s d=3.30$, range $=25-40)$ and the LOT ( $M=$ 30.82 , $s d=3.71$, range $=21-39)$ correlate significantly $(r=.47, p<.001)$. The partial correlations between the trait measures and the VAS ratings associated with ES 1 resulted in significant correlations between LOT and anticipatory fear of pain ( $r=-.36, p=.001)$, LOT and fear of pain as experienced ( $r=-.33, p=.003)$, and GSES and the anticipatory fear of pain $(r=-.22, p=.05)$.

The prediction of the VAS ratings that were given in response to ES 2 by the manipulations, the trait measures, and their interactions was explored with linear regression analyses (see statistical analyses section for an overview of the procedure that was followed in building the regression models). Entering the interaction terms as predictor of the dependent variables in the last step of each model did not result in additional predictive value for the subjective pain ratings. The only exception was the observation of significant predictive value of the GSES $\times$ SE interaction ( $B=$ $2.74, t=2.73, p=.008)$ for the anticipatory fear variable $\left(F(4,74)=5.61, p=.001, R^{2}=.23\right)$. Higher scores on the GSES were associated with lower ratings of anticipatory fear of pain in the low SE group $(r=-.29, p=.07)$, but not in the high SE group $(r=-.03, p=87)$. 


\section{Discussion}

The current study examined the effects of perceived control and SE on the subjective evaluation of experimentally induced pain. It was hypothesized that having perceived control over pain would lead to a reduction in pain intensity, pain unpleasantness, and fear of pain ratings as provided prior to and following upon pain induction, and this beneficial influence was expected to be especially enhanced for those who possess high SE beliefs regarding their ability to exert control over pain. In line with this hypothesis, results demonstrated that participants in the high SE condition expected the second ES to be significantly less intense and less unpleasant when they had perceived control over the pain. Furthermore, participants in the high SE condition evaluated the second pain stimulus as significantly less intense, and this was independent of the control manipulation. Perceived control significantly influenced fear of pain ratings. These results demonstrate that the combination of having at one's disposal a technique that can reduce the pain experience and a high self-efficacy of applying this technique leads to a reduction in the pain intensity and pain unpleasantness that one expects as well as in the actually experienced pain intensity. Although the predicted control by self-efficacy interaction was only significant for the expected pain unpleasantness ratings, expected and experienced pain intensity ratings consistently showed the largest decreases in the high perceived control - high self-efficacy condition. Indeed, for the expected pain intensity ratings, the effect of the self-efficacy manipulation reached significance within the perceived control group only.

Previous studies have demonstrated the mutually strengthening beneficial effects of perceived control and associated SE beliefs on pain tolerance and endurance of pain (Jensen \& Karoly, 1991; Litt, 1988; Rokke et al., 2004). This study adds to these findings by demonstrating similar effects for the subjective experience of pain. Moreover, further analysis indicated that the decrease in experienced pain intensity may be mediated by the expected pain intensity, i.e., high self-efficacy beliefs regarding the ability to exert control over pain may lead to less pain expectations which in turn leads to actually less pain experience. A direct relation between pain expectancies and pain reports has been reported in both laboratory and clinical studies, and may be accounted for by the self-confirming nature of the pain expectancies (e.g., Devine \& Spanos, 1990; Kirsch, 1997; Subotnik \& Shapiro, 1984). Outside the domain of pain, the self-confirming effects of response expectancies have amongst others been found in placebo effects and prevention and treatment effects on anxiety disorders, substance abuse and depression (for an overview see Kirsch, 1997).

It may be noted that several previous studies have shown that the introduction of a pain reducing (cognitive) strategy or technique leads to reductions in expected pain intensity (Baker \& Kirsch, 1991; Bandura, 1983; Devine \& Spanos, 1990). Moreover, it has been hypothesized that when pain expectancies are dependent upon the performance of a specific skill, they will be determined by SE beliefs for that skill (Baker \& Kirsch, 1991; Bandura, 1983). In line with this suggestion, performing the biofeedback strategy in the present study can be conceived as a skill that one has to master in order to obtain beneficial effects on the following pain experience. Taken together, the present study stresses the importance of high SE beliefs regarding the ability to exert a specific control strategy in order to observe beneficial influences on the subjective perception of pain (Arnstein, 2000; Jackson et al., 2002; Rokke et al., 2004). 


\section{k $k$ aument}

An unexpected finding was that the manipulation of self-efficacy also led to a substantial decrease in expected and experienced pain intensity in the group that was supposed to have no perceived control. The decrease in the neutral - high self-efficacy condition was somewhat less strong than in the perceived control - high self-efficacy condition but the time by control by selfefficacy effect was non-significant. Based upon this observation, it may be speculated that the perceived control manipulation was not as effective as we had intended. The manipulation check revealed that participants in the neutral condition believed to the same moderate extent that the biofeedback strategy would influence the pain stimulus as participants in the perceived control condition. In retrospect the groups may not have been distinctive enough with respect to perceived control beliefs because both groups learned a biofeedback procedure and applied this procedure during the second pain stimulus. Although we never told the participants in the neutral group that the procedure would affect pain experience, we cannot rule out the possibility that participants' expectations on the strategy were affected by the general knowledge that people have about the use of biofeedback. The cover-up story in the neutral group that we were interested in whether people could still effectively apply biofeedback when in pain, may not have been sufficient to alter their pre-existing expectations. This may be especially true in the high self-efficacy condition: these participants may have been convinced that since they were very efficacious in applying the technique, the pain stimulus would not deter them from using the technique as a means to influence pain. The manipulation check indeed indicated that the belief that the biofeedback strategy would influence pain was more determined by the self-efficacy manipulation than by the control manipulation. In addition, caution is warranted in interpreting the manipulation check of perceived control, since this question asks about 'the extent to which the respondent believes that the biofeedback strategy will have an influence on the pain stimulus'. It can be argued that the presentation of this particular question to participants in the neutral group might have induced perceived control expectations on biofeedback strategy as a possible technique to influence the pain stimulus.

An alternative explanation for the observed beneficial influence of high SE in the neutral condition might originate by assuming unanticipated general beneficial effects to influence the pain experience that result from the mere conviction of being good in something. At least one study has come to our attention in which beneficial effects on pain tolerance were observed in participants who had induced high SE beliefs on the performance on a task that was not specifically related to pain or its reduction (i.e., a mathematical problem solving task) (Bandura, Cioffi, Taylor, \& Brouillard, 1988). In addition, it might even be speculated that participants in the neutral group with high SE beliefs on the biofeedback strategy have benefited from the fact that they practiced a skill in which they were good at the same time that the pain stimulus was administered. Hence, performing the biofeedback strategy during ES2 might serve as a positive distractor from the pain, resulting in reduced experienced pain intensity. In a similar vein, the effect of SE on the reduction of experienced fear of pain might be attributed to this same positive distractor effect. These alternative explanations are of course post-hoc explanations and need further addressing in future studies.

Although we have reasons to assume that the control manipulation may have been suboptimal, perceived control did affect fear of pain. Interestingly, the perceived control group 
already displayed lower fear levels than the neutral group at ES1. At this time in the experiment, the only difference between the neutral and control group was the information that they had received in the participant information letter and through the pre-experimental instructions. Participants in the perceived control condition were informed that this was an experiment to study the effects of biofeedback on pain and that they would learn a technique to control pain. Participants in the neutral condition never received information that they would learn a control technique, and since the biofeedback technique itself was not introduced yet, they probably had no expectations in this direction. Thus it seems that the mere expectation that later on in the experiment a control possibility will be offered is sufficient to lower fear of pain. The effect remained during the second pain stimulus, with the actual practice of the technique and the self-efficacy manipulation not further adding to this effect, i.e., there was no time $x$ control or time $x$ self-efficacy effect for fear.

In addition to the effects of perceived control and specific SE beliefs, we were interested in the influence of optimism and generalized SE on the subjective pain evaluation. Correlations between these stable trait constructs and both the expectancy and experience ratings as provided in response to the first ES demonstrated that optimism correlated inversely with anticipatory and experienced fear of pain, while high levels of general SE were found to be associated with lower levels of anticipatory fear as well. These correlations offer additional evidence for the hypothesized positive influence of both optimism and general SE on the perception of aversive events (Luszczynska et al., 2005; Scheier \& Carver, 1992). In addition, we explored whether the personality traits moderated the effects of the manipulations by entering the interaction terms between the manipulations and the trait constructs in a multiple regression analyses. These analyses demonstrated that anticipatory fear of pain was significantly predicted by the interaction between generalized SE and manipulated SE. Generalized SE was a significant determinant of the fear that is elicited by the forecast of pain in the low manipulated SE condition only. Thus, all participants benefited from the induction of the believe that they are good in applying the pain reduction technique, but when low self-efficacy was induced individuals with high generalized selfefficacy beliefs may still hold on to their a prior beliefs.

Some limitations and recommendations are to be considered in interpreting the current results. The choice for a biofeedback strategy as control technique might have impacted the results in an undesirable way. Although we choose to use of a fictitious strategy that was not based on any existing or currently practiced treatment approach, we cannot entirely rule out that this strategy has raised pain-reducing expectations in participants who possess prior knowledge on the well-acknowledged benefits of biofeedback strategies in diminishing psychopathological complaints. This would have been particularly problematic for pain ratings made by participants in the neutral control group, who are not assumed to foresee beneficial effects of the strategy on the pain experience. In addition, further research should devote attention to the ecological validity and the generalizability of the current findings. Participants in this study were all healthy students, and were well aware of the fact that the pain stimulus would be administered in a controlled way and for a preset limited number of times. Replication of the current findings in a patient population is therefore advisable, in order to examine whether the effects of manipulated SE beliefs on a control strategy has beneficial effects on the subjective perception a long-term pain experience as well.

Despite these shortcomings, the current study has demonstrated that the induction 


\section{Kanter}

of high SE beliefs regarding a pain control method elicits anticipations of less intense and less unpleasant pain for an upcoming pain experience. Moreover, the expected pain intensity is found to be directly predictive of the pain that is reported after experiencing the electrical stimulus. These findings are interesting in the light of treatment approaches aiming at reducing pain and disability. As such, they suggest that if one wants to achieve both objective and subjective reductions in pain and disability, it is important to not only offer the possibility to exert control over the pain, but to induce high SE beliefs regarding this control opportunity as well. These high SE beliefs might for example be induced by means of providing positive feedback and motivational support to the attempts that patients undertake in managing their pain.

\section{ACKNOWLEDGEMENTS}

The authors would like to thank Prof. Dr. Johan Vlaeyen for his thoughtful and very useful comments on an earlier draft of this manuscript. Furthermore, the authors would like to express their gratitude to Nathalie van Aken for her help with the recruitment of participants and data collection, and to Theo van Aerts and Charlie Bonnemayer for programming and implementing the fictitious skin conductance program and the electrical stimulator. This research was supported by a grant from the Netherlands organisation for Scientific Research (NWO) with grant no. 015-001050. 


\section{- - \\ Chapter 9}

Summary and General Discussion 
Contemporary cognitive fear-avoidance models of chronic musculoskeletal pain have emphasized that the tendency to exaggerate the negative meaning and consequences of pain and the associated fearfulness of pain, (re)injury, or movement, constitute risk factors for the development and persistence of chronic pain complaints (Vlaeyen \& Linton, 2000). Extending on this perspective, the main aim of the current thesis was to provide more insight into psychological factors and mechanisms that can predispose or protect persons towards responding to physical threat in a fearful or catastrophic manner, and as such constitute putative vulnerability factors for the development of chronic pain. More specifically, starting from the conceptualisation of pain as an emotional disorder that comprises a large cognitive component (Merskey \& Bugduk, 1994; Turk \& Okifuji, 2002), the relative importance of various pain-related anxiety constructs (chapter 2 and 3 ), as well as the relation between individual levels of these constructs and the cognitive processing of pain-related information (chapters 4, 5, 6, and 7) were examined. Furthermore, this thesis aimed to contribute to the scarce number of studies that is currently available on cognitive mechanisms that can protect, rather than predispose, persons against responding to physical threat in a maladaptive way in one study (chapter 8). The current chapter intends to provide a summary and an integrative discussion on the findings of the studies that were described in the preceding chapters.

\section{SUMMARY OF MAIN FINDINGS}

\section{Part l: Establishing the role of injury/illness sensitivity in the context of pain and exploring the evidence for a hierarchical model of pain-related anxiety constructs}

In chapter 2, the role of injury illness sensitivity (IS) and its putative differential predictive value in relation to anxiety sensitivity (AS) in the explanation of fearful responses to pain was addressed in a survey study and an experimental pain induction study. In line with our hypotheses, IS resulted as the single best predictor for fear of pain (FoP) and pain catastrophizing (PC) in the survey study, and for subjective anticipatory fear ratings in the pain induction study. These results were supportive of the suggestion that IS might be an important factor to be considered in further research that is directed at understanding fearful responses to pain (Carleton et al., 2005; Keogh \& Asmundson, 2004). Corroborating previous research findings, chapter 2 furthermore demonstrated that besides IS, AS remains a distinctive valuable factor to be considered in the explanation of fearful responses to pain as well (Asmundson et al., 1999; Asmundson et al., 2000). More specifically, when the multi-componential pain anxiety symptoms scale (PASS) was taken as the self-report index of pain-related fear (McCracken \& Dhingra, 2002), IS and AS were found to be differentially predictive of the escape/avoidance subscale and the physiological anxiety subscale of this measure, respectively, whereas both constructs possessed equally predictive power for the fearful appraisal of pain and the cognitive anxiety subscales of the PASS. In addition, chapter 2 offered support for the distinctiveness of AS and IS by demonstrating that both constructs 
accounted independently for variance in trait anxiety in linear regression analyses that tested the unique predictive value of three fundamental fears (IS, AS, and fear of negative evaluation (FNE) for trait anxiety.

In chapter 3, further empirical evidence for the hierarchical model was sought by conducting two exploratory multivariate classification analyses (i.e., multidimensional scaling (MDS) and additive tree analysis (ADDTREE) on the similarity data that were obtained from a similarity card-sorting task on the separate items of questionnaires that are most prevalently used to assess each pain-relevant anxiety construct that resides in the model. This study was predominantly motivated by the observation that the various self-report measures that are used to assess each separate anxiety construct in pain research are closely interrelated and show a certain degree of content-overlap (Hadjistavropoulos et al., 2004; Keogh \& Asmundson, 2004). Even though the psychometric qualities (e.g., reliability, validity, and factor structure) of these self-report measures have been well demonstrated, it can be questioned whether respondents are sensitive enough for recognizing the slight differences in the content of the individual items of these instruments. Hence, chapter 3 examined which clusters of items were identified within the whole set of individual items on the basis of their perceived similarity with an ADDTRREE cluster analysis. This analysis resulted in a theoretically well interpretable tree solution, clustering individual questionnaire items into meaningful groups that corresponded largely to either the specific subscales or the total composition of the self-report measures included in the study. Thus, despite overlap in semantic meaning and formulation of the individual items, persons seem to be well capable to differentiate between these items and their intended underlying meaning. Chapter 3 furthermore examined whether support could be found for the specificity dimensionality that is assumed to run through the hierarchical model with MDS analysis (Keogh \& Asmundson, 2004; Lilienfeld et al., 1993; Watson \& Clark, 1992). Two interpretable dimensions resulted from the MDS: (1) a pain-specific - general concerns dimension echoing the suggested specificity in the model as formulated by the advocates of the hierarchical model (Lilienfeld et al., 1993; Watson \& Clark, 1992), and (2) an inter - intra-personal concerns dimension. Given the fact that the hierarchical model aims to reflect 'negative emotional constructs involved in pain', this latter dimension can be easily understood within the perspective that pain-related anxiety and concerns are assumed to be directed at the individual's personal state, as well as at the impact of the pain or disability on the individual's social environment, e.g., work, evaluation by others (McNeil \& Vowles, 2004; Morley \& Eccleston, 2004). Taken together, the findings in chapter 2 and 3 favour further work with IS and the other unitary anxiety constructs in subsequent research.

\section{Part II: Experimental studies on the link between personality factors, cognitive mechanisms, and responses to pain}

In chapters 4, 5, 6, and 7, both implicit and explicit testing paradigms were used to examine the cognitive processing of health-threatening or pain-related information in function of elevated levels of pain-related anxieties. Extending on the conceptualisation of pain as an 
emotional disorder and the central role of (pain-related) anxiety in the onset and maintenance of pain complaints, these studies were largely fed by the extensive body of research that is already available on the role of cognitive processing biases in other emotional disorders, like anxiety and depression (Beck \& Clark, 1997; Eysenck, 1997; Mathews \& Mackintosh, 1998; Mathews \& MacLeod, 1994; McNally, 1995; Teachman, 2005).

Using an implicit association measure (EAST; De Houwer, 2003) chapter 4 examined whether elevated levels of AS and IS were associated with an enhanced automatic threat appraisal towards pain and health-threatening word stimuli. Following information-processing theory, such an automatic threat appraisal might prompt reflexive and spontaneous dysfunctional responses to pain, that are not under voluntarily control of the individual (Beck \& Clark, 1997; Fazio \& Olson, 2003; Nosek, 2007). Results demonstrated that in general, persons showed an automatic threat appraisal towards the pain and health stimuli incorporated in the task. More importantly, and supporting the main hypothesis of chapter 4, elevated levels of IS, and to a lesser extent AS were found to be positively associated with this automatic threat appraisal. Extending on the suggested differential predictive power of AS and IS for responses to pain in chapter 2, chapter 4 additionally examined the differential and independent predictive value of both constructs for two behavioural correlates of pain; that is, the use of health care services and the engagement in protective and preventive health behaviour. Results demonstrated AS and IS to be independently and uniquely predictive of the use of health care services and the engagement in preventive and protective health behaviours, respectively. Based on this finding, it was suggested that both AS and IS might be predictive of divergent behavioural responses to pain.

The findings in chapter 4 were congruent with the cognitive model of emotional disorders in demonstrating the automatic activation of negative associations with pain and health-related stimuli in the early stages of information processing (Beck \& Clark, 1997). In chapter 5 and 6, further evidence for the occurrence of cognitive processing bias in function of individual painrelated anxiety levels was sought by focussing on interpretation bias. Relying on explicit measures of interpretation bias, former research has demonstrated that pain patients and persons with elevated levels of AS are characterized by a tendency to interpret ambiguous stimuli in a negative or pain-related fashion (Keogh \& Cochrane, 2002; Keogh et al., 2004; Pincus \& Morley, 2001). It has been proposed that cognitive biases that are tapped with explicit measures are reflective of elaborative processing in the later stages of information processing, and do therefore possess a significant degree of specificity, relating to individuals' concerns specifically (Beck \& Clark, 1997; Mathews \& MacLeod, 1994). This proposed domain-specificity was the focus of study in chapter 5. More specifically, negative interpretations on four domains (panic-related sensations, other bodily symptoms, social events, and general events) were examined in relation to individual levels of pain-specific and more general anxiety constructs as derived from the hierarchical model of pain-relevant anxiety constructs. Multiple linear regression analyses demonstrated that AS, IS, and FNE were specifically predictive of negative interpretations on the domains of panic, other bodily symptoms, and social events respectively. In addition, PC and FoP were found to be most predictive of the pain-relevant other bodily symptoms domain. It is furthermore noteworthy that optimism, which was also assessed in this study, proved to be an independent strong predictor of less negative interpretations on all domains, whereas trait anxiety did not contribute to the 


\section{$\Uparrow$ chaperes}

explanation of the negative interpretative bias at all. Despite limitations pertaining the correlational design and the healthy study population in this chapter, this study constitutes a good first step towards further studying content-specific negative interpretations of ambiguity in the context of pain.

It can be questioned to what extent the explicitly measured interpretation bias in chapter 5 was reflective of the spontaneous and automatic interpretations that persons make in daily life upon the confrontation with ambiguity (Fazio \& Olson, 2003). To examine these spontaneously made interpretations, chapter 6 made use of a lexical decision paradigm that aims to provide an indirect measure of automatic and spontaneous interpretations of ambiguity (Hirsch \& Mathews, 1997; Hirsch \& Mathews, 2000). This lexical decision paradigm was borrowed from social anxiety research (Hirsch \& Mathews, 1997; Hirsch \& Mathews, 2000), and was modified for its applicability in the context of pain. With this paradigm, it was examined whether individual levels of pain-related anxiety and fear (AS, IS, PC, and FoP) were associated with an enhanced tendency to make automatic negative interpretations to ambiguous situations that imply physical health threats. Results of chapter 6 suggested that irrespective of individual fear levels, persons are generally inclined to make spontaneous negative inferences when confronted with ambiguity. As a possible explanation for this general negative interpretation bias, it might be suggested the severe threat value of the stimulus material in the task was responsible for initiating a negative processing template in the majority of individuals, and this irrespective of individual fear level (Mathews \& Mackintosh, 1998; Mogg \& Bradley, 1998). Furthermore, the automatic negative interpretation bias was unexpectedly found to be especially pronounced in persons possessing elevated levels of pain-related fear, and was not found associated with AS or IS. This raised the possibility that automatic negative interpretations of health-threatening ambiguity occur in function of the presence of fear that is very proximally related to pain only. Nevertheless, given the methodological shortcomings of the study on the examination of automatic negative interpretation bias (see discussion section of chapter 6) caution is warranted on drawing firm conclusions regarding the observed association between fear of pain and the automatic interpretation bias. Although the lexical decision paradigm appeared as a promising tool to study automatic negative interpretation bias in the context of pain, it seems appropriate to fine-tune this measure in future research in order to enhance its applicability for the assessment of automatic negative interpretations biases of pain-related stimuli.

Chapter 7 focussed on the 'attentional interference effect', which refers to the disruptive effect of pain on attention and ongoing cognitive activities (Crombez et al., 1996, 1998b; Crombez et al., 1999; Eccleston, 1994; Eccleston \& Crombez, 1999). At present, an extensive amount of research has established the occurrence of attentional interference by pain, and most of these studies have relied on the primary task paradigm to measure this effect. In this testing paradigm, persons perform a simple cognitive task (e.g., distinguishing high and low pitch tones) while they are occasionally confronted with experimentally induced pain. The effect of the pain administration on cognitive task performance is then taken as the measure of attentional interference (e.g., Crombez et al., 1998b). Several pain characteristics have been identified to influence the disruptive effect of pain on attention, such as the perceived threat value, the novelty, and the temporal unpredictability of the pain (e.g., (Crombez et al., 1998a; Van Damme, Crombez, Eccleston, \& Roelofs, 2004). Moreover, it has been demonstrated that attentional interference is especially pronounced in 
persons who are inclined to amplify the meaning and consequences of painful sensations (i.e., PC) (Crombez et al., 1998a, 1998b; Van Damme, Crombez, Eccleston et al., 2004). Chapter 7 aimed to replicate prior findings on the occurrence of the interference effect in relation to $\mathrm{PC}$ and to further extend on these findings by examining the relation between the interference effect and levels of AS and IS. The replication part of chapter 7 was successful, and strengthened the evidence for an enhanced interference effect in relation to PC. The interference effect did not show significant associations with either AS nor IS, though, suggesting that elevated levels of these constructs do not incline persons to attend more to pain than necessary allowing pain to interfere with other activities.

Chapter 8, finally, describes the findings of a study that was specifically designed to examine the putative beneficial influence of cognitive factors on the experience of pain. In an experimental study design, the influence of manipulations of perceived control and specific selfefficacy (SE) on subjective responses to electrically induced pain was examined. Corroborating earlier research findings, perceived control was found to be associated with lower levels of anticipatory fear of pain (Arntz \& Schmidt, 1989; Litt, 1988). Furthermore, induced high SE beliefs were associated with a significant reduction in anticipatory pain intensity and pain unpleasantness ratings, and the anticipated pain intensity mediated the relation between SE and experienced pain intensity. These findings led to the conclusion that high SE beliefs constitute an important role in tempering the subjective experience of pain. In addition, chapter 8 examined the moderating role of dispositional optimism and general self-efficacy on the effects of perceived control and specific selfefficacy beliefs. These two stable personality traits are assumed to contribute to general well being and the adjustment to pain (e.g., Carver \& Scheier, 2005; Peters \& Vancleef, in press; Schwarzer et al., 2005). Prior to the inductions of perceived control and SE beliefs, optimism inversely correlated with fear of pain ratings whilst general SE showed an inverse significant correlation with the anticipatory fear of pain. Furthermore, analyses on moderating effects of the positive personality traits demonstrated that generalized SE was a significant predictor of anticipatory fear of pain scores in participants who possessed low induced SE beliefs on their ability to exert control over their pain. In sum, findings of chapter 8 have indicated the importance of perceived control and especially SE cognitions in determining the subjective evaluations of pain. It is therefore suggested that in order to achieve subjective adjustment to pain, it is not only important that one has the idea that the pain is controllable, but also the conviction that one is able to effectively exert this control over the pain. 


\title{
INTEGRATIUE DISCUSSION AND THEORETICAL IMPLICATIONS OF MAIN FINDINGS
}

\author{
CONSIDERING SPECIFIC AND GENERAL ANXIETY-RELATED PERSONALITY CONSTRUCTS \\ AS VULNERABILITY FACTORS FOR PAIN
}

In the current thesis, trait anxiety (TA; chapter 2, 3, 5), anxiety sensitivity (AS; chapter 2, $3,4,5,6,7$ ) injury illness sensitivity (IS; chapter 2, 3, 4, 5, 6, 7), pain catastrophizing (PC; chapter $2,3,5,6,7)$ and fear of pain (FoP; chapter 2, 3, 5, 6) were examined for their putative vulnerability role in the chronic course of pain. By studying several anxiety constructs collectively, this thesis aimed to add to the understanding of the distinctiveness and relative importance of each of these constructs in their contribution to the onset and persistence of pain.

\section{Injury/illness sensitivity as a putative vulnerability factor for chronic pain}

Injury/illness sensitivity (IS) has been proposed to constitute one of three fundamental fears that underlie the common fears and anxiety-related psychopathology that we encounter in daily society (Reiss, 1991; Reiss et al., 1986). Conceived as the exaggerated fearfulness and catastrophic appraisal of potential illness and or injury, IS has been suggested to constitute a specific vulnerability role in the development of health-related fears (e.g., blood phobia) and chronic health conditions (e.g., chronic pain) (Carleton et al., 2005; Carleton, Park, \& Asmundson, 2006; Keogh \& Asmundson, 2004; Reiss et al., 1988; Taylor, 1993). In a review chapter on the contribution of emotional factors to the perception and experience of pain, Keogh \& Asmundson (2004) proposed IS to form a higher-order factor of PC and FoP. Nevertheless, until very recently, no empirical studies had been conducted on examining the association between IS and other painrelated anxiety constructs, or the contribution of IS to dysfunctional responses to pain. Six out of the seven chapters in the current thesis have incorporated a measure of IS in order to elucidate the precise role and importance of IS in the context of pain. In these studies, IS was measured with a Dutch translation (obtained via a back-translation procedure) of the 11-item injury/illness sensitivity index (ISI), containing 6 face-valid items for injury and 5 face-valid items for illness (Taylor, 1993). A recent factor analytic study suggested a two-factor solution for the scale comprising Fear of Injury and Fear of Illness that loaded onto the single higher-order factor Fear of Physical Harm (Carleton et al., 2005). Furthermore, the ISI has been demonstrated to possess good internal consistency (Cronbach's $\square>$.80) and adequate construct validity (Carleton et al., 2005; R. N. Carleton et al., 2006). Nevertheless, Carleton et al. (Carleton et al., 2005; Carleton et al., 2006) have suggested that two items were better to be removed from the scale because of overly inclusive wording and poor factor loadings. Since the psychometric analyses of the translated Dutch ISI did not reveal similar difficulties with these two specific items (see chapter 2 for details on psychometric statistics), it was decided to retain the 11-item ISI in the studies in this thesis.

In support of the construct validity of IS, moderate to high positive correlations were 
found between IS and (1) AS, the other fundamental fear considered an important contributor to the chronic course of pain (chapter 2, 4, 5, 6, 7); (2) FoP and PC, the pain-specific fear constructs considered important in the transition from acute to chronic pain (chapter 2, 5, 6, 7), and (3) trait anxiety, the general and stable personality trait assumed to constitute vulnerability for a wide variety of anxiety-related disorders (chapter 2,5 ) (see the specified chapters for details on exact correlation coefficients). Furthermore, a positive association was found between individual levels of IS on the one hand and cognitive (automatic threat appraisal, negative interpretation bias), behavioural (engaging in health protective and preventive behaviour), and affective (anticipatory fear of upcoming pain stimulus) responses to the threat of pain in chapter 2, 4, and 5 .

In their proposal of the hierarchical model of pain-associated anxiety constructs, Keogh \& Asmundson (2004) have suggested IS as the higher-order factor that subsumes the lower-order factors FoP and PC. In this perspective, influences of the distal IS construct on pain and disability are assumed to run via the more proximally to pain related constructs FoP and PC (Lilienfeld et al., 1993; Watson \& Clark, 1992). Several findings in this thesis are supportive of this suggestion, including the unique predictive value of IS for FoP and PC (chapter 2) and the observed loss in predictive power of IS for the negative interpretation bias when the pain-specific constructs were entered simultaneously with IS in the predictive model of this bias (chapter 5). Additionally, the MDS analysis in chapter 3 positioned the ISI items higher towards the general pole of the resulting general-specific dimension than FoP and PC items, which were positioned more towards the specific pole of this dimension. Furthermore, the ADDTREE analysis clearly distinguished the ISI items in a well separable cluster as distinct from the PC and FoP items.

Hence, studies within this thesis indicate that IS does entail at least some predictive power for fearful responses to pain. Consequently, it seems advisable to incorporate this construct in further studies that aim to examine putative risk factors for the development and persistence of chronic pain.

Differential importance of two fundamental fears in the context of pain: anxiety sensitivity versus injury/illness sensitivity

In addition to establishing evidence for the role of injury/illness sensitivity (IS) in the context of pain, this thesis also attempted to elucidate the putative differential predictive value of IS and anxiety sensitivity (AS). This research objective was addressed in chapters 2 till 7 . AS has been defined as the fear of anxiety-related symptoms (e.g., heart palpitations, sweating) arising from the belief that these symptoms will have negative or harmful somatic, psychological, or physical consequences (Peterson \& Heilbronner, 1987). AS implies the amplification of innocuous internal bodily sensations, and was originally proposed to constitute a risk factor for panic disorder (Clark, 1986; Peterson \& Heilbronner, 1987; Reiss, 1991; Teachman, 2005). At present, AS is conceived as a risk factor within the development of chronic pain, and to play a role in acute pain episodes as well. The relation between AS, pain, and disability has been frequently reported in both basic laboratory and applied clinical studies (Andersson, 1996; Asmundson et al., 2000; Stewart \& 


\section{$\Uparrow$ chaperer}

Asmundson, 2006).

From their definition, it follows that IS and AS entail different, though related concerns that might serve independent roles in the contribution to psychopathology. As such, AS is assumed to relate predominantly to the amplification of present innocuous bodily sensations because of their putative prediction of serious health-damage. Conversely, IS relates to the catastrophic and exaggerated worrying on possible future injury and illness in general. This difference in content of the fears was clearly demonstrated in chapter 6 , where AS was found to be specifically predictive of negative interpreting ambiguous descriptions that related to internal anxiety symptoms (e.g., sweating), whilst IS was found to be predictive of negative interpreting ambiguous descriptions that referred to other (non-anxiety related) bodily symptoms (e.g., skin bulb, digestive pain) that might predict serious illness or injury. Furthermore, IS and AS each resulted as the sole significant predictor of the self-reported tendency to engage in preventive and protective health behaviour, and the self-reported use of health care services, respectively. In addition, IS, but not AS was found to predict anticipatory FoP ratings for an upcoming pain stimulus. Taken together, these findings suggest that IS and AS might contribute to complementary components of the pain problem.

Despite the fact that several findings in this thesis are indicative that AS and IS are sensitive for explaining diverging components of pain behaviour, it can be questioned whether these findings have originated from (a) genuine differences with respect to the content and feared object of both constructs or (b) apparent differences that resulted from the properties of the measures that were chosen to represent IS and AS (i.e., the ISI and the ASI). In other words, are IS and AS actually different constructs or do statistical differences originate from drawbacks in the usage of the ISI and the ASI for assessing the constructs? This question will be addressed into detail in the paragraph below.

Inspecting the results regarding IS and AS in the studies of this thesis, it is notable that in some instances, IS resulted as the only significantly associated construct with some outcome variables (e.g., automatic threat appraisal in chapter 4, negative interpretations for other bodily symptoms subscale of BSIQ in chapter 5), while AS was found to be associated with these outcomes in a comparable, yet insignificant extent as well. Moreover, in these studies, the ISoutcome association and the AS-outcome association were not statistically deviating from one another. This suggests the possibility that certain dysfunctional responses to pain-related cues can be equally well predicted by AS and IS. It might be suggested that the absence of statistically significant relations between AS and the negative responses to pain-related stimuli has resulted from the fact that the ASI total score was taken to represent AS in these studies. As was already mentioned in the discussion sections of chapter 3 and chapter 5 , the composite ASI is considered to subsume three lower-order factors: physical concerns, cognitive concerns, and social concerns (Carter, Suchday, \& Gore, 2001; Taylor \& Cox, 1998; Zinbarg et al., 1997). Several authors have suggested that the physical concerns subscale of the ASI is particularly important to consider when exploring the influence of AS on pain maintaining behaviour, since this subscale pertains specifically to fearing the negative physical consequences of experiencing anxiety-related somatic sensations (Asmundson et al., 2001; Drahovzal et al., 2006; Keogh, 2004). In this view, it might be argued hat the ASI physical concerns factor and IS sensitivity are assessing one and the same theoretical construct. This suggestion is tentatively supported by the ADDTREE analysis in chapter 
3 , where the items of the physical concerns subscale were found to cluster together with the ISI items on the basis of the perceived content similarity. Furthermore, the other two subscales of the ASI were found to group in another main cluster. Thus in contrast to the ISI, the ASI is not perceived as a homogeneous measure that entails items that share similar meaning. It is possible that an association between ASI-physical concerns and responses to the (threatening) pain stimuli in this thesis were statistically counteracted by the absence of a correlation between these responses and the other two subscales of the ASI (i.e., cognitive concerns and social concerns).

To test for this possibility, post hoc analyses with the physical concerns subscale instead of the ASI total score have been conducted on the data files of this thesis. First, correlations were calculated between the ASI physical concerns subscale, the ISI, and the ASI total score. Correlations between ASI physical concerns and ISI were generally found to be slightly ( $r$ ranging between 0.53 and 0.68), though not significantly, higher than correlations between the ISI and the ASI composite score ( $r$ ranging between .45 and .67). Furthermore, correlation coefficients between the ASI total score and the physical concerns subscale were found to be high, with $r$ ranging between .83 and .91 . Hence, it can be concluded that the physical concerns subscale of the ASI and the ISI share a significant amount of common variance. Nevertheless, the magnitude of the correlation coefficients does not provide reasons to assume that both measures are tapping the same construct. Second, analyses were re-ran for all data files in which differential associations between AS and IS had been found. Overall, these post-hoc analyses revealed the same pattern of findings when the physical concerns factor, rather than the ASI total score was examined next to IS for its relation with the various outcome variables in this thesis. This finding supports the suggestion that both AS and IS are indeed distinct constructs, that contribute uniquely and independently to different components of responses to pain and pain-related cues. A recent study that incorporated measures of both AS and IS supported this idea by demonstrating that both AS and IS were independently associated with other pain-related fears (fear of pain, fear of movement/(re)injury) and with a combined score of social anxiety and trauma related symptoms. Along the suggestions made in the current thesis, the authors of this study concluded that both AS and IS might constitute vulnerabilities for displaying pain-related fears (Asmundson \& Carleton, 2005).

\section{Considering multiple pain-related anxiety and fear constructs in pain research}

In addition to AS and IS, this thesis has also studied the influence of other painrelated anxieties (Fear of Pain (FoP), pain catastrophizing (PC)). These pain-related anxieties were conceptualised as individual components of a hierarchical model of 'pain-relevant negative emotional constructs' (Keogh \& Asmundson, 2004; Lilienfeld et al., 1993). In this model, disordercommon constructs are assumed to reside in the higher levels of the hierarchy whilst disorderspecific constructs are positioned at the lower levels (Lilienfeld et al., 1993; Watson \& Clark, 1992; Zinbarg \& Barlow, 1996). In this view, AS and IS, form lower-order factors of the higher disordercommon construct TA, and are understood as trait-like factors that possess some degree of specificity in their relation with physical health problems and anxiety. Subordinating AS and IS, both FoP and PC are conceived as disorder-specific constructs that are very proximally related to the 


\section{$\Uparrow$ chapter 9}

actual confrontation with pain (Keogh \& Asmundson, 2004).

One of the merits of the hierarchical structure lies in its premise that constructs in the model will be intercorrelated, yet possess unique variance that can explain unique relations with specific components of pain (Lilienfeld et al., 1993; Taylor, 1993). Hence, conceptualizing multiple pain-related anxieties and fears in a hierarchical structure can account for the fact that moderate to high correlations are frequently observed between these constructs (chapters 2, 4, 5, 6, and 7 in the present thesis; Hadjistavropoulos et al., 2004; Keogh \& Asmundson, 2004). More importantly, the hierarchical structure can account for findings in which two or more correlated constructs have shown to be independently or uniquely related with divergent components of pain. For example, in chapter 4 of this thesis, AS and IS showed unique predictive value for the self-reported use of health care services and the tendency to engage in health protective behaviour, respectively, despite a significant correlation between AS and IS. In chapter 7, PC showed significant correlations with AS and IS, yet proved to be the sole construct associated with the attentional interference effect. In the study on negative explicit interpretation bias in chapter 5, TA, FoP, AS, IS, and PC were substantially intercorrelated $(p<.01 ; p<.001)$, while specific and independent predictive value of each construct was found for negative interpreting ambiguous descriptions in various domains (i.e., panic-related sensations, other bodily sensations, social events, and general events).

Similar findings have been demonstrated in other studies. In a recent study on the contribution of PC and AS in the development of persistent headache, Drahovzal et al (2006) concluded that PC and AS are empirically separate constructs that show overlap because of their common reference to the general domain of fearing physical catastrophe. Irrespective of this overlap, independent predictive value was found of AS for weekly headache and headache pain intensity and of PC for weekly headache only (Drahovzal et al., 2006). In a prospective study, Hadjistavropoulos \& Asmundson (2004) examined the combined and unique contribution of TA, AS, health anxiety, and pain-related fear to the adjustment to pain over a 3-month period of time in musculoskeletal pain patients. Results of this study could be interpreted along the lines of the existence of hierarchical relations between the anxiety constructs. Hence, albeit moderate intercorrelations ( $r$ between 0.38 and 0.56 , all $p<.01$ ) each of the anxiety constructs showed to be related to the adjustment to pain, although the importance of this relation was dependent on the specific outcome measure that was adopted for adjustment to pain (i.e., disability, negative affect, or perceived control over pain). In addition, Hadjistavropoulos \& Asmundson, (2004) reported a shift in predictive value of some of the anxiety constructs from the acute onset phase of pain to the 3-month follow-up measurement. In the acute phase, disability was best predicted by painrelated fear, negative affect (emotional distress) was significantly and uniquely predicted by TA, pain-related fear and AS, and perceived control was best predicted by TA. Notably, at 3-month follow-up, health anxiety became the only significant predictor of disability, and both AS and health anxiety were found to be predictive of negative affect. Based on these findings, Hadjistavropoulos and Asmundson (2004) suggested that in understanding pain and its consequences, it is important to consider the influence of pain-specific fears as well as the influence of more general anxiety construct that imply the general tendency to worry about health and future disability, as they are reflected by AS and IS for example. In addition, these authors suggested that the former might be especially predictive of short-term disability while the latter might be especially predictive of 
long-term disability. In a comparison of several measurement instruments of FoP, McCracken et al. (1996) found that pain-related fears were better predictors of pain, disability and pain severity than trait anxiety. Moreover, McCracken et al. (1996) emphasized the value of relying on various measures to assess pain-related fear because of the different response modalities that typify these measures (e.g., cognitive, motoric, physiological). More precisely, specific predictive value was observed of the PASS physiological anxiety subscale for pain severity, the PASS escape/avoidance subscale for disability because of the pain, and the FABQ for complaint behaviours (McCracken et al., 1996). These latter findings implicitly advocate a broader conceptualisation of the FoP construct than the fear of present sensory signals alone.

In line with the suggestions made by McCracken et al. (1996), it has been proposed that the conceptualisation of FoP in research is largely dependent on the measure that is used to assess this construct (McCracken, 2004; McNeil \& Vowles, 2004; Morley \& Eccleston, 2004). Throughout time, several FoP scales have been developed (i.e., Pain Anxiety Symptoms Scale (PASS), the Tampa Scale of Kinesiophobia (TSK), the Fear Avoidance Beliefs Questionnaire (FABQ), and the FoP Questionnaire (FPQ)), which have all proven fruitful in establishing the role of FoP in relation to other pain-anxieties or responses to pain). Because of the different response modalities (cf. different feared objects) that are implied in each of these scales (i.e., fear of present physical pain, fear of potential pain, fear of movement/(re)injury, fear of being active or working), unique relations with divergent pain-related outcome measures have been observed with different scales (i.e., pain-related disability, negative affectivity, catastrophizing, pain tolerance, and subjective pain intensity) (e.g., Crombez et al., 1999; McCracken et al., 1996; McNeil \& Vowles, 2004; Zvolensky, Feldner, Eifert, \& Stewart, 2001). In the present thesis, the Fear of Pain Questionnaire (FPQ-III (McNeil \& Rainwater, 1998) was used to tap pain-related fear. This 30-item questionnaire was specifically developed for the assessment of FoP in both clinical and non-clinical populations, and taps the fearfulness for pain in a large variety of life domains (McNeil \& Rainwater, 1998). Consequently, FPQ scores are understood to reflect one's potential to avoid painful or putatively painful situations (McNeil \& Rainwater, 1998). Because of its ability to tap fearfulness for pain in a broad variety of life domains, the FPQ constitutes a particular good measure to adopt when trying to examine vulnerabilities for developing chronic pain from acute pain experiences (McNeil \& Vowles, 2004). Nevertheless, the reverse side of the broad object of fear as implied in the FPQ might be that this scale serves a less good instrument for studying influences of FoP on specific components of dysfunctional responses to pain.

Taken together, it can be concluded that the simultaneous study of multiple painrelated anxieties, as well as keeping into account the object of the feared, is elucidating in terms of disentangling the precise contribution of each separate construct to the complex experience of pain. In addition, the hierarchical framework might offer a fruitful framework within which relations between the various construct can be understood. Up to now, the hierarchical model of pain-relevant negative emotional constructs has not been formally tested yet. Nevertheless, using principal components factor analyses or structural equation modelling, several authors have provided support for the hierarchical relation between negative affectivity and TA, between TA and the three fundamental fears, and between TA, AS, and the componential fears of AS (i.e., physical concerns, cognitive concerns, social concerns) (e.g., Sexton et al., 2003; Watson \& Clark, 1992; 


\section{tameso}

Zinbarg et al., 1997). It is suggested that future research addresses the issue of formal testing of the pain-relevant hierarchical model by means of similar statistical tests.

\section{COGNITIVE PROCESSING BIAS IN FUNCTION OF PAIN-RELATED ANXIETY}

One of the main objectives of this thesis concerned the examination of cognitive processing biases in function of pain-related anxieties. Information processing approaches to emotional disorders state that negative affective states and the current concerns of individuals are associated with favouring the processing of information that is congruent with these states and concerns (Beck \& Clark, 1997; Mathews \& Mackintosh, 1998; Mathews \& MacLeod, 1994). Given the notion that various pain-related anxieties are directed at different components of the pain problem (e.g., fear of current physical sensation, fear of future disability and illness, fear of movement/(re)injury), it is interesting to examine the extent to which these different constructs are associated with cognitive bias towards the specific concerns of the individual.

Relation between elevated levels of pain-related anxiety and the processing of painrelated information: Content-specificity

The present thesis has made use of both direct (Body Sensations Interpretation Questionnaire) and indirect measures (EAST, Primary Task Paradigm, Automatic lexical decision paradigm) to assess the occurrence of cognitive bias in relation to the emotional vulnerability constructs that were previously discussed. Although early cognitive models assumed for cognitive biases occurring in the later, strategic stages of processing to be characterized by contentspecificity only, contemporary cognitive models postulate that content-specificity can occur in the early phases of information processing already (e.g., Beck \& Clark, 1997; Jacoby, 1991; Mathews \& MacLeod, 1994; McNally, 1995). These contemporary models assume that both automatic and strategic processes are involved in all cognitive bias to some degree (Mathews \& MacLeod, 1994; McNally, 1995). Results of the current thesis were generally supportive of the hypothesized association between the biased processing of information on the one hand and elevated levels of pain-related anxiety on the other hand at both an automatic and a more controlled levels of processing. More specifically, a positive and significant association was found between: (1) IS and the automatic threat appraisal towards pain-related stimuli in chapter 4; (2) IS, PC, FoP and the explicit negative interpretation of ambiguous bodily symptoms in chapter 5; and (3) PC and the attentional interference effect in chapter 7. In addition, FoP levels were found to be associated with the tendency to favour health threatening over positive resolutions of ambiguity in the automatic assessment of negative interpretations in chapter 6. This latter finding has to be interpreted with caution, though, given the fact that the lexical decision paradigm in chapter 6 might have been unsuccessful in tapping genuine automatic negative interpretations (due to undesirable priming effects caused by methodological drawbacks of the stimulus material and 
the testing paradigm, see limitations chapter 6). Nevertheless, the association between FoP and speeded responses to the health-threatening resolution of ambiguity is an interesting finding in the light of the hypothesized relation between (automatic) cognitive responses to pain-related stimuli in function of present pain-directed anxious states. It is important to acknowledge that findings of content-specific relations between current concerns and cognitive bias are largely dependent upon the stimulus material that is selected to assess the bias (e.g., McKellar et al., 2003). This is illustrated in chapter 4, where IS was found to be significantly associated with the automatic threat appraisal, whilst the relation with AS did not come to reach significance. Motivated by the notion that automatic priming effects (as assessed with the EAST) are presumed to occur in response to personally relevant stimuli only, target stimuli in this task were chosen to possess relevance for a healthy population (Teige et al., 2004). These stimuli did not refer directly to the state of pain, but represented physical health threat in general (physician, blood, infection, disabled, cancer, wound). In this light, the stimuli were specifically representative of the current concerns assumed to be involved in IS. Illustrating the importance of the stimulus material used in cognitive testing paradigms as the EAST, elevated levels of AS have been found related with an automatic healththreatening appraisal towards target-stimuli that represented anxiety-related sensations (e.g., breathless, palpitation) (Lefaivre et al., 2006). Because of the omission of more direct affective and sensory pain stimuli (e.g., throbbing, pounding, aching, nagging, unbearable, agonizing) or more general negative stimuli (e.g., burglary, robbing, fight), conclusions on the observed association between IS and the automatic threat appraisal are limited. More precisely, it cannot be concluded whether IS is related with an automatic threat appraisal towards general health stimuli only, or whether this selective threatening processing extrapolates to pain-specific, or general negative stimuli as well. In the study on the attentional interference effect, an induced pain experience was used to represent the threatening stimulus. It needs no explanation that this stimulus serves a better and more ecological valid representation of physical pain than verbal words as used in the EAST. Given the fact that neither IS or AS showed associations with the attentional interference effect, while pain catastrophizing did, it might be concluded that the processing of an actual pain stimulus is specifically biased in function of elevated levels of pain catastrophizing. Last, contentspecificity was specifically addressed in chapter 5 of this thesis, where an explicit interpretation measure was used to assess negative interpretations of situational descriptions on several contentdomains. The major advantage of this study is that besides the inclusion of situations referring to bodily symptoms and sensations, situations referring to general threat and social events were incorporated as well (see chapter 5 for detailed results on the findings of this study). Important with respect to the issue of content-specific interpretations of pain-related information in this study is that both PC, FoP, and IS were found to be predictive of negative interpretations on the other bodily symptoms subscale. This latter subscale was assumed to be most representative of pain-related ambiguous situations. In addition, both IS and PC did not predict negative interpretations on any of the other domains assessed in this study. Furthermore and supportive of the content specificity of $\mathrm{PC}$ and FoP, the predictive value of IS for interpretations on this subscale disappeared when the pain-specific constructs were considered simultaneously with IS as predictors of this subscale.

When combining findings of the current thesis with those of other studies on the assessment of cognitive bias in function of pain-related anxiety, it has to be concluded that 


\section{$\Uparrow$ chaperer}

robust evidence on this matter is inconclusive yet. As such, there are studies that demonstrate associations between elevated levels of FoP or AS and the occurrence of memory, attentional, and interpretation biases towards either negative stimuli in general, pain stimuli in general, sensory pain words solely, or affective pain words solely (Asmundson et al., 2005; Keogh \& Cochrane, 2002; McKellar et al., 2003; Pincus \& Morley, 2001). Nevertheless, studies that have failed to detect cognitive bias in relation to pain-related anxiety levels have been published as well (e.g., Asmundson \& Hadjistavropoulos, 2007; Keogh, Thompson, \& Hannent, 2003; Roelofs, Peters, van der Zijden et al., 2003). It might be suggested that mixed findings on this matter can be partly accounted for by methodological issues that typify the studies have been conducted on testing cognitive bias in the area of pain up to date, constituting of a lack of the assessment of pain-related anxiety in pain patients, the omission of including various types of pain-related stimuli, the lack of including control groups, the lack of including pain specific stimuli altogether, or the reliance on different testing paradigms (both indirect and direct). In this light further research on examining the content-specificity of cognitive bias in the area of pain is definitely warranted.

\section{The orientation towards pain and health-related stimuli in cognitive processing}

One notable finding in the current thesis was that irrespective of individual fear levels, a general automatic threat appraisal towards the pain-related stimuli was found with the EAST in chapter 4, and a general attentional interference effect of pain on cognitive performance was observed in chapter 7 . These findings are not surprising, though, given the evolutionary benefits that are inherently connected to the fast and early detection of severe physical threat in terms of optimizing safety and survival chances. The benefits of the automatic detection and processing of severe threat are acknowledged in cognitive models of information processing as well (Beck \& Clark, 1997; Mathews \& Mackintosh, 1998; Mogg \& Bradley, 1998). As such, immediately upon the confrontation with a stimulus, the automatic, fast, and largely unconscious recognition of threatening stimuli is presumed to be ensured by the rapid activation of the orienting mode in the three-stage cognitive model (Beck \& Clark, 1997). This orienting mode is conceived to function as an 'early warning system' that allows the individual to prepare eventual fight/flight responses in order to protect against or prevent the occurrence of serious bodily harm. Congruent to this idea, others authors report about a threat evaluation system (Mathews \& Mackintosh, 1998), or a significance evaluator (Öhman, 1993) to operate in the earliest and most automatic stages of information processing that is directed at the detection of threat for evolutionary purposes. This automatic and fast threat detection process is assumed to involve a rapid evaluation of imminent threat with respect to its meaning and gravity (Norman \& Shallice, 1986; Öhman, 1979). If this evaluation results in a non severe threatening appraisal of the stimulus, processing will go on as usual, and the individual continues his or her activities without even being aware of this evaluation process. It might be suggested that this evaluation process is illustrated in chapter 7 , where the attentional interference effect was tapped at two time lags in the processing of the pain stimulus; immediately after pain onset $(250 \mathrm{~ms}$ ), and $750 \mathrm{~ms}$ after pain onset. Replicating prior results by Crombez et al. (1997, 1998a, 1998b) the disruptive effect of pain on attention was found to be 
especially pronounced at $250 \mathrm{~ms}$ after pain onset, and to have diminished substantially at $750 \mathrm{~ms}$ after pain onset. It might be suggested that at $250 \mathrm{~ms}$ after pain onset, the pain stimulus is still under evaluation; whilst at $750 \mathrm{~ms}$ this evaluation process is presumably in its end phase, leading to much smaller task deterioration. Furthermore, it might be suggested that the general automatic threat appraisal as measured with the EAST can be accounted for by the functioning of an early threat detection system as well.

Nevertheless, some cautious remarks should be placed with this latter interpretation, since it can be questioned whether the temporal path within which the EAST taps cognitive processes does still fall within the earliest and most automatic stage of information processing. Despite the fact that the EAST is an automatized task requiring responses 'as fast as possible' (mean reaction times around $500 \mathrm{~ms}$ ) it might be suggested that responses to this task involve some primitive, basic elaborative processing at least. After all, responses are based on making a decision about the colour of the target words under the assumption that the semantic and affective meaning of the targets is unconsciously processed as well (De Houwer, 2003). Hence, the EAST, and possibly also the primary task paradigm might tap automatic processes in a later stage of information processing, involving some basic degree of elaborative processing already. Another explanation might be in order to explain the counterintuitive finding of automatic negative processing bias in healthy individuals. Such an explanation might be sought in the severity of the threatening stimuli. More precisely, it has been suggested that healthy individuals might display automatic negative biases for stimuli that entail a severe threat value because of the evolutionary benefits of early threat detection, whereas stimuli that entail a moderate or no threat value are presumed to be negatively processed by high anxious individuals only (Mathews \& Mackintosh, 1998; Mogg \& Bradley, 1998). This explanation seems to fit the findings of the current thesis well. After all, stimuli referring to serious health damage can be proposed to possess severe threat value indeed and it is beneficial for an individual's safety and well being that attention is devoted to these types of stimuli. The automatic threatening evaluation of health threatening stimuli does not necessarily lead to the instigation of further response patterns in function of this initial threat impression, though. In contrary, it can be suggested that in low anxious individuals, constructive primitive elaborative processes might be responsible for blocking off the display of further maladaptive responses. As Beck \& Clark (1997) stated in their cognitive model of information processing, the primal threat mode involves a goal-directed strategy that allows for some primitive reflexive and elaborative, yet unconscious, processing already.

In contrast, the early warning system and primal threat mode are assumed to have lost their evolutionary value in high anxious individuals, and to have evolved into some sort of 'anxious processing mode' that is characterized by an excessive orientation towards the negative altogether. In anxious individuals, the excessive orientation towards the negative is assumed to dominate cognitive, physiological, affective, and behavioural responses, and to inhibit more constructive and adaptive processing. This excessive orientation might explain the more pronounced magnitude of both the automatic threat appraisal and the attentional interference effect in persons possessing elevated levels of IS and PC respectively. 


\section{k $k$ antere}

\section{Cognitive bias and the prediction of behaviour}

One issue that remains to be dealt with in the discussion of negative cognitive bias as a vulnerability factor for pain chronicity concerns the relation between such biases and behaviour. More specifically, in assuming cognitive biases to underlie the maintenance and possibly also the onset of pain chronicity, it is crucial that these cognitive processing biases are found to be associated with maladaptive responses to pain. There is quite a bulge of literature available on the assumed predictive value of both automatic and strategic cognitive processes to behaviour. In brief, there seems to be general consensus that fast and automatic cognitive processes will be especially predictive of spontaneous, reflexive and uncontrolled behavioural patterns, whereas slow, strategic processes will be most predictive of controlled, reflective behavioural patterns (Beck \& Clark, 1997; Fazio \& Olson, 2003; McNally, 1995; Mogg \& Bradley, 1998; Wilson et al., 2000). Illustrating the value of considering both automatic and controlled processes in the prediction of behaviour, research has demonstrated that both types of processes can predict different components of one and the same behaviour, whereas evidence on the divergent predictive value of automatic versus controlled processes to behaviour is available as well (e.g., de Jong et al., 2003; Huijding \& De Jong, 2005). For example, in examining the divergent influence of automatic and self-reported fearrelated associations on fear responses, Huijding \& De Jong (2006) found automatically assessed spider-fear associations (i.e., EAST) to be especially predictive of automatic, non-controlled fear responses (i.e., eye blink startle probe response) whereas the self-reported fear of spiders (i.e. Fear of Spiders Questionnaire) showed to be the best predictor of controlled strategic avoidance behaviour (i.e., behavioural approach towards spider). In another study, automatically assessed spider-fear responses were found to possess explanatory value over and above this of self-reported fear in the prediction of avoidance behaviour (Huijding \& De Jong, 2005). Furthermore, evidence for the strength of automatic processes in explaining behaviour was offered in a study demonstrating positive automatic alcohol associations to be uniquely predictive of alcohol (misuse), and to form the single best predictor of individuals' alcohol problems (de Jong et al., 2007).

In the present thesis, only chapter 4 has included a behavioural measure to test for the predictive value of self-reported pain-related anxiety levels and the automatic threat appraisal to pain-related behaviour. These behavioural measures constituted self-report instruments, in which respondents were asked to report about their use of health care services in the past twelveand three-month period, and about their tendency to engage in preventive and protective health behaviours providing that they would find themselves in a number of hypothetically sketched situations that involve imminent long-term health-threat. Results of the regression analyses showed that the self-reported pain-related anxieties were predictive of both behavioural correlates only, whereas the automatic threat appraisal did not add anything to this prediction. In single correlations, the automatic threat appraisal was found to be marginally related $(p<.10)$ to the selfreported tendency to engage in protective and preventive behaviour, but showed zero-correlations with the self-reported use of health care services. In general, these findings seem to indicate that automatic threat appraisal towards health-threatening stimuli does not possess additional predictive value over the explicitly reported pain anxieties in the explanation of the behaviours assessed with both behavioural correlates. Nevertheless, the self-reported behavioural measures 
in the current thesis might be unsuccessful in tapping the spontaneous behaviours that persons will display in response to the threat of pain or health damage. It is suggested that the spontaneous and reflexive behaviours proposed to contribute to pain might be objectively assessed by means of psychophysiological measures (i.e., increase in muscle tension), startle probe responses, and observational methods. The finding of a marginal single correlations between the automatic threat appraisal and the self-reported tendency to engage in health protecting behaviour might be indicative of a contribution of automatic appraisals of health threatening stimuli to the display of maladaptive responses that will lead to increased disability in the long term.

In contrast to the recent increase in studies on the examination of the occurrence of cognitive processing biases to pain, relatively few studies are available yet on the prediction of such cognitive biases for either strategic or controlled responses to pain. In order to be able to make more firm predictions on the contribution of both strategic and automatic cognitive processing bias on the persistence of pain complaints, future research should address this issue in both experimental laboratory and more applied clinical studies.

\section{LIMITATIONS OF THE STUDIES PRESENTED IN THIS THESIS AND FUTURE RESEARCH DIRECTIONS}

\section{LIMITATIONS}

One limitation to the current thesis concerns the inclusion of healthy participants only. The choice for conducting studies in a healthy population was motivated by the research objective of identifying vulnerability factors within the chronic course of pain. By examining the role of these factors in healthy individuals, it was possible to ascribe putative findings and effects to the presence or functioning of these factors, rather than to the presence of actual pain. Nevertheless, since the role of the subsumed risk factors of interest (i.e., pain-related anxiety and cognitive processing biases) was not studied in interaction with the state of pain, caution is warranted in generalizing findings on the influence of these factors to the persistence and maintenance of chronic pain complaints. This is especially true with respect to the negative emotional constructs that are studied in this thesis. As such, it might be proposed that in pain patients, other concerns or factors are of importance in maintaining pain than the ones that have been discussed in this thesis. In addition, it is possible that the self-report measures that are used to assess the constructs will be differentially responded to by patients than by healthy individuals because of different perspectives between both groups on the items of these constructs, being affected by suffering from continuous pain or not. To overcome this limitation, future research will benefit from conducting studies in acute or chronic pain populations. Furthermore, the vast majority of participants in this thesis were college students of relatively young age and with presumed above-moderate IQ levels. In this respect, this study sample does not entail full representativeness of the general population in which chronic pain problems are observed. Future studies should therefore study the role of vulnerability factors 


\section{$\Uparrow$ chapter 9}

in pain in more representative community samples as well.

A second limitation of the current thesis concerns the cross-sectional design of the studies that it incorporates in examining vulnerability for developing and maintaining chronic pain problems. Ideally, the role of vulnerability factors would have to be examined within a prospective study design that collects longitudinal data on the development and exacerbation of chronic pain problems. Nevertheless, such a research design would be difficult to implement, since this requires the selection of participants prior to the experience of pain. One alternative to this option would be to study participant groups that are known to be subjected to a pain experience in the future (e.g., persons in the prospect of undergoing surgery or medical painful procedure), and to gather data on the variables assumed to be important for instigating long-term pain complaints prior to this procedure and at follow-up moments.

A third limitation of this thesis might concern power problems due to the inclusion of relatively small participant samples in relation to the study of influences of multiple independent variables in each study. It is possible that stronger effects and associations between the cognitive biases and the presence of anxiety levels would have resulted when more participants were included in these studies. Although it is strongly recommended that future studies continue to include multiple variables for achieving a more thorough insight on their relative importance, it is advisable that large enough participant groups are concordantly recruited to test for the influence of these factors.

Finally, most studies in this thesis are limited by the omission of behavioural measures as the dependent variables assessing responses to pain. Due to this limitation, we can only speculate on the direct influence of the various anxiety constructs as well as the cognitive processing biases on specific maladaptive responses to pain. Future research will have to address this issue by including both indirect (e.g., psychophysiological responses, measures of muscle tension) and more direct (e.g., pain activity task, pain tolerance, avoidance behaviour, observational measures) measures of responses to pain in studies that aim to examine the contribution of anxiety states and automatic and strategic cognitive processing biases to these responses.

\section{FUTURE RESEARCH DIRECTIONS}

Based on the combination of findings presented in the present thesis and other findings in the research area on the examination of negative emotional and cognitive factors involved in the development and maintenance of chronic pain, the following directions for future research may be proposed:

First, given the complex nature of pain and the close association between various painrelated emotional constructs it might be suggested that future research will benefit substantially by the collective study of multiple pain-related anxiety constructs when trying to understand their respective roles in the development persistence of chronic pain. Taking a broader perspective on the role of anxiety in pain and studying the interplay between various constructs allows for the identification of the unique and relative importance of each of these constructs for specific components of the pain problem. The merits of this type of research have been emphasized in the 
studies incorporated in the present thesis as well as those conducted by several other researchers in the field (e.g., Hadjistavropoulos et al., 2004; McCracken et al., 1996). It is suggested that a hierarchical structure might serve a useful theoretical framework within which findings of divergent influences can be understood and interpreted, and further formal testing of this model is warranted. In addition, it should be noted that the hierarchical model of pain-relevant constructs as presented in this thesis does not intend to be definitive, and leaves open the possibility for influences of other recently introduced (e.g., health anxiety; Hadjistavropoulos, Asmundson, LaChapelle, \& Quine, 2002; Hadjistavropoulos \& Hadjistavropoulos, 2003) or yet to be discovered constructs. Since incorporating multiple independent variables in single study designs increases the risk at Type II errors of measurement, it is furthermore advocated that future studies on this subject include large enough participant samples, as well as adequate statistical testing techniques (e.g., structural equation modelling) for exploring or confirming hypothesized individual and conjoint influences of multiple constructs on pain.

Second, in examining pain-related anxieties and fears in relation to pain further, it might be valuable to consider the precise object of these anxieties or fears more thoroughly. It is well acknowledged that fears and anxieties in the context of pain can be directed at the actual presence of physical pain and sensations and the direct functional consequences of activity, (re)injury, and work on the exacerbation and continuation of pain. In addition, the feared object may also extend the scope of the direct physical impact of pain on the individual. As such, one might fear the possibility of putative future pain, disability or physical health problems, the impact of pain on one's social status and relationships, or fears on the impact of pain on financial resources (McCracken, 2004; McNeil \& Vowles, 2004; Morley \& Eccleston, 2004). The object of fear or anxiety may be proposed to depend upon prior personal learning history, prior knowledge, environmental contexts, and social influences. More than the distinguishable level of specificity in various pain-related anxiety and fear constructs, the exact object of this anxiety or fear may be suggested to be of particular importance in explaining divergent findings on rather broad or more specific relations between anxiety-related constructs and components of pain and disability. Drawing on earlier suggestions made by Hadjistavropoulos et al. (2004) and on findings regarding the distinctiveness of AS and IS in this thesis, it might be suggested that present-oriented fears and anxieties on physical pain or the actual presence of physical threat might be especially predictive of short-term disability and maladaptive responses to pain, whereas future-oriented fears or anxieties, directed at putative physical harm, future long-term disability and the functional and social consequences of injury and illness might be more predictive of long-term disability. These different objects may be proposed to guide different behavioural response patterns, with the former being directed at the escape from and dealing with present pain complaints, and the latter being directed at the prevention and protection against eventual serious physical harm.

A third direction for further research concerns the further examination of the role of cognitive processing biases in the aetiology and persistence of chronic pain. The substantial evidence that is presently available on the occurrence of both automatic and strategic cognitive biases in both pain patients and high pain anxious individuals has paved the path for further research on precise influences of these cognitive processes on dysfunctional responses to pain. In order to examine this precise influence, it is suggested that further research includes measures of both strategic 


\section{$\Uparrow$ chaperer}

and more spontaneous pain-related behavioural measures, including measures of avoidance, pain tolerance, muscle tension and other psychophysiological responses assumed to be of importance in pain. Furthermore, congruently with the benefits connected to the collective study of painrelated anxieties in relation to pain and disability, it might be suggested that studying the combined effects of multiple cognitive processing biases (e.g., attention bias, interpretation bias, memory bias) can add significantly to our understanding of the unique and relative importance of these separate biases as well. Since high pain-anxious individuals are assumed to be characterized by the propensity to process pain-related information negatively, it is not very likely that the influence of cognitive bias will be solitary. It seems more appropriate to assume that one particular bias will be influenced by other biases or that several biases exert conjoint influences on the maintenance of pain. Recently, Hirsch, Clark, \& Mathews (2006) have emphasized the importance of studying cognitive biases in combination for their influence on the maintenance of a given disorder in what they refer to as the 'combined cognitive bias hypothesis'. These authors applied this hypothesis in the area of social phobia, by presenting and discussing evidence on the reciprocal relation between mental imagery and interpretation bias and their combined effects on the exacerbation of social phobia. The potential utility of the combined cognitive bias hypothesis is probably not confined to the area of social phobia, but applicable and testable in other emotional disorders as well, including the area of pain. Another issue that remains to be established is the causality between anxiety, cognitive biases, and the exacerbation of pain complaints. One way to study causality could be by the induction of cognitive bias in persons who are not prone for selective processing pain-related or health-threatening information and study effect on pain-related behavioural measures as well as on mood. Evidence on the possibility to induce cognitive biases successfully was recently offered with respect to automatic interpretation bias and attention bias (Mathews \& Mackintosh, 2000; Mathews \& MacLeod, 2002; Salemink, van den Hout, \& Kindt, 2007; Yiend \& Mackintosh, 2004; Yiend, Mackintosh, \& Mathews, 2005). Given the fact that cognitive biases in anxiety can indeed be induced yields the challenge for examining the extent to which these biases can be reduced then, and serve as potential valuable additions to the treatment of persons characterized by irrational negative beliefs on pain.

Another question that presents itself from the present thesis concerns the importance of the fast and automatic general threat appraisal that seems to exist in the general population towards health-threatening stimuli. More specifically, it would be interesting to examine the critical components that dampen or enhance this initial threat impression in the later stages of information processing. It is very likely that, according to the most common view on the role of cognitive processing bias in pain, the presence of pain-related anxiety serves one of the basic and necessary conditions for this threat appraisal to guide further dysfunctional responses. Nevertheless, it might be valuable to examine the importance of other characteristics of the person (e.g., positive personality traits), the (threat of) pain (e.g., severity, perceived threat value, identifiable causes) and the context within which the (threat of) pain occurs (e.g., social context, developmental history, care giving, relational goals) on the further functionality or the putative inhibition of this initial threat impression. For example, it has been demonstrated that the severity, novelty, and perceived threat value of the pain stimulus are critical factors in determining the impact of the interruptive effect of pain on attention (Van Damme, Crombez, Eccleston et al., 2004). With respect to context influences, 
studies have demonstrated the role of practitioners' attitudes and pain-related fear (e.g., Houben et al., 2005), and this of caregivers or significant others (e.g., Goubert, Eccleston, Vervoort, Jordan, \& Crombez, 2006) on the exacerbation of fearfulness and catastrophizing on pain. Furthermore, it has been suggested that instrumental, relational, or caregiving goals of individual might affect the way in which persons give expression to their pain and are prone for further fearful and catastrophic appraisals of pain (Sullivan et al., 2004; Sullivan et al., 2001)

Last, in addition to studying factors that contribute in a negative fashion to pain and disability, it is proposed that further research devotes attention to the role of psychological factors that might have positive influences on the development and persistence of pain. The present thesis demonstrated the importance of perceived control and self-efficacy beliefs in this light, as cognitive factors that have a beneficial influence on the experience of pain in terms of a subjective decrease in pain intensity and fearfulness for pain. Other cognitive factors presumed to exert positive influences on pain are acceptance and benefit finding. In addition, several stable personality traits have been suggested to possess promising value in protecting against the development of chronic pain conditions, for example dispositional optimism, general self-efficacy, and dispositional hope. It goes without saying that gathering knowledge on processes and factors that might contribute to the adjustment to and adequate coping with pain provides useful information for theoretical and management perspectives on chronic pain.

\section{Clinical implications of this thesis}

Given the fundamental nature of the studies in this thesis, the direct clinical implications of its findings are limited. Nevertheless, it can be argued that the value of this thesis for clinical purposes lies exactly within the attempts that are made to disentangle the divergent influences of several psychological factors on the development and the persistence of pain. Treatment approaches in clinical practice can benefit from a more crystallized view on the (relative) importance of psychological factors and cognitive mechanisms that can make persons more or less prone for developing chronic pain from acute pain episodes. More precisely, insight in these factors can promote the development of tailored pain management techniques that are directed at counteracting dysfunctional response patterns to acute pain and at promoting functional and adaptive processes that might contribute to the healing process. Moreover, it can be proposed that the identification of assessable psychological vulnerability factors can be helpful for the early screening of individuals who are at risk for developing chronic pain complaints. An early identification of the presence of vulnerability for developing chronic pain can promote the early application of pain management techniques that are specifically tailored to the needs of the individual at risk. Furthermore, it may be proposed that the assessment of the occurrence of automatic cognitive processing biases might provide a testable means to check for the effectiveness of treatment in terms of a reduction in automatically favouring the processing of negative and pain-related information and an increase in constructive and functional elaborative information processing that counteracts threat processing templates (Dehghani, Sharpe, \& Nicholas, 2004).

The advantage of identifying psychological factors involved in pain chronicity for treatment 


\section{tomeno}

approaches is illustrated by the effectiveness of current cognitive-behavioural approaches that have evolved from contemporary cognitive fear-avoidance models of pain. These treatment approaches are primarily directed at tackling FoP and pain catastrophizing beliefs in order to reduce painrelated disability and to learn persons to cope with their pain more adequately. Drawing on the successfulness of exposure treatments in phobias, the exposure-in-vivo treatment for chronic musculoskeletal pain has recently proven to be a promising treatment for those pain patients who are characterized by irrational beliefs that pain is a signal of impending threat to the body (Boersma et al., 2004; de Jong et al., 2005; Vlaeyen \& Linton, 2000; Vlaeyen \& Morley, 2005). It will be interesting to examine in future studies whether the effectiveness of this exposure-in-vivo treatment does result in dampened or inhibited cognitive processing biases towards pain-related information as well.

Besides a focus on tackling those factors that can contribute to the onset and persistence of pain, it is furthermore suggested that pain management programs can benefit substantially from an additional focus on factors and processes that can promote adaptive responses to pain. Earlier in this thesis, it was suggested that perceived control and self-efficacy beliefs are important cognitive factors to consider in this light. It is proposed that in pain management programs, practitioners consider the importance of patients' beliefs over their possibility and capability to control and deal with their pain. These patient beliefs might be strengthened by means of the practitioner providing motivational support and positive feedback on the progress and efforts of the patient in following the treatment programme. Further research will be needed to clarify the independent and interacting influence of both perceived control and self-efficacy beliefs in order to fine-tune their imbedding in intervention programs that are directed at the adaptive adjustment to and coping with pain. 


\section{- - \\ Samenvatting (Dutch summary)}


Het ervaren van pijn is een welbekende sensatie voor de meesten onder ons. Een specifiek kenmerk van pijn is dat het, ondanks zijn universele aard, een sterk subjectieve ervaring is, die door verschillende personen op verschillende manieren ervaren en beleefd wordt. Bovendien is pijn niet altijd van voorbijgaande aard. Hoewel de meeste personen na een pijnervaring snel weer genezen door tijdelijk rust te nemen of een (medische) behandeling te volgen, is er ook een beperkt aandeel van de bevolking (ongeveer 5\%) dat continu met pijnklachten heeft te kampen. Bij de meeste mensen met aanhoudende pijnklachten (meer dan drie maanden) kan geen duidelijke medische oorzaak gevonden worden en spreken we van aspecifieke chronische pijn. In dit proefschrift staan een aantal studies beschreven waarin persoonlijkheidskenmerken, denkprocessen en denkfouten onderzocht worden als mogelijke psychologische kwetsbaarheidfactoren voor de ontwikkeling en het blijven voortbestaan van chronische aspecifieke pijn.

Hoofdstuk 1 van dit proefschrift start met een korte schets van de problematiek en prevalentie van chronische aspecifieke pijn, en een beschrijving van de meestinvloedrijke theoretische verklaringsmodellen van pijn die doorheen de tijd ontwikkeld werden. Op dit moment wordt pijn over het algemeen benaderd vanuit een biopsychosociale invalshoek, waarbij biologische, sociale en psychologische componenten van belang geacht worden. Een belangrijk verklaringsmodel is het cognitief gedragsmatige model van chronische pijn (Vlaeyen et al, 1995), waarin chronische aspecifieke pijn gerepresenteerd wordt als het resultaat van een vicieus proces. In dit model vormen catastrofale interpretaties van pijn (bijv. 'mijn pijn is het ergste dat mij kan overkomen' of 'mijn pijn gaat nooit meer weg') en de vrees voor pijn (bijv. 'wanneer ik pijn heb ben ik bang dat er iets ernstigs kan gebeuren' of 'pijn is angstaanjagend') kritieke componenten die de vicieuze cirkel in stand houden. Hoofdstuk 1 besteedt verder aandacht aan de introductie en beschrijving van negatieve emotionele persoonlijkheidsconstructen (meer bepaald angst en vreesconstructen) en informatieverwerkingsfouten, die mogelijk kunnen verklaren waarom personen in meer of mindere mate kwetsbaar zijn om catastroferend en met vrees te reageren op pijn. Het zijn met name deze psychologische risicofactoren die in de studies in dit proefschrift nader onderzocht werden.

De hoofddoelstelling van hoofdstuk 2 is om de rol van injury/lilness sensitivity (IS), gedefinieerd als de overdreven bezorgdheid om in de toekomst ernstig gewond, ernstig ziek, of invalide te geraken, nader te onderzoeken als een mogelijk belangrijke kwetsbaarheidfactor binnen het domein van chronische pijn. Hoewel eerdere literatuur wel al melding maakte van deze factor als een 'fundamentele'angst die mogelijk een invloed heeft op psychopathologie, was er tot op heden weinig onderzoek voorhanden dat de rol van dit construct in pijn nader onderzocht heeft (Keogh \& Asmundson, 2004). Daarentegen was er al vrij veel bekend over de rol van anxiety sensitivity (AS) als een kwetsbaarheidfactor voor chronische pijn. Een additionele vraagstelling van hoofdstuk 2 onderzocht of IS mogelijk een groter belang had in het bepalen van dysfunctionele responsen ten aanzien van pijn dan AS. Gezonde studenten vulden een aantal vragenlijsten in waarin onder andere AS, IS, pijn catastroferen, en vrees voor pijn gemeten werden. Correlationele en regressie analyses toonden aan dat IS en AS beiden significante voorspellers waren van pijn catastroferen en pijngerelateerde vrees, terwijl IS als de beste voorspeller naar voren kwam. Een willekeurige groep van de grotere groep studenten die de vragenlijsten invulden werden vervolgens in het testlab uitgenodigd waar zij verschillende pijninducties ondergingen (elektrische stimulatie, warmte, druktest). Geanticipeerde angst voor pijn en pijntolerantie werden gemeten. Noch AS, 


\section{Samenvatting (Dutch Summary)}

noch IS bleken voorspellend te zijn voor pijntolerantie scores van de drie verschillende inducties. Echter, IS, maar niet AS, resulteerde als een significante voorspeller van de geanticipeerde angst die proefpersonen voorafgaand aan elk van de drie inducties aangaven. De resultaten wijzen erop dat het zinvol is om IS nader te onderzoeken als een mogelijke kwetsbaarheidfactor voor pijn. Onderzoek naar deze factor naast de rol van AS kan mogelijk een beter inzicht bieden in de unieke en gemeenschappelijke bijdrage van beide constructen aan bepaalde pijnresponsen.

In hoofdstuk 3 werd verdere evidentie gezocht voor het hiërarchisch model van negatieve emotionele constructen relevant voor pijn (zie beschrijving en figuur in hoofdstuk 1; Lilienfeld et al.,1993; Keogh \& Asmundson, 2004). De verschillende constructen die in het hiërarchisch model staan weergegeven worden in de praktijk veelal geoperationaliseerd en gemeten met behulp van specifieke vragenlijsten. Wanneer we willen aannemen dat deze lijsten ook effectief deze verschillende angstconstructen representeren, is het van cruciaal belang dat personen in staat zijn om de dimensionaliteit en de inhoudelijke verschillen in de betekenis van de items van deze lijsten te herkennen. Om dit nader te onderzoeken heeft een grote groep studenten een kaart sorteer taak uitgevoerd. Alle items (225 in totaal) van de meest courant gebruikte lijsten voor het meten van pijnrelevante angstconstructen werden apart op een kaartje uitgeprint (zonder de bijhorende antwoordschalen). Proefpersonen kregen de opdracht om de kaartjes zodanig in stapels te sorteren dat iedere stapel items bevatte met een inhoudelijke verwantschap. Een clusteranalyse op deze sorteerdata toonde aan dat items samen clusterden in groepen op een manier die in grote lijnen overeenstemde met de structuur van het hiërarchisch model. Meer nog, items uit specifieke subschalen van deze lijsten werden vaak samen gegroepeerd op basis van hun waargenomen gelijkenis op inhoudelijk vlak. Verder bood een muldimensionale schaal-analyse op de sorteerdata ondersteuning voor de dimensionaliteit die doorheen het hiërarchisch model verondersteld wordt, namelijk dat inhoudspecifieke constructen (items) in de onderste lagen van het hiërarchisch model geplaatst worden terwijl meer algemene en diffuse constructen (items)in de bovenste lagen van het model gelokaliseerd zijn. Een tweede dimensie die resulteerde uit de schaling analyse situeerde de items van de vragenlijsten op een dimensie die liep van interpersoonlijke naar meer intrapersoonlijke bezorgdheid over pijn en zijn gevolgen. De bevindingen uit hoofdstuk 3 suggereren dat het zinvol is om met verschillende angst en vreesconstructen te werken wanneer we de rol van deze constructen in pijn willen onderzoeken en dat het adequaat is om verschillende individuele vragenlijsten te gebruiken om de verschillende constructen uit het model te meten.

In hoofdstuk 4 werd de relatie tussen de pijnrelevante fundamentele angsten (AS en IS) en het voorkomen van een automatische dreigassociatie ten aanzien van gezondheidsbedreigende en pijngerelateerde woordstimuli onderzocht. Deze vraagstelling was gefundeerd op de cognitieve informatieverwerkingstheorieën, die stellen dat automatische attitudes en associaties mogelijk betere voorspellers zijn voor spontane gedragingen (zo ook pijngedragingen) dan expliciet gemeten attitudes (bijv. Shiffrin \& Schneider, 1977; McNally, 1995). De automatische dreigassociatie werd gemeten met de extrinsic affective simon task (EAST; De Houwer, 2003). In deze gecomputeriseerde taak worden automatische dreigassociaties indirect gemeten middels de registratie van reactietijden en fouten op een classificatie taak. In hoofdstuk 4 werden ook twee expliciete gedragsmaten meegenomen; het zelfgerapporteerde gebruik van gezondheidsdiensten (zoals medicatiegebruik, artsenbezoek etc.) en de zelfgerapporteerde neiging om gezondheidsbeschermende en 
preventieve acties te ondernemen (zoals preventieve medische onderzoeken ondergaan of het mijden van plaatsen waar mogelijk ziektegevaar geldt). De resultaten tonen aan dat naarmate personen een hoger niveau van AS of IS bezitten, zij ook sterkere associaties bezitten tussen dreiging en woordstimuli die gerelateerd zijn aan pijn of ziekte. Daarnaast bleek er een verschil te bestaan in de voorspellende waarde van AS en IS voor de expliciete gedragsmaten. IS resulteerde als de enige voorspeller voor het ondernemen van gezondheidsbeschermende acties, terwijl AS de beste voorspeller was van het zelfgerapporteerde gebruik van gezondheidsvoorzieningen. Deze resultaten suggereren dat beide fundamentele angstconstructen gerelateerd zijn aan het bestaan van een automatische dreigassociatie ten aan zien van gezondheidsbedreigende en pijngerelateerde woorden, maar dat beide constructen differentieel bijdragen aan expliciet gerapporteerde gedragingen.

Hoofdstuk 5 beschrijft een studie waarin onderzocht werd of er een inhoudsspecifieke relatie bestaat tussen verschillende angstgerelateerde persoonlijkheidsconstructen en een expliciete negatieve interpretatie bias voor ambigue situaties die overeenstemmen met de inhoud van deze specifieke constructen. In deze studie vulden gezonde vrijwilligers een aantal vragenlijsten in. De interpretatiebias werd gemeten met een vignet vragenlijst, de Body Sensations Interpretation Questionnaire (BSIQ: Clark et al., 1997), waarin 27 ambigue situaties geschetst worden in de volgende 4 domeinen: (i) paniekgerelateerde sensaties, (ii) andere lichamelijke symptomen, (iii), sociale gebeurtenissen en (iv) algemene gebeurtenissen. Daarnaast vulden de deelnemers vragenlijsten in die verschillende angst- en vreesconstructen uit het hiërarchisch model maten, namelijk trekangst, AS, IS, angst voor negatieve evaluatie, pijn catastroferen en vrees voor pijn. Eveneens werd optimisme gemeten. Resultaten van correlationele en multipele regressie analyses, met negatieve interpretatiescores op de vier BSIQ domeinen als afhankelijke variabelen toonden aan dat optimisme voorspellend was voor minder negatieve interpretaties op ieder domein. Bovendien resulteerden AS, IS, en angst voor negatieve evaluatie als de beste voorspellers voor negatieve interpretatiescores op het domein van respectievelijk paniekgerelateerde sensaties, andere lichamelijke symptomen en sociale gebeurtenissen. Wanneer specifieke aan pijn gerelateerde constructen (pijn catastroferen en pijngerelateerde vrees) aan het regressiemodel werden toegevoegd bleek overigens dat niet langer IS, maar wel deze laatst toegevoegde constructen voorspellend waren voor negatieve interpretaties in het domein van andere lichamelijke symptomen. Ondanks het correlationele karakter van de studie zoals beschreven in hoofdstuk 5, wijzen deze resultaten in de richting van de aanwezigheid van een inhoudsspecifieke relatie tussen bepaalde angst- en vrees constructen en interpretatiefouten die specifiek zijn voor situaties die refereren naar de inhoud van deze angst of vrees.

In hoofdstuk 6 wordt onderzocht of individuele niveaus van pijngerelateerde angst en vrees geassocieerd zijn met een verhoogde tendens om ambigue situaties die een gezondheidsdreiging kunnen impliceren negatief te interpreteren op een automatisch niveau. Eerdere studies, waaronder die in hoofdstuk 5, toonden reeds aan dat pijnpatiënten of personen met een verhoogde mate van pijngerelateerde angst een negatieve interpretatiebias vertonen voor pijngerelateerd of gezondheidsbedreigend materiaal. Men kan zich echter afvragen in welke mate deze veelal expliciet gemeten interpretaties ook overeenkomen met de automatische en spontane interpretaties (cf. on-line interpretaties) die personen maken op het moment dat zij geconfronteerd 


\section{Samenvatting (Dutch Summary)}

worden met ambiguiteit. Automatische interpretaties werden in hoofdstuk 6 indirect gemeten met behulp van een lexicaal beslissingsparadigma (Hirsch \& Mathews, 1997; Hirsch \& Mathews, 2000). Dit paradigma was gebaseerd op onderzoek in het domein van sociale angst en werd gemodificeerd voor toepasbaarheid binnen het domein van chronische pijn. Gezonde proefpersonen voerden de lexicale beslissingstaak uit en vulden tevens een aantal vragenlijsten in waarmee pijngerelateerde angst en vrees gemeten werden. De resultaten toonden aan dat, onafhankelijk van het niveau van angst of vrees, er een algemene tendens bestond voor het negatief interpreteren van de ambigue situaties die werden aangeboden in de lexicale beslissingstaak. Deze algemene interpretatiebias was gecorreleerd met de mate van pijngerelateerde vrees, maar niet met de andere persoonlijkheidsconstructen die gemeten werden in deze studie. In het discussiegedeelte van hoofdstuk 6 wordt beargumenteerd dat het waarschijnlijk is dat methodologische tekortkomingen , met name op het niveau van het gebruikte stimulusmateriaal, aan de basis liggen van de bevindingen uit dit hoofdstuk. Hoewel het lexicale beslissingparadigma op zich een veelbelovend paradigma lijkt voor het meten van spontane, automatische interpretaties, dient het aanbeveling dat dit paradigma verder afgestemd en gemodificeerd wordt in toekomstige studies om de toepasbaarheid ervan binnen het domein van chronische pijn te optimaliseren.

Hoofdstuk 7 van dit proefschrift gaat nader in op het onderbrekende en aandachtsopeisende karakter van pijn, het zogenaamde 'interferentie-effect' van pijn op aandacht (Crombez et al., 1996, 1998b; Crombez et al., 1999; Eccleston, 1994; Eccleston \& Crombez, 1999). Het interferentie-effect werd reeds veelvuldig onderzocht in voorgaande studies middels het primaire taakparadigma. Deze studies tonen aan dat pijn inderdaad aandacht opeist ten koste van andere cognitieve activiteiten, en dat onder andere de waargenomen dreigwaarde, de nieuwheid, en de temporele onvoorspelbaarheid van pijn dit effect beïnvloeden (Crombez et al., 1998a; Van Damme, Crombez, Eccleston, \& Roelofs, 2004). Daarnaast blijkt het interferentie-effect meer uitgesproken te zijn bij personen die geneigd zijn om de betekenis en gevolgen van pijn uit te vergroten, zoals bijvoorbeeld het geval is bij personen die een verhoogd niveau van pijn catastrofen bezitten (Crombez et al., 1998a, 1998b; Van Damme, Crombez, Eccleston et al., 2004). De studie die beschreven staat in hoofdstuk 7 van dit proefschrift heeft enerzijds tot doel om deze eerdere bevindingen te repliceren, en anderzijds om na te gaan of het interferentie-effect ook gerelateerd kan worden aan niveaus van IS en AS. Het replicatie gedeelte van dit hoofdstuk was succesvol, en versterkt eerdere bevindingen over een verhoogd interferentie-effect van pijn op aandacht in personen die catastroferen over pijn. Het interferentie-effect bleek echter niet gerelateerd te zijn aan de mate van IS of AS.

Hoofdstuk 8 beschrijft een studie waarin de mogelijk positieve invloed van twee cognitieve factoren, waargenomen controle en self-efficacy, op de pijnervaring onderzocht werd. Hiertoe werd een experiment opgezet waarbij zowel waargenomen controle als self-efficacy gemanipuleerd werden. Pijn werd geïnduceerd door het toedienen van een (afgestemde) elektrische pijnprikkel. Afhankelijk van de experimentele conditie waaraan de deelnemers willekeurig werden toegewezen, hadden zij al dan niet het idee dat de elektrische pijnprikkel controleerbaar was (manipulatie waargenomen controle) en of zij al dan niet goed in het toepassen van een techniek waarmee de pijnprikkel beïnvloed kon worden (manipulatie self-efficacy). Resultaten toonden aan personen die het idee hadden dat de pijnprikkel controleerbaar was over het algemeen minder 


\section{At risk for pain}

angst vertoonden voor de aankomende pijnstimulus. Daarnaast bleek geïnduceerde self-efficacy geassocieerd met een significante reductie in verwachte intensiteit en onplezierigheid van de aankomende pijnprikkel, en werd de relatie tussen SE en ervaren pijnintensiteit gemedieerd door de verwachte pijnintensiteit. De bevindingen uit hoofdstuk 8 tonen het belang aan van factoren als waargenomen controle en vooral self-efficacy in het bepalen van subjectieve responsen op een pijnervaring. Het wordt aanbevolen dat, om subjectieve aanpassing aan pijn te bekomen, pijnbehandelingen meer aandacht moeten schenken aan deze specifieke factoren.

Naast een samenvatting van de resultaten uit dit proefschrift, bevat hoofdstuk $\mathbf{9}$ een bediscussiëring van deze resultaten tegen de achtergrond van relevante literatuur die in dit onderzoeksdomein verschenen is. In hoofdstuk 9 wordt verder aandacht besteedt aan de beperkingen van de studies in dit proefschrift, de klinische implicaties van de bevindingen en het toelichten van aanbevelingen voor vervolgonderzoek.

In het algemeen kan geconcludeerd worden dat de studies in dit proefschrift ondersteuning bieden voor de gehypothetiseerde rol van de angstgerelateerde constructen en informatieverwerkingsfouten die centraal stonden in ditproefschriftals mogelijkekwetsbaarheidfactor voor (chronische) pijn. Verder onderzoek zal moeten uitwijzen welke nu de precieze unieke, maar ook de interactieve, bijdrage van deze psychologische factoren is aan de ontwikkeling en het blijven voortbestaan van langdurige aspecifieke pijnklachten. 


\section{- - \\ References}


Amir, N., Beard, C., \& Bower, E. (2005). Interpretation bias and social anxiety. Cognitive Therapy and Research, 29, 433-443.

Amir, N., Foa, E. B., \& Coles, M. E. (1998). Negative interpretation bias in social phobia. Behaviour Research and Therapy, 36(945-957).

Andersson, G. (1996). The benefits of optimism: A meta-analytic review of the Life Orientation Test. Personality and Individual Differences, 21, 719-725.

Arnstein, P. (2000). The mediation of disability by self efficacy in different samples of chronic pain patients. Disability and Rehabilitation: An International Multidisciplinary Journal, 22, 794-801.

Arntz, A., \& Schmidt, J. M. (1989). Perceived control and the experience of pain. In A. Steptoe \& A. Appels (Eds.), Stress, personal control, and health. (pp. 131-162). Chichester: Wiley.

Asendorpf, J. B. (2007). Implicit representations and personality. International Journal of Psychology, 42, 145-148.

Asendorpf, J. B., Banse, R., \& Mucke, D. (2002). Double dissociation between implicit and explicit personality selfconcept: the case of shy behavior. Journal of Personality and Social Psychology, 83, 380-393.

Asmundson, G. J., \& Carleton, R. (2005). Fear of pain is elevated in adults with co-occurring trauma-related stress and social anxiety symptoms. Cognitive Behaviour Therapy, 34, 248-255.

Asmundson, G. J., \& Hadjistavropoulos, H. D. (2007). Is high fear of pain associated with attentional bias for pain-related or general threat?A categorical reanalysis. Journal of Pain, 8, 11-18.

Asmundson, G. J., Kuperos, J. L., \& Norton, G. R. (1997). Do patients with chronic pain selectively attend to painrelated information?: preliminary evidence for the mediating role of fear. Pain, 72, 27-32.

Asmundson, G. J., \& Norton, G. R. (1995). Anxiety sensitivity in patients with physically unexplained chronic back pain: a preliminary report. Behav Res Ther, 33(7), 771-777.

Asmundson, G. J., \& Taylor, S. (1996). Role of anxiety sensitivity in pain-related fear and avoidance. J Behav Med, 19(6), 577-586.

Asmundson, G. J. G., Carleton, N. R., \& Ekong, J. (2005). Dot-probe evaluation of selective attentional processing of pain cues in patients with chronic headaches. Pain, 114, 250-256.

Asmundson, G. J. G., Norton, P. J., \& Norton, G. R. (1999). Beyond pain: The role of fear and avoidance in chronicity. Clinical Psychology Review, 19, 97-119.

Asmundson, G. J. G., Wright, K. D., \& Hadjistavropoulos, H. D. (2000). Anxiety sensitivity and disabling chronic health conditions: State of the art and future directions. Scandinavian Journal of Behaviour Therapy, 29, 100117.

Asmundson, G. J. G., Wright, K. D., Norton, P. J., \& Veloso, F. (2001). Anxiety sensitivity and other emotionality constructs in predicting headache medication use in patients with recurring headaches: implications for abuse and dependency. Addictive Behaviours, 26, 827-840.

Austin, D. W., Richards, J. C., \& Klein, B. (2006). Modification of the Body Sensations Interpretation Questionnaire (BSIQ-M): validity and reliability. Journal of anxiety Disorders, 20, 237-251.

Baker, S. L., \& Kirsch, I. (1991). Cognitive mediators of pain perception and tolerance. Journal of Personality and Social Psychology, 61, 504-510.

Bandura, A. (1977). Self-efficacy: toward a unifying theory of behavior change. Psychological Review, 84, 191-215.

Bandura, A. (1983). Self-efficacy determinants of anticipated fears and calamities. Journal of Personality and Social Psychology, 45, 464-469.

Bandura, A., Cioffi, D., Taylor, C. B., \& Brouillard, M. E. (1988). Perceived self-efficacy in coping with cognitive stressors and opioid activation. Journal of Personality and Social Psychology, 55, 479-488. 


\section{References}

Barlow, D. H. (2000). Unraveling the mysteries of anxiety and its disorders from the perspective of emotion theory. American Psychologist, 55, 1247-1263.

Baron, R. M., \& Kenny, D. A. (1986). The moderator-mediator variable distinction in social psychological research: Conceptual, strategic, and statistical considerations. Journal of Personality and Social Psychology, 51, 1173-1182.

Beck, A. T., \& Clark, D. A. (1997). An information processing model of anxiety: Automatic and strategic processes. Behaviour Research and Therapy, 35(1), 49-58.

Benini, A., \& DeLeo, J. A. (1999). Rene Descartes' physiology of pain. Spine, 24, 2115-2119.

Bentler, P. M., \& Bonnet, D. G. (1980). Significance tests and goodness-of-fit in the analysis of covariance structures. Psychological Bulletin, 88, 588-606.

Blais, M. A., Otto, M. W., Zucker, B. G., McNally, R. J., Schmidt, N. B., Fava, M., et al. (2001). The Anxiety Sensitivity Index: Item analysis and suggestions for refinement. Journal of Personality Assessment, 77, 272-294.

Boersma, K., Linton, S. J., Overmeer, T., Jansson, M., Vlaeyen, J. W. S., \& de Jong, J. (2004). Lowering fear-avoidance and enhancing function through exposure in vivo. A multiple baseline study across six patients with back pain. Pain, 108, 8-16.

Bonica, J. J. (1991). History of pain concepts and pain therapy. The Mount Sinai Journal of Medicine, 58, 191-202.

Bosson, J. K., Swann, W. B., \& Pennebaker, J. W. (2000). Stalking the perfect measure of implicit self-esteem: the blind man and the elephant revisited? Journal of Personality and Social Psychology, 27, 631-643.

Brown, M., Smits, J. A. J., Powers, M. B., \& Telch, M. J. (2003). Differential sensitivity of the three ASI factors in predicting panic disorder patients' subjective and behavioral response to hyperventilation challenge. Journal of Anxiety Disorders, 17, 583-591.

Calvo, M. G., Eysenck, M. W., \& Castillo, M. D. (1997). Interpretation bias in test anxiety: the time course of predictive inferences. Cognition and Emotion, 11, 43-63.

Carleton, N. R., Asmundson, G. J. G., \& Taylor, S. (2005). Fear of physical harm: factor structure and psychometric properties of the injury/llness sensitivity index. Journal of Psychopathology and Behavioural Assessment, 27, 235-241.

Carleton, N. R., McCreary, D. R., Norton, P. J., \& Asmundson, G. J. G. (2006). Brief fear of negative evaluation scalerevised. Depression and Anxiety, 23, 297-303.

Carleton, R. N., Park, I., \& Asmundson, G. J. (2006). The Illness/Injury Sensitivity Index: an examination of construct validity. Depression and Anxiety, 23, 340-346.

Carter, M. M., Suchday, S., \& Gore, K. L. (2001). The utility of the ASI factors in predicting response to voluntary hyperventilation among nonclinical participants. Journal of Anxiety Disorders, 15, 217-230.

Carver, C. S., \& Scheier, M. F. (2005). Optimism. In C. R. Snyder \& S. J. Lopez (Eds.), Handbook of positive psychology. (pp. 231-243). Oxford: University Press.

Chulef, A. S., Read, S. J., \& Walsh, D. A. (2001). A hierarchical taxonomy of human goals. Motivation and Emotion, 25, 191-232.

Clark, D. M. (1986). A cognitive approach to panic. Behaviour Research and Therapy, 24, 461-470.

Clark, D. M., Salkovskis, P. M., Ost, L. G., Breitholtz, E., Koehler, K. A., Westling, B. E., et al. (1997). Misinterpretation of body sensations in panic disorder. Journal of Consulting and Clinical Psychology, 65, 203-213.

Clark, L. A., \& Watson, D. (1991). Tripartite model of anxiety and depression: psychometric evidence and taxonomic implications. Journal of Abnormal Psychology, 100, 316-336. 
Clark, W. C., Ferrer Brechner, T., Janal, M. N., Carroll, J. D., \& Yang, J. C. (1989). The dimensions of pain: a multidimensional scaling comparison of cancer patients and healthy volunteers. Pain, 37, 23-32.

Clark, W. C., Janal, M. N., Hoben, E. K., \& Carroll, J. D. (2001). How separate are the sensory, emotional, and motivational dimensions of pain? A multidimensional scaling analysis. Somatosensory and Motor Research, 18, 31-39.

Collins, K. A., Westra, H. A., Dozois, D. J. A., \& Stewart, S. H. (2005). The validity of the brief version of the Fear of Negative Evaluation Scale. Journal of Anxiety Disorders, 19, 345-359.

Coons, M. J., Hadjistavropoulos, H. D., \& Asmundson, G. J. G. (2004). Factor structure and psychometric properties of the Pain Anxiety Symptoms Scale-20 in a community physiotherapy clinic sample. European Journal of Pain, 8, 511-516.

Corter, J. (1996). Tree models of similarity and association. Thousands Oaks, CA: Sage.

Corter, J. E. (1982). ADDTREE/P: A PASCAL program for fitting additive trees based on Sattah, \& Tversky's ADDTREE program. Behaviour reserach methods and instrumentation., 14, 353-354.

Cox, B. J. (1996). The nature and assessment of catastrophic thoughts in panic disorder. Behaviour Research and Therapy, 34, 363-374.

Crombez, G., Baeyens, F., \& Eelen, P. (1994). Sensory and temporal information about impending pain: the influence of predictability on pain. Behaviour Research and Therapy, 32, 611-622.

Crombez, G., Eccleston, C., Baeyens, F., \& Eelen, P. (1996). The disruptive nature of pain: an experimental investigation. Behaviour Research and Therapy, 34, 911-918.

Crombez, G., Eccleston, C., Baeyens, F., \& Eelen, P. (1997). Habituation and the interference of pain with task performance. Pain, 70, 149-154.

Crombez, G., Eccleston, C., Baeyens, F., \& Eelen, P. (1998a). Attentional disruption is enhanced by the threat of pain. Behaviour Research and Therapy, 36, 195-204.

Crombez, G., Eccleston, C., Baeyens, F., \& Eelen, P. (1998b). When somatic information threatens, catastrophic thinking enhances attentional interference. Pain, 75, 187-198.

Crombez, G., Eccleston, C., Baeyens, F., Van Houdenhove, B., \& Van Den Broeck, A. (1999). Attention to chronic pain is dependent upon pain-related fear. Journal of Psychosomatic Research, 47, 403-410.

Crombez, G., Eccleston, C., van den Broeck, A., van Houdenhove, B., \& Goubert, L. (2002). The effects of catastrophic thinking about pain on attentional interference by pain: No mediation of negative affectivity in healthy volunteers and in patients with low back pain. Pain Research and Management, 7, 31-39.

Crombez, G., \& Vlaeyen, J. W. S. (1996). The Pain Catastrophizing Scale. Unpublished Dutch/Flemisch translation.

De Houwer, J. (2001). A structural and process analysis of the Implicit Association Test. Journal of Experimental and Social Psychology, 37, 443-451.

De Houwer, J. (2003). The extrinsic affective Simon task. Experimental Psychology, 50, 77-85.

de Jong, J. R., Vlaeyen, J. W. S., Onghena, P., Goossens, M. E. J. B., Geilen, M., \& Mulder, H. (2005). Fear of Movement/ (Re)injury in Chronic Low Back Pain: Education or Exposure In Vivo as Mediator to Fear Reduction? Clinical Journal of Pain, 21, 9-17.

de Jong, P. J., Hout van den, M. A., Rietbroek, H., \& Huijding, J. (2003). Dissociations between implicit and explicit attitudes toward phobic stimuli. Cognition and Emotion, 17, 521-545.

de Jong, P. J., Wiers, R. W., van den Braak, M., \& Huijding, J. (2007). Using the Extrinsic Affective Simon Test as a measure of implicit attitudes toward alcohol: Relationship with drinking behavior and alcohol problems. Addictive Behaviors, 32, 881-887. 


\section{References}

Deacon, B. J., Abramowitz, J. S., Woods, C. M., \& Tolin, D. F. (2003). The Anxiety Sensitivity Index - Revised: psychometric properties and factor structure in two nonclinical samples. Behaviour Research and Therapy, $41,1427-1249$.

Dehghani, M., Sharpe, L., \& Nicholas, M. K. (2004). Modification of attentional biases in chronic pain patients: a preliminary study. European Journal of Pain, 8, 585-594.

Denison, E., Asenlof, P., \& Lindberg, P. (2004). Self-efficacy, fear avoidance, and pain intensity as predictors of disability in subacute and chronic musculoskeletal pain patients in primary health care. Pain, 111, 245-252.

Devine, D. P., \& Spanos, N. P. (1990). Effectiveness of maximally different cognitive strategies and expectancy in attenuation of reported pain. Journal of Personality and Social Psychology, 58, 672-678.

Drahovzal, D. N., Stewart, S. H., \& Sullivan, M. J. L. (2006). Tendency to catastrophize somatic sensations: pain catastrophizing and anxiety sensitivity in predicting headache. Cognitive Behaviour Therapy, 35, 226-235.

Eccleston, C. (1994). Chronic pain and attention: A cognitive approach. British Journal of Clinical Psychology, 33, 535-547.

Eccleston, C., \& Crombez, G. (1999). Pain demands attention: A cognitive-affective model of the interruptive function of pain. Psychological Bulletin, 125, 356-366.

Eccleston, C., Crombez, G., Aldrich, S., \& Stannard, C. (1997). Attention and somatic awareness in chronic pain. Pain, 72, 209-215.

Edwards, L. C., Pearce, S., Collett, B., \& Pugh, R. (1992). Selective memory for sensory and affective information in chronic pain and depression. British Journal of Clinical Psychology, 31, 239-248.

Edwards, L. C., \& Pearce, S. A. (1994). Word completion in chronic pain: Evidence for schematic representation of pain? Journal of Abnormal Psychology, 103, 379-382.

Eysenck, M. W. (1997). Anxiety and Cognition: A unified theory. Hove: Psychology Press/Erlbaum.

Fazio, R. H., \& Olson, M. A. (2003). Implicit measures in social cognition research: their meaning and use. Annual Review of Psychology, 54, 297-327.

Feldner, M. T., \& Hekmat, H. (2001). Perceived control over anxiety-related events as a predictor of pain behaviors in a cold pressor task. Journal of Behaviour Therapy and Experimental Psychiatry, 32, 191-202.

Fitzgerald, T. E., Tennen, H., Affleck, G., \& Pransky, G. S. (1993). The relative importance of dispositional optimism and control appraisals in quality of life after coronary artery bypass surgery. Journal of Behavioral Medicine, 16, $25-43$.

Fritz, J. M., George, S. Z., \& Delitto, A. (2001). The role of fear-avoidance beliefs in acute low back pain: relationships with current and future disability and work status. Pain, 94, 7-15.

Garcia Lopez, L. J., Olivares, J., Hidalgo, M. D., Beidel, D. C., \& Turner, S. M. (2001). Psychometric properties of the social phobia and anxiety inventory, the social anxiety scale for adolescents, the fear of negative evaluation scale, and the social avoidance and distress scale in an adolescent Spanish-speaking sample. Journal of Psychopathology and Behavioural Assessment, 23, 51-59.

Gardiner, H. M., Metcalf, R. C., \& Beebe Center, J. G. (1937). The Doctrine of Pleasure, Pain, and Emotion in Aristotle. In Feeling and emotion: A history of theories. (pp. 26-57). Salt Lake City, UT, US: American Book Publishing.

Gatchel, R. J., Peng, Y. B., Peters, M. L., Fuchs, P. N., \& Turk, D. C. (in press). The biopsychosocial approach to chronic pain: scientific advances and future directions. Psychological Bulletin.

Giummarra, M. J., Gibson, S. J., Georgiou Karistianis, N., \& Bradshaw, J. L. (2007). Central mechanisms in phantom limb perception: the past, present and future. Brain Research Reviews, 54, 219-232. 
Goubert, L., Crombez, G., \& De Bourdeaudhuij, I. (2004). Low back pain, disability and back pain myths in a community sample: prevalence and interrelationships. European Journal of Pain, 8, 385-394.

Goubert, L., Crombez, G., Hermans, D., \& Vanderstraeten, G. (2003). Implicit attitude towards pictures of back-stressing activities in pain-free subjects and patients with low back pain. European Journal of Pain, 7, 33-42.

Goubert, L., Crombez, G., Van Damme, S., Vlaeyen, J. W. S., Bijttebier, P., \& Roelofs, J. (2004). Confirmatory factor analysis of the Tampa Scale for Kinesiophobia: invariant two-factor model across low back pain patients and fibromyalgia patients. Clinical Journal of Pain, 20, 103-110.

Goubert, L., Eccleston, C., Vervoort, T., Jordan, A., \& Crombez, G. (2006). Parental catastrophizing about their child's pain. Pain, 123, 254-263.

Greenberg, J., \& Burns, J. W. (2003). Pain anxiety among chronic pain patients: Specific phobia or manifestation of anxiety sensitivity? Behaviour Research and Therapy, 41, 223-240.

Greenwald, A. G., McGhee, D. E., \& Schwartz, J. L. K. (1998). Measuring individual differences in implicit cognition: an affective priming study. Journal of Personality and Social Psychology, 74, 1464-1480.

Hadjistavropoulos, H. D., Asmundson, G. J., LaChapelle, D. L., \& Quine, A. (2002). The role of health anxiety among patients with chronic pain in determining response to therapy. Pain Research and Management, 7, 127133.

Hadjistavropoulos, H. D., Asmundson, G. J. G., \& Kowalyk, K. M. (2004). Measures of anxiety: Is there a difference in their ability to predict functioning at three-month follow-up among pain patients? European Journal of Pain, 8, 1-11.

Hadjistavropoulos, H. D., \& Hadjistavropoulos, T. (2003). The relevance of health anxiety to chronic pain: research findings and recommendations for assessment and treatment. Current Pain and Headache Reports, 7 , 98-104.

Harvey, J. M., Richards, J. C., Dziadosz, T., \& Swindell, A. (1993). Misinterpretation of ambiguous stimuli in panic disorder. Cognitive Therapy and Research, 17, 235-248.

Hirsch, C., Clark, D. M., \& Mathews, A. (2006). Imagery and interpretations in social phobia: support for the combined cognitive bias hypothesis. Behavior Therapy, 37, 223-236.

Hirsch, C., \& Mathews, A. (1997). Interpretive inferences when reading about emotional events. Behaviour Research and Therapy, 35, 1123-1132.

Hirsch, C. R., \& Mathews, A. (2000). Impaired positive inferential bias in social phobia. Journal of Abnormal Psychology, 109, 705-712.

Houben, R. M. A., Gijsen, A., Peterson, J., De Jong, P. J., \& Vlaeyen, J. W. S. (2005). Do health care providers' attitudes towards back pain predict their treatment recommendations? Differential predictive validity of implicit and explicit measures. Pain, 114, 491-498.

$\mathrm{Hu}$, L. t., \& Bentler, P. M. (1999). Cutoff criteria for fit indexes in covariance structure analysis: Conventional criteria versus new alternatives. Structural Equation Modeling, 6, 1-55.

Huijding, J., \& De Jong, P. J. (2005). A pictorial version of the Extrinsic Affective Simon Task: sensitivity to generally affective and phobia-relevant stimuli in high and low spider fearful individuals. Experimental Psychology, 52, 289-295.

Huijding, J., \& de Jong, P. J. (2006). Specific predictive power of automatic spider-related affective associations for controllable and uncontrollable fear responses toward spiders. Behaviour Research and Therapy, 44, 161176. 


\section{$\star$ netereneses}

Hunt, C., Keogh, E., \& French, C. C. (2006). Anxiety Sensitivity: The Role of Conscious Awareness and Selective Attentional Bias to Physical Threat. Emotion, 6, 418-428.

Jackson, T., lezzi, T., Gunderson, J., Nagasaka, T., \& Fritch, A. (2002). Gender differences in pain perception: The mediating role of self-efficacy beliefs. Sex Roles, 47, 561-568.

Jacoby, L. L. (1991). A process dissociation framework, separating automatic from intentional uses of memory. Journal of Memory and Language, 30, 513-541.

Janssen, S. A., Spinhoven, P., \& Arntz, A. (2004). The effects of failing to control pain: an experimental investigation. Pain, 107, 227-233.

Jensen, M. P., Brant-Zawadzki, M., Obuchowski, N., Modic, M., Malkasian, D., \& Ross, J. (1994). Magnetic resonance imaging of the lumbar spine in people without back pain. The New England Journal of Medicine, 331, 6973.

Jensen, M. P., \& Karoly, P. (1991). Control beliefs, coping efforts, and adjustment to chronic pain. Journal of Consulting and Clinical Psychology, 59, 431-438.

Jensen, M. P., Romano, J. M., Turner, J. A., Good, A. B., \& Wald, L. H. (1999). Patient beliefs predict patient functioning: further support for a cognitive-behavioural model of chronic pain. Pain, 81, 95-104.

Jöreskog, K. G. (1990). New developments in LISREL: analysis of ordinal variables using polychoric correlations and weighted least squares. Quality and Quantity, 24, 387-404.

Jöreskog, K. G., \& Sörbom, D. (2001). LISREL 8.54. Chicago: Scientific Software International.

Keefe, F. J., Rumble, M. E., Scipio, C. D., Giordano, L. A., \& Perri, L. M. (2004). Psychological aspects of persistent pain. The Journal of Pain, 5, 195-211.

Keogh, E. (2004). Investigating invariance in the factorial structure of the anxiety sensitivity index across adult men and women. Journal of Personality Assessment, 83, 153-160.

Keogh, E., \& Asmundson, G. J. G. (2004). Negative affectivity, catastrophizing, and anxiety sensitivity. In G. J. G. Asmundson, J. W. S. Vlaeyen \& G. Crombez (Eds.), Understanding and treating fear of pain. (pp. 91-115). New York: Oxford University press.

Keogh, E., Barlow, C., Mounce, C., \& Bond, F. W. (2006). Assessing the relationship between cold pressor pain responses and dimensions of the anxiety sensitivity profile in healthy mean and women. Cognitive Behaviour Therapy, 35, 198-206.

Keogh, E., \& Birkby, J. (1999). The effect of anxiety sensitivity and gender on the experience of pain. Cognition and Emotion, 13, 813-829.

Keogh, E., \& Cochrane, M. (2002). Anxiety sensitivity, cognitive biases, and the experience of pain. Journal of Pain, 3 , 320-329.

Keogh, E., Dillon, C., Georgiou, G., \& Hunt, C. (2001). Selective attentional biases for physical threat in physical anxiety sensitivity. Journal of Anxiety Disorders, 15, 299-315.

Keogh, E., Ellery, D., Hunt, C., \& Hannent, I. (2001). Selective attentional bias for pain-related stimuli amongst pain fearful individuals. Pain, 91, 91-100.

Keogh, E., Hamid, R., Hamid, S., \& Ellery, D. (2004). Investigating the effect of anxiety sensitivity, gender and negative interpretative bias on the perception of chest pain. Pain, 111, 209-217.

Keogh, E., \& Mansoor, L. (2001). Investigating the effects of anxiety sensitivity and coping on the perception of cold pressor pain in healthy women. European Journal of Pain, 5, 11-22.

Keogh, E., Thompson, T., \& Hannent, I. (2003). Selective attentional bias, conscious awareness and the fear of pain. Pain, 104, 85-91. 
Kerssens, J. J., Verhaak, P. F., Bartelds, A. I., Sorbi, M. J., \& Bensing, J. M. (2002). Unexplained severe chronic pain in general practice. European Journal of Pain, 6, 203-212.

Kirsch, I. (1997). Response expectancy theory and application: A decennial review. Applied and Preventive Psychology, 6, 69-79.

Kline, P. (2000). The handbook of psychological testing. (2nd ed.). London: Routledge.

Koster, E. H. W., Crombez, G., Verschuere, B., Van Damme, S., \& Wiersema, J. R. (2006). Components of attentional bias to threat in high trait anxiety: Facilitated engagement, impaired disengagement, and attentional avoidance. Behaviour Research and Therapy, 44, 1757-1771.

Kruskal, J. B., \& Wish, M. (1978). Multidimensional scaling. Beverly Hills, CA: Sage.

Lang, A. J., \& Craske, M. G. (1997). Information processing in anxiety and depression. Behaviour Research and Therapy, 35, 451-455.

Lang, A. J., Sorrell, J. T., Rodgers, W., \& Lebeck, M. M. (2006). Anxiety Sensitivity as a predictor of labor pain. European Journal of Pain, 10, 263-270.

Leary, M. R. (1983). A brief version of the fear of negative evaluation scale. Personality and Social Psychology Bulletin, 9, 371-375.

Leeuw, M., Goossens, M. E., Linton, S. J., Crombez, G., Boersma, K., \& Vlaeyen, J. W. (2007). The fear-avoidance model of musculoskeletal pain: current state of scientific evidence. Journal of Behavioral Medicine, 30, 77-94.

Lefaivre, M. j., Watt, M. C., Stewart, S. H., \& Wright, K. D. (2006). Implicit associations between anxiety-related symptoms and catastrophic consequences in high anxiety sensitive individuals. Cognition and Emotion, 20, 295-308

Lethem, J., Slade, P. D., Troup, J. D., \& Bentley, G. (1983). Outline of a Fear-Avoidance Model of exaggerated pain perception--I. Behav Res Ther, 21, 401-408.

Lilienfeld, S. O. (1996). Anxiety sensitivity is not distinct from trait anxiety. In R. M. Rapee (Ed.), Current controvesries in anxiety disorders (pp. 228-253). New York: The Guilford Press.

Lilienfeld, S. O., turner, S. M., \& Jacob, R. G. (1993). Anxiety sensitivity:an examination of theoretical and methodological issues. Advances in Behaviour Reserach and Therapy, 15, 147-183.

Lilienfeld, S. O., Turner, S. M., \& Jacob, R. G. (1998). Déjà vu all over again: critical misunderstandings concerning anxiety sensitivity and constructive suggestions for future research. Journal of Anxiety Disorders, 12, 71 . 82.

Litt, M. D. (1988). Self-efficacy and perceived control: cognitive mediators of pain tolerance. Journal of Personality and Social Psychology, 54, 149-160.

Luszczynska, A., Gutierrez Dona, B., \& Schwarzer, R. (2005). General self-efficacy in various domains of human functioning: Evidence from five countries. International Journal of Psychology, 40, 80-89.

Marlowe, D., \& Crowne, D. P. (1961). Social desirability and response to perceived situational demands. Journal of Counseling Psychology, 25, 109-115.

Mathews, A., \& Mackintosh, B. (1998). A cognitive model of selective processing in anxiety. Cognitive Therapy and Research, 22, 539-560.

Mathews, A., \& Mackintosh, B. (2000). Induced emotional interpretation bias and anxiety. Journal of Abnormal Psychology, 109, 602-615.

Mathews, A., \& MacLeod, C. (1994). Cognitive approaches to emotion and emotional disorders. Annual Review of Psychology, 45, 25-50. 


\section{References}

Mathews, A., \& MacLeod, C. (2002). Induced processing biases have causal effects on anxiety. Cognition and Emotion, $16,331-354$

McCracken, L. M. (2004). A behavioral analysis of pain-related fear responses. In G. J. G. Asmundson, J. W. S. Vlaeyen \& G. Crombez (Eds.), Understanding and treating fear of pain (pp. 51-69). New York: Oxford University press.

McCracken, L. M., \& Dhingra, L. (2002). A short version of the Pain Anxiety Symptoms Scale (PASS--20): Preliminary development and validity. Pain Research and Management, 7, 45-50.

McCracken, L. M., Gross, R. T., Aikens, J., \& Carnrike, C. L. M., Jr. (1996). The assessment of anxiety and fear in persons with chronic pain: A comparison of instruments. Behaviour Research and Therapy, 34, 927-933.

McCracken, L. M., Zayfert, C., \& Gross, R. T. (1992). The pain anxiety symptoms scale: development and validation of a scale to measure fear of pain. Pain, 50, 67-73.

McKellar, J. D., Clark, M. E., \& Shriner, J. (2003). The cognitive specificity of associative responses in patients with chronic pain. British Journal of Clinical Psychology, 42, 27-39.

McMurtry, B. W. (2005). Catastrophizing, fear and avoidance in the development of chronic pain. Dissertation Abstracts International: Section B: The Sciences and Engineering, 65, 4295.

McNally, R. J. (1995). Automaticity and the anxiety disorders. Behaviour Research and Therapy, 33, 747-754.

McNally, R. J. (1996). Anxiety sensitivity is distinguishable from trait anxiety. In R. M. Rapee (Ed.), Current controversies in anxiety disorders. (pp. 214-227). New York: The Guilford Press.

McNally, R. J., Hornig, C. D., Hoffman, E. C., \& Han, E. M. (1999). Anxiety sensitivity and cognitive biases for threat. Behavior Therapy, 30, 51-61.

McNeil, D. W., \& Rainwater, A. J. (1998). Development of the Fear of Pain Questionnaire--III. Journal of Behavioral Medicine, 21, 389-410.

McNeil, D. W., \& Vowles, K. E. (2004). Assessment of fear and anxiety associated with pain: Conceptualization, methods, and measures. In G. J. G. Asmundson, J. W. S. Vlaeyen \& G. Crombez (Eds.), Understanding and treating fear of pain. (pp. 189-211). New York: Oxford University Press.

McWilliams, L. A., \& Cox, B. J. (2001). How distinct is anxiety sensitivity from trait anxiety? A re-examination from a multidimensional perspective. Personality and Individual Differences, 31, 813-818.

Melzack, R., \& Wall, P. D. (1965). Pain Mechanisms: A new theory. Science, 150, 971-979.

Merskey, H., \& Bugduk, N. (1994). Report by the IASP Task Force on Taxonomy. In (2nd ed.). Seattle, WA: IASP Press.

Miller, R., Kori, S. H., \& Todd, D. (1991). The Tampa Scale for Kinesiophobia. Unpublished report.

Mogg, K., \& Bradley, B. P. (1998). A cognitive-motivational analysis of anxiety. Behaviour Research and Therapy, 36, 809-848.

Morley, S., \& Eccleston, C. (2004). The object of fear in pain. In G. J. Asmundson, J. W. Vlaeyen \& G. Crombez (Eds.), Understanding and treating fear of pain. (pp. 163-188). New York: Oxford University Press.

Muris, P., Vlaeyen, J. W. S., \& Meesters, C. (2001). The relationship between anxiety sensitivity and fear of pain in healthy adolescents. Behaviour Research and Therapy, 39, 1357-1368.

Norman, D. A., \& Shallice, T. (1986). Attention to action: willed and automatic control of behaviour. In R. J. Davidson, G. E. Schwartz \& D. Shapiro (Eds.), Consciousness and self-regulation. (pp. 1-18). New York: NY, Oxford University Press.

Norton, P. J., \& Asmundson, G. J. G. (2004). Anxiety sensitivity, fear, and avoidance behavior in headache pain. Pain, $111,218-223$. 
Nosek, B. (2007). Understanding the individual implicitly and explicitly. International Journal of Psychology, 42, 184188.

Öhman, A. (1979). The orienting response, attention, and learning: An information processing perspective. In H. D. Kimmel, E. H. Van Olst \& J. F. Orlebeke (Eds.), The orienting reflex in humans. (pp. 443-471). Hillsdale, NY: Lawrence Erlbaum Associates.

Öhman, A. (1993). Fear and anxiety as emotional phenomena. In M. Lewis \& J. Haviland (Eds.), Handbook of emotions (pp. 511-536). New York: Guilford Press.

Öhman, A. (2000). Fear and Anxiety: Evolutionary, Cognitive, and Clinical Perspectives. In M. Lewis \& J. M. HavilandJones (Eds.), Handbook of emotions. New York: Guilford Press.

Olatunji, B. O., Sawchuk, C. N., Deacon, B. J., Tolin, D. F., Lilienfeld, S. O., Williams, N. L., et al. (2005). The Anxiety Sensitivity Profile revisited: Factor structure and psychometric properties in two nonclinical samples. Journal of Anxiety Disorders, 19, 603-625.

Osman, A., Barrios, F. X., Kopper, B. A., Hauptmann, W., Jones, J., \& O’Neill, E. (1997). Factor structure, reliability, and validity of the Pain Catastrophizing Scale. Journal of Behavioral Medicine, 20, 589-605.

Osman, A., Barrios, F. X., Osman, J. R., Schneekloth, R., \& Troutman, J. A. (1994). The pain anxiety symptoms scale: psychometric properties in a community sample. Journal of Behavioral Medicine, 17, 511-522.

Paulhus, D. L. (1998). Two-component models of socially desirable responding. Journal of Personality and social psychology, 46, 598-609.

Pellino, T. A., \& Ward, S. E. (1998). Perceived control mediates the relationship between pain severity and patient satisfaction. Journal of Pain and Symptom Management, 15, 110-116.

Peters, M. L., Sommer, M., de Rijke, J. M., Kessels, A., Heineman, E., Patijn, J., et al. (2006). Somatic and psychological predictors of long-term unfavourable outcome after surgical intervention. Annals of Surgery, 245, 487494.

Peters, M. L., \& Vancleef, L. M. G. (in press). The role of personality traits in pain perception and disability. Reviews in Analgesia.

Peters, M. L., Vlaeyen, J. W. S., \& Kunnen, A. M. W. (2002). Is pain-related fear a predictor of somatosensory hypervigilance in chronic low back pain patients? Behaviour Research and Therapy, 40, 85-103.

Peterson, R. A., \& Heilbronner, R. L. (1987). The anxiety sensitivity index: construct validity and factor analytic structure. Journal of Anxiety Disorders, 1, 117-121.

Peterson, R. A., \& Reiss, R. J. (1992). Anxiety sensitivity index manual. (2nd ed.). Worthington, OH: International Diagnostic Systems.

Philips, H. C. (1987). Avoidance behaviour and its role in sustaining chronic pain. Behaviour Research and Therapy, 25, 273-279.

Picavet, H. S., \& Schouten, J. S. (2003). Musculoskeletal pain in the Netherlands: prevalences, consequences and risk groups, the DMC(3)-study. Pain, 102, 167-178.

Pincus, T., \& Morley, S. (2001). Cognitive-processing bias in chronic pain: A review and integration. Psychological Bulletin, 127, 599-617.

Pincus, T., Pearce, S., McClelland, A., Farley, S., \& et al. (1994). Interpretation bias in responses to ambiguous cues in pain patients. Journal of Psychosomatic Research, 38, 347-353.

Pincus, T., Pearce, S., McClelland, A., \& Isenberg, D. (1995). Endorsement and memory bias for pain stimuli in pain patients. British Journal of Clinical Psychology, 34, 267-277. 


\section{References}

Pincus, T., Pearce, S., \& Perrott, A. (1996). Pain patients' bias in the interpretation of ambiguous homophones. British Journal of Medical Psychology, 69, 259-266.

Ploeg van der, H. M., Defares, P. B., \& Spielberger, C. D. (1980). Handleiding bij de zelf-beoordelingsvragenlijst ZBV. Een nederlandstalige bewerking van de Spielberger State-trait Inventory. In. Lisse: Swets \& Zeitlinger B.V.

Reiss, S. (1991). Expectancy model of fear, anxiety, and panic. Clinical Psychology Review, 11, 141-153.

Reiss, S. (1997). Trait anxiety: it's not what you think it is. Journal of Anxiety Disord, 11, 201-214.

Reiss, S., Peterson, R. A., \& Gursky, D. M. (1988). Anxiety sensitivity, injury sensitivity, and individual differences in fearfulness. Behaviour Research and Therapy, 26, 341-345.

Reiss, S., Peterson, R. A., Gursky, D. M., \& McNally, R. J. (1986). Anxiety sensitivity, anxiety frequency and the prediction of fearfulness. Behaviour Research and Therapy, 24, 1-8.

Richards, J. C., Austin, D. W., \& Alvarenga, M. E. (2001). Interpretation of ambiguous interoceptive stimuli in panic disorder and nonclinical panic. Cognitive Therapy and Research, 25, 235-246.

Riemann, B. C., \& McNally, R. J. (1995). Cognitive processing of personally relevant information. Cognition and Emotion, 9, 325-340.

Rodriguez, B. F., Bruce, S. E., Pagano, M. E., Spencer, M. A., \& Keller, M. B. (2004). Factor structure and stability of the Anxiety Sensitivity Index in a longitudinal study of anxiety disorder patients. Behaviour Research and Therapy, 42, 79-91.

Roelofs, J., Goubert, L., Peters, M. L., Vlaeyen, J. W., \& Crombez, G. (2004). The Tampa Scale for Kinesiophobia: further examination of psychometric properties in patients with chronic low back pain and fibromyalgia. European Journal of Pain, 8, 495-502.

Roelofs, J., McCracken, L. M., Peters, M. L., Crombez, G., van Breukelen, G., \& Vlaeyen, J. W. S. (2004). Psychometric evaluation of the Pain Anxiety Symptoms Scale (PASS) in chronic pain patients. Journal of Behavioral Medicine, 27, 167-183.

Roelofs, J., Peters, M. L., Deutz, J., Spijker, C., \& Vlaeyen, J. W. S. (2005). The Fear of Pain Questionnaire (FPQ): Further psychometric examination in a non-clinical sample. Pain, 116, 339-346.

Roelofs, J., Peters, M. L., Fassaert, T., \& Vlaeyen, J. W. (2005). The role of fear of movement and injury in selective attentional processing in patients with chronic low back pain: a dot-probe evaluation. Journal of Pain, 6 , 294-300.

Roelofs, J., Peters, M. L., van der Zijden, M., Thielen, F. G. J. M., \& Vlaeyen, J. W. S. (2003). Selective Attention and Avoidance of Pain-Related Stimuli: A Dot-Probe Evaluation in a Pain-Free Population. Journal of Pain, 4, 322-328.

Roelofs, J., Peters, M. L., \& Vlaeyen, J. W. S. (2003). The modified Stroop paradigm as a measure of selective attention towards pain-related information in patients with chronic low back pain. Psychological Reports, 92, 707715.

Roelofs, J., Peters, M. L., Zeegers, M. P. A., \& Vlaeyen, J. W. S. (2002). The modified stroop paradigm as a measure of selective attention towards pain-related stimuli among chronic pain patients: a meta-analysis. European Journal of Pain, 6, 273-281.

Roelofs, J., Sluiter, J. K., Frings-Dresen, M. H. W., Goossens, M., Thibault, P., Boersma, K., et al. (in press). Fear of movement and (re)injury in chronis musculoskeletal pain: Evidence for an invariant two-factor model of the Tampa Scale for Kinesiophobia across pain diagnoses and Dutch, Swedish, and Canadian samples. Pain.

Rokke, P. D., Fleming Ficek, S., Siemens, N. M., \& Hegstad, H. J. (2004). Self-efficacy and choice of coping strategies for tolerating acute pain. Journal of Behavioral Medicine, 27, 343-360. 
Rosenberg, S., \& Gara, M. A. (1983). Contemporary perspectives and future directions of personality and social psychology. Journal of Personality and Social Psychology, 45, 57-73.

Salemink, E., van den Hout, M. A., \& Kindt, M. (2007). Trained interpretive bias: Validity and effects on anxiety. Journal of Behavior Therapy and Experimental Psychiatry, 38, 212-224.

Sandin, B., Chorot, P., \& McNally, R. J. (2001). Anxiety sensitivity index: normative data and its differentiation from trait anxiety. Behav Res Ther, 39, 213-219.

Sattah, S., \& Tversky, A. (1977). Additive similarity trees. Psychometrika, 42, 319-345.

Scheier, M. F., \& Carver, C. S. (1985). Optimism, coping, and health: Assessment and implications of generalized outcome expectancies. Health Psychology, 4, 219-247.

Scheier, M. F., \& Carver, C. S. (1992). Effects of optimism on psychological and physical well-being: Theoretical overview and empirical update. Cognitive Therapy and Research, 16, 201-228.

Scheier, M. F., Carver, C. S., \& Bridges, M. W. (1994). Distinguishing optimism from neuroticism (and trait anxiety, selfmastery, and self-esteem): A reevaluation of the Life Orientation Test. Journal of Personality and Social Psychology, 67, 1063-1078.

Scheier, M. F., Matthews, K. A., Owens, J. F., Magovern, G. J., \& et al. (1989). Dispositional optimism and recovery from coronary artery bypass surgery: The beneficial effects on physical and psychological well-being. Journal of Personality and Social Psychology, 57, 1024-1040.

Schmidt, N. B., \& Cook, J. H. (1999). Effects of anxiety sensitivity on anxiety and pain during a cold pressor challenge in patients with panic disorder. Behaviour Research and Therapy, 37, 313-323.

Schmidt, N. B., \& Joiner, T. E. (2002). Structure of the Anxiety Sensitivity Index psychometrics and factor structure in a community sample. Journal of Anxiety Disorders, 16, 33-49.

Scholz, U., Dona, B. G., Sud, S., \& Schwarzer, R. (2002). Is general self-efficacy a universal construct? Psychometric findings from 25 countries. European Journal of Psychological Assessment, 18, 242-251.

Schwarzer, R., Boehmer, S., Luszczynska, A., Mohamed, N. E., \& Knoll, N. (2005). Dispositional self-efficacy as a personal resource factor in coping after surgery. Personality and Individual Differences, 39, 807-818.

Schwarzer, R., \& Jerusalem, M. (1995). Generalized self-efficacy scale. In J. weinman, S. Wright \& M. Johnston (Eds.), Measures in health psychology: A user's portfolio. Causal and control beliefs. (pp. 35-37). Windsor, UK: NFER-NELSON.

Severeijns, R., van den Hout, M. A., Vlaeyen, J. W., \& Picavet, H. S. (2002). Pain catastrophizing and general health status in a large Dutch community sample. Pain, 99, 367-376.

Severeijns, R., Vlaeyen, J. W., van den Hout, M. A., \& Weber, W. E. (2001). Pain catastrophizing predicts pain intensity, disability, and psychological distress independent of the level of physical impairment. Clinical Journal of Pain, 17, 165-172.

Sexton, K. A., Norton, P. J., Walker, J. R., \& Norton, G. R. (2003). Hierarchical model of generalized and specific vulnerabilities in anxiety. Cognitive Behaviour Therapy, 32, 82-94.

Shiffrin, R. M., \& Schneider, W. (1977). Controlled and automatic human information processing-II.Perecptual learning, automatic attending, and a general theory. Psychological Review, 84, 127-190.

Snider, B. S. M. A., Asmundson, G. J. G., \& Wiese, K. C. (2000). Automatic and strategic processing of threat cues in patients with chronic pain: a modified-Stroop evaluation. Clinical Journal of Pain, 16, 144-154.

Spielberger, C. D., Gorsuch, R. L., \& Lushene, R. E. (1970). State-trait anxiety inventory. Palo Alto: Consulting Psychologists press. 


\section{References}

Spielberger, C. D., Gorsuch, R. L., Lushene, R. E., Vagg, P. R., \& Jacobs, G. A. (1983). Manual for the state and trait anxiety inventory (Form Y). In. Palo Alto, CA: Consulting Psychologists Press.

Spinhoven, P. H., Ormel, J., Sloekers, P. P. A., \& Kempen, G. I. J. M. (1997). A validation study of the Hospital Anxiety and Depression scale (HADS) in different groups of Dutch subjects. Psychological Medicine, 27, 363-370.

Stegen, K., Van Diest, I., Van de Woestijne, K. P., \& Van den Bergh, O. (2001). Do persons with negative affect have an attentional bias to bodily sensations? Cognition and Emotion, 15, 813-829.

Stewart, S. H., \& Asmundson, G. J. G. (2006). Anxiety sensitivity and its impact on pain experiences and conditions: a state of the art. Cognitive Behaviour Therapy, 35, 185-188.

Stewart, S. H., Conrod, P. J., Gignac, M. L., \& Pihl, R. O. (1998). Selective processing biases in anxiety-sensitive men and women. Cognition and Emotion, 105, 105-133.

Stopa, L., \& Clark, D. M. (2001). Social phobia: Comments on the viability and validity of an analogue research strategy and British norms for the fear of negative evaluation questionnaire. Behavioural and Cognitive Psychotherapy, 29, 423-430.

Subotnik, K. L., \& Shapiro, D. (1984). Heart rate biofeedback and cold pressor pain: Effects of expectancy. Biofeedback and Self Regulation, 9, 55-75.

Sullivan, M. J., Adams, H., \& Sullivan, M. E. (2004). Communicative dimensions of pain catastrophizing: social cueing effects on pain behaviour and coping. Pain, 107, 220-226.

Sullivan, M. J., Thorn, B., Haythornthwaite, J. A., Keefe, F., Martin, M., Bradley, L. A., et al. (2001). Theoretical perspectives on the relation between catastrophizing and pain. Clinical Journal of Pain, 17, 52-64.

Sullivan, M. J. L., Bishop, S. R., \& Pivik, J. (1995). The Pain Catastrophizing Scale: Development and validation. Psychological Assessment, 7, 524-532.

Sullivan, M. J. L., Lynch, M. E., \& Clark, A. J. (2005). Dimensions of catastrophic thinking associated with pain experience and disability in patients with neuropathic pain conditions. Pain, 113, 310-315.

Sullivan, M. J. L., Stanish, W., Waite, H., Sullivan, M. E., \& Tripp, D. A. (1998). Catastrophizing, pain, and disability in patient with soft-tissue injuries. Pain, 77, 253-260.

Tan, G., Jensen, M. P., Robinson-Whelen, S., Thornby, J. I., \& Monga, T. (2002). Measuring control appraisals in chronic pain. The Journal of Pain, 3, 385-393.

Tanner, R. J., Stopa, L., \& De Houwer, J. (2006). Implicit views of the self in social anxiety. Behaviour Research and Therapy, 44, 1397-1409.

Taylor, S. (1993). The structure of fundamental fears. Journal of Behaviour Therapy and Experimental Psychiatry, 24. 289-299.

Taylor, S. (1995). Anxiety sensitivity: theoretical perspectives and recent findings. Behaviour Research and Therapy, 33, 243-258.

Taylor, S., \& Cox, B. J. (1998). Anxiety sensitivity: multiple dimensions and hierarchic structure. Behaviour Research and Therapy, 36, 37-51.

Taylor, W. J., Dean, S. G., \& Siegert, R. J. (2006). Differential association of general and health self-efficacy with disability, health-related quality of life and psychological distress from musculoskeletal pain in a cross-sectional general adult population survey. Pain, 125, 225-232.

Teachman, B. A. (2005). Information Processing and Anxiety Sensitivity: Cognitive Vulnerability to Panic Reflected in Interpretation and Memory Biases. Cognitive Therapy and Research, 29, 479-499.

Teige, S., Schnabel, K., Banse, R., \& Asendorpf, J. B. (2004). Assessment of multiple implicit self-concept dimensions using the extrinsic affective simon task (EAST). European Journal of Personality, 18, 495-520. 
Tellegen, A. (1982). Brief Manual for the Differential Personality Questionnaire (Unpublished report). Minnesota: University of Minnesota.

Thompson, S. C. (1981). Will it hurt if I can control it? A complex answer to a simple question. Psychological Bulletin, 90, 89-101.

Thorn, B. E., Clements, K. L., Ward, L. C., Dixon, K. E., Kersh, B. C., Boothby, J. L., et al. (2004). Personality factors in the explanation of sex differences in pain catastrophizing and response to experimental pain. Clinical Journal of Pain, 20, 275-282.

Turk, D. C., \& Flor, H. (1999). Chronic pain: A biobehavioral perspective. In Psychosocial factors in pain: Critical perspectives (pp. 18-34). New York, NY: Guilford Press.

Turk, D. C., \& Gatchel, R. J. (2002). Psychological approaches to pain management: A practitioner's handbook (2nd ed.).

Turk, D. C., \& Okifuji, A. (2002). Psychological factors in chronic pain: evolution and revolution. Journal of Consulting and Clinical Psychology, 70, 678-690.

Turk, D. C., Wack, J. T., \& Kerns, R. D. (1985). An empirical examination of the 'pain-behaviour' construct. Journal of Behavioral Medicine, 8, 119-130.

Van Damme, S., Crombez, G., Bijttebier, P., Goubert, L., \& Van Houdenhove, B. (2002). A confirmatory factor analysis of the Pain Catastrophizing Scale: Invariant factor structure across clinical and non-clinical populations. Pain, 96, 319-324.

Van Damme, S., Crombez, G., \& Eccleston, C. (2004). Disengagement from pain: the role of catastrophic thinking about pain. Pain, 107, 70-76

Van Damme, S., Crombez, G., Eccleston, C., \& Roelofs, J. (2004). The role of hypervigilance in the experience of pain. In G. J. G. Asmundson, J. W. S. Vlaeyen \& G. Crombez (Eds.), Understanding and treating fear of pain (pp. 71-89). New York: Oford University Press.

van Wijk, A. J., \& Hoogstraten, J. (2006). Dutch translation of the Fear of Pain Questionnaire: Factor structure, reliability and validity. European Journal of Pain, 10, 479-486.

Vancleef, L. M. G., \& Peters, M. L. (2006). Pain catastrophizing, but not injury/llness sensitivity or anxiety sensitivity, enhances attentional interference by pain. Journal of Pain, 7, 23-30.

Vancleef, L. M. G., \& Peters, M. L. (in press). Examining content specificity of negative interpretation biases with the Body Sensations Interpretation Questionnaire (BSIQ). Journal of Anxiety Disorders.

Vancleef, L. M. G., Peters, M. L., Gilissen, S. M. P., \& de Jong, P. J. (2007). Understanding the role of injury/illness sensitivity and anxiety sensitivity in (automatic) pain processing: an examination using the Extrinsic Affective Simon Task. Journal of Pain, 8, 563-572.

Vancleef, L. M. G., Peters, M. L., Roelofs, J., \& Asmundson, G. J. G. (2006). Do fundamental fears differentially contribute to pain-related fear and pain catastrophizing? An evaluation of the sensitivity index. European Journal of Pain, 10, 527-536.

Vassilopoulos, S. P. (2006). Interpretation and judgemental biases in socially anxious and nonanxious individuals. Behavioural and Cognitive Psychotherapy, 34, 243-254.

Veldhuizen, D. S., Kenemans, J. L., M., B. d., Olivier, B., \& Volkerts, E. R. (2006). Pain and Attention: attentional disruption or distraction? Journal of Pain, 7, 11-20.

Verhaak, P. F., Kerssens, J. J., Dekker, J., Sorbi, M. J., \& Bensing, J. M. (1998). Prevalence of chronic benign pain disorder among adults: a review of the literature. Pain, 77, 231-239. 


\section{References}

Verkes, R.-J., Van der Kloot, W. A., \& Van der Meij, J. (1989). The perceived structure of 176 pain descriptive words. Pain, 38, 219-229.

Vincent, N., \& Walker, J. (2001). Anxiety Sensitivity: Predictor of sleep-related impairment and medication use in chronic insomnia. Depression and Anxiety, 14, 238-243.

Vinck, J., Wels, G., Arickx, M., \& Vinck, S. (1998). Optimisme gemeten: Validatie van de Nederlandstalige Levensorientatietest bij jongeren / Assessing optimism in youth: Validation of the Dutch Life Orientation Test. Gedrag and Gezondheid: Tijdschrift voor Psychologie en Gezondheid, 26, 79-90.

Vlaeyen, J. W. S., Kole Snijders, A. M. J., Rotteveel, A. M., Ruesink, R., \& et al. (1995). The role of fear of movement/ (re)injury in pain disability. Journal of Occupational Rehabilitation, 5, 235-252.

Vlaeyen, J. W. S., \& Linton, S. J. (2000). Fear-avoidance and its consequences in chronic musculoskeletal pain: A state of the art. Pain, 85, 317-332.

Vlaeyen, J. W. S., \& Morley, S. (2005). Cognitive-behavioral treatments for chronic pain: what works for whom? Clinical Journal of Pain, 21, 1-8.

Vlaeyen, J. W. S., Seelen, H., Peters, M. L., De Jong, P. J., Aretz, E., Beisiegel, E., et al. (1999). Fear of movement/ (re)injury and muscular reactivity in chronic low back pain patients: An experimental investigation. Pain, 82, 297-304

Vlaeyen, J. W. S., van Eek, H., Groenman, N. H., \& Schuerman, J. A. (1987). Dimensions and components of observed chronic pain behaviour. pain, 31, 65-75.

Waddel, G. (2004). The biopsychosocial model. In G. Waddel (Ed.), The back pain revolution (pp. 265-282). Edinburgh: Churchill Livingstone.

Waddell, G. (2004). The epidemiology of back pain. In G. Waddel (Ed.), The back pain revolution (pp. 71-89). Edinburgh: Churchill Livingstone.

Waddell, G., Newton, M., Henderson, I., Somerville, D., \& et al. (1993). A Fear-Avoidance Beliefs Questionnaire (FABQ) and the role of fear-avoidance beliefs in chronic low back pain and disability. Pain, 52, 157-168.

Waldrop, D., Lightsey, O. R., Jr., Ethington, C. A., Woemmel, C. A., \& Coke, A. L. (2001). Self-efficacy, optimism, health competence, and recovery from orthopedic surgery. Journal of Counseling Psychology, 48, 233-238.

Watson, D., \& Clark, L. A. (1992). Affects separable and inseparable: On the hierarchical arrangement of the negative affects. Journal of personality and social psychology., 62, 489-505.

Williams, J. M. G., Watts, F. N., MacLeod, C., \& Mathews, A. (1988). Cognitive psychology and emotional disorders.

Williams, S. L., \& Kinney, P. J. (1991). Performance and nonperformance strategies for coping with acute pain: The role of perceived self-efficacy, expected outcomes, and attention. Cognitive Therapy and Research, 15, 1-19.

Wilson, T. D., Lindsey, S., \& Schooler, T. Y. (2000). A model of dual attitudes. Psychological Review, 107, 101-126.

Woby, S. R., Roach, N. K., Urmston, M., \& Watson, P. (2005). Psychometric properties of the TSK-11: a shortened version of the Tampa Scale for Kinesiophobia. Pain, 117, 137-144.

Yiend, J., \& Mackintosh, B. (2004). The experimental modification of processing biases. In J. Yiend (Ed.), Cognition, emotion and psychopathology: Theoretical, empirical and clinical directions (pp. 190-210). New York, NY: Cambridge University Press.

Yiend, J., Mackintosh, B., \& Mathews, A. (2005). Enduring consequences of experimentally induced biases in interpretation. Behaviour Research and Therapy, 43, 779-797.

Zigmund, A. S., \& Snaith, R. P. (1983). The Hospital Anxiety and Depression Scale. Acta Psychiatrica Scandinavia, 67, 361-370. 
Zinbarg, R. E., \& Barlow, D. H. (1996). Structure of anxiety and the anxiety disorders: a hierarchical model. Journal of Abnormal Psychology, 105, 181-193.

Zinbarg, R. E., Barlow, D. H., \& Brown, T. A. (1997). Hierarchical structure and general factor saturation of the Anxiety Sensitivity Index: Evidence and implications. Psychological Assessment, 9, 277-284.

Zvolensky, M. J., Feldner, M. T., Eifert, G. H., \& Stewart, S. H. (2001). Evaluating differential predictions of emotional reactivity during repeated $20 \%$ carbon dioxide-enriched air challenge. Cognition and Emotion, 15, 767786.

Zvolensky, M. J., Goodie, J. L., McNeil, D. W., Sperry, J. A., \& Sorrell, J. T. (2001). Anxiety sensitivity in the prediction of pain-related fear and anxiety in a heterogeneous chronic pain population. Behaviour Research and Therapy, 39, 683-696. 


\section{- 一 \\ Dankwoord}


Als je wil werken in de wetenschap, is - na je universitaire opleiding - een promotietraject de meest aangewezen te volgen weg. Die weg leidt dan naar een proefschrift, zoals het deze, dat je de nodige basiskennis en ervaring geeft om weer nieuwe wegen in te slaan.

In de allereerste plaats is dit proefschrift voor mij een beschrijving en samenvatting van hetgeen waarmee ik mij in de afgelopen vier jaar met veel plezier en passie dagelijks heb mogen bezighouden. Daarbij heb ik het geluk gehad om tijdens die periode ondersteund, begeleid en gemotiveerd te worden door een aantal belangrijke mensen. Ere wie ere toekomt, en daarom wil ik mij in dit dankwoord richten tot al diegenen die, soms op heel directe wijze, en soms vanop een ietwat verdere afstand, hebben bijgedragen aan de tot stand koming van dit proefschrift.

Madelon, als aanvrager en dus eerste bezieler van dit onderzoeksproject, stond jij de afgelopen vier jaar in voor mijn dagelijkse begeleiding. En er zijn periodes geweest waarin dit dagelijks echt letterlijk te nemen was! Dankzij je open-deur-beleid kon ik steeds bij je binnenlopen met eender welke vraag. En hoewel je eigen agenda doorheen de tijd steeds maar drukker en voller werd, was je nooit minder bereikbaar voor mij, en heb je er steeds voor gezorgd dat mijn manuscript-, presentatie-, en posterversies in een mum van tijd van feedback werden voorzien. Ik heb genoten van onze regelmatige brainstormsessies, waarin we op zoek gingen naar nieuwe onderzoeksvragen, alternatieve verklaringen voor op het eerste zicht vreemde resultaten, of het bedenken van gepaste onderzoeksdesigns. Ik heb veel respect voor jouw kwaliteiten als onderzoeker en als persoon: je gedrevenheid, je inhoudelijke diepgang en brede kennis van zaken; je eerlijkheid, betrokkenheid, enthousiasme en immer optimistische ingesteldheid. Je hebt mij de vrijheid en zelfstandigheid gegeven om van jouw oorspronkelijke onderzoeksproject mijn 'eigen kindje' te maken, en wanneer ik overvallen werd door twijfels of onzekerheid, was jij degene die mij weer deed geloven in mijn eigen kunnen, die mij aanmoedigde en haar vertrouwen in mij uitsprak. Tegen het einde van mijn aio-periode werd jij hoogleraar en bijgevolg ook officiee/ mijn eerste promotor. Ik ben trots, dankbaar en vereerd dat jij mijn mentor was, en dat ik als eerste 'telg' onder jouw eerste promotorschap mag worden opgetekend!

Johan, ik ben blij dat jij mijn tweede promotor wilde zijn. Je stond in het begin van mijn project wat aan de zillijn, maar vanop die plek heb je wel veel interesse getoond voor mijn bezigheden. Je was steeds bereid advies te geven, en naar het einde van mijn project toe zijn we ook nauwer gaan samenwerken, in de 'kaartjesstudie', en tijdens het afwerken van dit proefschrift natuurlijk. Ik vind het inspirerend en leuk om met jouw samen te werken. Jij bent iemand die aanvankelijke problemen met een kwinkslag en ongekende rust de kop indrukt, altijd vriendelijk en positief. Hoewel je een enorm druk bezet persoon bent, maak(te) je toch regelmatig de tijd om met mij te brainstormen over de betekenis en implicaties van de bevindingen uit mijn studies, om nieuwe denkpistes uit te werken, en plannen voor de toekomst op te zetten. Je bescheidenheid en 'downto-earth-heid' zijn jouw handelsmerk, en ik vind het bewonderenswaardig hoe je steeds op een (schijnbaar) dromerige, maar absoluut succesvolle, manier op zoek bent naar het letterlijke en figuurlijke verleggen van onderzoeksgrenzen!

Madelon en Johan, jullie hebben beiden mede vorm gegeven aan de wetenschapper in mij! Ik kijk vol spanning en met veel plezier uit naar een gezamelijke samenwerking in de toekomst! 


\section{x}

Remco, tijdens het onderzoeksblok, mijn jaarwerkstuk en later ook mijn onderzoeksstage zag ik in jou iets dat ik ook graag wilde hebben, namelijk een ongekend enthousiasme voor en plezier in je werk. Jij wist het enthousiasme voor onderzoek op mij over te brengen, en vlak na mijn afstuderen was jij ook degene die mij stimuleerde en aanmoedigde om ook effectief verder te gaan in de wetenschap. Dank je wel daarvoor!

I would like to thank those who have collaborated with me throughout the design, data interpretation or writing process of the studies in this thesis. Gordon Asmundson, Geert Crombez, Jeffrey Roelofs, and Peter de Jong: many thanks for sharing your ideas with me and for the fast draft readings of manuscripts. Peter, aan verschillende studies uit dit proefschrift heb jij constructief meegewerkt en meegedacht. Tijdens ons eerste contact, zo'n 4 jaar geleden, was ik sterk onder de indruk van de snelheid (letterlijk èn figuurlijk) waarmee jij al mijn prangende vragen over de EAST en consoorten wist te beantwoorden. Jij bent de meest associatieve persoon die ik ooit ben tegengekomen, een gedegen en gerespecteerd onderzoeker, maar vooral ook een heel aardige en lollige man, die ergens vanuit het verre noorden van Nederland steeds bereid is om advies te geven, manuscriptversies op recordtempo door te lezen, alternatieve analyse methoden te bedenken en de motivatie erin te houden. Dank je wel!

I furthermore would like to express my gratitude to the members of the examination board for this dissertation, Jacques van Lankveld, Geert Crombez, Edmund Keogh, Maaike Cima, and Reinout Wiers, for taking the time to read and evaluate this thesis.

Dank ook aan de studenten die, in het kader van hun bachelor of master thesis, vele uren gespendeerd hebben aan het testen van proefpersonen en het ingeven van data; maar ook aan het meedenken over opzet en resultaten van de studies die beschreven staan in dit proefschrift: Susan Gilissen, Nicole van den Ham, Vera Matti, Nathalie van Aken, Kristie van Montfort, Claudia Bongers en Miriam Egberink. Jullie inbreng was erg waardevol!

Zonder proefpersonen geen data, en zonder data, geen proefschrift! Daarom wil ik ook de vele proefpersonen bedanken die vrijwillig hebben deelgenomen aan één of meerdere van mijn experimenten. Een aantal onder jullie zijn zelfs bereid geweest om 'voor het goede doel der wetenschap' gepijnigd te worden met elektrische schokje!

Beste collega's allemaal: aio's van de oude en nieuwe garde, mensen van het secretariaat, wpers en obp-ers: bedankt voor de vele plezierige momenten tussendoor, jullie bereidwilligheid om mijn vragen over vanalles-en-nog-wat te beantwoorden, de koffie-pit-stops, en de gezelligheid tijdens de frekwente 'vlaai-momenten', feestjes, borrels, of congressen. De collega's van het tweewekelijkse somato-overleg, en van de pijngroep binnen CPS in het bijzonder: Hanne, Ivan, Jeroen, Johan, Karoline, Maaike, Madelon, Marielle, Petra, Saskia en Saskia. Het is een enorme luxe om deel uit te maken van deze groep, en om onderzoeksideeën en -resultaten met jullie te kunnen kortsluiten! Angela, bedankt voor het beantwoorden en oplossen van zovele declaratie, reisbudget, kamerruimte, en personele vragen/probleempjes! Charlie, jouw wil ik extra bedanken voor de tijd en energie die je steeds gestoken hebt in het programmeren en implementeren van mijn computertaakjes. 
Lieve Jill: Toen ik net een paar maanden bij DMKEP aan het werk was, kwam Angela mij het volgende meedelen: "Linda, je gaat straks een nieuwe kamergenoot krijgen, het is een aardig Belgisch meisje, een perfecte match voor jou, denk ik". Ze had helemaal gelijk! Ik had me geen beter kamergenootje kunnen wensen! De afgelopen vier jaar heb ik enorm veel aan jou gehad: een luisterend oor, pep-talks en steun wanneer het op persoonlijk of werk vlak even tegenzat, gedeelde frustraties wanneer de vertwijfeling toesloeg, samen analyses, hypotheses, review comments en presentaties onder de loep nemen, maar vooral en bovenal ook enorm veel plezier en gezelligheid: 'melige' momenten aan het einde van de werkdag (eigenlijk gewoon op eender welk moment als de tijd ervoor rijp was), goede gesprekken tijdens lunch of microgolf-soepje tijd, mini kamer feestjes en een heus eigen kamerlied (hiep-hiep-hoi)! Sinds kort zijn we 'van bureau en pc gescheiden' en ex-kamergenootjes geworden. Maar we blijven natuurlijk vriendinnen en gelukkig ook collega's, en ik ben blij dat jij straks als mijn paranimf naast me staat!

Katrijn, wij trekken al met mekaar op sinds onze studietijd, en zijn daarna beiden 'blijven plakken' binnen de Randwijck gebouwen, waardoor we ook collega's werden. De afgelopen vier jaar gaven wij regelmatig rendez-vous voor een korte (en soms ook ietwat langere (:)) pauze, waarin dan vanalles en nog wat besproken werd: van het analyseren van impliciete taakparadigma's en het overlopen van onze werkperikelen, tot de organisatie van trouw en -promotiefeest en het bespreken en plannen van aankoop,(ver)bouwen en inrichten van onze huisjes. Waar het ook precies over ging, deze intermezzo's hebben mij altijd veel deugd gedaan, en vorm(d)en een leuke onderbreking van de dagelijkse werkactiviteiten. Bedankt daarvoor en natuurlijk ook omdat jij mijn andere paranimf wil zijn!

Mijn andere 'Maastricht' vriendinnetjes: Eva, Greetje, Tineke, Inne en Liesje. Ik vind het tof dat wij contact zijn blijven houden, en het is steeds leuk om elkaar weer te zien of te horen, en bij te babbelen tijdens etentjes of andere gelegenheden. Lieve Diana, ook jij hoort in dit groepje thuis. Veel te vroeg zijn jij jouw toekomstdromen en plannen je ontnomen, maar weet dat je met mij meereist in het realiseren van de mijne, je bent nog vaak in mijn gedachten!

Ik wil ook alle vrienden en familieleden bedanken voor de interesse en betrokkenheid die zij getoond hebben voor mijn bezigheden. Inge, jij bent een goede en lieve vriendin bij wie ik altijd terecht kan, mercikes! De 'barakkers': bedankt voor de vele plezierige avonden, beach parties en wijntjes samen! Ons geregeld samenzijn betekent veel voor mij, en biedt een aangename afleiding en de broodnodige ontspanning...dat er nog vele van die activiteiten mogen volgen!! Sonja, naast het feit dat je een goede vriendin bent, wil ik jou extra bedanken voor het verzorgen van de omslag en layout van mijn proefschrift! Zoals je intussen zelf hebt mogen ondervinden, ben ik zelf een ramp als het op opmaak-en grafische aspecten aankomt. Ik ben blij dat jij deze taak, waar ik als een berg tegenop zag, met zoveel plezier en inzet van mij hebt overgenomen! Het resultaat mag er zeker zijn! 


\section{tonem}

Papa en mama, jullie ben ik nog het meeste dank van iedereen verschuldigd. Het is dankzij de kansen die jullie mij gegeven hebben (en die heb ik soms risicovol bijna verspeeld; cf. mijn 'feestjaren' in Leuven), en het vertrouwen dat jullie mij geschonken hebben dat dit proefschrift er nu ligt. Jullie hebben ervoor gezorgd dat ik de persoon ben die ik nu ben, en jullie hebben mij de waarden en normen meegegeven die ik nu ook nastreef. Een promotietraject afwerken is leuk en belangrijk, maar wat mij betreft zijn familiale gezelligheid en steun toch nog steeds het allerbelangrijkste! Daarom wil ik jullie, papa en mama, maar ook jij, Kristel, mijn 'grote zus' en jij, Geert, mijn 'kleine' broertje :-; bedanken voor de gezelligheid, steun, en hulp die ik op alle vlak en alle momenten bij jullie kan vinden. Yvonne, Robert, Joeri, Sigrid, Jana, Brent, Werner, Tamara, Gunther en Leen, ook jullie maken zonder meer deel uit van die familiale gezelligheid, dank jullie wel!

Eddy, al meer dan 10 jaar ben jij mijn vaste rots in de branding, mijn man, die persoon die ik het liefst van al op deze wereld zie. De laatste maanden waren hectisch, en heb ik veel beroep gedaan op jouw (overigens indrukwekkende!) 'echte-man-nieuwe-man' kwaliteiten. Hoewel ik best aan deze situatie zou kunnen wennen $(-)$, beloof ik dat we het vanaf nu terug evenrediger gaan verdelen. Bedankt voor alles: je relativeringsvermogen, je steun, je liefde, en het feit dat je er gewoon altijd voor me bent! 


\section{- - \\ Curriculum Uitae}




\section{Curriculum Uitae}

Linda Martha Gerda Vancleef was born on July 17 th 1979 , in Hasselt, Belgium. In 1997 she graduated from secondary school, Stedelijke Humaniora in Dilsen-Stokkem, Belgium. She started her study in psychology at the Catholic University Leuven in Belgium and in 1999, she continued her study in psychology at Maastricht University, The Netherlands. She graduated in April 2003, and received her master's degree in cognitive psychology. In August 2003, she was appointed as a PhD-student at the Department of Clinical Psychological Science (at that time still Department of Medical, Clinical, and Experimental Psychology) of Maastricht University. During her PhD-research, she carried out the studies that are included in this thesis. Since July 2007, she is assistant professor at the Department of Clinical Psychological Science at Maastricht University.

\section{Publications}

Vancleef, L. M. G., \& Peters, M. L. (in press) Examining content specificity of negative interpretation biases with the Body sensations Interpretation Questionnaire (BSIQ). Journal of Anxiety Disorders.

Vancleef, L. M. G., Peters, M. L., Gilissen, S M. P., De Jong, P. J. (2007) Understanding the role of injury/illness sensitivity and anxiety sensitivity in (automatic) pain processing: an examination using the Extrinsic Affective Simon Task. The Journal of Pain, 7, 563-572.

Vancleef, L. M. G., \& Peters, M. L. (2006). Pain catastrophizing, but not injury/illness sensitivity or anxiety sensitivity enhances attentional interference by pain. The Journal of Pain, 7 , 23-30.

Vancleef, L. M. G., \& Peters, M. L. (2006). The Interruptive Effect of Pain on Attention. The Journal of Pain, 7, 21-22.

Vancleef, L. M. G., Peters, M. L., Roelofs, J., \& Asmundson, G. J. G. (2006). Do fundamental fears differentially contribute to pain-related fear and pain catastrophizing? An evaluation of the Sensitivity Index. European Journal of Pain, 10, 527-536.

Vancleef, L. M. G., \& Peters, M. L. (2006). De rol van angst bij de ontwikkeling en instandhouding van chronische pijn. Gedrag en Gezondheid, 34, 331-343.

Vancleef, L M. G., Vlaeyen, J. W. S., \& Peters, M. L. (2004). Psychologische aspecten bij Failed Back surgery. In: Crul, B. J. P., van Houdenhove, B., Perez, R. S. G. M., Vissers, K., de Wit, R., \& Mattie, H. (red): Pijninfo, Bohn Stafleu van Loghum. pp. 11-22.

Peters, M. L., \& Vancleef, L. M. G. (in press). The role of personality traits in pain perception and disability. Reviews in Analgesia. 


\section{Curriculum Vitae}

Vlaeyen, J. W. S., \& Vancleef, L. M. G. (2007). Behavioral analysis, fear of movement/(re) injury and cognitive-behavioral management of chronic low back pain. In A. Vleeming, V. Moonry, \& R. Stoeckart (Eds.), Movement, stability and Lumbopelvic Pain. Integration of research and therapy (2nd ed., pp. 475-485). Edinburgh: Churchill Livingstone.

Havermans, R. C., Vancleef, L. M. G., Bylois, E., Wiers, R. W., \& Jansen, A. (2004). Context dependent access to alcohol-related concepts stored in memory. Alcohol Research, 9 , 219-222.

Havermans, R. C., Vancleef, L. M. G. , Bylois, E., \& Jansen, A. (2004). Denken aan drank: de rol van drinkomgeving en drinkervaring. Gedrag en Gezondheid, 32, 175 - 181

\section{SUBMITTED MANUSCRIPTS}

Vancleef, L. M. G., Peters, M. L., \& De Jong, P. J. Interpreting ambiguous health and bodily threat: are individual differences in pain-related vulnerability constructs associated with an online negative interpretation bias?

Vancleef, L. M. G., \& Peters, M. L. Does it hurt less when you are convinced you can control it? The influence of perceived control and self-efficacy on the subjective evaluation of experimentally induced pain.

Vancleef L. M. G., Vlaeyen, J. W. S., \& Peters, M. L. A hierarchical representation of negative emotionality constructs contributing to pain: an empirical examination of the underlying dimensional and componential structure of its individual components.

\section{CONFERENCE PRESENTATIONS}

Vancleef, L. M. G., \& Peters, M. L. (2007, July). The influence of perceived control and SE on the subjective evaluation of experimentally induced pain. Poster session at the World congress of Behavioural and Cognitive Therapies (WCBCT), Barcelona, Spain.

Vancleef, L. M. G., \& Peters, M. L. (2007, July). Examining content-specificity of negative interpretation biases with the Body Sensations Interpretation Questionnaire (BSIQ). Poster session at World Congress of Behavioural and Cognitive Therapies (WCBCT), Barcelona, Spain.

Vancleef, L. M. G. (2007, February). An experimental investigation into psychological factors and mechanisms that might contribute to the (chronic) course of pain. Presentation at EPP symposium, Heeze, The Netherlands. 
Vancleef, L. M. G., \& Peters, M. L. (2006, September). Negative interpretations of ambiguous information in relation to vulnerability constructs for pain. Poster session presented at the 5th congress of the European Federation of IASP Chapters (EFIC). Pain in Europe, Istanbul, Turkey.

Vancleef, L. M. G., \& Peters, M. L. (2006, May). Chronic Pain: vulnerability factors and errors in information processing. In A. Evers \& S. Van Damme (chairs), Maintaining and triggering factors of chronic physical symptoms. Symposium conducted at the sixth conference on psychopathology and health, Kerkrade, The Netherlands.

Vancleef, L. M. G., Peters M. L., Roelofs J., \& Asmundson, G. J. G. (2005, August). Do fundamental fears differentially contribute to pain-related fear and pain catastrophizing? An evaluation of the Sensitivity Index. Poster session presented at the 11th World Congress on pain, IASP, Sydney, Australia. 
